\title{
WestVirginiaUniversity
}

THE RESEARCH REPOSITORY @ WVU

Graduate Theses, Dissertations, and Problem Reports

2017

\section{A CBCT Analysis of Optimal Maxillary and Mandibular Incisor Inclination}

Marina Gonchar

Follow this and additional works at: https://researchrepository.wvu.edu/etd

\section{Recommended Citation}

Gonchar, Marina, "A CBCT Analysis of Optimal Maxillary and Mandibular Incisor Inclination" (2017). Graduate Theses, Dissertations, and Problem Reports. 5692.

https://researchrepository.wvu.edu/etd/5692

This Thesis is protected by copyright and/or related rights. It has been brought to you by the The Research Repository @ WVU with permission from the rights-holder(s). You are free to use this Thesis in any way that is permitted by the copyright and related rights legislation that applies to your use. For other uses you must obtain permission from the rights-holder(s) directly, unless additional rights are indicated by a Creative Commons license in the record and/ or on the work itself. This Thesis has been accepted for inclusion in WVU Graduate Theses, Dissertations, and Problem Reports collection by an authorized administrator of The Research Repository @ WVU. For more information, please contact researchrepository@mail.wvu.edu. 


\title{
A CBCT ANALYSIS OF OPTIMAL MAXILLARY AND MANDIBULAR INCISOR INCLINATION
}

Marina Gonchar, D.M.D.

\author{
Thesis submitted \\ to the School of Dentistry \\ at West Virginia University
}

in partial fulfillment of the requirements for the degree of

\section{Master of Science in Orthodontics}

Timothy Tremont, D.M.D.

Peter Ngan, D.M.D.

Chris Martin, D.D.S.

Department of Orthodontics

Morgantown, West Virginia

2017

Keywords: Incisor Inclination, CBCT, Optimal

Copyright 2017 Marina Gonchar, D.M.D 


\title{
ABSTRACT \\ A CBCT ANALYSIS OF OPTIMAL MAXILLARY AND MANDIBULAR INCISOR INCLINATION
}

\author{
Marina Gonchar, D.M.D.
}

Background and Objectives: One of the most challenging questions faced in the field of orthodontics is defining the envelope of tooth movement, and answering a fundamental question, where do teeth belong in relation to bone? Incisor position, both in the maxilla and mandible, are often compromised in order to accommodate an unfavorable skeletal pattern in the sagittal, vertical, and transverse dimensions during orthodontic therapy. Optimal incisor inclination has been a continuous debate in the field of orthodontics leaving the experts divided. The question still remains what are the clinical limits of orthodontic tooth movement, which will result in the most stable occlusion without any detrimental effects to the supporting bone and soft tissues. Therefore, it is imperative to identify the optimal location of the bucco-lingual position of the incisors in the alveolar housing.

Experimental Design and Methods: A sample of 100 CBCT scans of pre-treatment orthodontic patients aged 17-20 from the private practice of Dr. Thomas Shipley was used for this study. IRB-approval was obtained. Pre-treatment CBCT images were de-identified and DICOM files were analyzed using Anatomage InVivo 5 software. CBCTs were oriented in all three planes of space which was saved used for all subsequent measurements. The images were digitized in 3D in order to extract angular measurements of interest, specifically, maxillary and mandibular incisor inclinations. Incisor inclination was derived based on reference planes from the Steiner, Andrews, and Burstone analyses for the maxilla, and from the Steiner, Andrews, Downs, Tweed, and Ricketts analyses for the mandible. The maxillary and mandibular incisors were further analyzed for the presence or absence of dehiscences and fenestrations. The data was examined using correlation and chi-square analyses.

Results: Maxillary incisors inclined in the optimal range according to Steiner, Andrews, and Burstone analyses were statistically significantly $(\mathrm{p}<.05)$ to result in unequal distribution of bone bucco-lingually at the center of resistance and apex. Mandibular incisors inclined in the optimal range according to Downs and Tweed analyses were statistically significantly $(\mathrm{p}<.05)$ to result in equal distribution of bone bucco-lingually at the apex.

Conclusions: The existing landmarks for ideal maxillary incisor inclination (as defined by Steiner, Andrews, Burstone) do not result in roots centered in the bone. The existing landmarks for ideal mandibular incisor inclination (as defined by Steiner, Andrews, Downs, Tweed, Ricketts) do not result in roots centered in bone at the center of resistance. Mandibular incisors deemed as retroclined and normoinclined according to the Downs, Tweed, and Ricketts analyses have more dehiscences than incisors with more positive inclinations. 


\begin{abstract}
AKNOWLEDGEMENTS
I would like to acknowledge the support and assistance I have received during this project and throughout my orthodontic residency. I would not be able to complete this project or succeed in this residency without everyone's support, and I thank you.

Dr. Tim Tremont, for serving as my thesis advisor and chair of my committee. You have provided an unbelievable foundation for my future orthodontic career and have provided invaluable guidance on this project. Thank you.
\end{abstract}

Dr. Peter Ngan, for your feedback and wisdom throughout this project. You have been a wonderful chairman, teacher, and mentor. I owe you a great debt of gratitude for allowing me to realize my dream of becoming an orthodontist. Thank you.

Dr. Chris Martin, for serving on my thesis committee and being a continual and constant presence during my orthodontic education. Thank you.

Dr. Thomas Shipley, for graciously allowing access to your patient database. Your dedication to moving the profession forward is greatly appreciated. Thank you.

Dr. Gerry Hobbs, for your time and effort in helping to interpret the statistical analyses conducted during this project. Thank you.

Dr. DoBin Choi and Dr. Kelly Nguyen - my classmates and my friends, for your company, your support, and your help. I couldn't imagine these last three years without you and I cannot wait to see what the future has in store for all of us. Thank you.

MacKenzie, Tyler, Amer, Carl, Ghaddy, Niki, and Mohamad - my fellow residents, for memorable experiences and a fun learning environment. I wish you all the best of luck in your careers ahead. Thank you. 


\section{TABLE OF CONTENTS}

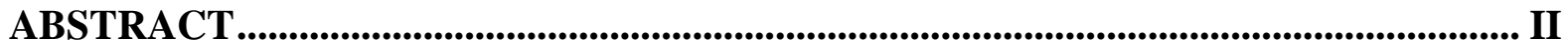

AKNOWLEDGEMENTS ............................................................................................

TABLE OF CONTENTS ....................................................................................................

LIST OF TABLES ..............................................................................................................................

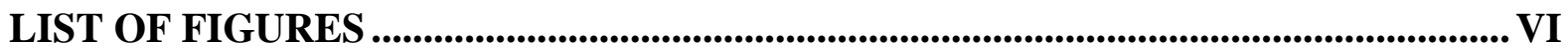

CHAPTER 1: INTRODUCTION............................................................................................1

BACKGROUND \& SIGNIFICANCE ………………………………………………………………....

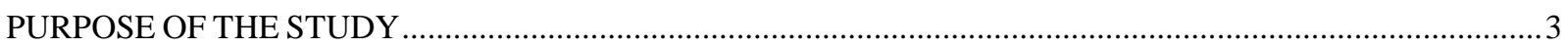

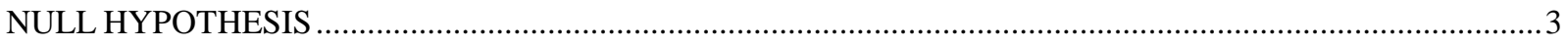

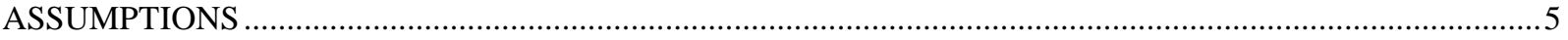

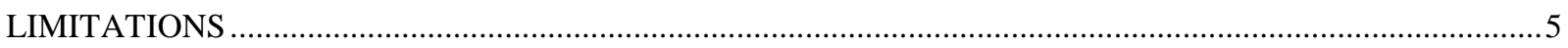

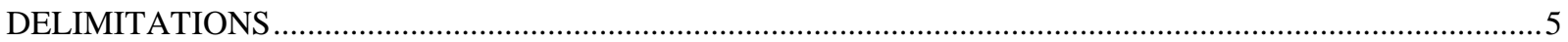

CHAPTER 2: REVIEW OF THE LITERATURE...................................................................6

TOOTH, BONE AND PERIODONTAL LIGAMENT DEVELOPMENT ……………………………………….....

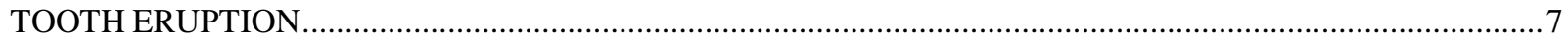

ORTHODONTIC TOOTH MOVEMENT ..................................................................................................

CEPHALOMETRIC DETERMINATION OF INCISOR INCLINATION.........................................................11

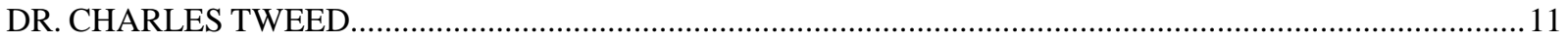

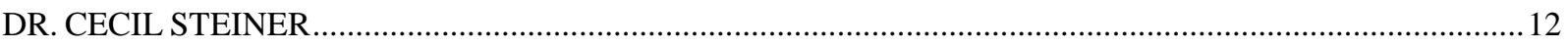

DR. CHARLES BURSTONE ............................................................................................................

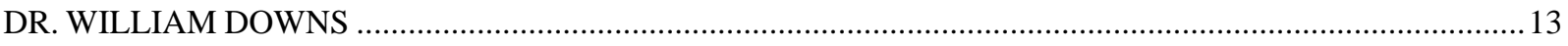

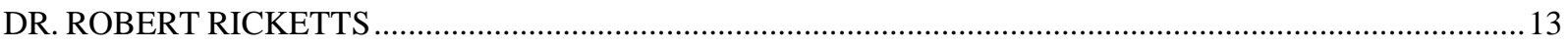

DR. LAWRENCE ANDREWS ........................................................................................................ 14

THE SIX ELEMENTS OF OROFACIAL HARMONY ……………………………………………………......

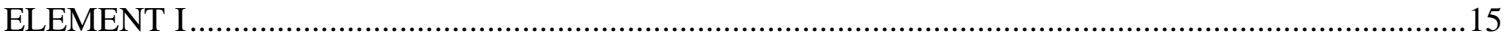

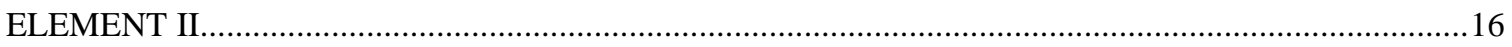


BOUNDARIES OF ORTHODONTIC TOOTH MOVEMENT

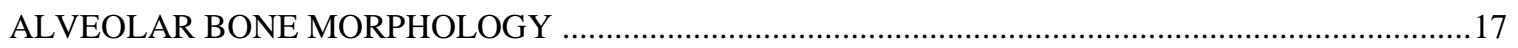

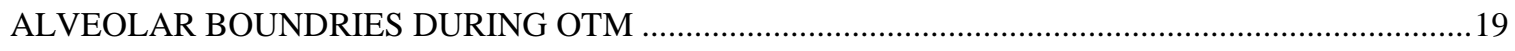

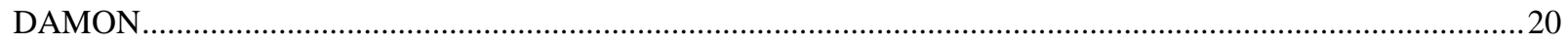

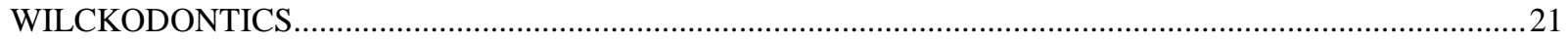

FACTORS LIMITING ORTHODONTIC TOOTH MOVEMENT ….......................................................22

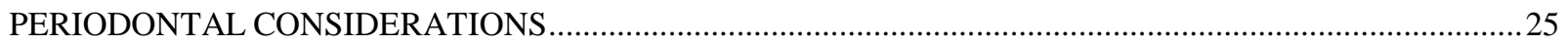

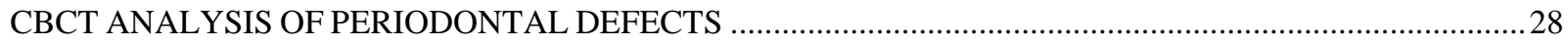

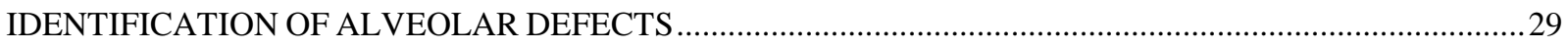

CHAPTER 3: RESEARCH DESIGN AND METHODOLOGY ..........................................29

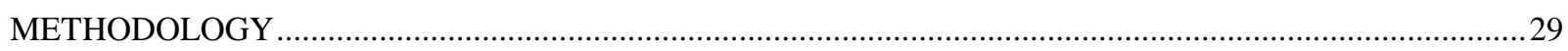

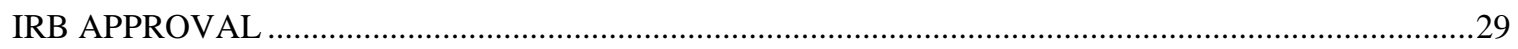

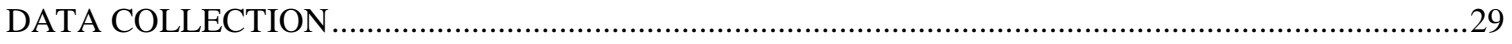

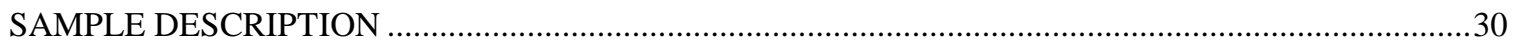

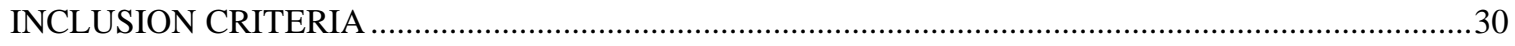

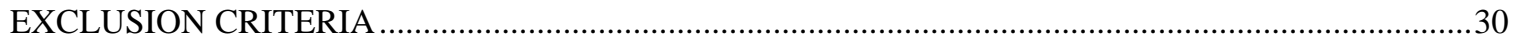

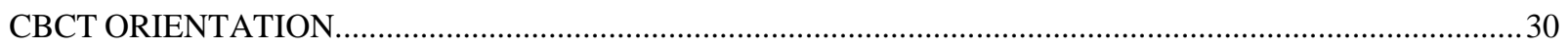

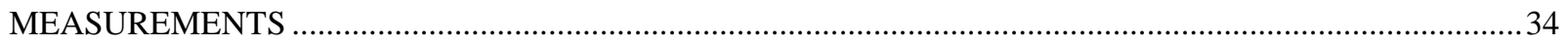

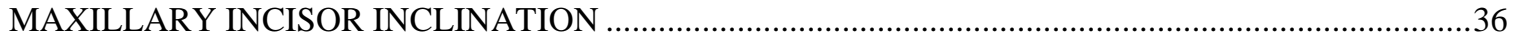

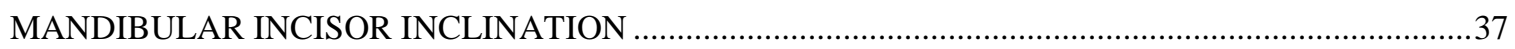

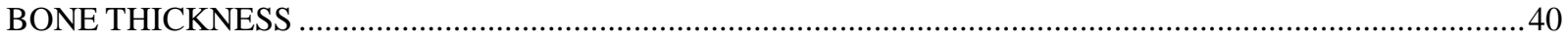

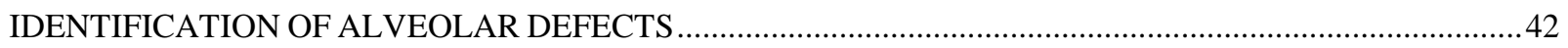

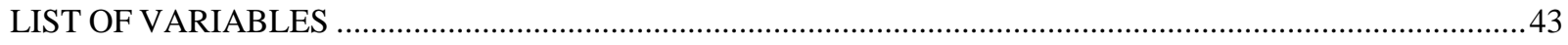

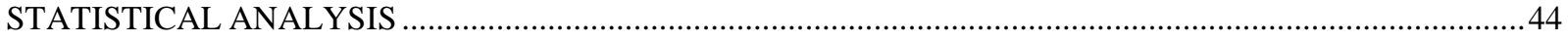

CHAPTER 4: RESULTS ....................................................................................................................44

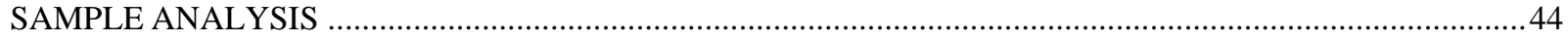

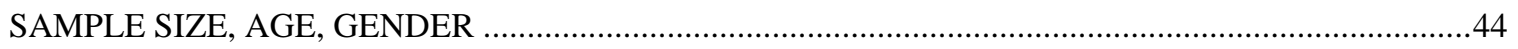

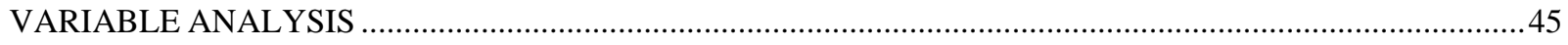




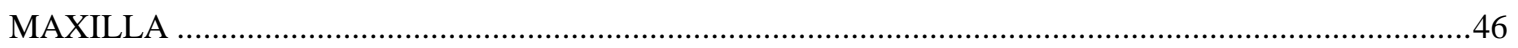

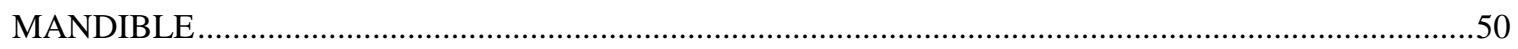

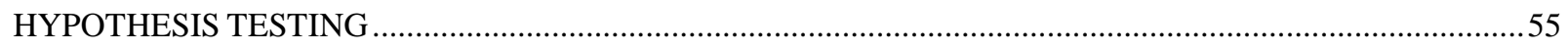

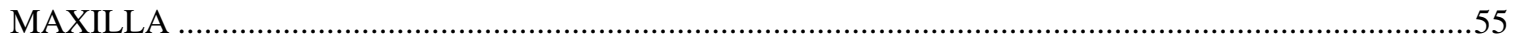

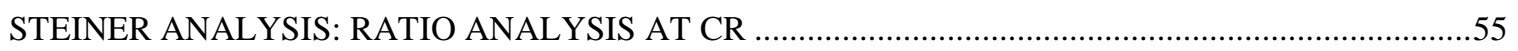

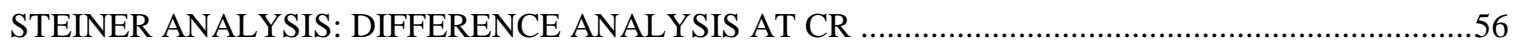

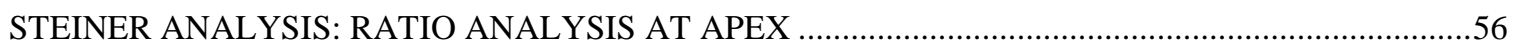

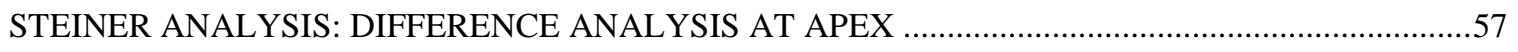

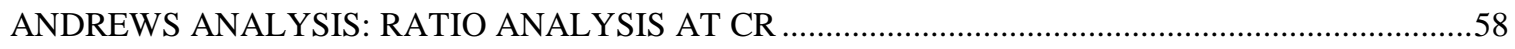

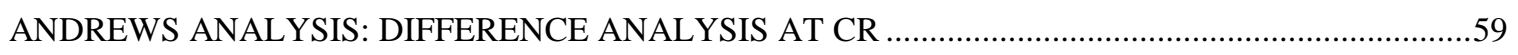

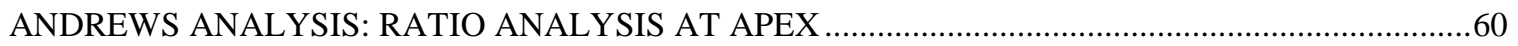

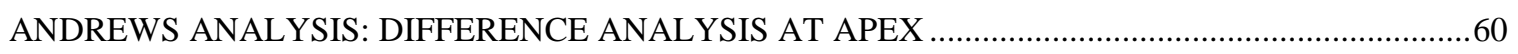

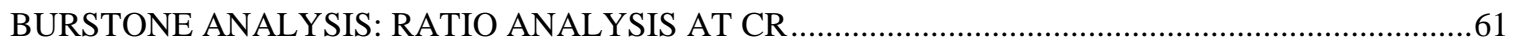

BURSTONE ANALYSIS: DIFFERENCE ANALYSIS AT CR ………………………............................63

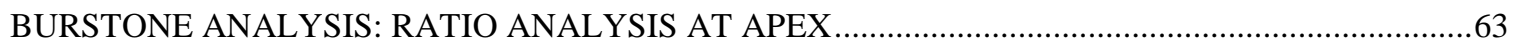

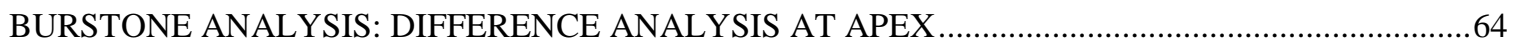

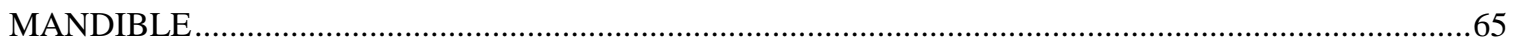

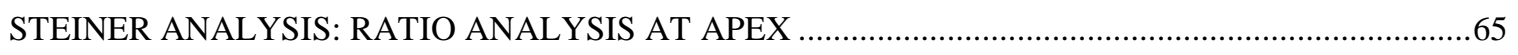

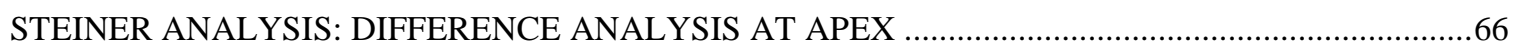

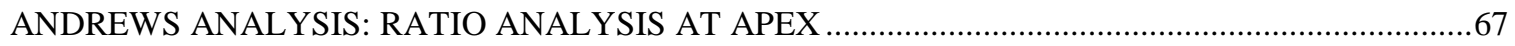

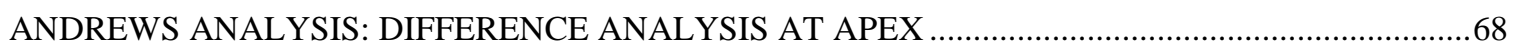

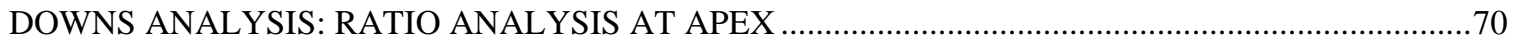

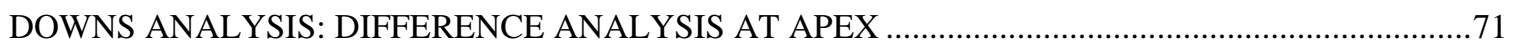

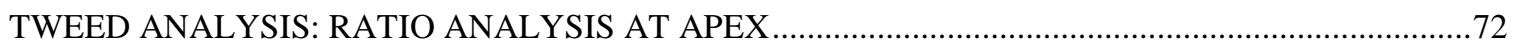

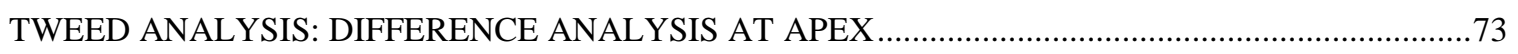

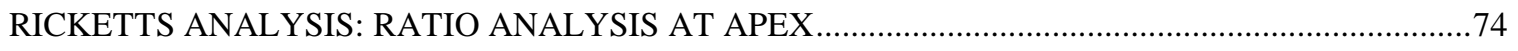

RICKETTS ANALYSIS: DIFFERENCE ANALYSIS AT APEX ........................................................

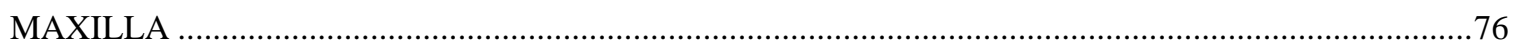




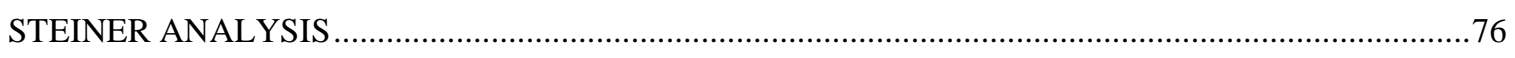

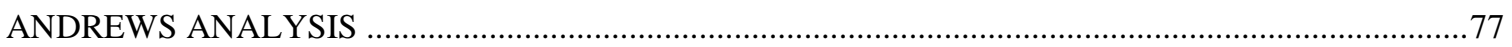

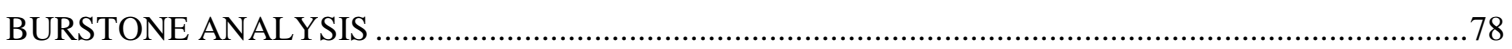

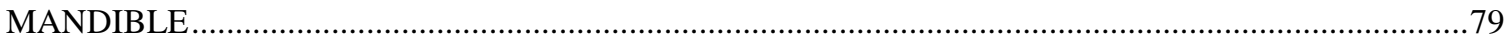

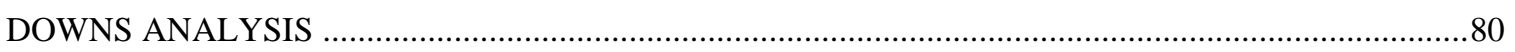

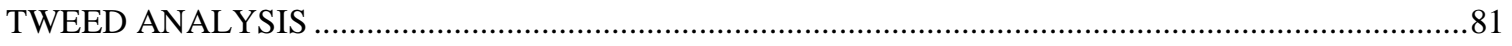

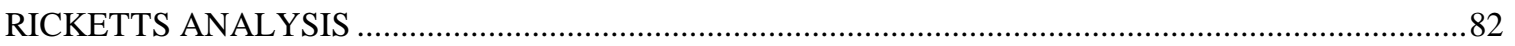

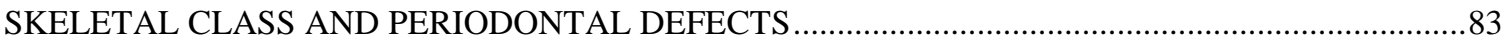

VERTICAL FACE HEIGHT AND PERIODONTAL DEFECTS ............................................................. 84

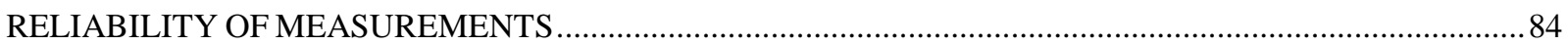

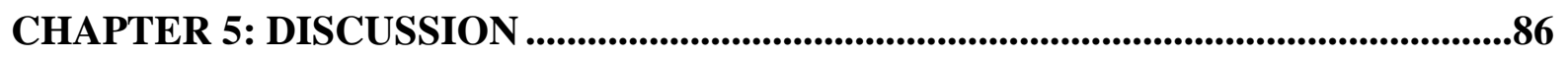

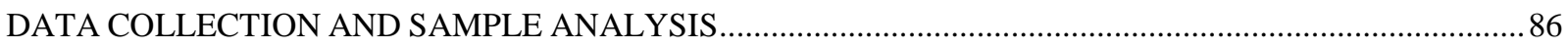

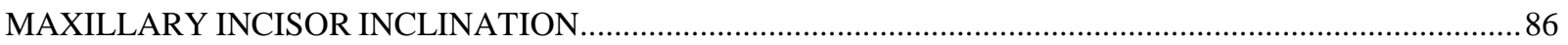

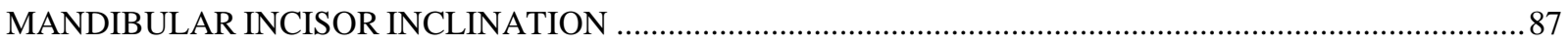

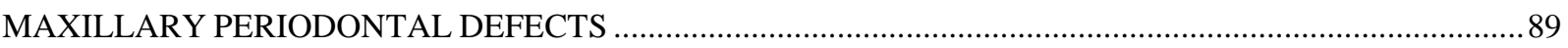

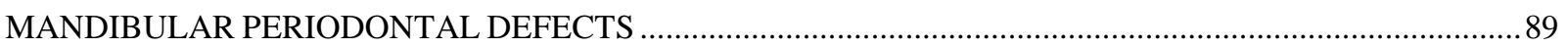

SKELETAL CLASSIFICATION AND PERIODONTAL DEFECTS ................................................................ 91

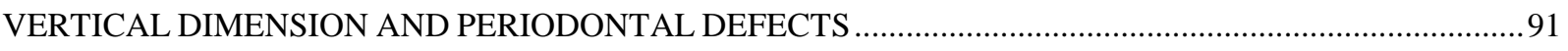

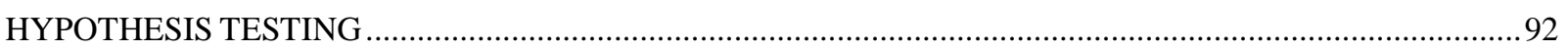

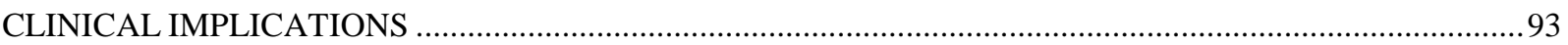

CHAPTER 6: SUMMARY AND CONCLUSIONS ....................................................94

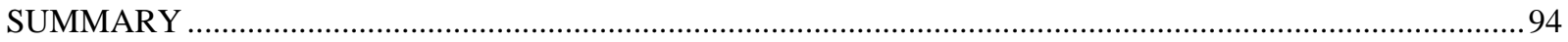

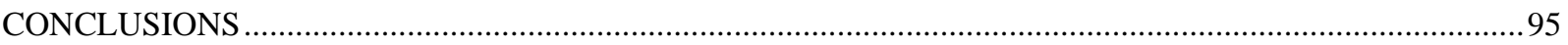

CHAPTER 7: RECOMMENDATIONS FOR FUTURE RESEARCH..........................95

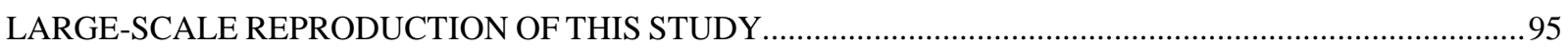

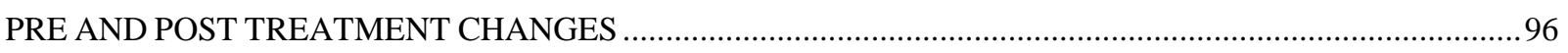

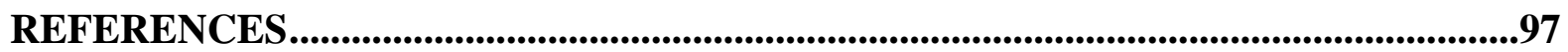

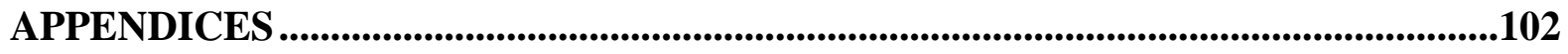

vii 


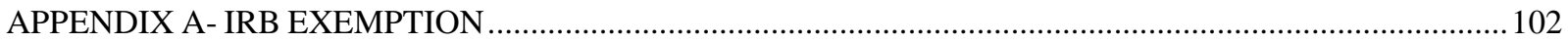

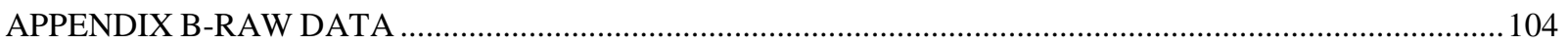

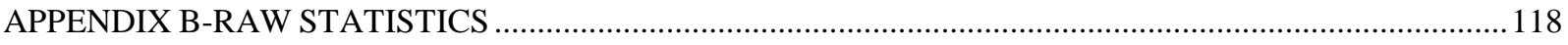

viii 


\section{LIST OF TABLES}

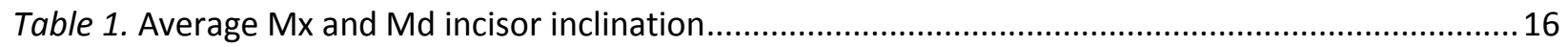

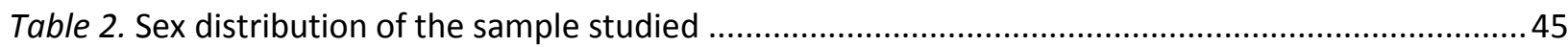

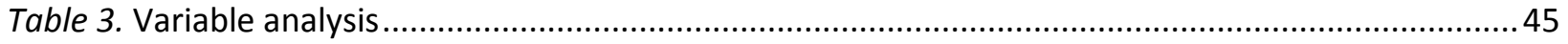

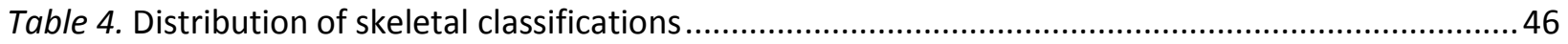

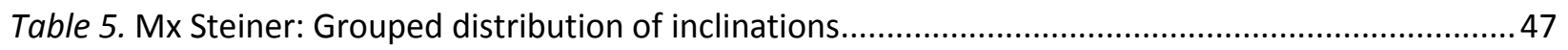

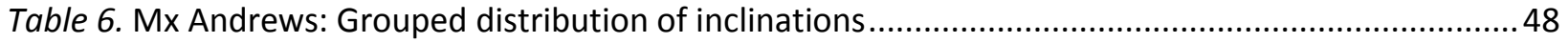

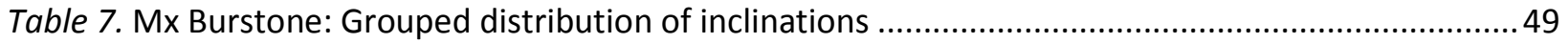

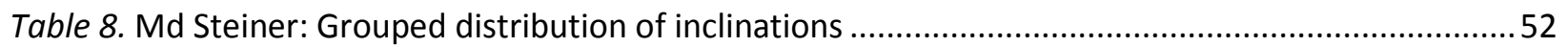

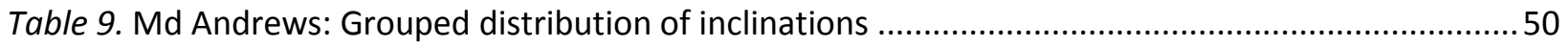

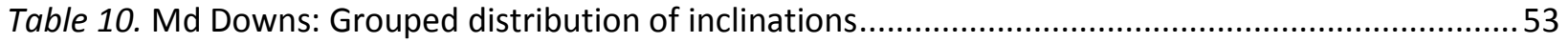

Table 11. Md Tweed: Grouped distribution of inclinations ...............................................................5 51

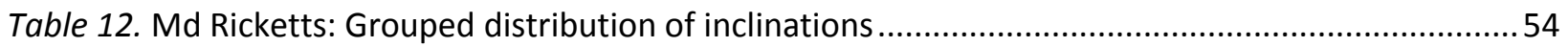

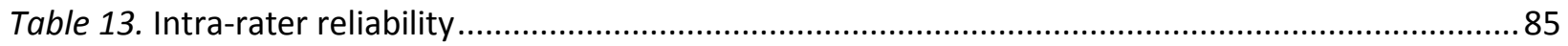




\section{LIST OF FIGURES}

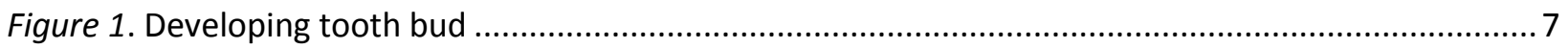

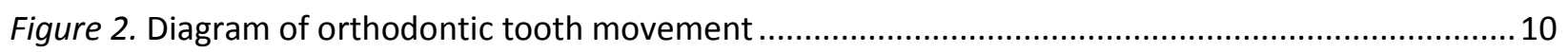

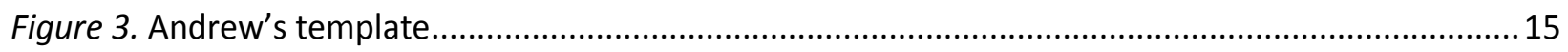

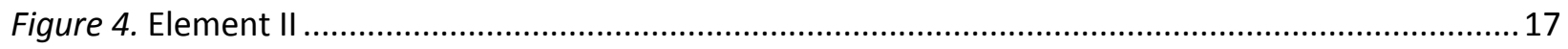

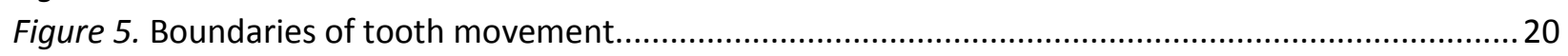

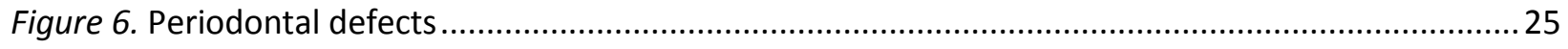

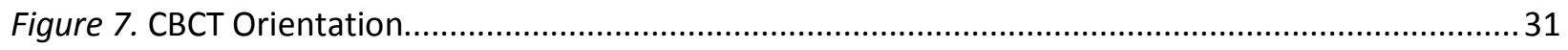

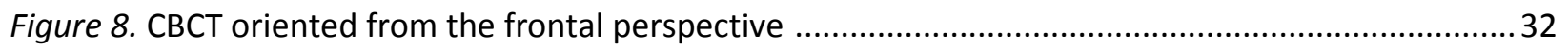

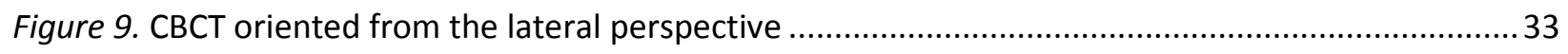

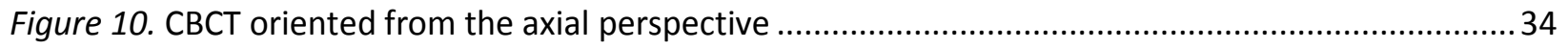

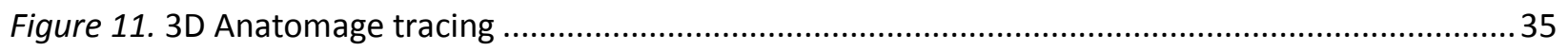

Figure 12. Linear and angular measurements in Anatomage software ................................................ 35

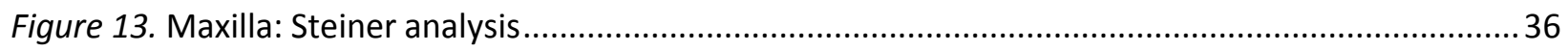

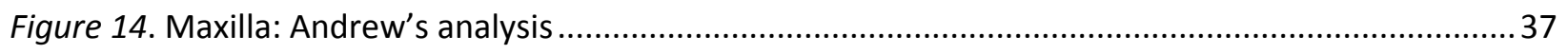

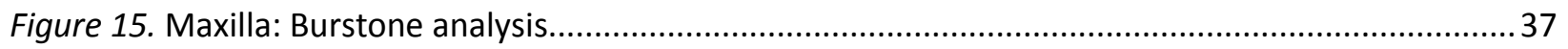

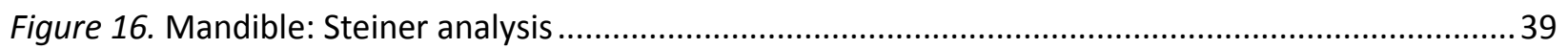

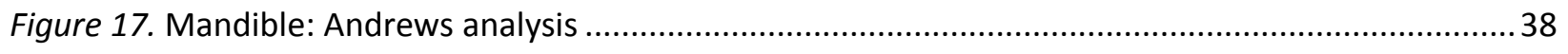

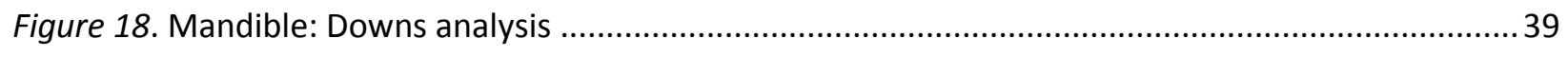

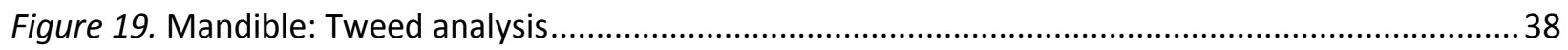

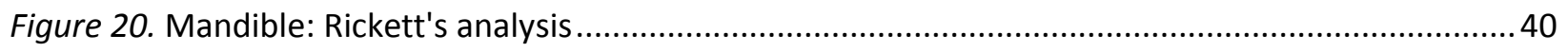

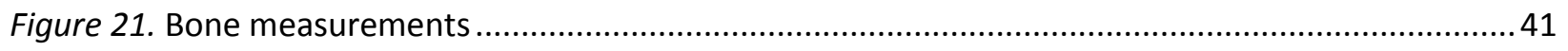

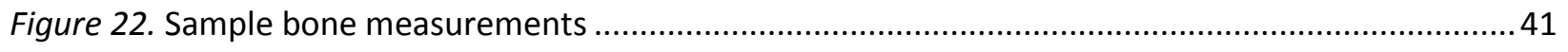

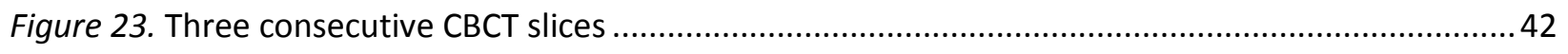

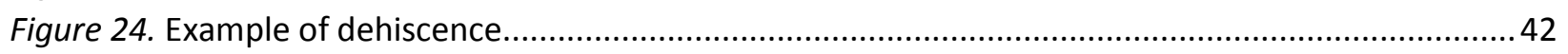

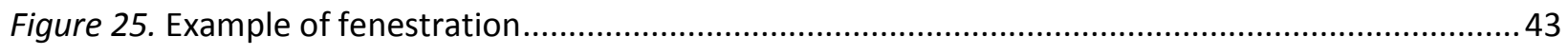

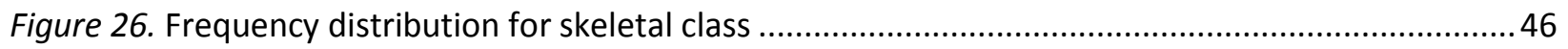

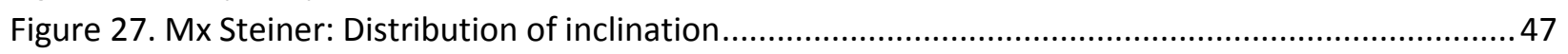

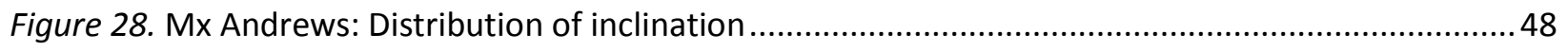

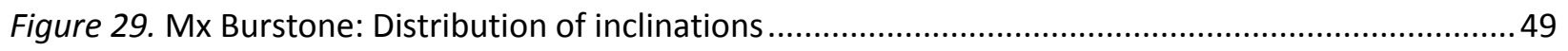

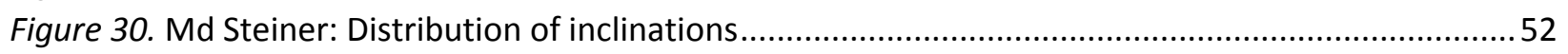

Figure 31. Md Andrews: Distribution of inclinations .................................................................... 50

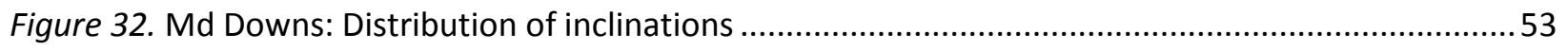

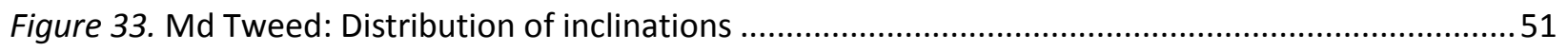

Figure 34. Md Ricketts: Distribution of inclinations ....................................................................... 54

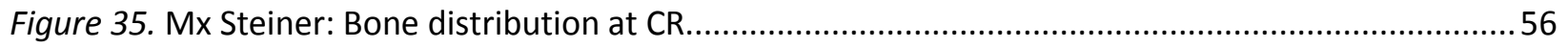

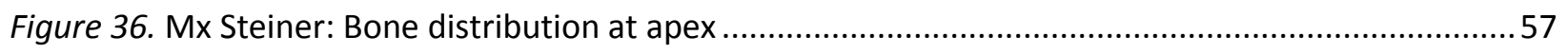

Figure 37. Mx Steiner: Difference in bone distribution at the apex .....................................................5

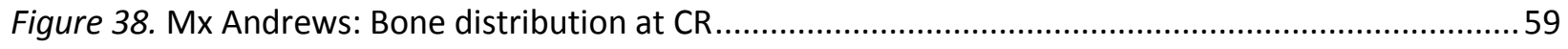

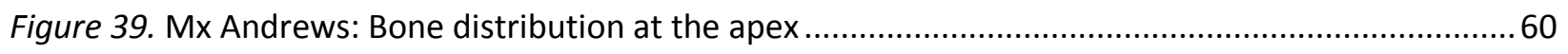

Figure 40. Mx Andrews: Difference in bone distribution at the apex .................................................61

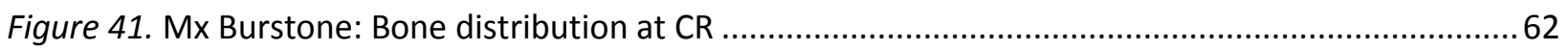




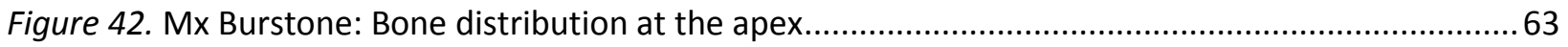

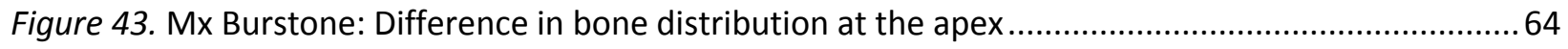

Figure 44. Md Steiner: Bone distribution at the apex ....................................................................... 70

Figure 45. Md Steiner: Difference in bone distribution at the apex................................................... 71

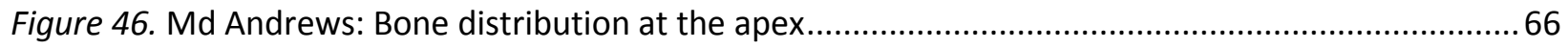

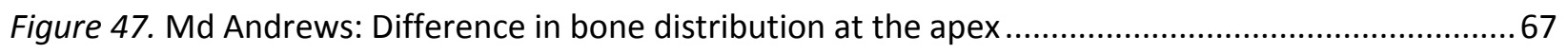

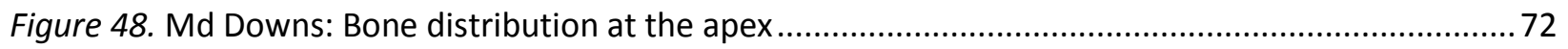

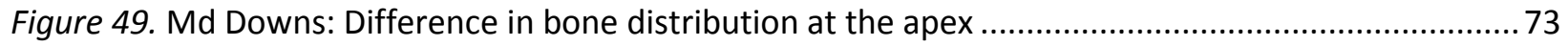

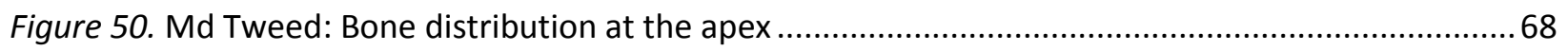

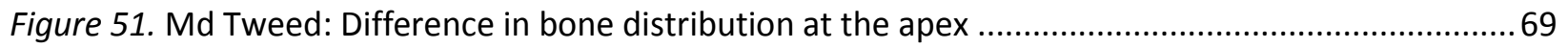

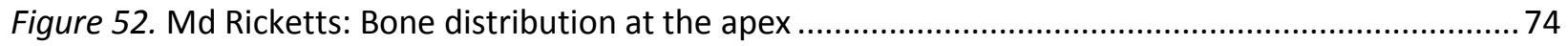

Figure 53. Md Ricketts: Difference in bone distribution at the apex ................................................... 75

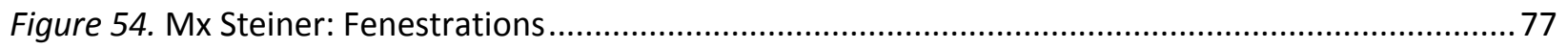

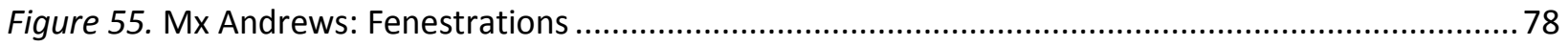

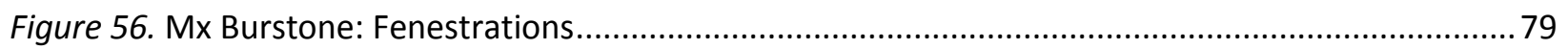

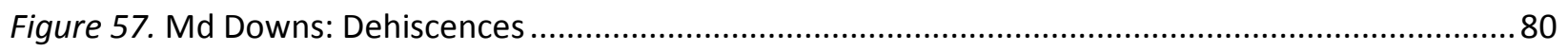

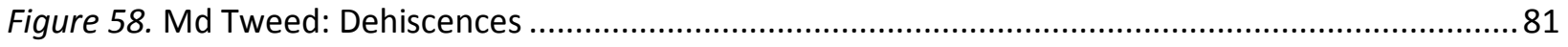

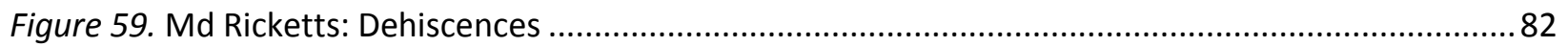




\section{CHAPTER 1: INTRODUCTION}

\section{BACKGROUND \& SIGNIFICANCE}

Teeth have the ability to move and migrate based on an intricate interplay between numerous factors, including growth of dental arch structures, remodeling of dental structures and functional demands on the dentition [1]. Orthodontic tooth movement tries to take advantage of this natural biological process in order to achieve a proper occlusion devoid of crowding or spacing. One of the most challenging questions faced in the field of orthodontics is defining the envelope of tooth movement, and answering a fundamental question, where do teeth belong in relation to bone? The thickness of alveolar bone defines the boundaries of orthodontic tooth movement [2]. Violating these boundaries can result in numerous unwanted consequences: bone dehiscence, fenestrations, and gingival recession [2, 3]. Nevertheless, alveolar bone is a remarkable tissue that can and does undergo remodeling during orthodontic tooth movement. The question remains what are the clinical limits of orthodontic tooth movement, which will result in the most stable occlusion without any detrimental effects to the supporting bone and soft tissues. Therefore, it is imperative to identify the optimal location of the bucco-lingual position of the teeth in the alveolar housing. Incisor position, both in the maxilla and mandible, are often compromised in order to accommodate an unfavorable skeletal pattern in the sagittal, vertical, and transverse dimensions during orthodontic therapy. Optimal incisor inclination has been a continuous debate in the field of orthodontics leaving the experts divided in the extraction v non-extraction debate. According to Dr. Charles Tweed the mandibular incisor inclination, measured through the long axis of the tooth, to the mandibular plane, should not violate 87 degrees, thus resulting in the most stable 
occlusal result. Tweed is just one of many orthodontist that tried to define the most stable inclination of the maxillary and mandibular incisors, leading to endless cephalometric analyses, with varying landmarks, varying degree measurements and undoubtedly varying results. After so many years, the question still remains, is there an optimal inclination of maxillary and mandibular incisors that results in optimal amount of bucco-lingual bone, serving as a guideline for all orthodontists.

Other studies support the idea that excessive incisor proclination leads to negative periodontal consequences. Mandibular incisor inclination of greater than 95 degrees showed significant buccal bone loss and gingival recession [4]. Based on cone beam computed tomography (CBCT) and the three-dimensional images of the alveolus, it can be concluded that the morphology of the alveolar bone displays minimal thickness in the bucco-lingual dimension [2]. The maxillary incisors exhibit thicker lingual bone plates, while the mandibular incisors show very thin bone plates both in the labial and lingual aspects [2]. Due to minimal bone thickness observed at the mandibular incisor region, bone dehiscence prior to orthodontic treatment is a common occurrence [2]. Correctly identifying the supporting structures of the incisors prior to orthodontic therapy can greatly influence the proposed treatment plan and treatment mechanics. Utilizing cephalometric guidelines in order to justify incisor position often does not consider the starting conditions of the underlying bone and gingiva and therefore cannot be used reliably to justify proper placement of incisors.

In 1972 Dr. Lawrence Andrews also tried to tackle the issue of normal occlusion and was able to draw some definitive conclusions regarding incisor inclination based on observations made on 120 casts of non-orthodontic patients with normal occlusions. According to Dr. Andrews maxillary and mandibular incisor inclination are complementary and significantly affect not only 
the overbite but also the posterior occlusion. To achieve proper occlusion, maxillary and mandibular incisors must be optimally inclined. According to Dr. Andrews maxillary incisors should be inclined 25 degrees to the occlusal plane while mandibular incisors should be inclined 15 degrees to the occlusal plane, centered over basal bone. Although, Andrew's Six Keys to Normal Occlusion, including incisor inclination, have been widely accepted as a gold standard for optimal occlusion, there is lack of scientific research to support the conclusion that optimally inclined incisors result in optimal bucco-lingual bone. Therefore, the current study looked to identify and quantify the amount of buccal and lingual bone present at different incisor inclinations, setting limits of forward and backward movement of the incisor. The question remains does placing an incisor at its proper inclination, based on the occlusal plane as a landmark, result in optimal bony support.

\section{PURPOSE OF THE STUDY}

1. To investigate if there is an optimal maxillary and mandibular incisor inclination that results in roots centered in the alveolar housing.

2. To investigate if maxillary and mandibular incisors centered in the alveolar housing are less prone to periodontal defects: dehiscences and fenestrations.

\section{NULL HYPOTHESIS}

1. Maxillary incisors inclined in the optimal range according to the Steiner, Andrews, Burstone analyses are not more centered in alveolar bone than incisors with more positive or negative inclination.

2. Mandibular incisors inclined in the optimal range according to the Downs, Steiner, Tweed, Andrews, and Ricketts analyses are not more centered in alveolar bone than incisors with more positive or negative inclination. 
3. Maxillary incisors inclined in the optimal range according to the Steiner, Andrews, Burstone analyses do not have less dehiscences than incisors with more positive or negative inclination.

4. Maxillary incisors inclined in the optimal range according to the Steiner, Andrews, Burstone analyses do not have less fenestrations than incisors with more positive or negative inclination.

5. Mandibular incisors inclined in the optimal range according to the Downs, Steiner, Tweed, Andrews, and Ricketts analyses do not have less dehiscences than incisors with more positive or negative inclination.

6. Mandibular incisors inclined in the optimal range according to the Downs, Steiner, Tweed, Andrews, and Ricketts analyses do not have less fenestrations than incisors with more positive or negative inclination.

7. Patients classified with skeletal Class I occlusion do not have less dehiscences than patients classified with skeletal Class II or III occlusion.

8. Patients classified with skeletal Class I occlusion do not have less fenestrations than patients classified with skeletal Class II or III occlusion.

9. Maxillary and mandibular incisors in patients with normal vertical dimension do not have less dehiscences than incisors in patients with increased or decreased vertical dimension.

10. Maxillary and mandibular incisors in patients with normal vertical dimension do not have less fenestrations than incisors in patients with increased or decreased vertical dimension. 


\section{ASSUMPTIONS}

1. The CBCT scan resolution utilized in this study was adequate to detect periodontal defects, dehiscences and fenestrations, without patient movement contributing to the introduction of radiographic artifacts.

2. The operator in this study had working knowledge of the technology utilized in the analysis.

3. Landmarks were accurately identified using the CBCT scans.

4. CBCT scans were taken on subjects prior to initiation of any type of orthodontic, orthopedic, or surgical treatment.

5. The CBCT scans were 1:1 without the need for calibration.

6. The landmarks, as identified by the operator, accurate represent the actual landmarks of interest.

7. The sample studied did not have any existing periodontal conditions.

8. The premaxilla, in general, always has more bone on the lingual than buccal.

\section{LIMITATIONS}

1. CBCT voxel size is not small enough to provide detail to the closest $.1 \mathrm{~mm}$ when measuring bucco-lingual bone.

2. Center of resistance point is an estimated landmark.

\section{DELIMITATIONS}

1. The study only analyzed maxillary and mandibular central incisors.

2. The study only analyzed incisors that were in reasonable alignment.

3. The age of the subjects was limited to 17-20 years of age.

4. Periodontal health history of each subject in the sample was not analyzed. 
5. The study used only one operator to make all landmark identifications and measurements.

\section{CHAPTER 2: REVIEW OF THE LITERATURE}

\section{TOOTH, BONE AND PERIODONTAL LIGAMENT DEVELOPMENT}

In trying to answer the question what is the optimal inclination of maxillary and mandibular incisors it is first prudent to review how teeth and the supporting structures, alveolar bone and periodontal ligament (PDL), develop. Establishing the interaction between these elements during development would allow for understanding of their interaction during orthodontic tooth movement (OTM). Tooth formation is a complex process under the control of numerous genes and their timely expression. Simplified, tooth formation ensues when the epithelial lining, referred to as the dental lamina, in the embryo, invaginates into the underlying ectomesenchyme [5]. During this stage of development, bud stage, the cells around the invading epithelial lining begin to condense. As the bud stage transitions to the cap stage, the developing tooth bud grows larger and is tethered to the oral cavity by a thin extension of the dental lamina [5]. The epithelial cells that sit over the condensed mass of ectomesenchymal cells are now identified as the enamel organ as they will form the enamel of the developing tooth. The condensed ectomesenchymal cells are now identified as the dental papilla and will form the dentin and pulp of the developing tooth [5]. The condensed echomesenchymal cells limit the extent of the dental papilla but they also serve to encapsulate the enamel organ, referred to as the dental sac, eventually giving rise to the supporting structures of the tooth [5]. Together, the enamel organ, dental papilla, and dental follicle constitute the tooth germ and will give rise to the dental tissues as well as the supporting tissues of the tooth [5]. It is evident that tooth formation is intimately related to the formation of the supporting structures, alveolar bone and PDL. 


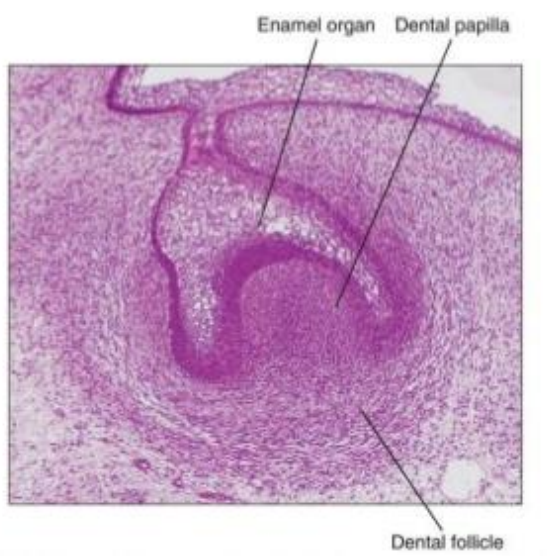

Figure 1. Developing tooth bud

Fig 1. Developing tooth bud in the cap stage with primitive formation of the enamel organ, dental papilla, and dental follicle giving rise to enamel, dentin and pulp, pdl and alveolar bone, respectively.

\section{TOOTH ERUPTION}

Discussing the process of tooth eruption and changes that occur in the surrounding structures, specifically the alveolar housing and PDL, will allow for parallels to be drawn between the events that occur during orthodontic tooth movement and tooth eruption.

Numerous experimental studies by Cahill \& Marks $(1980)^{6}$ were able to identify the dental follicle as the driving force behind tooth eruption. Although, the matter of tooth eruption is much more complicated, the dental follicle is an irreplaceable component. It is important to recall that the dental follicle or sac, eventually gives rise to the supporting structures of the tooth, including PDL, alveolar bone, and cementum. It is also important to highlight that the process of tooth eruption is a physiological process while orthodontic tooth movement is a process that combines both pathologic and physiologic responses to externally applied forces [7]. For tooth eruption to occur there are two basic requirements: the presence of a soft tissue component between the tooth and alveolar bone, and bone turnover. These two fundamental 
requirements can be identified during tooth eruption as well as orthodontic tooth movement. Bone turn over occurs in two phases: modeling and remodeling. Modeling is characterized by osteoclastogenesis and results in skeletal shape changes and translocation of hard-tissue structures [7]. An important aspect of bone modeling during tooth eruption is that formation of an eruption pathway through the process of osteoclastogenesis does not need to be accompanied by tooth eruption [7]. In other words, bone modeling during tooth eruption is genetically controlled and not mechanically regulated by the erupting tooth. Alveolar bone remodeling also must occur at the base of the erupting tooth bud, however alveolar bone resorption and formation are not coupled in the eruption process [7]. Overall, tooth eruption depends on the presence of the dental follicle, later to become the PDL, with the coronal aspect regulating the resorptive pathway while the apical portion regulates osteogenesis. The coronal and apical portions of the dental follicle do not work in concert but are both required for successful tooth eruption.

\section{ORTHODONTIC TOOTH MOVEMENT}

The biological processes that occur during orthodontic tooth movement and the reason we are so successful in achieving orthodontic tooth movements are essential to review and understand. Bone remodeling observed during orthodontic tooth movement (OTM) is a physiological and pathological interplay between osteoclast mediated bone resorption and osteoblast mediated bone formation. Orthodontic tooth movement is accompanied by minor reversible injury to the PDL, which then results in physiologic adaptation of the alveolar bone to the imposed mechanical strains [7]. It is important to recall that both tooth eruption and orthodontic tooth movement have two fundamental requirements. The presence of a soft tissue component between the tooth and alveolar bone, which in the case of orthodontic tooth movement is the PDL, while during eruption that role is filled by the dental follicle, later to become the PDL. The second 
requirement is bone turnover, and in the case of orthodontic tooth movement this is a strictly an adaptive mechanism due to an external strain while in tooth eruption this is a genetically controlled event.

Bone mass is directly determined by the balance between bone resorption and bone formation [8]. Bone resorption results in release of agents from the organic matrix, including bone morphegenic proteins (BMPs), fibroblast growth factor (FGF), and transforming growth factor-B (TGF-B), which then activate bone formation [8]. The interplay between osteoclast and osteoblast differentiation is complex and is under the control of many mediators including the receptor activator of nuclear factor-kB- (RANK)-RANK ligand (RANKL) osteoprotegerin (OPG) signaling pathway, parathyroid hormone, calcitonin, vitamin D, macrophage colonystimulating factor (MCSF), tumor necrosis factor (TNF), and multiple interleukins (IL) [8]. During orthodontic loading the PDL and alveolar bone experience fluid flow, mechanical strain and generation of piezoelectric signals [9]. This in turn activates an intra and intercellular cascade that leads to different bone cell responsiveness. Tensile strain on the PDL and alveolar bone upregulates the expression of osteogenic genes which leads to the differentiation osteogenic progenitor cells into mature osteoblasts with subsequent deposition of osteoid which undergoes mineralization [8]. Compressive strain on the PDL and alveolar bone on the other hand leads to the expression of RANK that initiates osteoclast mediated bone resorption [8].

The bone turnover phase of orthodontic tooth movement is characterized by modeling at the compression sites due to microdamage of the sites with subsequent production of inflammatory processes in the PDL and deformation of the alveolar bone, which leads to increased cellular activity [7]. Additionally, during orthodontic tooth movement the processes of modeling and remodeling seem to be coupled, due to release of paracrine factors on the compression side 
initiating the process of remodeling on the tension side [10]. Overall, it is evident that the compression sites in orthodontic tooth movement are primarily resorptive, while the tensile sites are osteogenic.

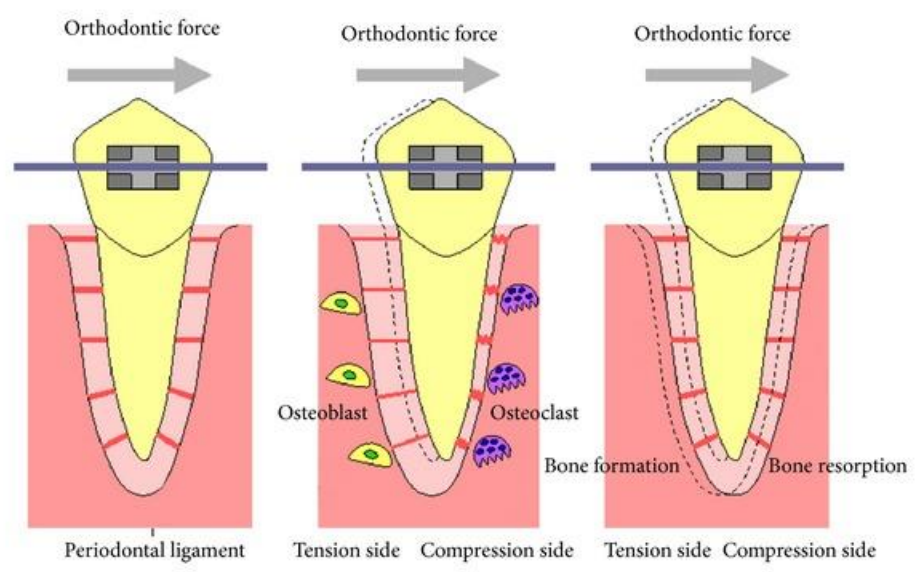

Figure 2. Diagram of orthodontic tooth movement

Fig 2. Orthodontic tooth movement with force application indicating the events occurring on the compression side, resorption, and tension side, osteogenesis.

One final consideration in orthodontic tooth movement is individual variability and response.

The PDL response of individuals varies during orthodontic tooth movement; the same cannot be said of the PDL during normal tooth eruption [7]. These differences can be due to a variety of reasons including biomechanical signals, occlusion, systemic metabolism, age, and variations in bony trabeculation $[11,12]$.

Although the cellular events of orthodontic tooth movement have been identified, we cannot confidently isolate the limits of the remodeling process, nevertheless, we are able to draw some important inferences. Orthodontic tooth movement, although similar to the process of tooth eruption in many ways, has distinct differences that maybe limit our ability to move the 
dentition. Orthodontic tooth movement relies on an underlying pathological process of tissue damage in order to achieve desired movements. Further, it is clear that the compression side during tooth movement is resorptive while the tension side is osteogenic, this in itself limits the amount of desired movement we are able to achieve. Tooth eruption is unique in that the dental follicle dictates the resorptive and osteogenic pattern of the tooth bud; therefore it ensures that the tooth regardless of its position in the arch should have adequate bony support. Orthodontic tooth movement does not have this advantage and solely relies on the existing alveolar conditions to move the dentition with subsequent phase of remodeling, which has its limitations. CEPHALOMETRIC DETERMINATION OF INCISOR INCLINATION

There is extensive research on incisor inclination and the associated alveolar housing, the limits of incisor retraction, the negative consequences of incisor over retraction/proclination, and the risk factors associated with improperly inclined incisors, however, we have yet to discuss how 'optimal' inclination has been defined. The position of the maxillary and mandibular incisors has been a long-standing debate in orthodontics and has many variations. The current standards and views of where the mandibular and maxillary incisors belong in the alveolar housing are vast and varied and must be considered individually.

\section{DR. CHARLES TWEED}

Dr. Charles Tweed was an outspoken proponent of the importance of proper mandibular incisor inclination for optimal orthodontic, esthetic and stable results. Although the norms Dr. Tweed established as optimal treatment goals were based on anecdotal evidence they are still currently used and accepted in the orthodontic community. Dr. Tweed advocated the use of three measurements: Frankfort-mandibular angle (FMA), Frankfort-mandibular incisor angle (FMIA), and incisor-mandibular plane angle (IMPA). These three planes when connected formed the 
Tweed triangle [13]. The average measurements were established by Dr. Tweed based on four cases that he felt were treated to optimal occlusion and esthetic results. The measurements that were established were as follows: $\mathrm{FMA}=25^{\circ}, \mathrm{FMIA}=65^{\circ}$, and IMPA $=87^{\circ}[13]$. Therefore, based on this the frequently proposed norm for mandibular incisor inclination is $87^{\circ}$ to the mandibular plane. There is error in trying to achieve this goal as incisor inclination will greatly vary based on the steepness of the mandibular plane and also the inclination of the symphysis.

\section{DR. CECIL STEINER}

Dr. Cecil Steiner is another prominent name in orthodontics that paved the way for cephalometric norms and numbers still used in current orthodontic practices. Dr. Steiner gives much credit to his predecessors, such as Downs, Riedel, and Thompson, for the foundation of his research and work [14]. This foundation led Steiner to make additions based on his clinical experience, and he believed they were valid because "time and the clinical experience of many practitioners have now tested them" [14]. Inclination of the maxillary and mandibular incisors, were just a few norms that Dr. Steiner was able to impart on the orthodontic community. According to Dr. Steiner the maxillary incisor should be measured relative to the line NA (Nasion-A point) and should measure $22^{\circ}$, while the mandibular incisor should be measured relative to the line NB (Nasion-B point) and should measure $25^{\circ}$. Although Dr. Steiner derived these measurements from an $\mathrm{N}$ of 1 as well as on his clinical experience and observations they are widely accepted in the field of orthodontics, in fact the American Board of Orthodontics currently uses them as the cephalometric norms.

\section{DR. CHARLES BURSTONE}

Dr. Burstone well known for his extensive explanation of orthodontic mechanics also added to the debate of proper incisor inclination. In 1978 Dr.Burstone developed an analysis to aid the 
orthodontist in diagnosis and treatment planning. One of those measurements was the upper incisor inclination relative to the palatal plane. The palatal plane was defined as a line connecting the posterior nasal spine (PNS) and anterior nasal spine (ANS). The angle was measured relative to the long axis of the tooth. Dr. Burstone established cephalometric norms of approximately $110^{\circ}$ for males and $112^{\circ}$ for females. Once again these measurements were based on clinical experience and existing patient pool. Some draw backs were mentioned in using this plane for maxillary incisor analysis, such as the different inclination of the palatal plane, nevertheless, those inadequacies were overlooked and became a standard cephalometric measure in orthodontics.

\section{DR. WILLIAM DOWNS}

Dr. Downs (1948) made a contribution to the debate of incisor inclination by analyzing 20 Caucasian subjects of range 17-21 years of both sexes. The subjects were judged to poses ideal occlusions and no previous orthodontic treatment. Dr. Downs determined incisor inclination based on the mandibular plane with a line drawn down the long axis of the mandibular incisors. Based on his sample, it was established that mandibular incisors inclined at 90 degrees to the mandibular plane were ideal. Dr. Downs defined 90 degree angle as zero, incisors proclined beyond ninety would be subtracted from 90 and would have a negative value associated with it, while retroclined incisors subtracted from 90 would have a positive value associated with it. Overall, Dr. Downs established that the norm for mandibular incisors is 1.4 degrees with a range of 7-(-)8.5 degrees.

\section{DR. ROBERT RICKETTS}


Dr. Robert Ricketts (1960) measured mandibular incisor inclination by the intersection of the long axis of the mandibular central incisors and the line A-Pogonion, with a mean of 22 degrees and a range of 18 to 26 degrees.

\section{DR. LAWRENCE ANDREWS}

Thus far we have discussed several prominent names in the orthodontic field and the many ways they utilized cephalometrics to establish norms for the maxillary and mandibular incisor inclinations. Nevertheless, there is lack of agreement upon orthodontist on the ideal measure that would allow us to identify the 'optimal' incisor inclination. Each cephalometric norm although applicable to some patient does not span the entirety of the orthodontic population and further has several limitations and inconsistencies. Let us now focus on the proposed method of measuring incisor inclination by Dr. Lawrence Andrews.

\section{THE SIX ELEMENTS OF OROFACIAL HARMONY}

The Six Elements of Orofacial Harmony is a diagnostic and treatment philosophy that identifies a clinically relevant method to assess and plan the position of the teeth and jaws. The six elements are arch development, jaws antero-posteriorly, and jaws in the transverse dimension, jaws in the vertical dimension, pogonion prominence, and inter-arch occlusion [16]. Andrews defined each element as optimal based on ideal occlusions and facial esthetics of 120 non-treated patients. He was able to identify six key features found in optimal occlusions that have been widely accepted. This is a unique classification system in that it does not rely on cephalometric norms. For brevity, only elements applicable to the current project will be discussed. For complete summary of Andrew's Six Elements of Orofacial Harmony please refer to the Andrews Foundation. 


\section{ELEMENT I}

Element I describes the shape and length of the maxillary and mandibular arches. Optimal arches are achieved when the teeth are in the correct inclination, the roots of the teeth are centered in basal bone, and the curve of spee does not exceed $2.5 \mathrm{~mm}$ 's. In order to determine the optimal inclination of the incisors, a lateral cephalogram is utilized. The inclination of the maxillary and mandibular incisors are identified based on the occlusal plane. The occlusal plane is defined as a plane that divides the maxillary and mandibular curve of spee and approximates the posterior occlusion. The maxillary and mandibular incisors are then identified using the Andrews template based on the existing occlusal plane with the roots centered in basal bone. The template incisor inclination relative to the occlusal plane provides an optimal inclination of the incisors. The maxillary incisor is defined optimal at $7^{\circ}$ to the occlusal plane from the facial surface or $25^{\circ}$ to the occlusal plane through the long axis of the tooth. The mandibular incisor is defined optimal at $-1^{\circ}$ to the occlusal plane from the facial surface or $15^{\circ}$ to the occlusal plane through the long axis of the tooth.

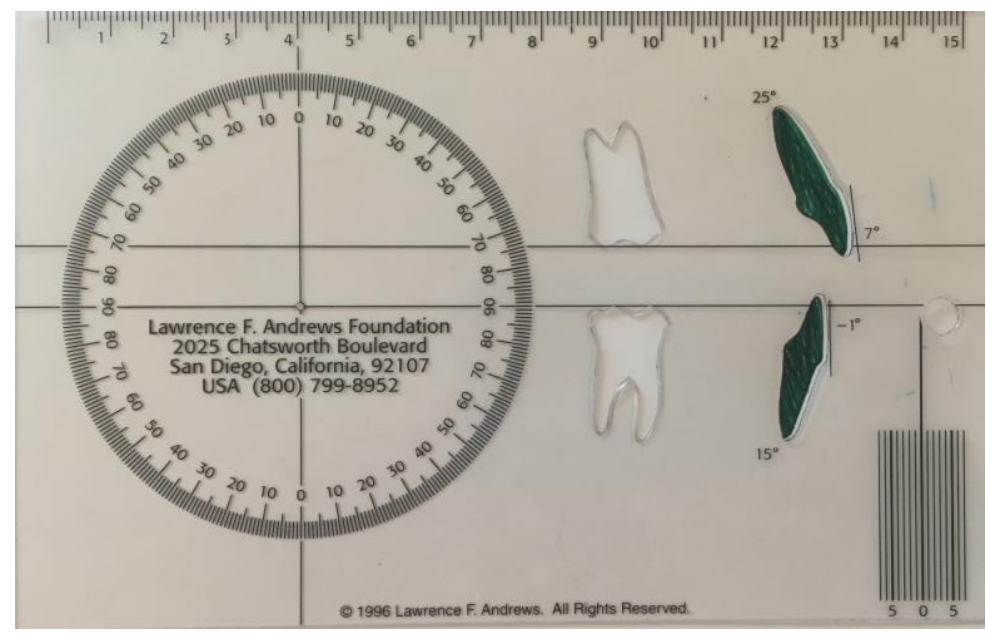

Figure 3. Andrew's template 
Fig 3. Andrew's template utilized to determine the optimal incisor inclination based on the occlusal plane.

Dr. Andrews derived the optimal incisor inclination based on carefully examining the 120 nontreated patients with optimal occlusions. Dr. Andrews was then able to generalize based on the averaged inclinations.

Table 1. Average Mx and Md incisor inclination. Average incisor inclinations with standard deviations based on a sample size of 120 non-treated patients with optimal occlusions. The range of maxillary and mandibular inclinations is also noted.

\begin{tabular}{|l|l|l|l|l|}
\hline Incisor Inclination & Average & Std. Dev. & Max Value & Min Value \\
\hline Maxillary & $6.11^{\circ}$ & $3.97^{\circ}$ & $15.00^{\circ}$ & $-7.00^{\circ}$ \\
\hline Mandibular & $-1.71^{\circ}$ & $5.79^{\circ}$ & $16.00^{\circ}$ & $-17.00^{\circ}$ \\
\hline
\end{tabular}

\section{$\underline{\text { ELEMENT II }}$}

Element II describes the anteroposterior position of the maxilla and the mandible relative to a reproducible landmark, the goal anterior limit line (GALL). An optimal Element II maxilla requires the facial axis of the maxillary central incisors to be on the GALL. The maxilla is classified as retrognathic, prognathic, or orthognathic by measuring the distance from the maxillary incisors facial axis to the GALL, with the teeth in Element I position. The mandible is classified as retrognathic, prognathic, or orthognathic by measuring the distance from the facial surface of the mandibular incisors to the lingual surface of the maxillary Element I incisors with the maxilla in an optimal Element II position, with the mandibular teeth in Element I position. 


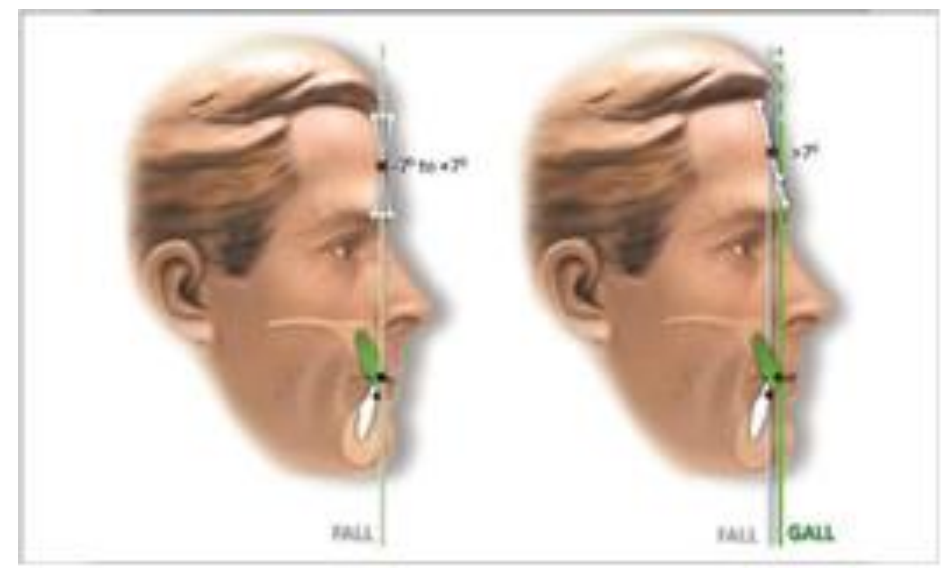

Figure 4. Element II

Fig 4. Utilizing this method of analysis, the jaws can measured as retrognathic, prognathic, or orthognathic based on the anterior-posterior distance from the GALL. Further, this analysis allows for classification of the inter-jaw discrepancy.

\section{BOUNDARIES OF ORTHODONTIC TOOTH MOVEMENT}

\section{ALVEOLAR BONE MORPHOLOGY}

Alveolar bone, the supporting structure for the dentition, is highly specialized and adaptive. Alveolar bone is structurally comparable to other bone tissue, with one essential exception, its ability to continually and rapidly remodel [17]. This unique quality of alveolar bone is essential for adaptation during tooth eruption. In fact, alveolar bone although continuous with the underlying basal bone of the maxillary and mandibular denture bases, forms in relation to the eruption of teeth, and requires dentition to be maintained [17]. This complex interplay between the dentition and alveolar bone leads to the question if incisor position can be altered during orthodontic therapy while still maintaining adequate periodontal support. According to Sodek \& $\mathrm{McKee}^{17}$, alveolar bone completely remodels when the primary dentition is replaced by their successors. Further, the bone associated with the primary dentition, along 
with the primary tooth, completely resorbs and is replaced by new alveolar bone as the permanent teeth erupt into the oral cavity. This amount of change and adaptability exhibited by the bone leads us to question if the same amount of adaptability and flexibility can be achieved during orthodontic therapy. Are the boundaries of tooth movement, particularly incisors, limited to the existing alveolar bone? The capability of alveolar bone to completely resorb and remodel during tooth eruption would suggest otherwise. This further leads to the question does physiologically determined tooth position, specifically incisor inclination, always result in optimal bucco-lingual bony support. Does incisor inclination matter?

Numerous studies have focused on assessing the bucco-lingual support in orthodontically treated patients. According to Sarikaya ${ }^{18}$. lingual alveolar bone loss was seen in a significant portion of patients treated with extractions to retract the mandibular incisors. Lund ${ }^{19}$ was able to bolster these findings by concluding that bone height decrease is seen in $84 \%$ of patients who undergo extraction treatment to retract the mandibular incisors. There are also multiple studies to support buccal bone loss on maxillary and mandibular incisors when they are proclined [14, 20]. Clearly the adaptability of alveolar bone has limitations in both the buccal and lingual directions. The boundaries of tooth movement is determined by numerous factors including anatomy prior to treatment, cortical bone thickness, ridge width thickness, bones adaptability during tooth movement, as well as the final position of the teeth [21]. The implication is that pre-treatment conditions may dictate the limitations of the planned tooth movement, however the assumption that pre-treatment conditions are devout of bony dehiscences and fenestrations are false. Although these factors are important to consider during orthodontic treatment the question still remains if there is an optimal inclination of incisors within the alveolus that will result in optimal bony support, which can then set guidelines for planned orthodontic tooth movement. 


\section{$\underline{\text { ALVEOLAR BOUNDRIES DURING OTM }}$}

An important aspect to consider when contemplating the topic of alveolar boundaries during tooth movement is the unique ability of alveolar bone to remodel during treatment. According to Handelman ${ }^{22}$, unlimited tooth movement assumes that the bony housing can fully regenerate itself in any direction the tooth is moved. The concept that "bone traces tooth movement" has been a long debated topic in orthodontics [23]. This debate focuses on the idea that during orthodontic tooth movement the bone around the socket remodels to the same extent regardless of the type and amount of movement. It should be stressed that if in fact any type of tooth movement results in the same amount of bone remodeling, as orthodontist we would not be concerned about the limitations of tooth movement in any direction. Nevertheless, clinical experience has shown that although alveolar bone can and does remodel during tooth movement there are limitations, if exceeded, can lead to unwanted consequences. This debate continues because although it is logical to state that teeth cannot be moved indefinitely in any dimension, those boundaries have yet to be defined. From a periodontal standpoint a serious concern of orthodontic tooth movement is the loss of periodontal support, dehiscences, and fenestrations. Proffit and Ackerman ${ }^{9}$ also tried to address the issue of the alveolar housing and its ability to remodel during orthodontic treatment and even proposed a theoretical model of limitations of tooth movement (Figure 5). They were able to define three envelopes: the inner envelope which represents limits of orthodontic incisor movement, the middle which represents the changes that can be achieved via growth, and the outer envelope which represents the limits that can be achieved via orthognathic surgery. Although, this serves as a guide to the orthodontic profession these markers were not based on any precise measurements or anatomical barriers and/or variations. Theoretically practical but clinically not applicable. 

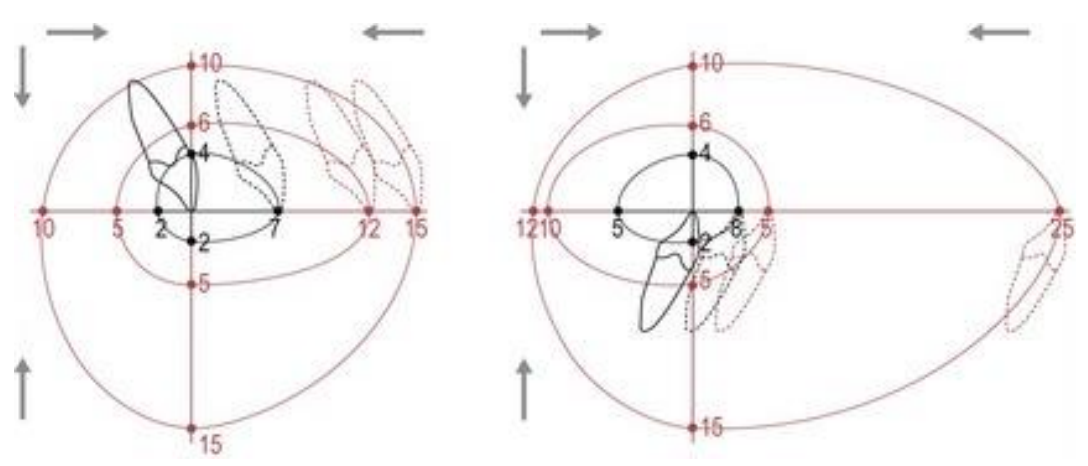

Figure 5. Boundaries of tooth movement

The study of bidental protrusion patients which required premolar extractions to resolve the incisor proclination lead to some interesting conclusions regarding alveolar housing remodeling. Edwards $^{24}$ found that despite the significant retraction of maxillary incisors the alveolar bone remodels at the midroot and alveolar margin to accommodate the tooth movement. However, he did identify that a thin alveolus placed greater restraints on orthodontic tooth movement. It can be concluded that one of the factors associated with the limit of orthodontic tooth movement is anatomy of the alveolus. More current studies also support the idea that alveolar bone remodels during orthodontic tooth movement. Retracting mandibular incisors in bidental protrusion patients resulted in increase of labial alveolar bone at the end of orthodontic treatment [25]. Therefore, it can be stated that alveolar bone does remodel during orthodontic tooth movement. Handelman ${ }^{22}$ postulated that the labial and lingual cortical plates at the level of the apex limit the boundaries of anatomic tooth movement. He was able to show thinner alveolar bone thickness both labially and lingually in patients identified as high angle, identifying yet another risk factor for limitation of incisor movement. Although much research has been focused on the limits of alveolar bone remodeling during orthodontic tooth movement, which have led to identifying multiple risk factors leading to unfavorable sequelae we are lacking definitive conclusions. DAMON 
Although we believe alveolar boundary conditions exist and violating these conditions can lead to unwanted periodontal consequences, advocates of the Damon philosophy oppose this view. According to Damon the use of very light forces can and does expand the alveolar bone while eliminating the negative sequelae, citing tooth movement compatible with physiologic bone

remodeling. We have already established that orthodontic tooth movement, regardless of force application, utilizes a pathologic process in order to take advantage of physiologic bone response. This is an interesting claim because it would then force the conclusion that alveolar boundaries do not limit OTM and can be used to allow the arch to reshape itself to accommodate the dentition [26]. There have been case reports that show tremendous results with increases in inter-molar widths of up to $10 \mathrm{~mm}$, claiming no negative consequences and stability $[27,28]$. Unfortunately, these claims have been unsubstantiated, and have failed to show buccal bone augmentation [26]. Thus, claims have been made that would suggested alveolar boundaries do not exist but they have yet to be supported with scientific evidence.

\section{WILCKODONTICS}

Although Damon claims alveolar boundaries do not limit tooth movement, Wilckodontics takes a different approach and expands the alveolar boundaries to accommodate desired tooth movement. Periodontally Accelerated Osteogenic Orthodontics (PAOO), also known as Wilckodontics, takes advantage of the healing properties of bone known as regional acceleratory phenomenon (RAP) [29]. Wilckodontics utilizes a surgical demineralization procedure of the cortical bone (corticotomy) and use of particulate bone grafting to expand the alveolar boundary conditions. This two-step procedure allows for acceleration of tooth movement due to inflammation created as a result of injury delivered to the cortical bone and adds additional bone 
in the transverse and/or sagittal dimensions to expand the alveolar boundaries and therefore expand the limits of orthodontic tooth movement [29].

\section{FACTORS LIMITING ORTHODONTIC TOOTH MOVEMENT}

We have identified the proposed boundaries of tooth movement and the new approaches to overcome those boundaries. However, we must not overlook the tremendous amount of research that has identified the patient factors that limit those boundary conditions and therefore orthodontic tooth movement.

Alveolar bone thickness at the incisor region has been shown to have a significant correlation to growth facial patterns $[30,2]$. Patient classified with a short face type, hypodivergent, presented with significantly greater alveolar bone thickness compared to long faced-patients $[30,31]$. In short faced-patients, the root apex was found to be further away from the lingual cortex [30]. This is an indication of a differential inclination of incisors in short-faced, hypodivergent patients. Hyperdivergent patients on the other hand present with a thinner mandibular symphysis and a thinner alveolar ridge in the anterior mandible [22]. This finding leads to the conclusion that orthodontic treatment of hypodivergent facial patterns leads to a greater envelope of incisor movement to achieve the proper occlusion or camouflage treatment. Nevertheless, this does not establish specific anatomic boundaries on which an orthodontist can rely on to achieve these goals. Different facial types exhibit differential symphasial shape and length, which contributes to the differential amount of bucco-lingual bone observed in these individuals. Regardless, of facial type we must identify a universal and stable landmark, which will allow us to position the maxillary and mandibular incisors in the proper inclination, resulting in equal amount of buccolingual bone. Although, the envelope of tooth movement maybe greater for hypodivergent 
individuals, the question still remains what is the optimal position of the incisors in the alveolar process.

Facial type is not the only predictive factor of bucco-lingual bone observed in the alveolus. Incisor inclination also plays a significant role in determining the amount of bucco-lingual bone. The apex of incisors shows significantly greater bone in both the buccal and lingual dimensions compared to the middle and cervical regions [32]. Furthermore, greater apical bone thickness was observed in incisors with greater inclination, as measured by an increase in the angle between the axis of the upper central incisor and the palatal plane [32]. Study of the mandibular central incisor inclination and bony changes; shows inconclusive results post orthodontic treatment.

A study conducted by Nayak ${ }^{33}$, retraction of maxillary and mandibular incisors in bi-maxillary protrusive patients, resulted in significant decreases in labial bone thickness in the mandibular incisor region while the maxillary incisors do not show any significant changes post retraction. Shaw $^{25}$ was able to draw the opposite conclusion, retraction of procumbent mandibular incisors results in an increase in the amount of buccal alveolar bone. Once again there is lack of evidence to indicate the anatomical boundary of bucco-lingual bone as it relates to incisor inclination. Another factor that must be considered when trying to define tooth position in the alveolus is the different types of skeletal and dental malocclusions. Patients with a high angle skeletal relationship present with thinner alveolus anteriorly in both the maxilla and mandible, while the low angle skeletal relationship show higher mean values of the labio-lingual anatomical limits [34]. In addition, analyzing lateral cephalograms of Class I, II, and III skeletal relationships reveals more inclination of the alveolar bone towards the mandibular plane, larger mandibular symphysis dimensions and area in the Class II skeletal relationship compared to Class I and III 
[35]. Inclination of incisors also varies based on the skeletal and dental relationship of Class I, II, and III patients. Class III malocclusions often present with more proclined maxillary incisors and lingually inclined mandibular incisors, exhibiting differential bucco-lingual bone support [37]. The question still remains, despite different skeletal and dental malocclusions, are there anatomical boundaries that must be respected during orthodontic treatment and is there an optimal incisor inclination, that if can be successfully achieved during orthodontic treatment will result in proper bony support and therefore periodontal stability and health.

Nauert ${ }^{37}$ concluded that identifying bone conditions prior to orthodontic treatment is essential for developing a treatment plan and proper treatment mechanics. Furthermore, Dayoub ${ }^{38}$ was able to show, using CBCT imaging, that the buccal apical and lingual apical region of the mandibular incisors had the greatest amount of supporting bone, while the buccal cervical region had the least, in untreated adults. Drawing the conclusion that treatment mechanics should avoid uncontrolled buccal tipping during orthodontic therapy. Nevertheless, they failed to conclude if there was a limit to forward incisor movement or if any forward movement was contraindicated. An interesting finding by Garlock et al. was that although orthodontic treatment causes changes in alveolar bone height and cortical bone thickness incisor inclination was not correlated with alveolar bone height changes. Overall, we can see there is lack of consensus and yet overwhelming amount of research.

Angle believed in the non-extraction approach to treatment, with the underlying belief that expansion in the sagittal and transverse dimensions could accommodate the dentition. While, Tweed took a different approach, stating that the envelope of tooth movement is limited in the sagittal and transverse dimensions and therefore extractions were often necessary. The debate 
didn't end there and still continues today, with so many confounding variables to consider it is no wonder there is lack of consensus on 'optimal' incisor position.

\section{PERIODONTAL CONSIDERATIONS}

Defining limits of orthodontic incisor movement prior to therapy has long plagued clinicians. The idea of limiting incisor movement based on the existing periodontal conditionals is not novel; nevertheless, they too fail to provide a definitive answer. Prior to analyzing the literature for scientific findings it's important to define the terminology. Orthodontists are often concerned with causing dehiscences and fenestrations during treatment. Dehiscence is defined as isolated areas in which the root is stripped of bone and the root surface is only covered by a thin layer of periosteum and the overlying gingiva, an important distinction is that the stripped areas extends through the marginal bone [39]. Fenestrations on the other hand are isolated areas in which the root is stripped of bone and the root surface is covered only by periosteum and the overlying gingiva, however, the marginal bone is intact [39].

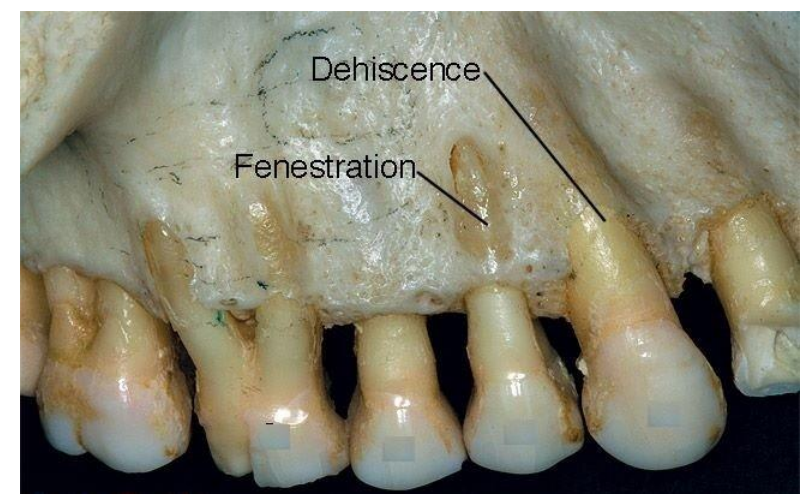

Figure 6. Periodontal defects

Gingival recession is the common result that arises as a consequence of dehiscences. Gingival recession is defined as "the exposure of the root surface by an apical shift in the position of the gingiva" [40]. Gingival recession can lead to poor aesthetics, root sensitivity, increased 
susceptibility to caries, tooth abrasion, and decline in oral hygiene [41]. It has been estimated that $10-12 \%$ of orthodontic patient exhibit gingival recession [41]. It has also been reported that the prevalence of dehiscences varies from 3.2-7.1\% based on the population [42]. During orthodontic tooth movement gingival recession is thought to occur as a result of roots moving through the alveolar cortical bone which in turn causes a dehiscence [43]. Many authors have suggested that tooth movement "within the envelope of alveolar bone" reduces the risk of harmful side effects [44]. However, the definition and boundaries of the "envelope of alveolar bone" alludes us. Gingival biotype has also been cited as an important risk factor in gingival recession. Patients with thick gingival biotype are considered to be at less risk than those with thin scalloped biotype $[45,46]$. Clearly, periodontal considerations during orthodontic tooth movement are multifactorial and are not mutually exclusive of each other.

Previous research has focused on assessing periodontal recession in the mandibular incisor region after orthodontic proclination. The results are varied, some supporting the idea that periodontal recession occurs after incisor proclination while others found no correlation between incisor proclination and negative periodontal sequelae [47]. According to Yared ${ }^{4}$ final inclination of greater than $95^{\circ}$ showed greater recession of the mandibular incisors. The authors utilized the mandibular plane as a reference to define the inclination of the mandibular incisors. The contention of the current project is that the mandibular plane is a not an adequate reference to properly describe the inclination of the incisors. A study conducted by Ruf ${ }^{48}$ utilized similar reference points in order to assess the periodontal consequences of incisor proclination. They confidently stated that "orthodontic proclination of lower incisors in children and adolescents seems not to result in gingival recession." Using the statement from the previous paper it may be concluded that there are no limits to incisor proclination. Additional research by Melsen \& 
Allais ${ }^{49}$ identified predisposing factors, such as, baseline recession, gingival biotype, and gingival inflammation, as possible risk factors during adult orthodontic treatment. But overall, they were able to conclude that gingival recession of mandibular incisors did not significantly increase during orthodontic adult treatment. An important aspect to contemplate while discussing periodontal considerations during orthodontic tooth movement are the periodontal conditions in untreated patients. Research has indicated that periodontal defects, dehiscences and fenestrations, can be found in untreated populations. Once again, multiple factors contribute to the presence of such defects. Vertical growth pattern is one of the factors analyzed as an element contributing to periodontal defects. According to Enhos ${ }^{50}$ there is a significant difference of presence of dehiscences in patients with different vertical growth patterns. Hypo-divergent patients exhibit lower prevalence of dehiscences compared to normo-divergent and hyper-divergent patients. Interestingly, the presence of fenestrations was not significantly different among facial types. Dehiscences and fenestrations were found to be more prevalent on the buccal aspect compared to the lingual. Finally, fenestrations were more commonly identified in the maxillary alveolar region while dehiscences were a common finding in the mandible [50]. Another study looking at untreated patients concluded that there is a difference in the presence of periodontal defects based on skeletal classification. Significant presence of fenestrations were identified in patients classified as skeletal Class II or skeletal Class III compared to skeletal Class I individuals [23]. Interestingly, the authors also concluded that fenestrations were more prevalent in the maxilla while dehiscences were more prevalent in the mandible. It seems that even in untreated patients there are unwanted periodontal consequences based on the existing malocclusion and facial 
pattern. Nevertheless, incisor inclination, regardless of malocclusion or facial type, were not analyzed, in order to conclude if optimal incisor inclination results in optimal bone support. CBCT ANALYSIS OF PERIODONTAL DEFECTS

An important aspect of trying to analyze periodontal defects utilizing CBCT imaging, is the accuracy and reliability of this method. Prior to 3D analysis researchers relied on analysis of dry skulls and flap surgery to identify these defects. Dehiscences and fenestrations cannot be reliably identified based on standard radiographic images due to the overlap of bone on the x-rays [42]. Intraorally, the soft tissue serves as a barrier to correctly identifying periodontal defects. Therefore, the only way to measure the existing periodontal defects in vivo is utilizing 3D imaging.

Currently, there has been a wave of research on the accuracy of CBCT images in identifying such defects in vivo. Research has shown that CBCT is very effective in identifying artificially created and naturally occurring dehiscences and fenestrations on dry skulls. It was recently reported by de-Azevedo-Vaz ${ }^{51}$ that using CBCT to identify periodontal defects created by the operator, including dehiscences and fenestrations, is very accurate and reliable. In addition, the authors reported that voxel size of the scanned image was not a significant predictor of the ability to detect these defects. Sun $^{52}$ was able to test the accuracy of 3D imaging in identifying periodontal defects in vivo. The results were compelling, the authors found that $83 \%$ of true dehiscences were detected, $27 \%$ of healthy teeth were misdiagnosed as having dehiscences, $71 \%$ of true fenestrations were detected, and $23 \%$ of healthy teeth were misdiagnosed as having fenestrations. The authors were able to conclude that for both dehiscences and fenestrations, CBCT imaging systematically overestimates their presence. Therefore, there is a risk of false positive results rather than false negatives. 


\section{IDENTIFICATION OF ALVEOLAR DEFECTS}

A recent study conducted by $\operatorname{Tian}^{53}$ analyzed alveolar bone thickness of maxillary incisors of varying inclinations. As part of their analysis they identified alveolar bone defects (dehiscences and fenestrations) as visualized on a CBCT. Tian and colleagues defined an alveolar bone defect as 'any site showing no cortical bone around the root in at least three sequential slices $.5 \mathrm{~mm}$ in thickness. Further, alveolar defects more than $2 \mathrm{~mm}$ from the cement-enamel junction (CEJ) was defined as a dehiscence, while an opening through the alveolar bone exposing parts of the root surface but not involving the alveolar crest was defined as a fenestration [53].

\section{CHAPTER 3: RESEARCH DESIGN AND METHODOLOGY}

\section{METHODOLOGY}

\section{$\underline{\text { IRB APPROVAL }}$}

IRB exemption was obtained from West Virginia University Institutional Review Board prior to the start of this study (see Appendix A).

\section{DATA COLLECTION}

A sample of 100 prospective orthodontic patients from the private practice of Dr. Thomas Shipley in Peoria, AZ was utilized for this study. Pre-treatment CBCT images taken with the iCAT 3D Cone Beam Dental Imaging System. Each scan met the technical specifications of a full field of view of $170 \mathrm{~mm}^{3}$, power of $120 \mathrm{kV}$, and exposure of $5 \mathrm{~mA}$ for 7 seconds. All scans were taken in natural head posture (NHP) and jaws positioned in centric relation (CR). The subjects ranged in age from 17 to 20 years. All scans were de-identified before analysis and assigned a subject number from 001 to 100 . 


\section{$\underline{\text { SAMPLE DESCRIPTION }}$}

The subjects ranged in age from 17 to 20 years to minimize the confounding variable of alveolar bone defects, such as dehiscences and fenestrations, and overall alveolar bone loss, which frequently occurs in older individuals.

\section{INCLUSION CRITERIA}

Subjects were included by the following criteria $(n=100)$

1. Full field view of CBCT scans of $170 \mathrm{~mm}^{3}$, including all pertinent anatomy vertically from glabella to hard tissue menton.

2. Patient aged 17-20 years at the time of pre-treatment CBCT scan.

3. No history of previous treatment recorded in patient chart.

\section{EXCLUSION CRITERIA}

Subjects were excluded by the following criteria $(n=100)$

1. Poor image quality, artifacts, or missing anatomy.

2. Craniofacial syndrome or developmental deformity.

3. Root resorption and/or abnormal root morphology.

4. Severe misalignment of the maxillary or mandibular incisors.

5. Missing/impacted maxillary or mandibular central incisors.

6. Prosthetic crowns on the maxillary or mandibular incisors. CBCT ORIENTATION 
Image orientation is an important factor in assuring accuracy and consistency of the measurements. According to Kapila ${ }^{54}$ the CBCT scans should be orientated in all three planes of space utilizing the triplane view found in 3D software analysis programs.
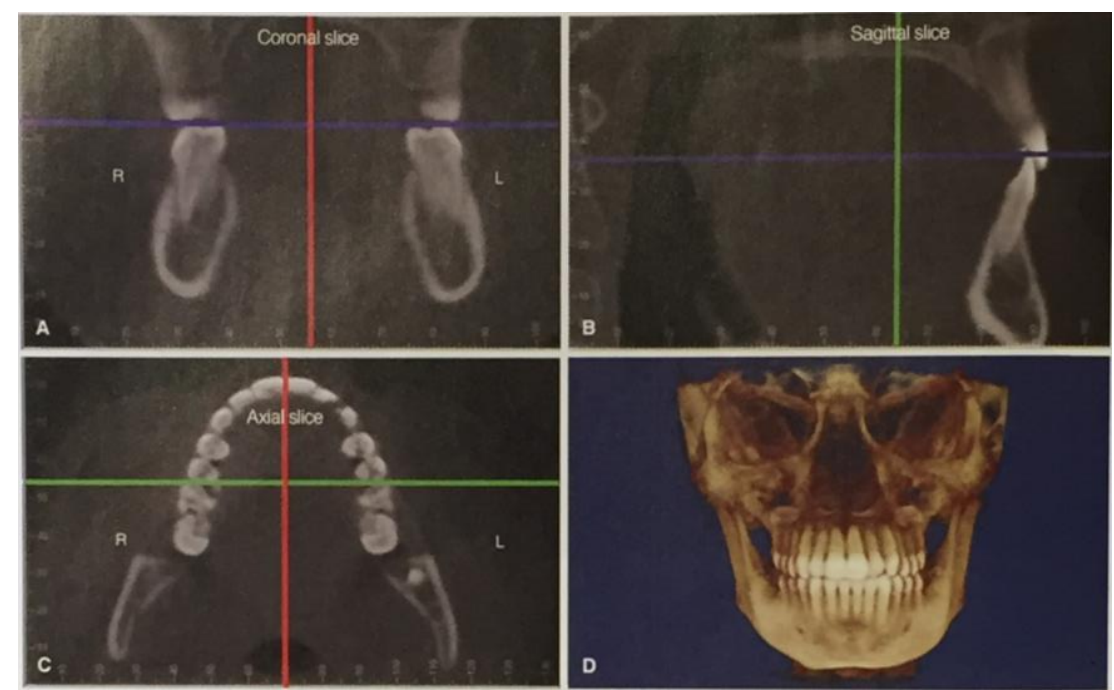

Figure 7. CBCT Orientation

Fig 7. Orientation of a CBCT in the frontal, lateral, and axial perspective based on proposed landmarks.

All DICOM files were uploaded into Anatomage InVivo 5 software for orientation and analysis. In order to achieve consistency in orientation a co-ordinate system was set, to define an axial line, a sagittal line and a coronal line. All CBCT images utilized in this research project were oriented in all three planes of space in order to achieve consistency. 
Zygomaticofrontal sutures ( $\mathrm{Z}$ points) were used to define an axial line based on previous studies utilizing a similar co-ordinate system $[55,54]$. Ricketts ${ }^{56}$ defined the zygomatic suture points as the medial termini of the zygomaticofrontal sutures. Previous studies have identified $\mathrm{Z}$ points as stable reference points located at a sufficient distance from most facial asymmetries [57]. By connecting the $\mathrm{Z}$ points the $\mathrm{CBCT}$ volume was oriented from the frontal perspective, establishing the roll of the image.
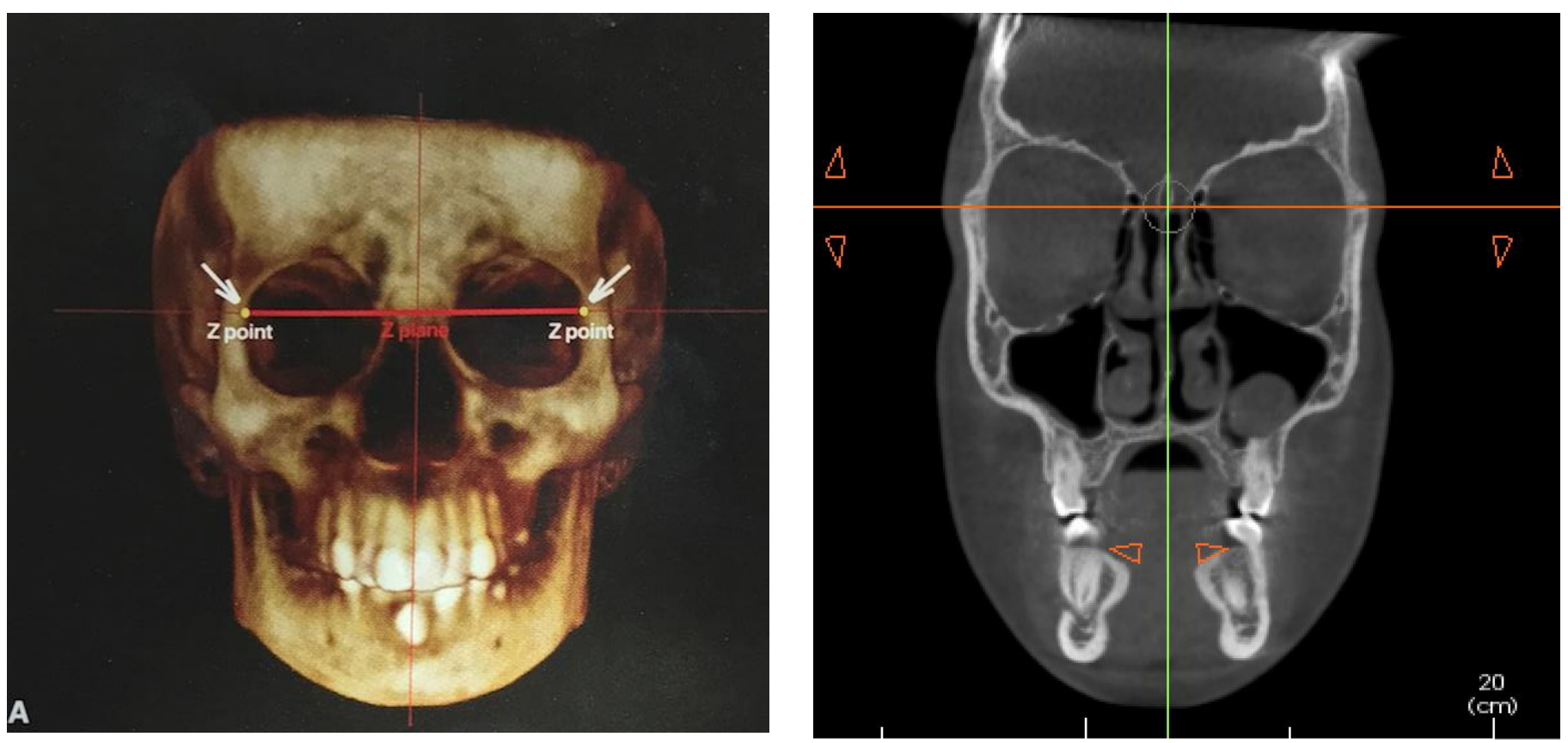

Figure 8. CBCT orientated from the frontal perspective

Fig 8. Orientation of a CBCT volume from the frontal perspective by connecting the Z-points, defining an axial line, establishing the roll of the image. 
Frankfort Horizontal was used to define a sagittal line. By connecting the superior portion of porion with the inferior portion of the orbit (bisecting the structures bilaterally) the CBCT volume was oriented from the lateral perspective, establishing the pitch of the image.
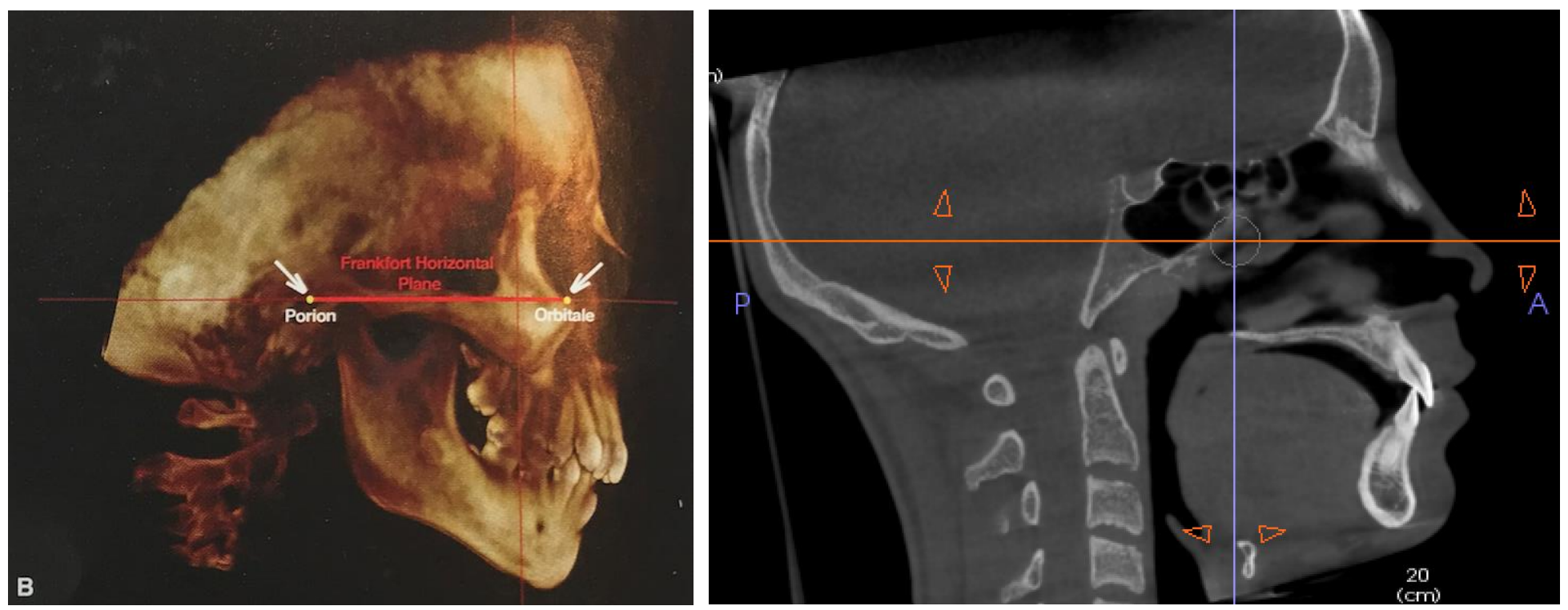

Figure 9. CBCT oriented from the lateral perspective

Fig 9. Orientation of a CBCT volume in the sagittal perspective by connecting superior portion of porion and inferior portion of the orbit (bisected bilaterally), defining a sagittal line, establishing the pitch of the image. 
Zygomaticotemporal suture points (ZT points) were used to define a coronal line. By connecting the ZT points the CBCT volume was oriented from the axial perspective, establishing the yaw of the image. Final head orientation was saved and used for all future measurements and analysis for each subject.
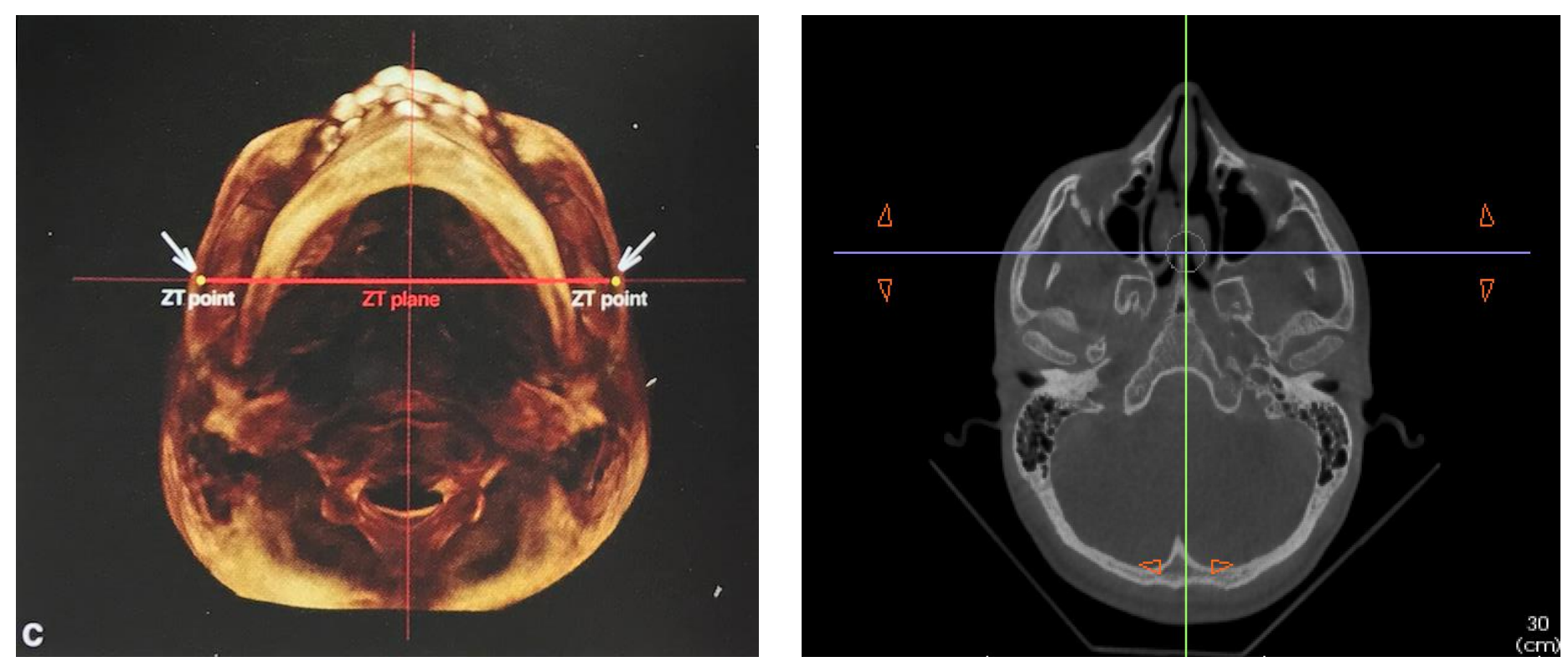

Figure 10. CBCT orientated from the axial perspective

Fig 10. Orientation of a CBCT volume in the axial perspective by connecting the ZT points, defining a coronal line, establishing the yaw of the image.

\section{MEASUREMENTS}

After image orientation was established each scan was traced and digitized, the right and left side of the image were traced independently, to obtain the relevant measurements. Each measurement was then recorded. 

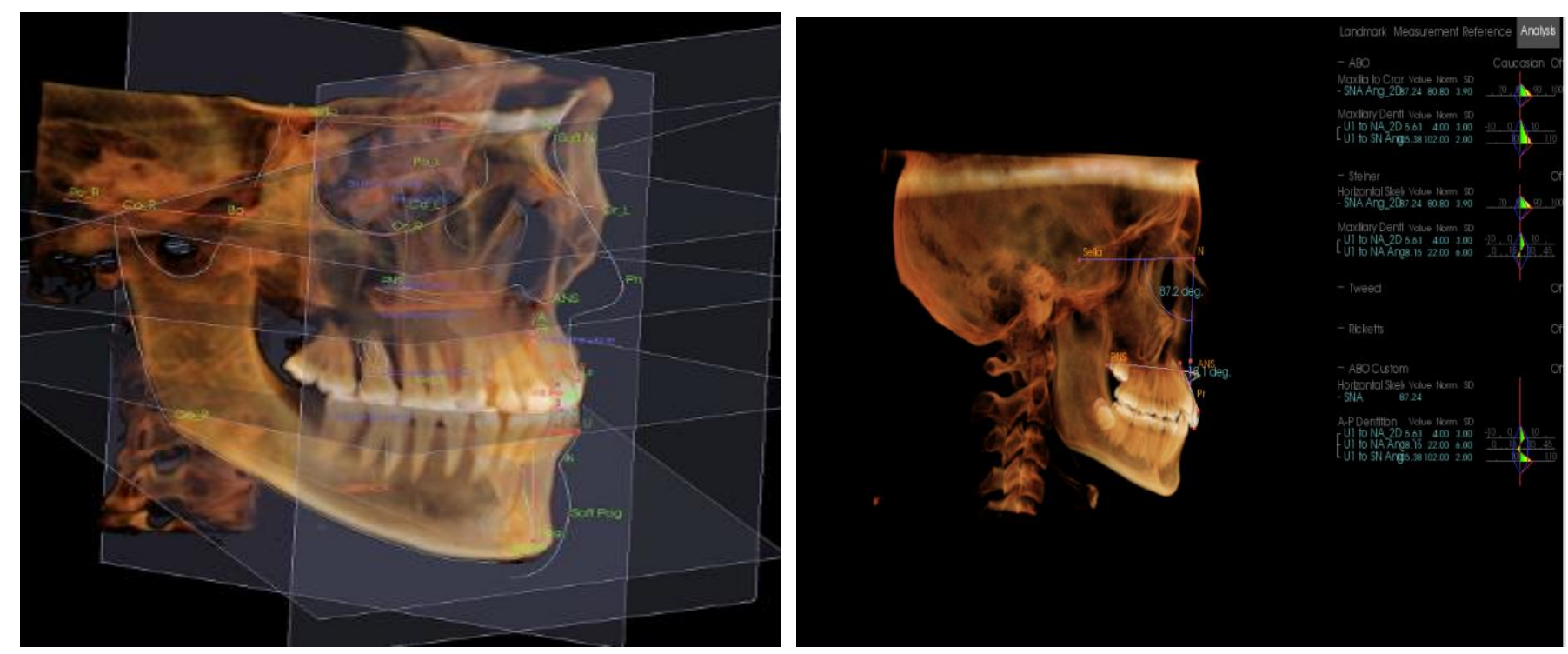

Figure 11.3D Anatomage tracing

Fig 11. A CBCT image traced in Anatomage InVivo 5 software with relevant points and landmarks identified.

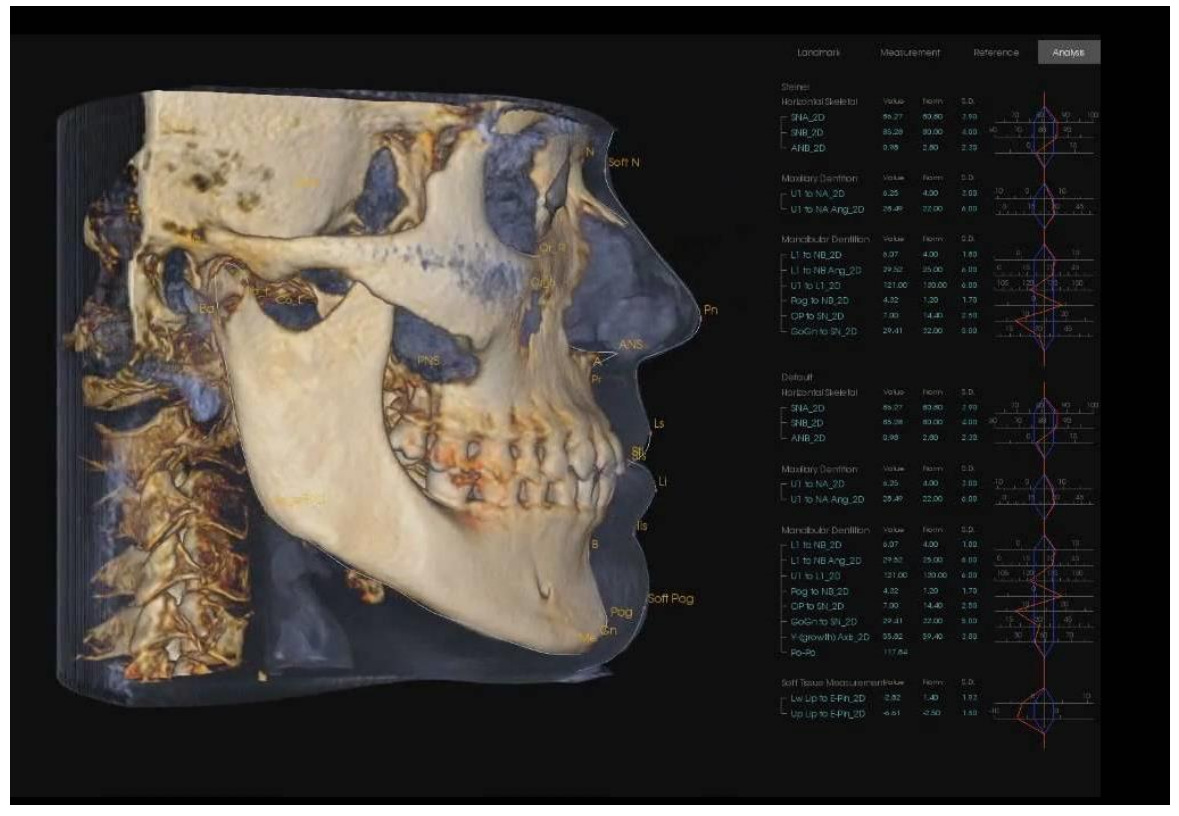

Figure 12. Linear and angular measurements in Anatomage software 
Fig 12. A CBCT image traced in Anatomage InVivo 5 software with relevant points and landmarks identified. Linear and angular measurements displayed on the right side of the image. MAXILLARY INCISOR INCLINATION

Maxillary incisor inclination was measured based on several different reference planes, derived from the Steiner, Andrews, and Burstone analyses.

The Steiner analysis measures maxillary incisor inclination relative to the line NA (Nasion-A point) with an optimal inclination of 22 degrees.

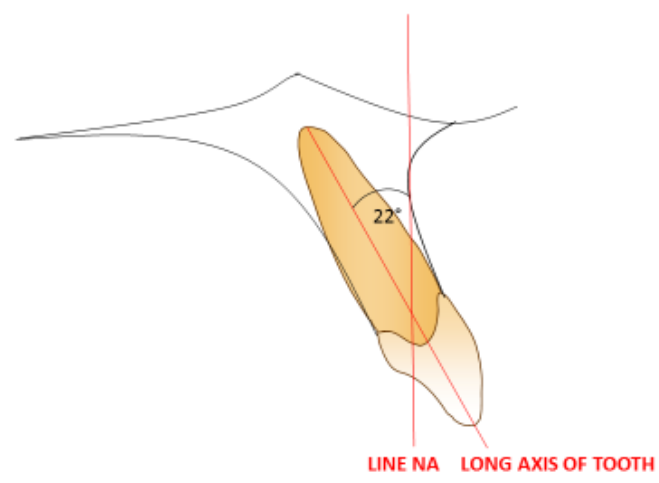

Figure 13. Maxilla: Steiner Analysis

Fig 13. Maxillary incisor inclination measured through the long axis of the tooth to the line NA (Nasion-A point).

The Andrews analysis measures maxillary incisor inclination through the long axis of the tooth perpendicular to the occlusal plane with an optimal inclination of 25 degrees. 


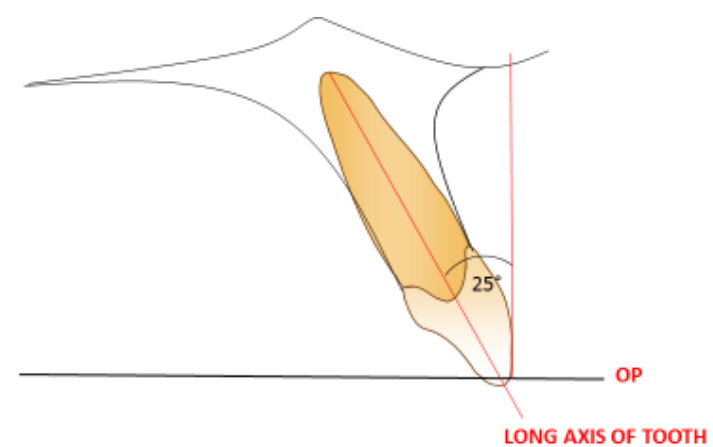

Figure 14. Maxilla: Andrew's Analysis

Fig 14. Maxillary incisor inclination measured through the long axis of the tooth perpendicular to the occlusal plane.

The Burstone analysis measures maxillary incisor inclination relative to the palatal plane with an optimal inclination of 110 degrees.

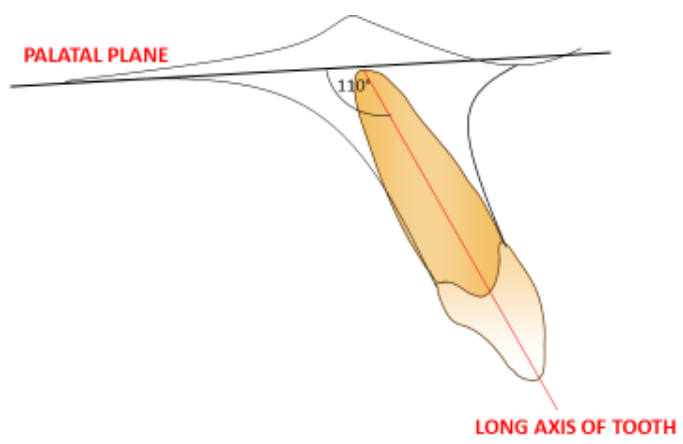

Figure 15. Maxilla: Burstone Analysis

Fig 15. Maxillary incisor inclination measured through the long axis of the tooth to the palatal plane.

\section{MANDIBULAR INCISOR INCLINATION}

Mandibular incisor inclination was measured based on several different reference planes, derived from the Steiner, Andrews, Downs, Tweed and Ricketts analyses. 
The Steiner analysis measures mandibular incisors inclination relative to the line NB (Nasion-B point) with an optimal inclination of 25 degrees.

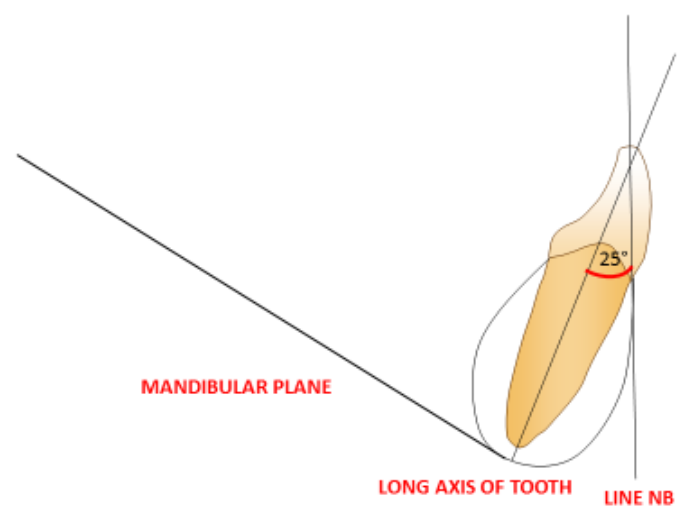

Figure 16. Mandible: Steiner Analysis

Fig 16. Mandibular incisor inclination measured through the long axis of the tooth to the line NB (Nasion-B point).

The Andrews analysis measures mandibular incisor inclination through the long axis of the tooth perpendicular to the occlusal plane with an optimal inclination of 15 degrees.

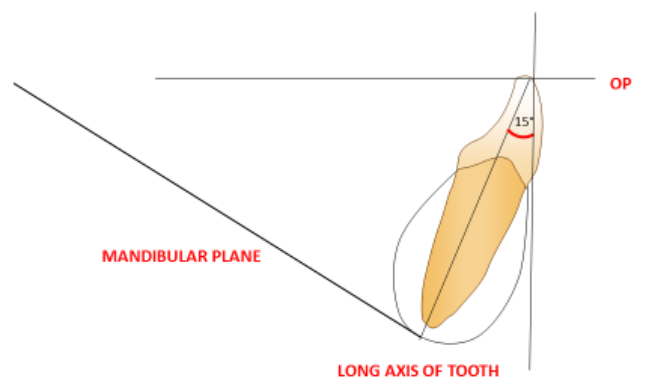

Figure 17. Mandible: Andrew's Analysis

Fig 17. Mandibular incisor inclination measured through the long axis of the tooth perpendicular to the occlusal plane. 
The Downs analysis measures mandibular incisor inclination relative to the mandibular plane, with a mean of 1.4 degrees and a range of -8.5 to 7 degrees (a negative value indicates a proclined incisor).

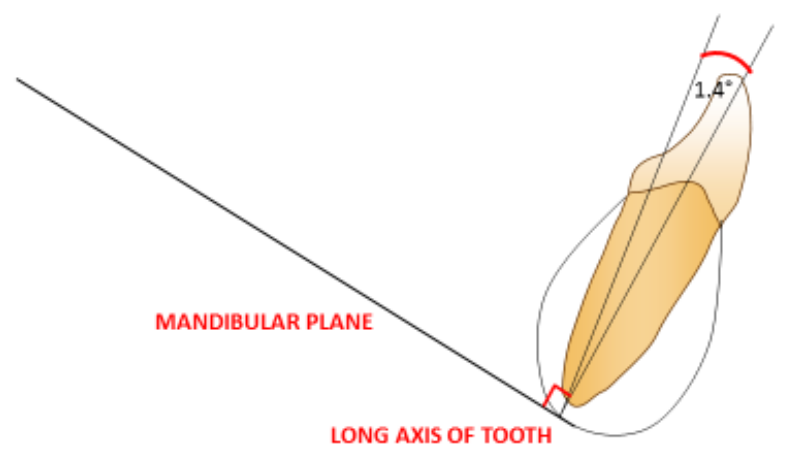

Figure 18. Mandible: Down's Analysis

Fig 18. Mandibular incisor inclination measured through the long axis of the tooth to the mandibular plane.

The Tweed analysis measures mandibular incisor inclination relative to the mandibular plane with an optimal inclination of 87 degrees.

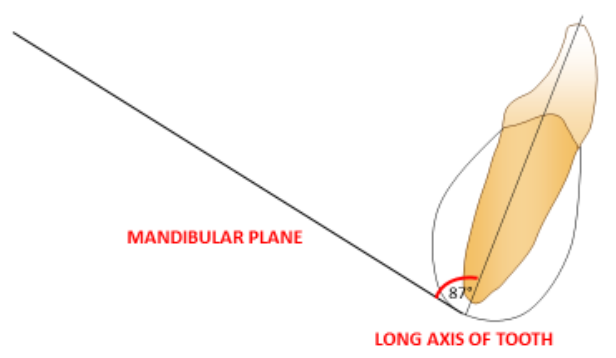

Figure 19. Mandible: Tweed Analysis

Fig 19. Mandibular incisor inclination measured through the long axis of the tooth to the mandibular plane. 
The Ricketts analysis measures mandibular incisor inclination relative to the line A-Po (A pointPogonion) with a mean of 22 degrees and a range of 18 to 26 degrees.

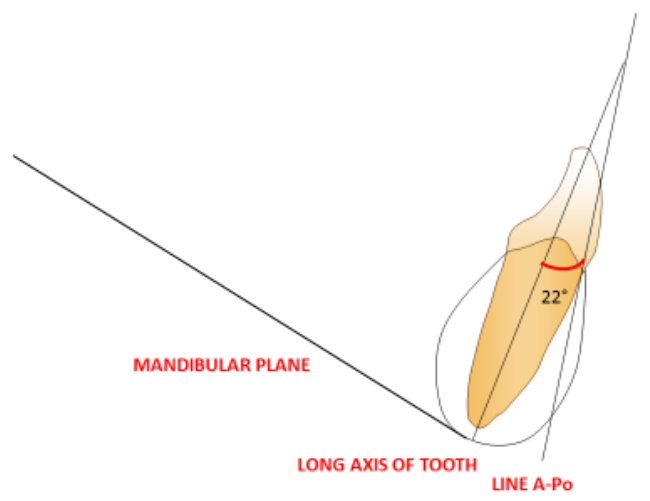

Figure 20. Mandible: Rickett's Analysis

Fig 20. Mandibular incisor inclination was measured through the long axis of the tooth to the the line A-Po (A point-pogonion).

\section{BONE THICKNESS}

In order to analyze bone thickness at different incisor inclinations several measurements were utilized. A study by Tong ${ }^{58}$ used the root apex and mid-occlusal markers to define the tooth's long axis, allowing the authors to determine the tooth angulation relative to the occlusal plane. A CBCT study conducted by Nauert \& Berg ${ }^{37}$, measuring bone volume of the lower incisors in untreated adults with normo-occlusion, utilized the long axis of the tooth and a line perpendicular to the long axis in order to assess bucco-lingual bone. Based on previous research this study utilized the long axis of the tooth and planes perpendicular to the long axis in order to assess the bucco-lingual bone of maxillary and mandibular incisors.

After identifying the inclination of the maxillary and mandibular incisors, the amount of bucco-lingual bone was assessed at the apex of the tooth and the center of resistance of the tooth. 
Center of resistance was defined and identified as 1/3 down the root of the tooth, measured from CEJ to the apex of tooth.
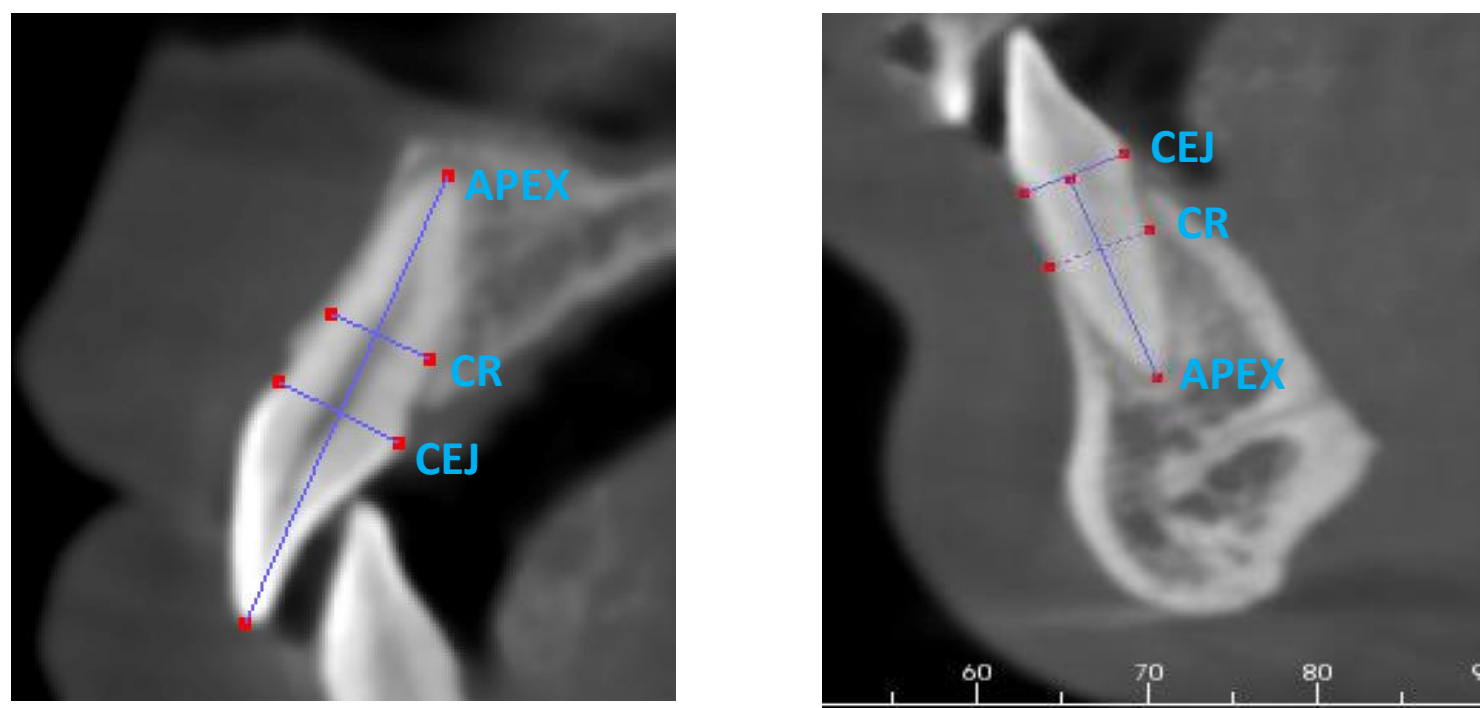

Figure 21. Bone measurements

Fig 21. Buccal and lingual bone measured at CR and apex for maxillary and mandibular incisors.
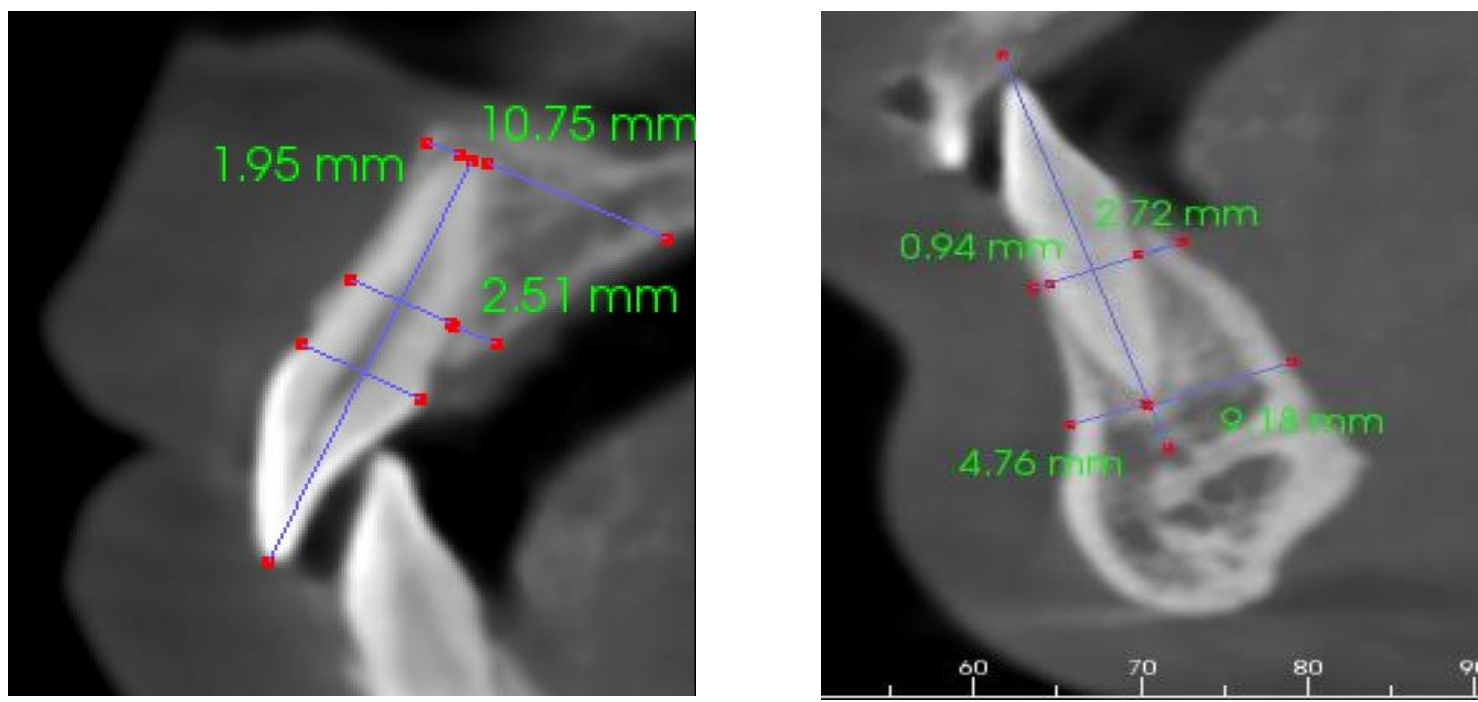

Figure 22. Sample bone measurements

Fig 22. Sample measurements at CR and apex on the buccal and lingual surfaces of maxillary and mandibular incisors. 
Based on the usual anatomy of the premaxilla it was assumed that the vast majority of data collected would show more palatal bone than buccal. Data correlation plotting would consequently show a very flat regression. Therefore, to have meaningful results it was necessary to normalize the data. It was assumed that the lingual bone would be twice as thick as the buccal bone, and therefore in the maxilla roots centered in the alveolus would results in lingual bone measurements twice as thick as the buccal bone measurements.

\section{IDENTIFICATION OF ALVEOLAR DEFECTS}

The current study analyzed three consecutive CBCT slices at an axial slice thickness of .5 $\mathrm{mm}$, in order to identify dehiscences and fenestrations. Defining a dehiscence as a defect more than $2 \mathrm{~mm}$ away from the CEJ and fenestrations as an opening on the root surface not involving the alveolar crest.

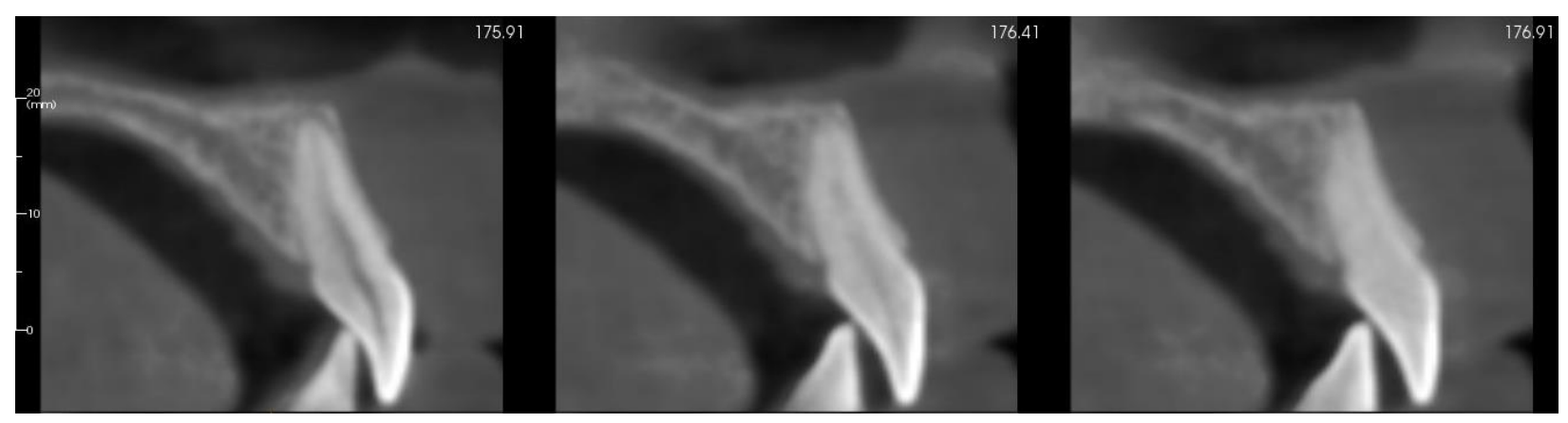

Figure 23. Three consecutive CBCT slices

Fig 23. Three consecutive CBCT slices of a left maxillary incisor at $.5 \mathrm{~mm}$ increments.

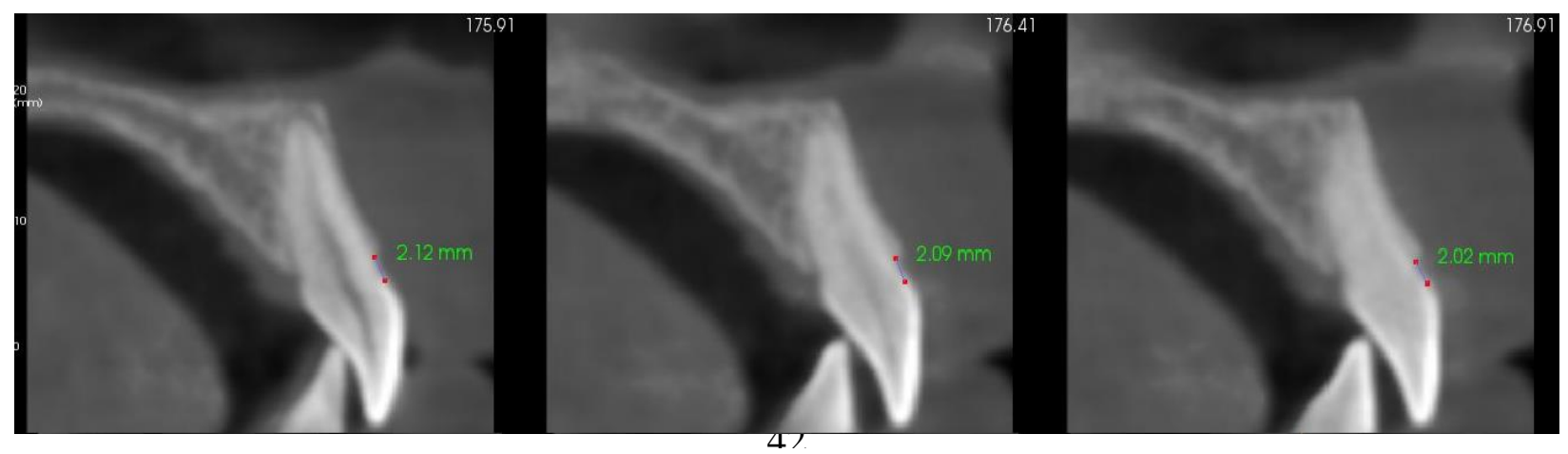

Figure 24. Example of a dehiscence 
Fig 24. Three consecutive CBCT slices of a left maxillary incisor at $.5 \mathrm{~mm}$ increments. The dehiscence measures $2 \mathrm{~mm}$ or greater from the CEJ in three consecutive CBCT slices.

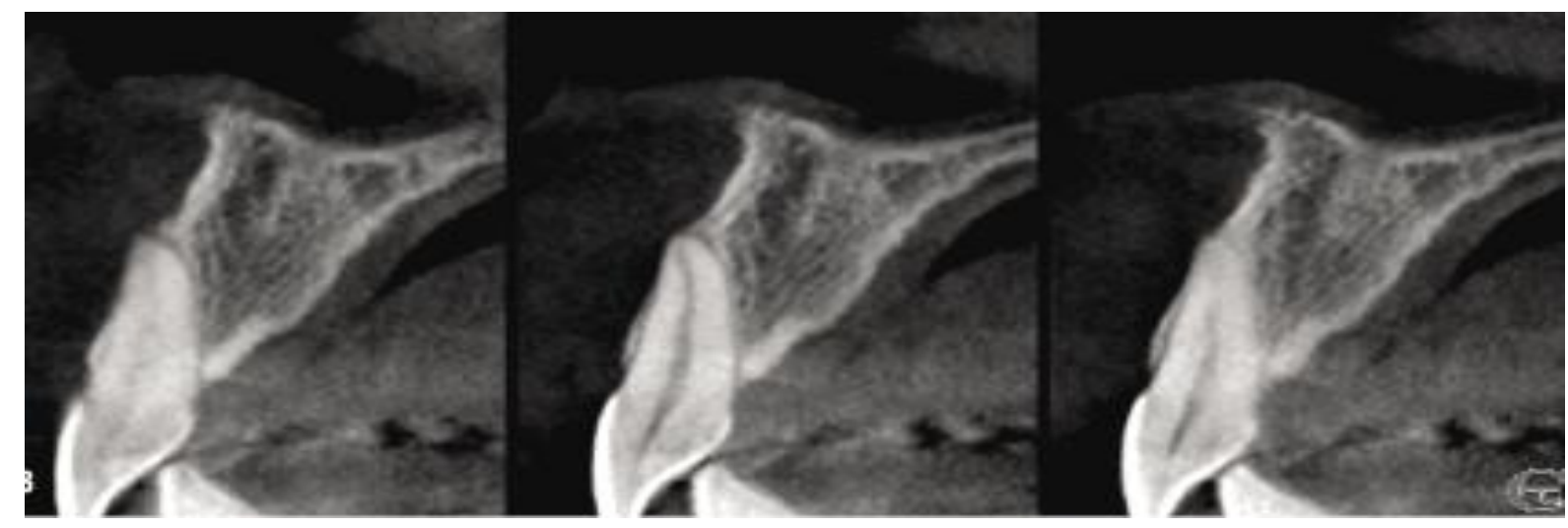

Figure 25. Example of a fenestration

Fig 25. Three consecutive CBCT slices of a right maxillary incisor at $.5 \mathrm{~mm}$ increments. An opening through the alveolar bone exposing part of the root surface but not involving the alveolar crest is seen in three consecutive CBCT slices, defined as a fenestration.

\section{LIST OF VARIABLES}

1. Age

2. SNA

3. SNB

4. ANB

5. UFH

6. $\mathrm{LFH}$

7. Maxillary incisor inclination
a. Steiner analysis
b. Andrews analysis
c. Burstone analysis

8. Mandibular incisor inclination

a. Steiner analysis 

b. Andrews analysis
c. Downs analysis
d. Tweed analysis
e. Ricketts analysis

9. Bone thickness
a. CR buccal
b. CR lingual
c. Apex buccal
d. Apex lingual

10. Presence of periodontal defects
a. Dehiscence
b. Fenestration

\section{STATISTICAL ANALYSIS}

The data was analyzed using correlational analysis and chi-square analysis in order to determine if statistical significant correlation exists between the different variables. Significance of results was determined as p-value $<0.05$ (95\% confidence interval).

\section{CHAPTER 4: RESULTS}

\section{SAMPLE ANALYSIS}

\section{$\underline{\text { SAMPLE SIZE, AGE, GENDER }}$}

The CBCT sample consisted of 100 subjects from 17 to 20 years old with an average age of 18.5 years of age. Of these, 56 were males and 44 were females (Table 2).

No differentiation was made in regards to any other variables aside from the exclusion criteria described earlier. 
Table 2. Sex distribution of the sample studied.

\begin{tabular}{|l|l|}
\hline Gender & $\mathrm{N}$ \\
\hline Male & 56 \\
\hline Female & 44 \\
\hline
\end{tabular}

\section{VARIABLE ANALYSIS}

Table 3. Variable analysis. Variables analyzed in the study with the N, mean, minimum, maximum, and SD values listed for each variable.

\begin{tabular}{|l|l|l|l|l|l|}
\hline Variable & N & Mean & Min & Max & SD \\
\hline Age & 100 & 18.48 & 17 & 20 & 1.16 \\
\hline SNA & 100 & 82.00 & 75 & 89.8 & 3.57 \\
\hline SNB & 100 & 78.87 & 70.7 & 87.9 & 3.84 \\
\hline ANB & 100 & 3.13 & -4.1 & 9.6 & 3.29 \\
\hline UFH & 100 & 50.15 & 43.53 & 56.58 & 3.16 \\
\hline LFH & 100 & 63.01 & 51.07 & 77.69 & 5.04 \\
\hline Mx Steiner & 100 & 23.41 & 1 & 45.7 & 9.62 \\
\hline Mx Andrews & 100 & 26.79 & 2.3 & 54.6 & 10.05 \\
\hline Mx Burstone & 100 & 112.72 & 89.8 & 141.9 & 10.56 \\
\hline Mx Buccal Bone CR & 100 & .95 & 0 & 2.18 & .64 \\
\hline Mx Buccal Bone Apex & 100 & 2.70 & 0 & 4.95 & 1.15 \\
\hline Mx Lingual Bone CR & 100 & 2.87 & 0 & 21.12 & 2.14 \\
\hline Mx Lingual Bone Apex & 100 & 8.92 & 3.5 & 17.2 & 3.16 \\
\hline Md Downs & 100 & -4.46 & -37.1 & 20.6 & 9.62 \\
\hline Md Steiner & 100 & 27.87 & 4.1 & 45.3 & 8.12 \\
\hline Md Tweed & 100 & 94.46 & 69.4 & 127.1 & 9.62 \\
\hline Md Andrews & 100 & 28.13 & 4.8 & 51 & 9.97 \\
\hline Md Ricketts & 100 & 27.33 & 11.7 & 46.6 & 6.97 \\
\hline Md Buccal Bone CR & 100 & .123 & 0 & 1.47 & .33 \\
\hline Md Buccal Bone Apex & 100 & 5.06 & 0 & 10.25 & 1.87 \\
\hline Md Lingual Bone CR & 100 & .97 & 0 & 4.3 & .95 \\
\hline Md Lingual Bone Apex & 100 & 4.5 & 2.07 & 7.79 & 1.05 \\
\hline
\end{tabular}

\section{VARIABLE DISTRIBUTION}

Variable distributions are presented in the following graphs and tables. 


\section{MAXILLA}

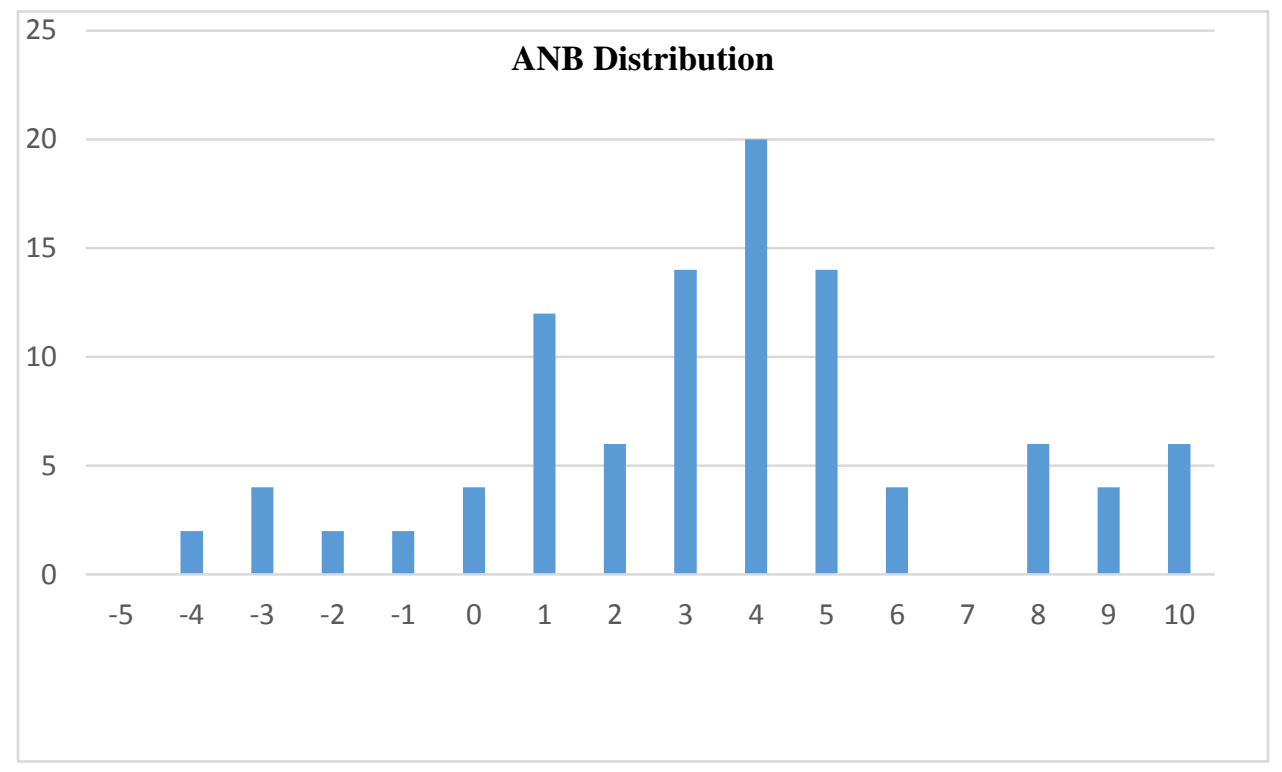

Figure 26. Frequency distribution for skeletal class

Table 4. Distribution of skeletal classifications. Distribution of skeletal classifications grouped into Class I, II, III.

\begin{tabular}{|l|l|}
\hline Skeletal Classification & N \\
\hline I & 52 \\
\hline II & 34 \\
\hline III & 14 \\
\hline
\end{tabular}




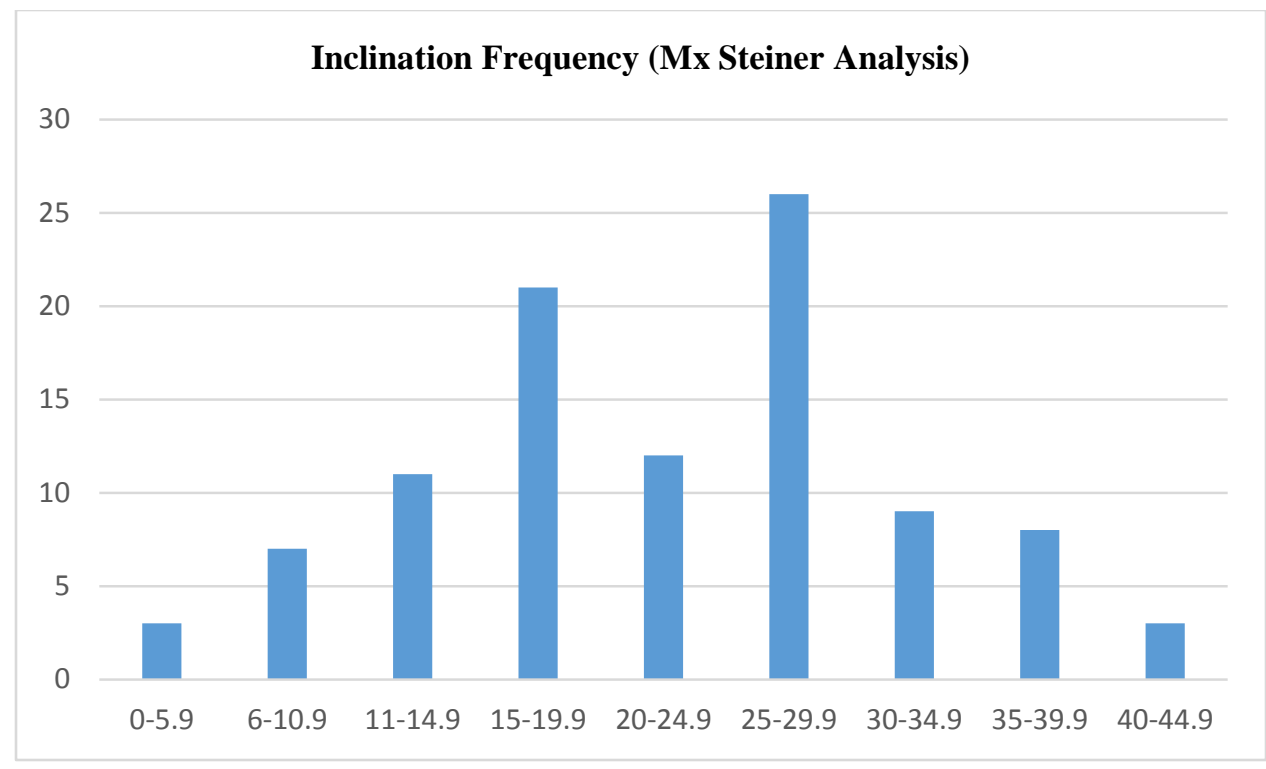

Figure 27. Mx Steiner: Distribution of inclination

Fig 27. Distribution of inclination for the Steiner analysis of the maxillary incisors.

Table 5. Mx Steiner: Grouped distribution of inclinations. Distribution of inclinations for the Steiner analysis of maxillary incisor grouped into proclined, normoinclined, and retroclined.

\begin{tabular}{|l|l|}
\hline Inclination (Steiner) & $\mathrm{N}$ \\
\hline$<17^{\circ}$ & 26 \\
\hline $17-27^{\circ}$ & 32 \\
\hline$>27^{\circ}$ & 42 \\
\hline
\end{tabular}




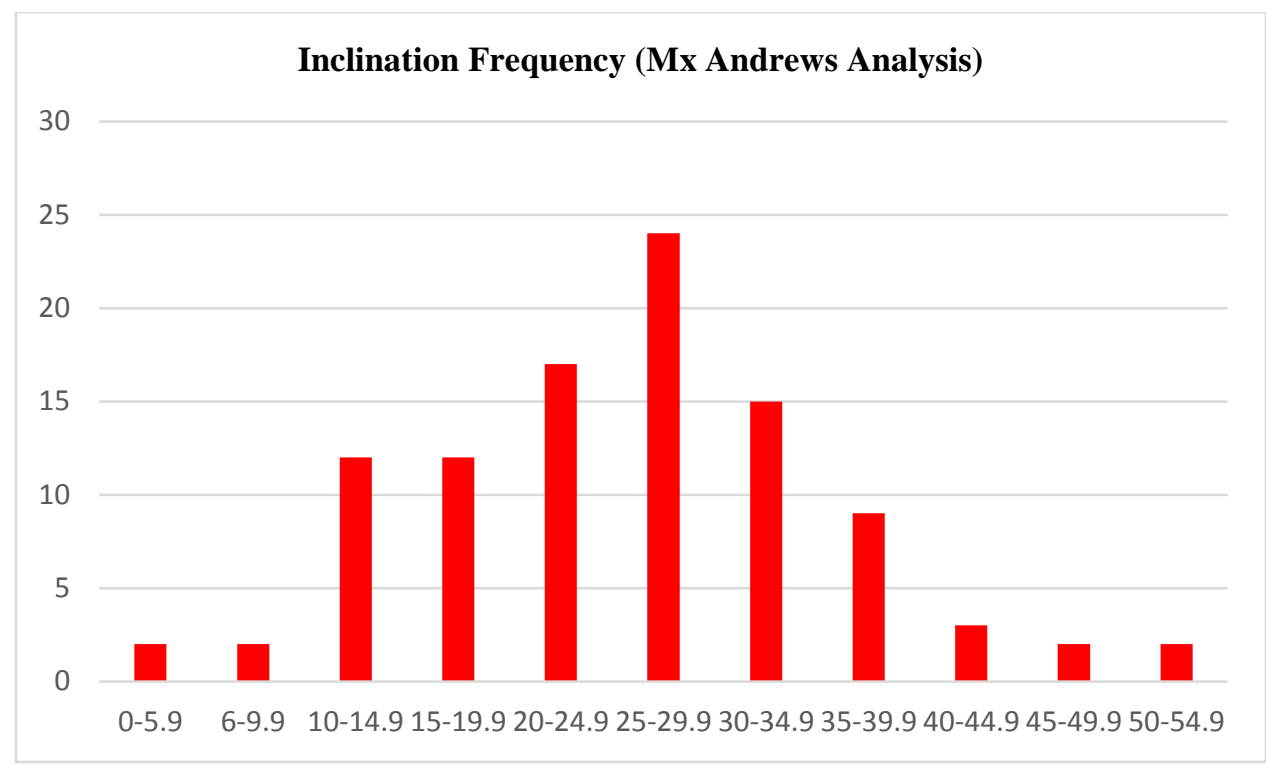

Figure 28. Mx Andrews: Distribution of inclination

Fig 28. Distribution of inclination for the Andrews analysis of the maxillary incisors.

Table 6. Mx Andrews: Grouped distribution of inclinations. Distribution of inclinations for the Andrews analysis of the maxillary incisors grouped into proclined, normoinclined, and retroclined.

\begin{tabular}{|l|l|}
\hline Inclination (Andrews) & $\mathrm{N}$ \\
\hline$<20^{\circ}$ & 22 \\
\hline $20-30^{\circ}$ & 44 \\
\hline$>30^{\circ}$ & 34 \\
\hline
\end{tabular}




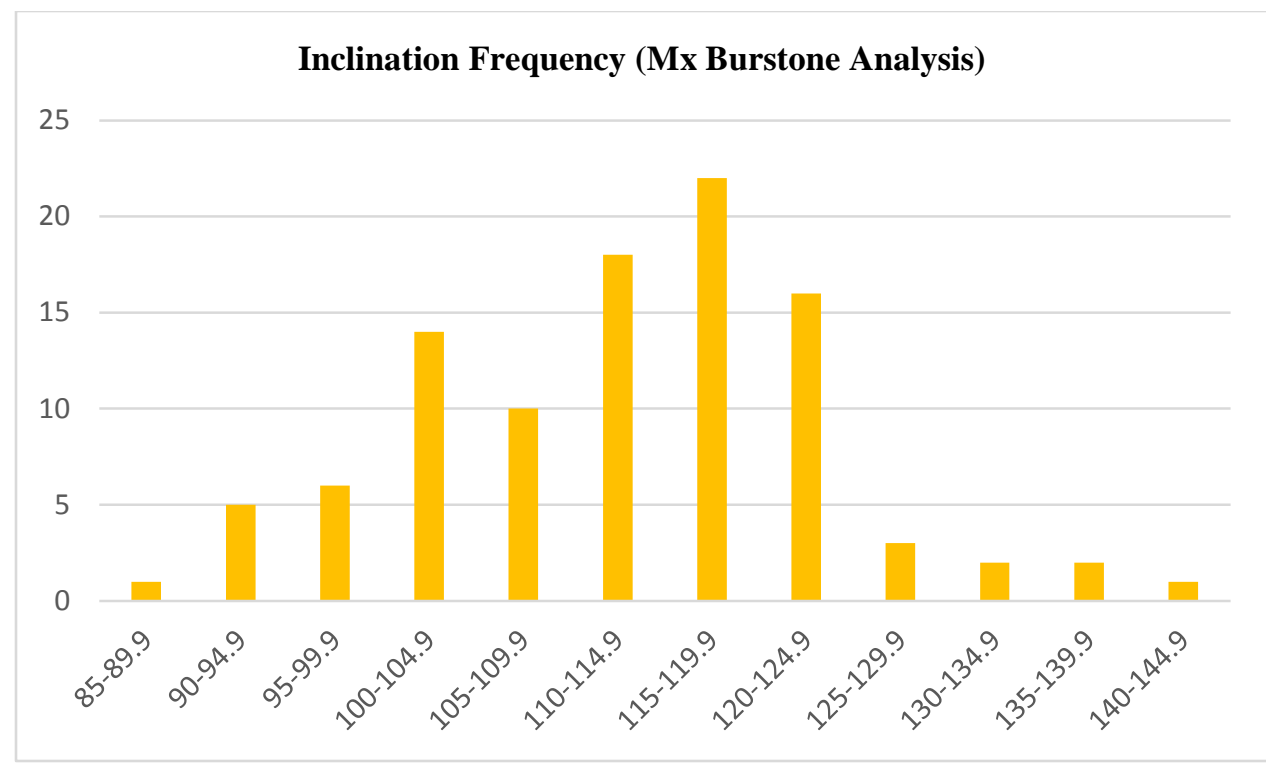

Figure 29. Mx Burstone: Distribution of inclinations

Fig 29. Distribution of inclination for the Burstone analysis of the maxillary incisors.

Table 7. Mx Burstone: Grouped distribution of inclinations. Distribution of inclination for the Burstone analysis of maxillary incisors grouped into proclined, normoinclined, and retroclined.

\begin{tabular}{|l|l|}
\hline Inclination (Burstone) & $\mathrm{N}$ \\
\hline$<101^{\circ}$ & 13 \\
\hline $101-121^{\circ}$ & 71 \\
\hline$>121^{\circ}$ & 16 \\
\hline
\end{tabular}




\section{MANDIBLE}

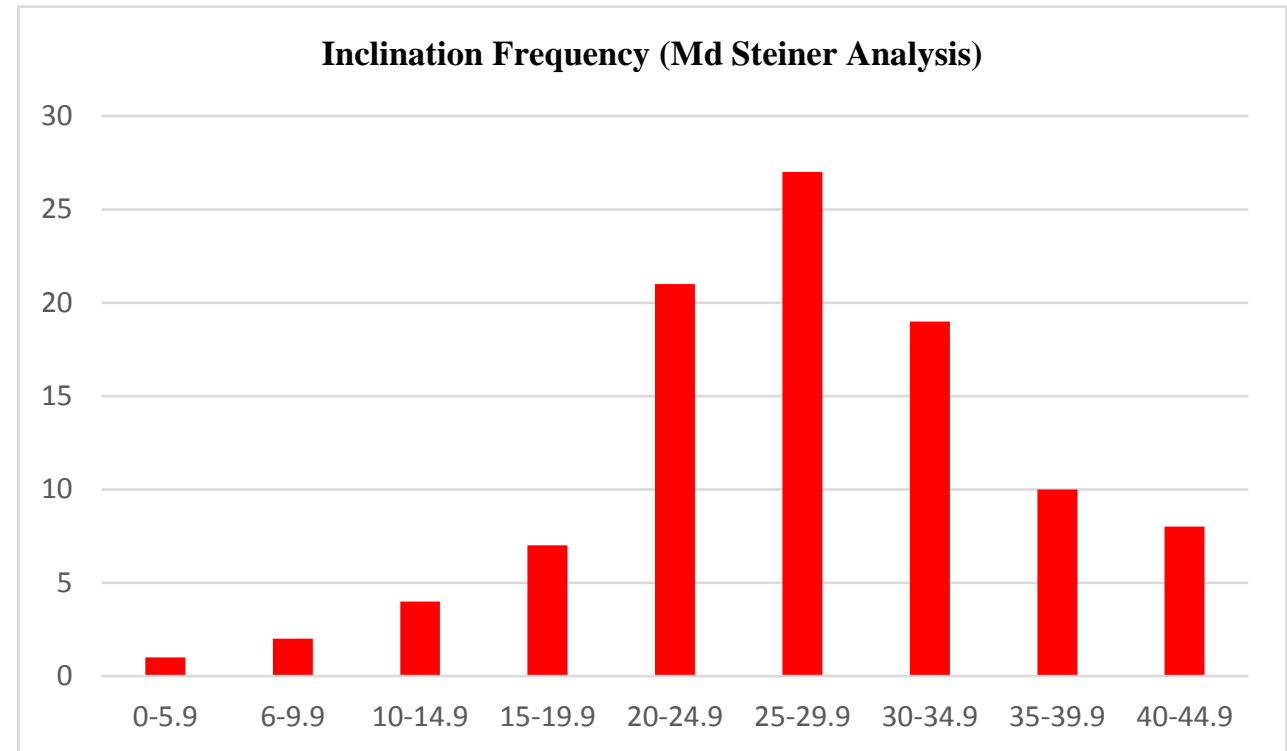

Figure 30. Md Steiner: Distribution of inclinations

Fig 30. Distribution of inclination for the Steiner analysis of the mandibular incisors.

Table 8. Md Steiner: Grouped distribution of inclinations. Distribution of inclination for the Steiner analysis of the mandibular incisors grouped into proclined, normoinclined, and retroclined.

\begin{tabular}{|l|l|}
\hline Inclination (Steiner) & $\mathrm{N}$ \\
\hline$<20^{\circ}$ & 14 \\
\hline $20-30^{\circ}$ & 48 \\
\hline$>30^{\circ}$ & 38 \\
\hline
\end{tabular}




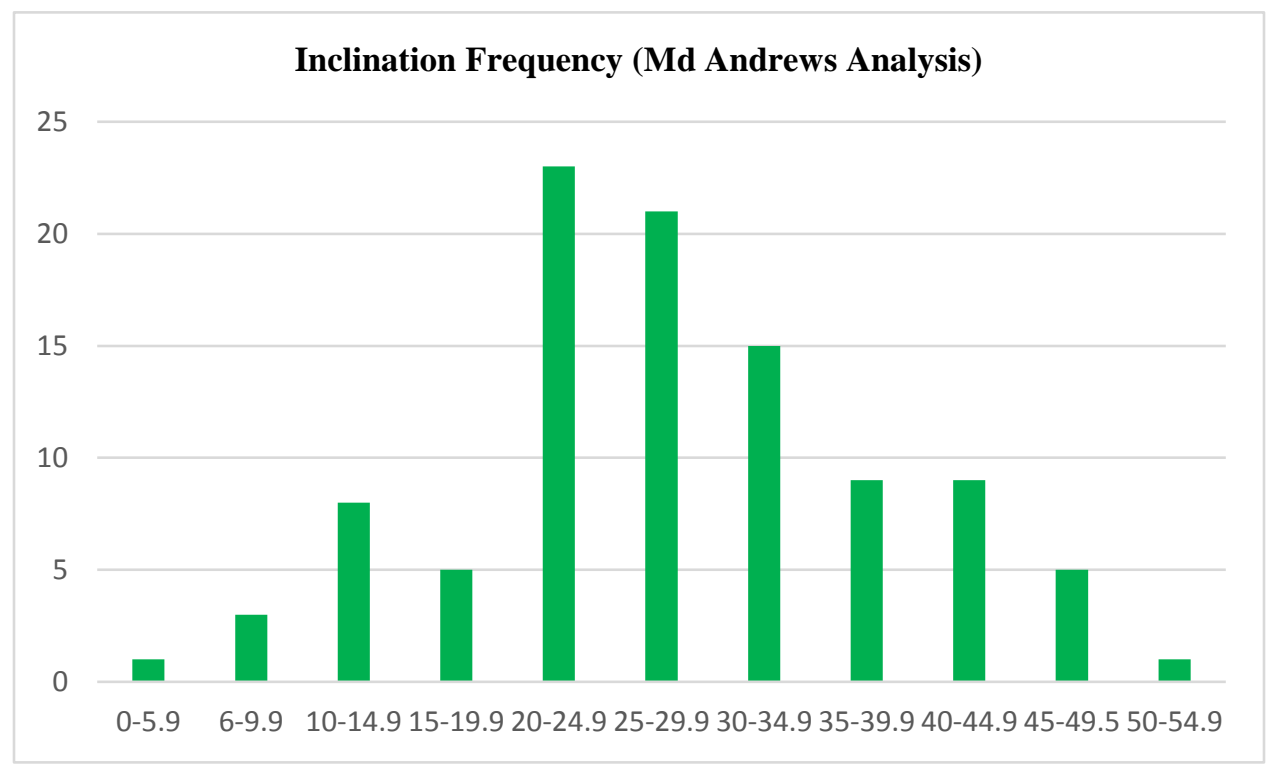

Figure 31. Md Andrews: Distribution of inclinations

Fig 31. Distribution of inclination for the Andrews analysis of the mandibular incisors.

Table 9. Md Andrews: Grouped distribution of inclinations. Distribution of inclination for the Andrews analysis of mandibular incisors grouped into proclined, normoinclined, and retroclined.

\begin{tabular}{|l|l|}
\hline Inclination (Andrews) & $\mathrm{N}$ \\
\hline$<10^{\circ}$ & 4 \\
\hline $10-20^{\circ}$ & 13 \\
\hline$>20^{\circ}$ & 83 \\
\hline
\end{tabular}




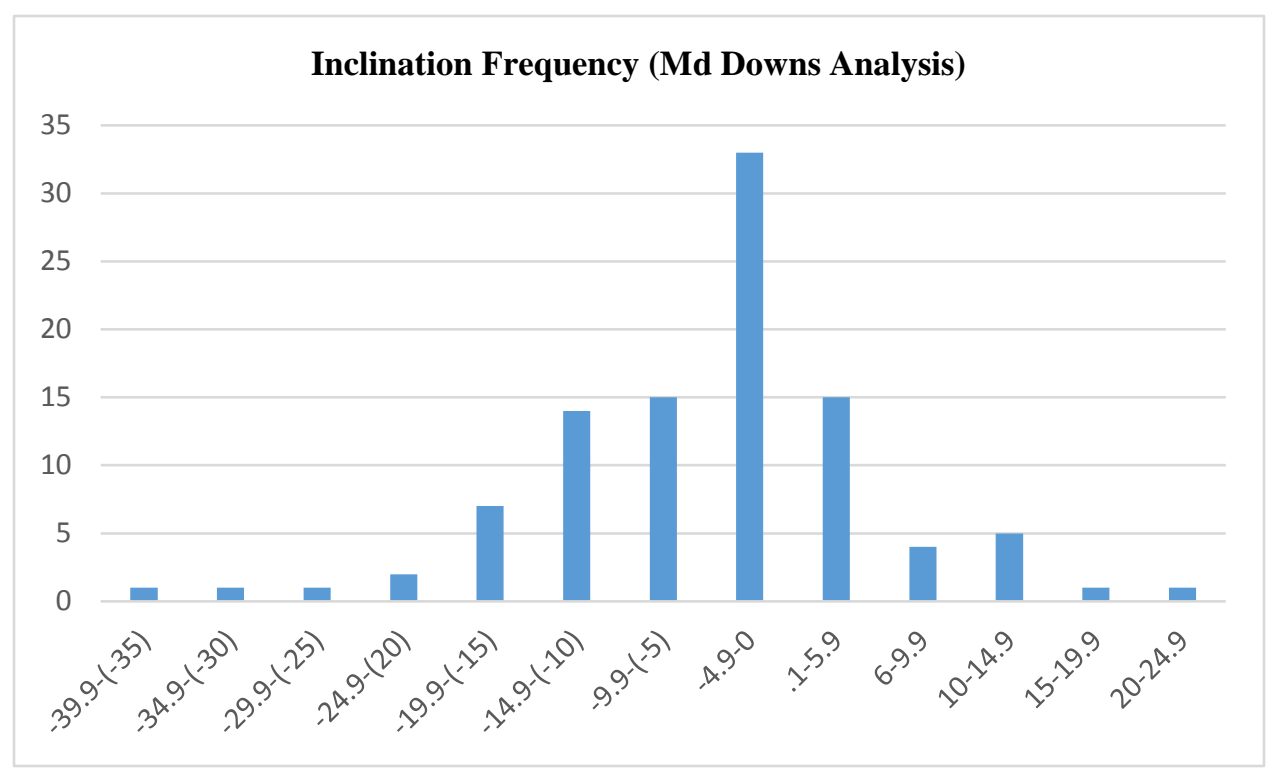

Figure 32. Md Downs: Distribution of inclinations

Fig 32. Distribution of inclination for the Downs analysis of the mandibular incisors.

Table 10. Md Downs: Grouped distribution of inclinations. Distribution of inclination for the Downs analysis grouped into proclined, normoinclined, and retroclined.

\begin{tabular}{|l|l|}
\hline Inclination (Downs) & $\mathrm{N}$ \\
\hline$<-8.5^{\circ}$ & 27 \\
\hline$-8.5-7^{\circ}$ & 62 \\
\hline$>7^{\circ}$ & 11 \\
\hline
\end{tabular}




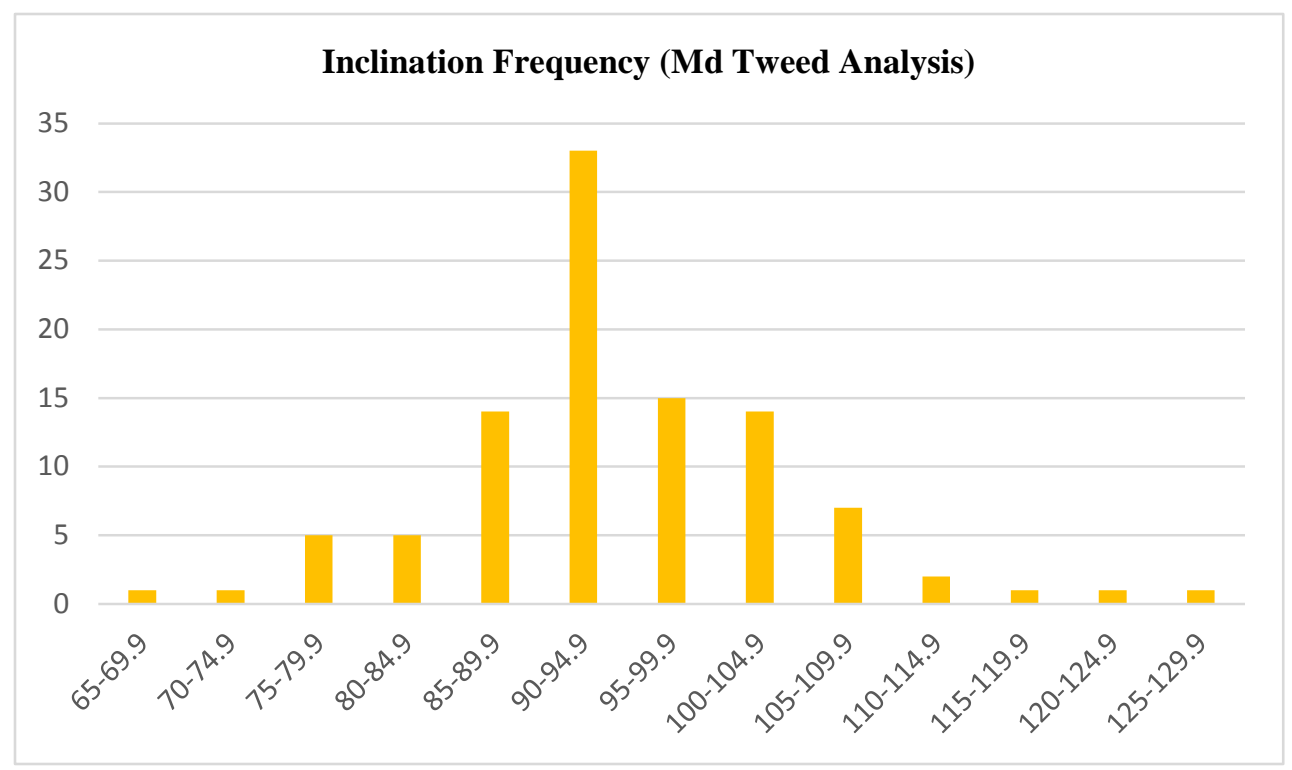

Figure 33. Md Tweed: Distribution of inclinations

Fig 33. Distribution of inclination for the Tweed analysis of the mandibular incisors.

Table 11. Md Tweed: Grouped distribution of inclinations. Distribution of inclination for the Tweed analysis of mandibular incisor grouped into proclined, normoinclined, and retroclined.

\begin{tabular}{|l|l|}
\hline Inclination (Tweed) & $\mathrm{N}$ \\
\hline$<82^{\circ}$ & 10 \\
\hline $82-92^{\circ}$ & 30 \\
\hline$>92^{\circ}$ & 60 \\
\hline
\end{tabular}




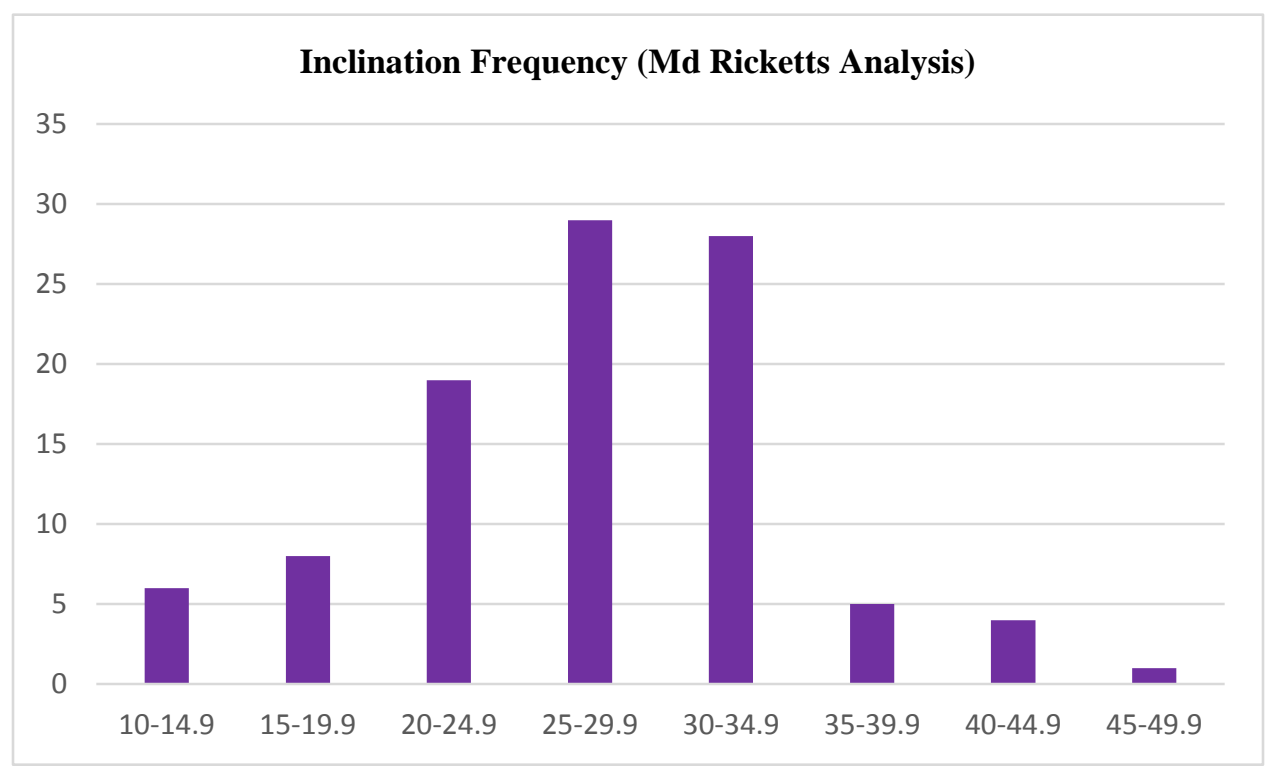

Figure 34. Md Ricketts: Distribution of inclinations

Fig 34. Distribution of inclination for the Ricketts analysis of the mandibular incisors.

Table 12. Md Ricketts: Grouped distribution of inclinations. Distribution of inclination for the Ricketts analysis of mandibular incisor grouped into proclined, normoinclined, and retroclined.

\begin{tabular}{|l|l|}
\hline Inclination (Ricketts) & $\mathrm{N}$ \\
\hline$<18^{\circ}$ & 10 \\
\hline $18-26^{\circ}$ & 33 \\
\hline$>26^{\circ}$ & 57 \\
\hline
\end{tabular}




\section{HYPOTHESIS TESTING}

\section{MAXILLA}

Maxillary bucco-lingual bone was analyzed at CR and apex at various inclinations. The thickness of buccal and lingual bone was analyzed statistically based on the assumption that incisors positioned in the maxillary alveolus would result in twice as much bone on the lingual aspect compared to the buccal aspect. The data was plotted as ratios against inclination in order to eliminate the variable of different alveolar thickness across the sample and to establish a relative difference between buccal and lingual bone thickness. The data was also plotted as the difference between buccal and lingual bone to assess overall difference and have a more complete impression of the sample.

$\mathrm{H}_{0}$ : Maxillary incisors inclined in the optimal range according to the Steiner, Andrews, and Burstone analyses are not more centered in alveolar bone, as measured at the CR and apex than incisors with more positive or negative inclination.

\section{STEINER ANALYSIS: RATIO ANALYSIS AT CR}

The Steiner analysis measures maxillary incisor inclination relative to the line NA (Nasion-A point) with an optimal inclination of 22 degrees.

Bivariate fit analysis revealed a significant correlation between the ratio of buccal and lingual bone thickness and incisor inclination at $\mathrm{CR}$, with an r-value $=.467 \mathrm{p}<.0001$. Optimally inclined incisors as indicated by the Steiner analysis were not significantly more likely to result in equal distribution of bone at CR, more bone was found on the lingual than buccal (Figure 35). 


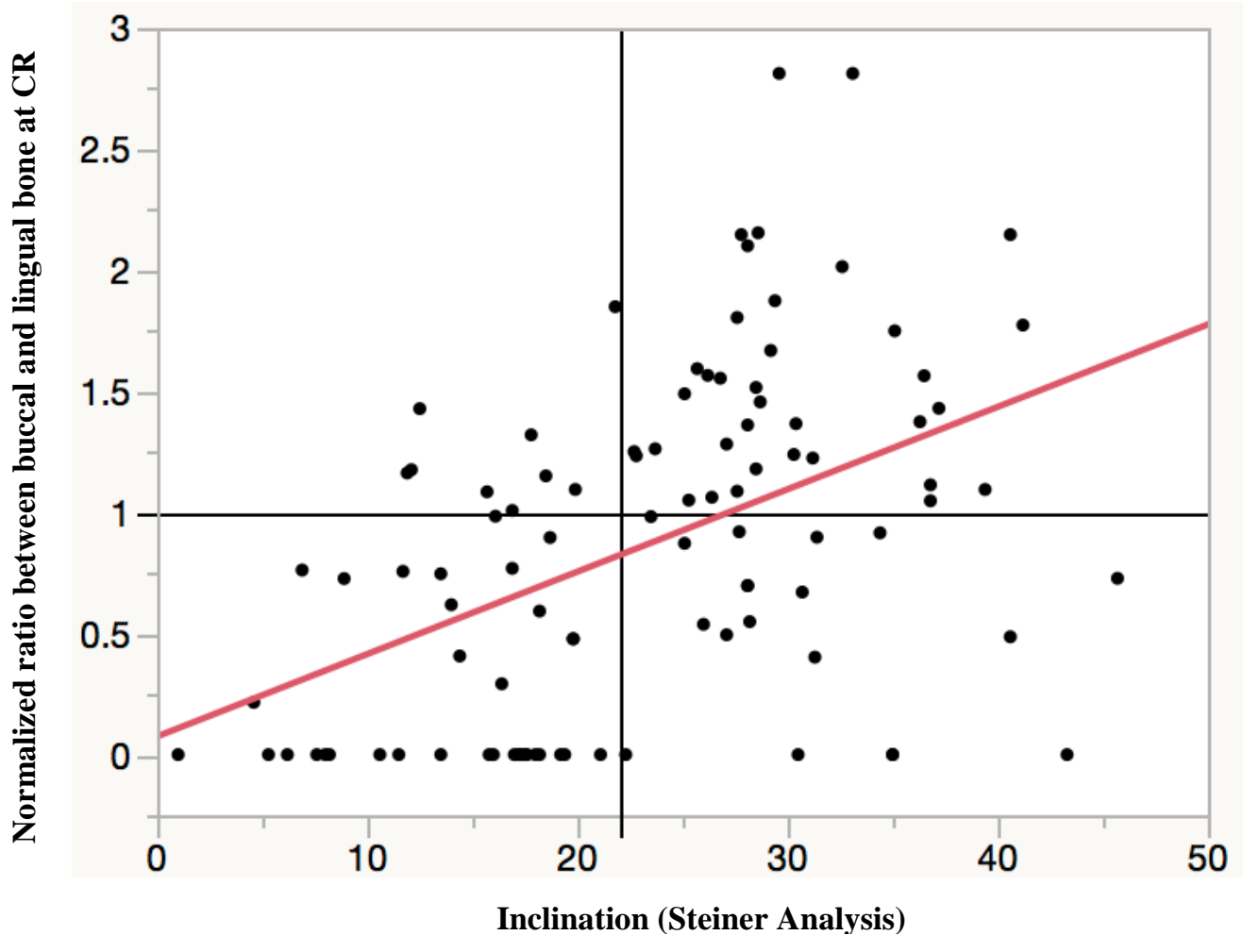

Figure 35. Mx Steiner: Bone distribution at CR

Fig 35. The ratio between buccal and lingual bone at $\mathrm{CR}$ of the maxillary incisors at various inclinations with a line of best-fit (red) and optimal range of inclination (Steiner analysis) indicated by a black line.

\section{STEINER ANALYSIS: DIFFERENCE ANALYSIS AT CR}

The difference in the thickness of buccal and lingual bone measured at CR based on inclination revealed no significant correlation utilizing the Steiner analysis, $r$-value $=.264 \mathrm{p}=.008$.

\section{STEINER ANALYSIS: RATIO ANALYSIS AT APEX}

Bivariate fit analysis revealed significant correlation between the ratio of buccal and lingual bone thickness and incisal inclination at the apex, with an $r-v a l u e=.617 p=.0001$. Optimally inclined incisors as indicated by the Steiner analysis were not significantly more likely to result in equal distribution of bone at the apex, more bone was measured on the lingual than buccal (Figure 36). 


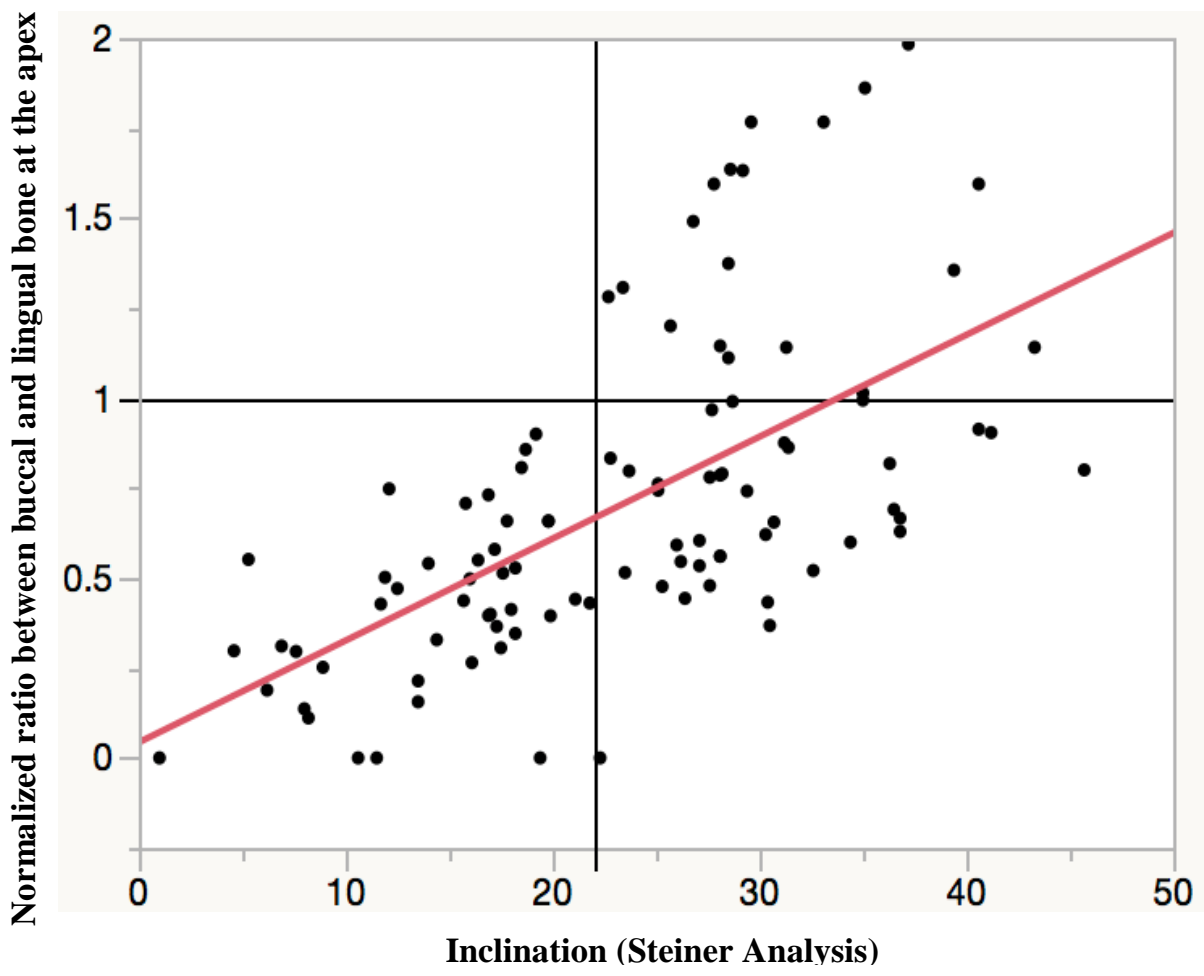

Figure 36. Mx Steiner: Bone distribution at apex

Fig 36. The ratio between buccal and lingual bone at the apex of the maxillary incisors at various inclinations with a line of best-fit (red) and optimal range of inclination (Steiner analysis) indicated by a black line.

\section{STEINER ANALYSIS: DIFFERENCE ANALYSIS AT APEX}

Bivariate fit analysis revealed a significant correlation between the difference of buccal and lingual bone thickness and incisal inclination at the apex, with an $\mathrm{r}$-value $=.729 \mathrm{p}=.0001$.

Optimally inclined incisors as indicated by the Steiner analysis were not significantly more likely to result in equal distribution of bone at the apex, more bone was measured on the lingual than buccal (Figure 37). 


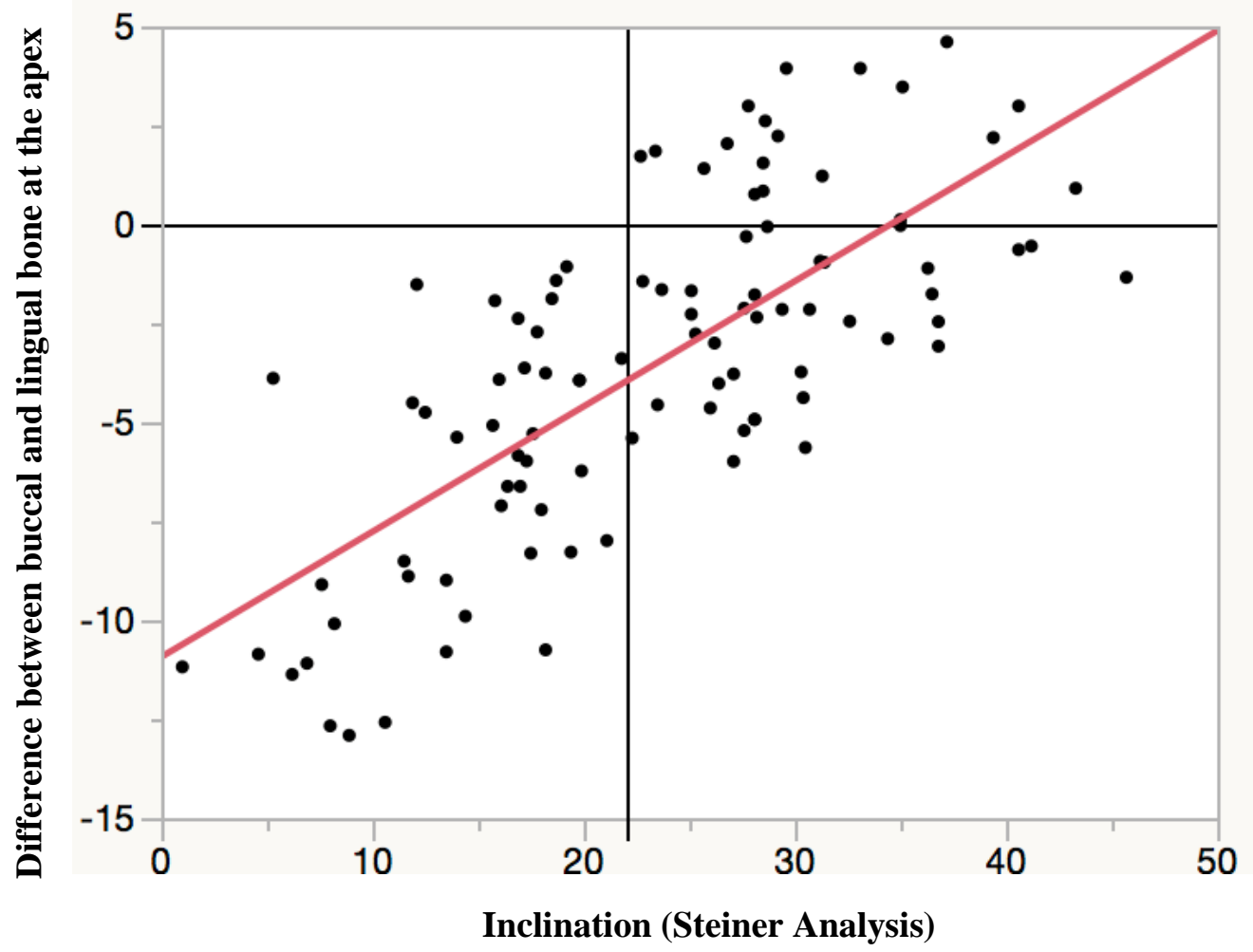

Figure 37. Mx Steiner: Difference in bone distribution at the apex

Fig 37. The difference between buccal and lingual bone at the apex of the maxillary incisors at various inclinations with a line of best-fit (red) and optimal range of inclination (Steiner analysis) indicated by a black line.

\section{ANDREWS ANALYSIS: RATIO ANALYSIS AT CR}

The Andrews analysis measures the maxillary incisor inclination perpendicular to the occlusal plane with an optimal inclination of 25 degrees.

Bivariate fit analysis revealed a significant correlation between the ratio of buccal and lingual bone thickness and incisal inclination at $\mathrm{CR}$, with an $\mathrm{r}$-value $=.422 \mathrm{p}<.0001$. Optimally inclined 
incisors as indicated by the Andrews analysis were not significantly more likely to result in equal distribution of bone at $\mathrm{CR}$, more bone was measured on the lingual than buccal (Figure 38).

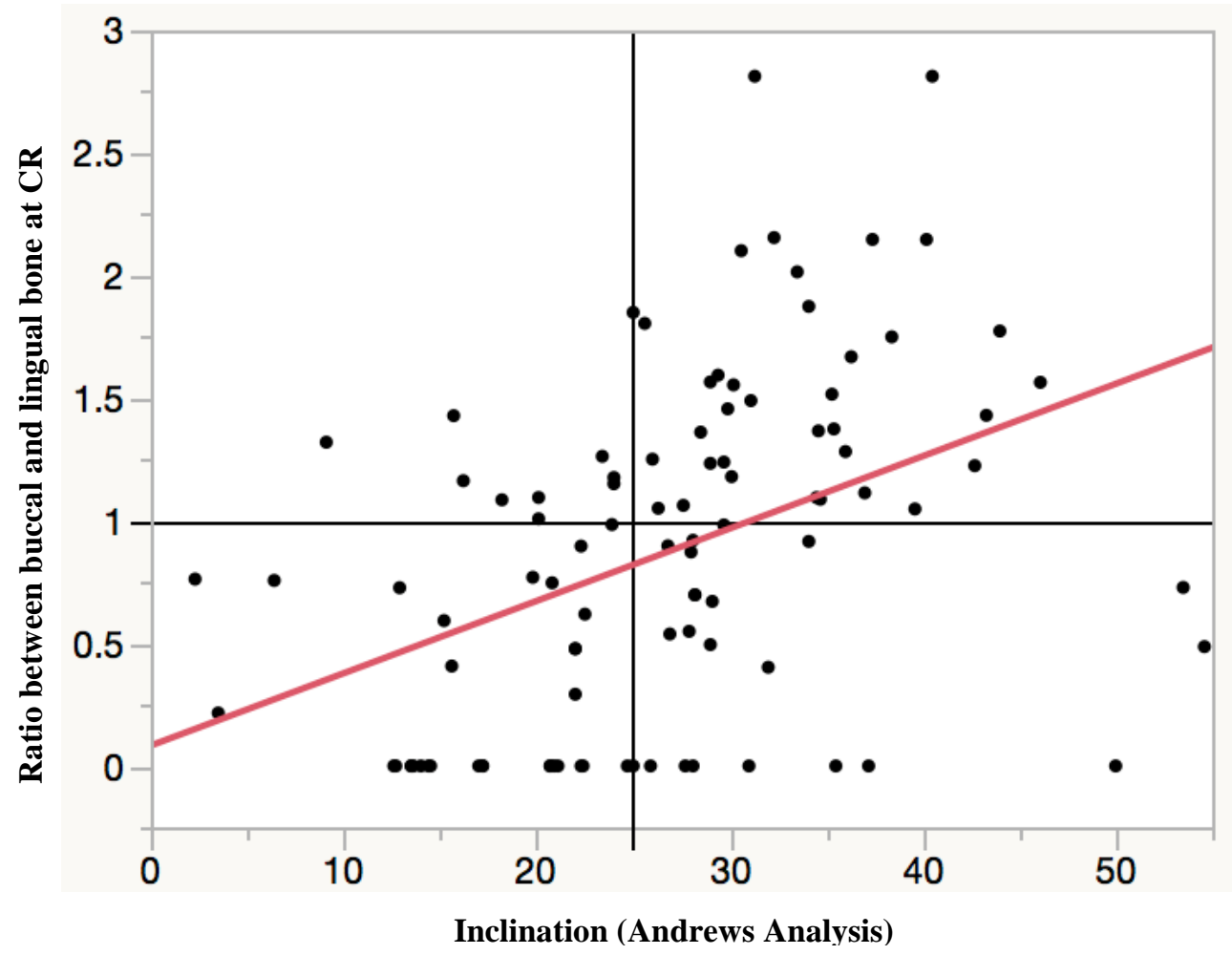

Figure 38. Mx Andrews: Bone distribution at CR

Fig 38. The ratio between buccal and lingual bone at CR of the maxillary incisors at various inclinations with a line of best-fit (red) and optimal range of inclination (Andrews analysis) indicated by a black line.

\section{ANDREWS ANALYSIS: DIFFERENCE ANALYSIS AT CR}

The difference in the thickness of buccal and lingual bone measured at CR based on inclination revealed no significant correlation utilizing the Andrews analysis, $r$-value $=.216 \mathrm{p}=.031$. 


\section{ANDREWS ANALYSIS: RATIO ANALYSIS AT APEX}

Bivariate fit analysis revealed a significant correlation between the ratio of buccal and lingual bone thickness and incisal inclination at the apex, with an $r$-value $=.608 p<.0001$. Optimally inclined incisors as indicated by the Andrews analysis were not significantly more likely to result in equal distribution of bone at the apex, more on the lingual than buccal (Figure 39).

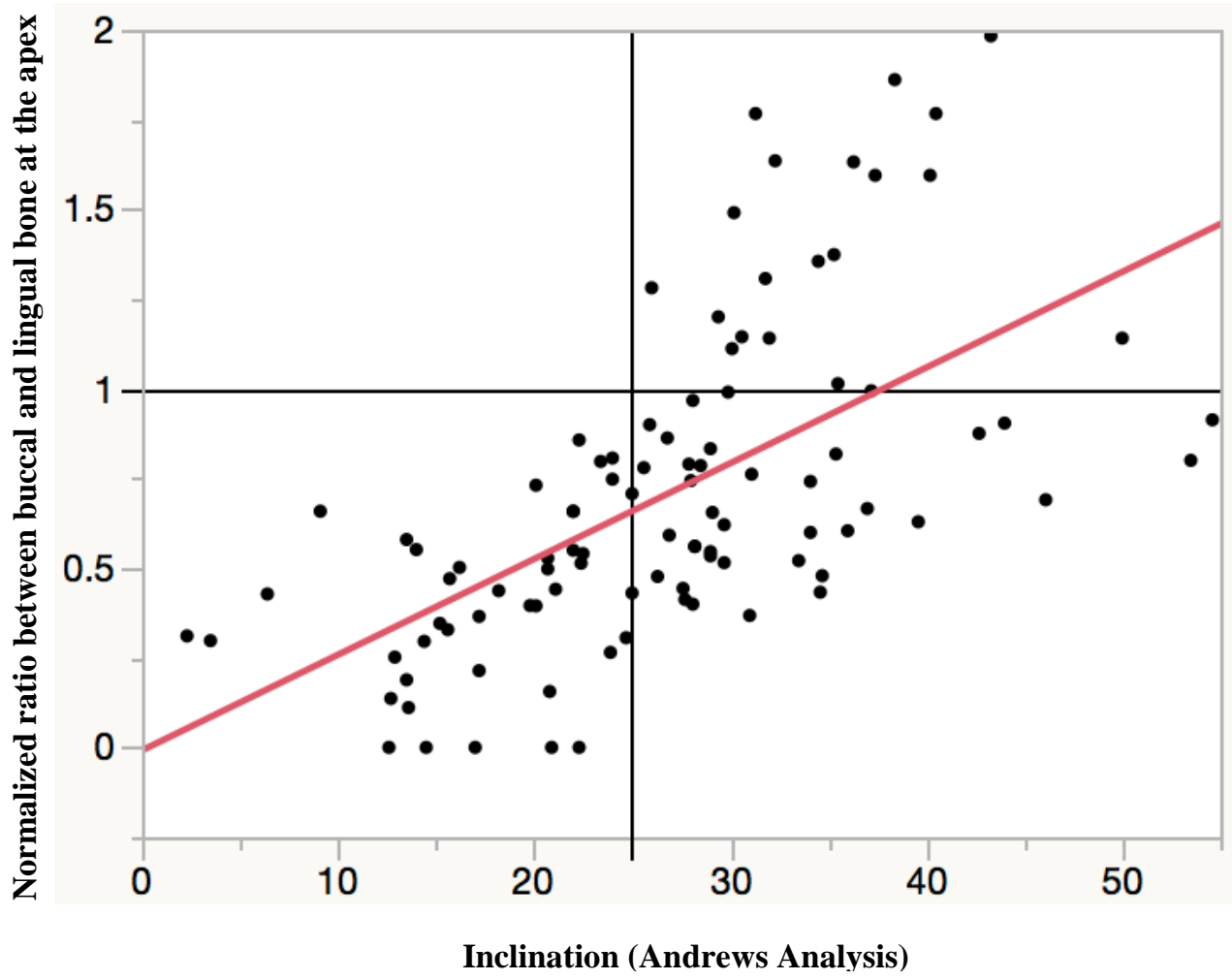

Figure 39. Mx Andrews: Bone distribution at the apex

Fig 39. The ratio between buccal and lingual bone at the apex of the maxillary incisors at various inclinations with a line of best-fit (red) and optimal range of inclination (Andrews analysis) indicated by a black line.

\section{ANDREWS ANALYSIS: DIFFERENCE ANALYSIS AT APEX}

Bivariate fit analysis revealed a significant correlation between the difference of buccal and lingual bone thickness and incisal inclination at the apex, with an r-value $=.709 p=.0001$. 
Optimally inclined incisors as indicated by the Andrews analysis were not significantly more likely to result in equal distribution of bone at the apex, more bone was measured on the lingual than buccal (Figure 40).

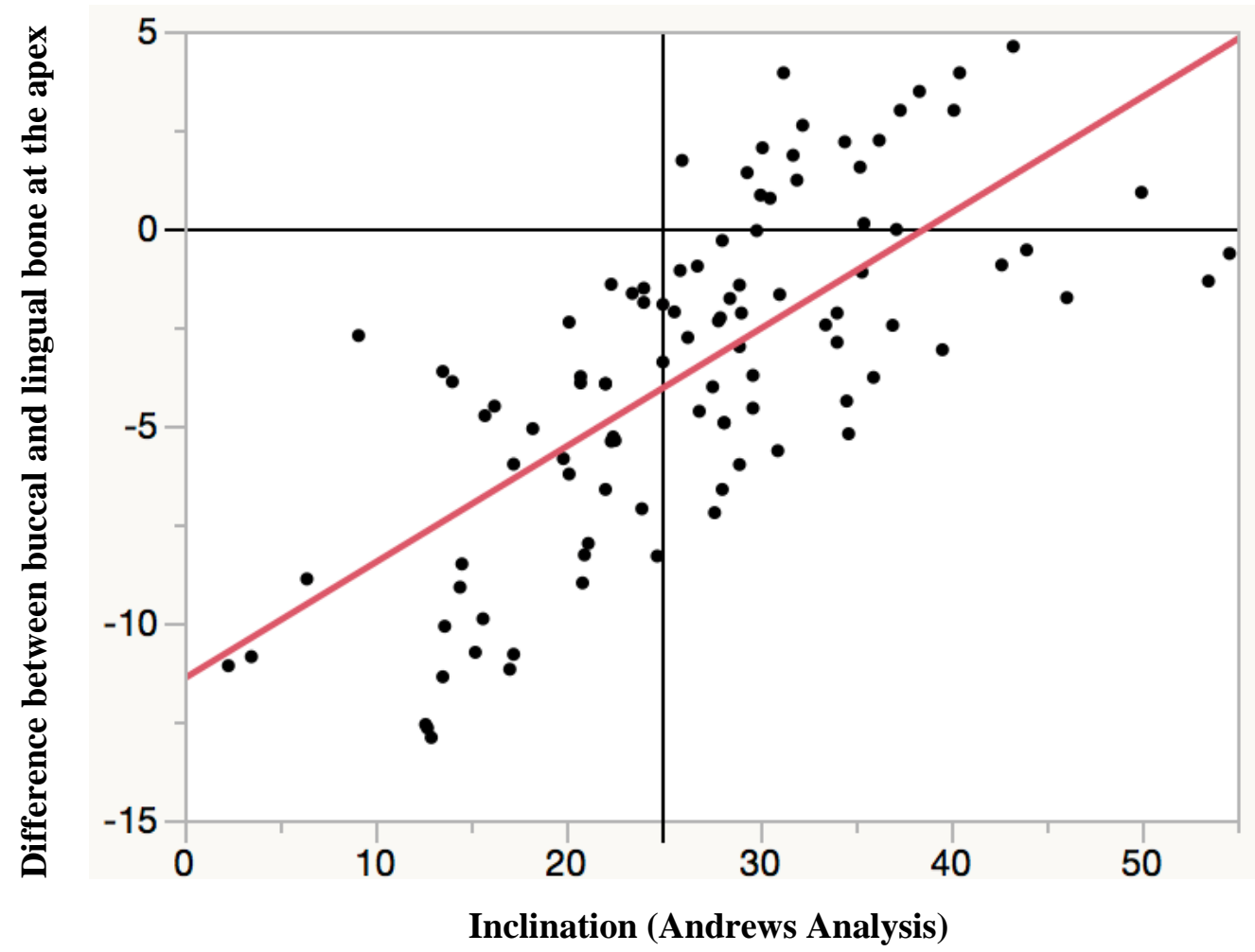

Figure 40. Mx Andrews: Difference in bone distribution at the apex

Fig 40. The difference between buccal and lingual bone at the apex of the maxillary incisors at various inclinations with a line of best-fit (red) and optimal range of inclination (Andrews analysis) indicated by a black line.

\section{BURSTONE ANALYSIS: RATIO ANALYSIS AT CR}

The Burstone analysis measures the maxillary incisor inclination relative to the palatal plane with an optimal inclination of 110 degrees. 
Bivariate fit analysis revealed a significant correlation between the ratio of buccal and lingual bone thickness and incisal inclination at $\mathrm{CR}$, with an $\mathrm{r}$-value $=.329 \mathrm{p}=.0009$. Optimally inclined incisors as indicated by the Burstone analysis were not significantly more likely to result in equal distribution of bone at $\mathrm{CR}$, more bone was measured on the lingual than buccal (Figure 41).

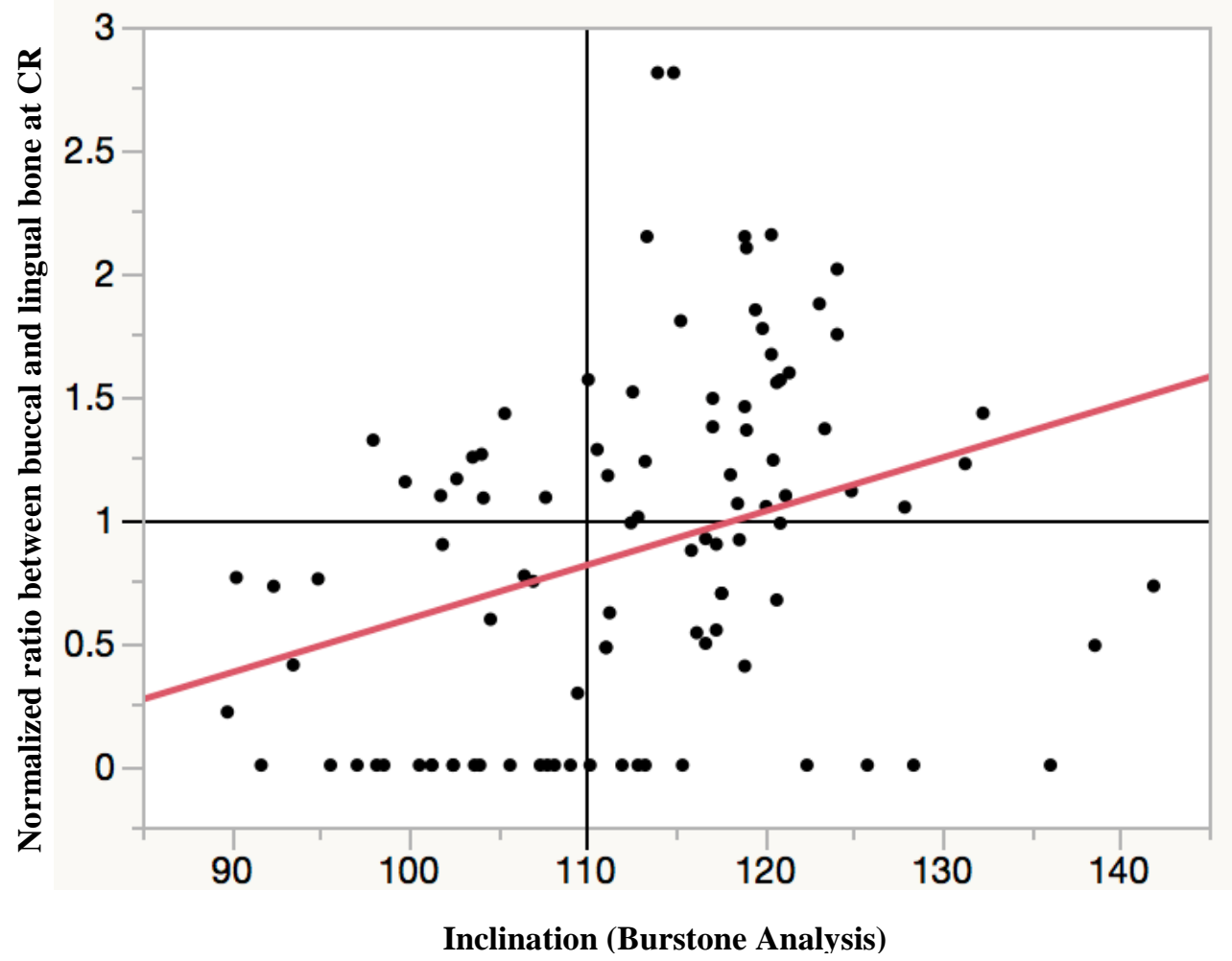

Figure 41. Mx Burstone: Bone distribution at CR

Fig 41. The ratio between buccal and lingual bone at $\mathrm{CR}$ of the maxillary incisors at various inclinations with a line of best-fit (red) and optimal range of inclination (Burstone analysis) indicated by a black line. 


\section{BURSTONE ANALYSIS: DIFFERENCE ANALYSIS AT CR}

The difference in the thickness of buccal and lingual bone measured at CR based on inclination revealed no significant association utilizing the Andrews analysis, r-value=.160 p =.112.

\section{BURSTONE ANALYSIS: RATIO ANALYSIS AT APEX}

Bivariate fit analysis revealed a significant correlation between the ratio of buccal and lingual bone thickness and incisal inclination at the apex, with an $r$-value $=.489 p<.0001$. Optimally inclined incisors as indicated by the Burstone analysis were not significantly more likely to result in equal distribution of bone at the apex, more on the lingual than buccal (Figure 42).

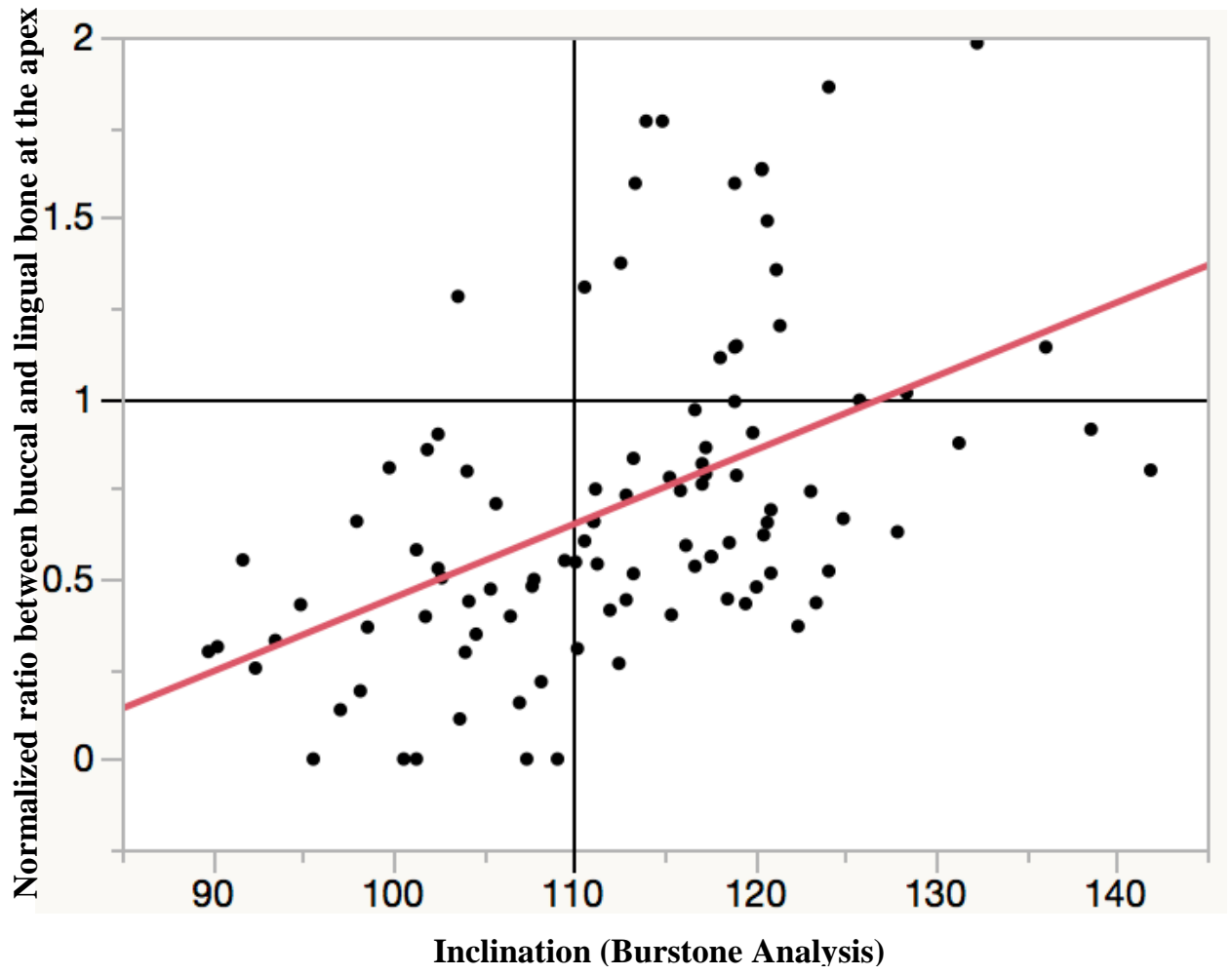

Figure 42. Mx Burstone: Bone distribution at the apex

Fig 42. The ratio between buccal and lingual bone at the apex of the maxillary incisors at various inclinations with a line of best-fit (red) and optimal range of inclination (Burstone analysis) indicated by a black line. 


\section{BURSTONE ANALYSIS: DIFFERENCE ANALYSIS AT APEX}

Bivariate fit analysis revealed a significant correlation between the difference of buccal and lingual bone thickness and incisal inclination at the apex, with an r-value $=.613 \mathrm{p}=.0001$.

Optimally inclined incisors as indicated by the Burstone analysis were not significantly more likely to result in equal distribution of bone at the apex, more bone was measured on the lingual than buccal (Figure 43).

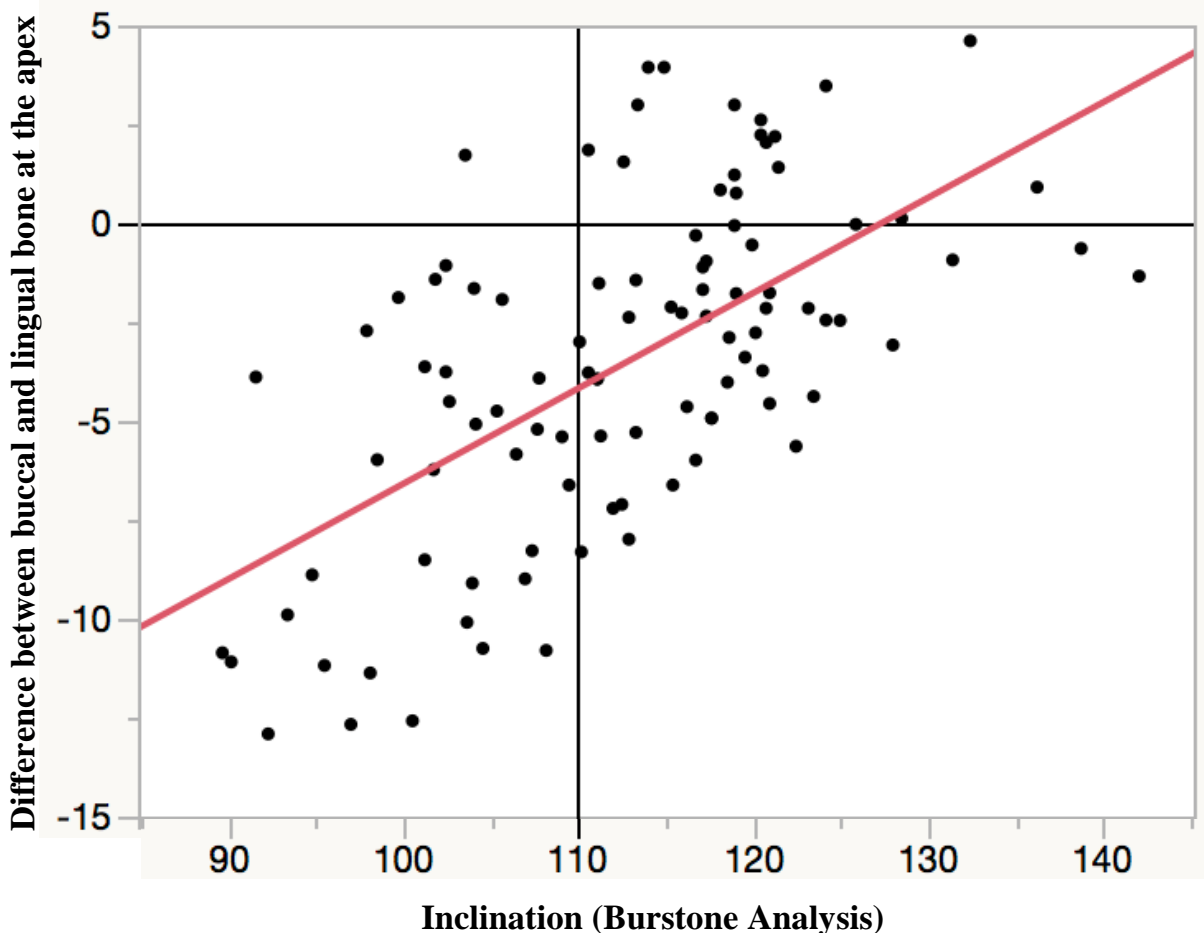

Figure 43. Mx Burstone: Difference in bone distribution at the apex

Fig 43. The difference between buccal and lingual bone at the apex of the maxillary incisors at various inclinations with a line of best-fit (red) and optimal range of inclination (Burstone analysis) indicated by a black line. 


\section{MANDIBLE}

Mandibular bucco-lingual bone was analyzed at $\mathrm{CR}$ and apex at various inclinations. The thickness of buccal and lingual bone was analyzed based on the assumption that incisors centered in bone in the mandibular alveolus would result in equal amount of bone on the lingual aspect and buccal aspect. Ratios were used to plot against inclination in order to eliminate the variable of different alveolar thickness across the sample and to establish a relative difference between buccal and lingual bone thickness. The data was also plotted as the difference between buccal and lingual bone to assess overall changes and have a more complete overview of the sample.

The thickness of buccal and lingual bone measured at CR based on inclination, utilizing ratios and differences, did not reveal any significant association regardless of the analysis utilized: Downs, Steiner, Tweed, Andrews, and Ricketts. The ratio and difference in bone thickness was found to be greater on the lingual for all incisal inclination measured.

$\mathrm{H}_{0}$ : Mandibular incisors inclined in the optimal range according to the Downs, Steiner, Tweed, Andrews, and Ricketts analyses are not more centered in alveolar bone, as measured at the CR and apex, than incisors with more positive or negative inclination.

\section{STEINER ANALYSIS: RATIO ANALYSIS AT APEX}

The Steiner analysis measures the mandibular incisor inclination relative to line NB (Nasion-B point) with an optimal inclination of 25 degrees.

Bivariate fit analysis did not show a significant correlation between the ratio of buccal and lingual bone thickness and incisal inclination at the apex, with an r-value $=.088 \mathrm{p}=.384$ (Figure 44). Incisors inclined in the optimal range as indicated by the Steiner analysis were not 
significantly more likely to result in equal distribution of buccal and lingual bone at the apex (Figure 44).

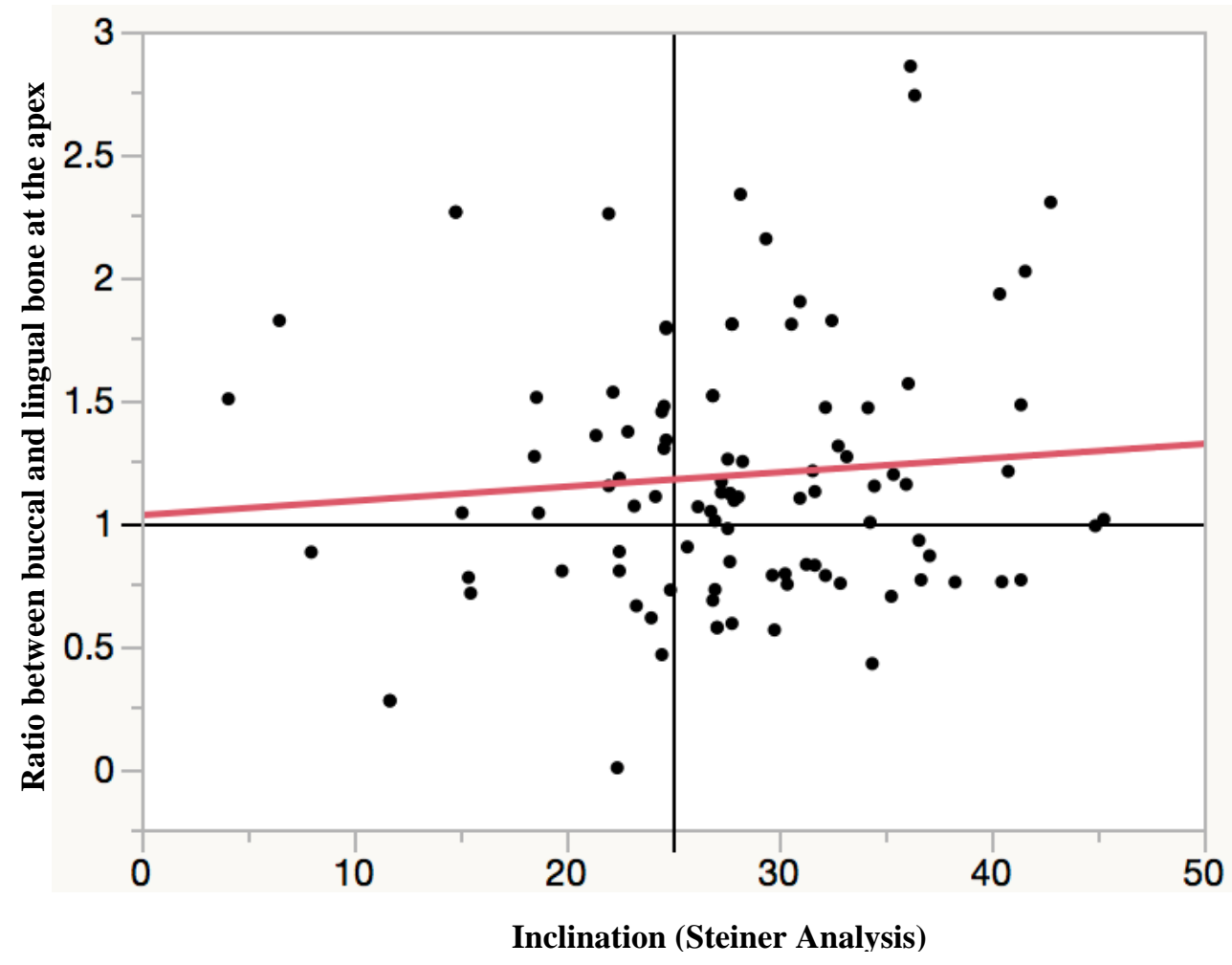

Figure 44. Md Steiner: Bone distribution at the apex

Fig 44. The ratio between buccal and lingual bone at the apex of the maxillary incisors at various inclinations with a line of best-fit (red) and optimal range of inclination (Steiner analysis) indicated by a black line.

\section{STEINER ANALYSIS: DIFFERENCE ANALYSIS AT APEX}

Bivariate fit analysis revealed a significant correlation between the difference of buccal and lingual bone thickness and incisal inclination at the apex, with an $r$-value $=.103 p=.308$.

Optimally inclined incisors as indicated by the Steiner analysis were not significantly more likely to result in equal distribution of bone at the apex (Figure 45). 


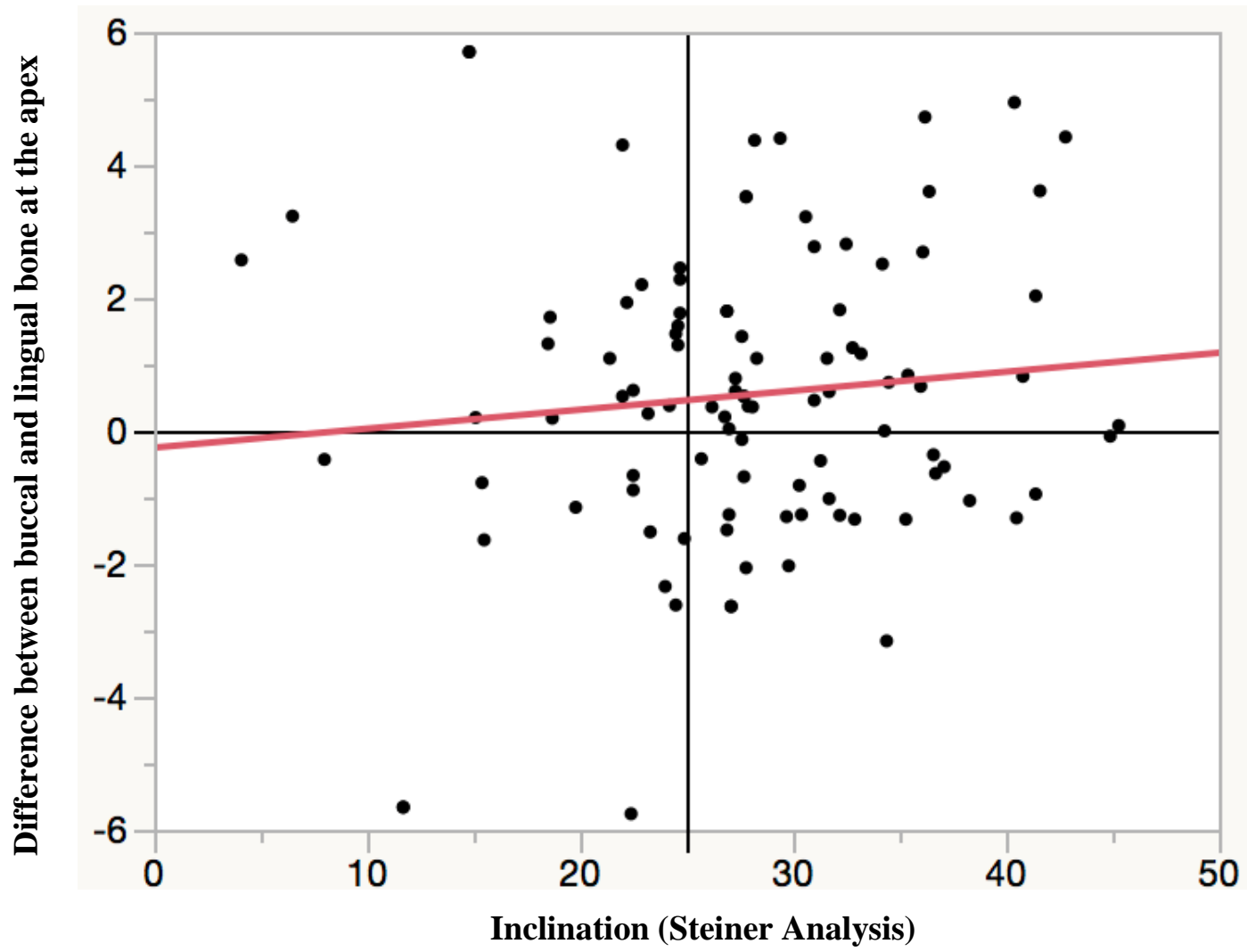

Figure 45. Md Steiner: Difference in bone distribution at the apex

Fig 45. The difference between buccal and lingual bone at the apex of the maxillary incisors at various inclinations with a line of best-fit (red) and optimal range of inclination (Steiner analysis) indicated by a black line.

\section{ANDREWS ANALYSIS: RATIO ANALYSIS AT APEX}

The Andrews analysis measures the mandibular incisor inclination relative to the occlusal plane, with an optimal inclination of 15 degrees.

Bivariate fit analysis did not show a significant correlation between the ratio of buccal and lingual bone thickness and incisal inclination at the apex, with an $\mathrm{r}$-value $=.114 \mathrm{p}=.259$ (Figure 46). Incisors inclined in the optimal range as indicated by the Andrews analysis were not 
significantly more likely to result in equal distribution of buccal and lingual bone at the apex (Figure 46).

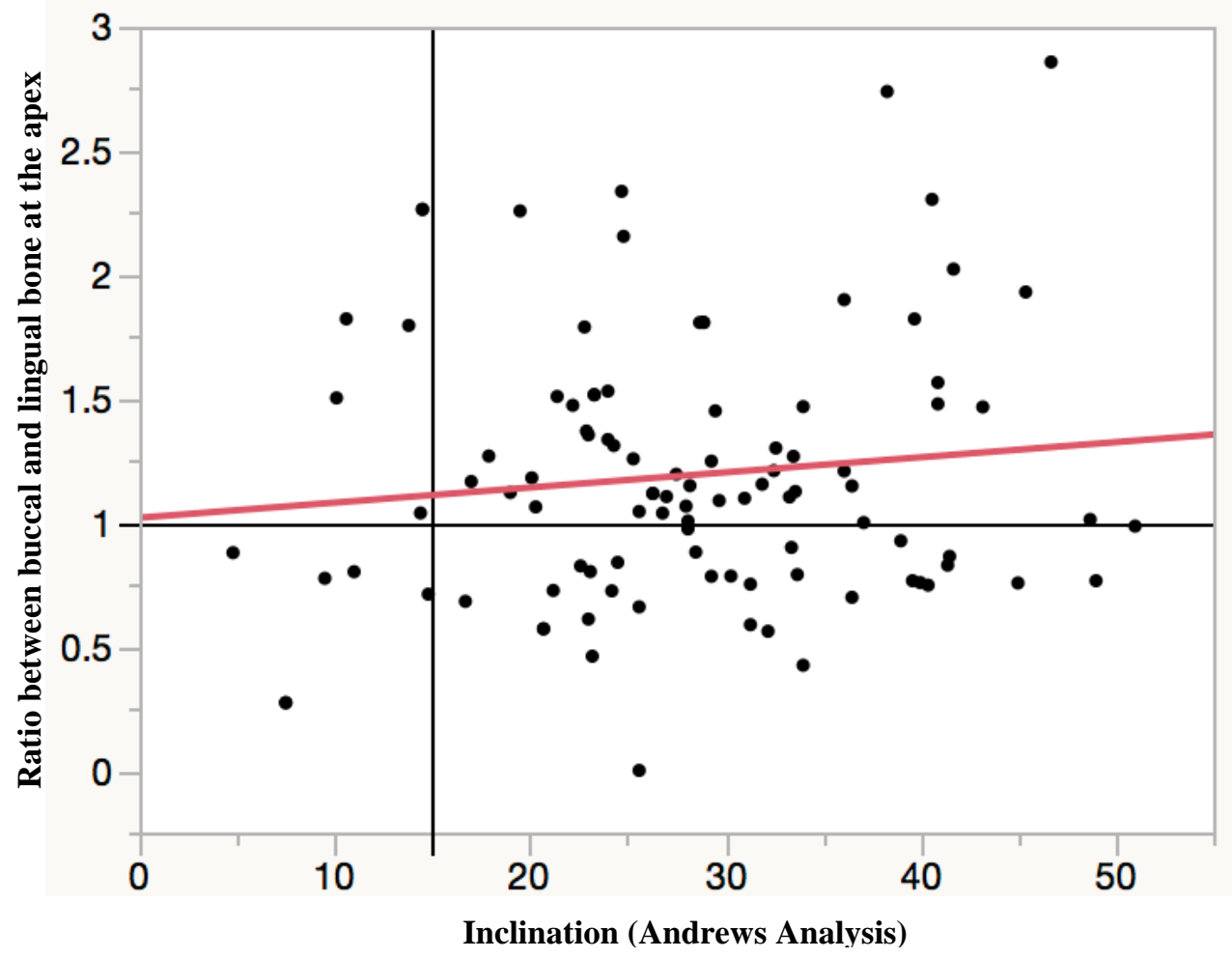

Figure 46. Md Andrews: Bone distribution at the apex

Fig 46. The ratio between buccal and lingual bone at the apex of the maxillary incisors at various inclinations with a line of best-fit (red) and optimal range of inclination (Andrews analysis) indicated by a black line.

\section{ANDREWS ANALYSIS: DIFFERENCE ANALYSIS AT APEX}

Bivariate fit analysis revealed a significant correlation between the difference of buccal and lingual bone thickness and incisal inclination at the apex, with an r-value=.138 $\mathrm{p}=.171$. 
Optimally inclined incisors as indicated by the Andrews analysis were not significantly more likely to result in equal distribution of bone at the apex (Figure 47).

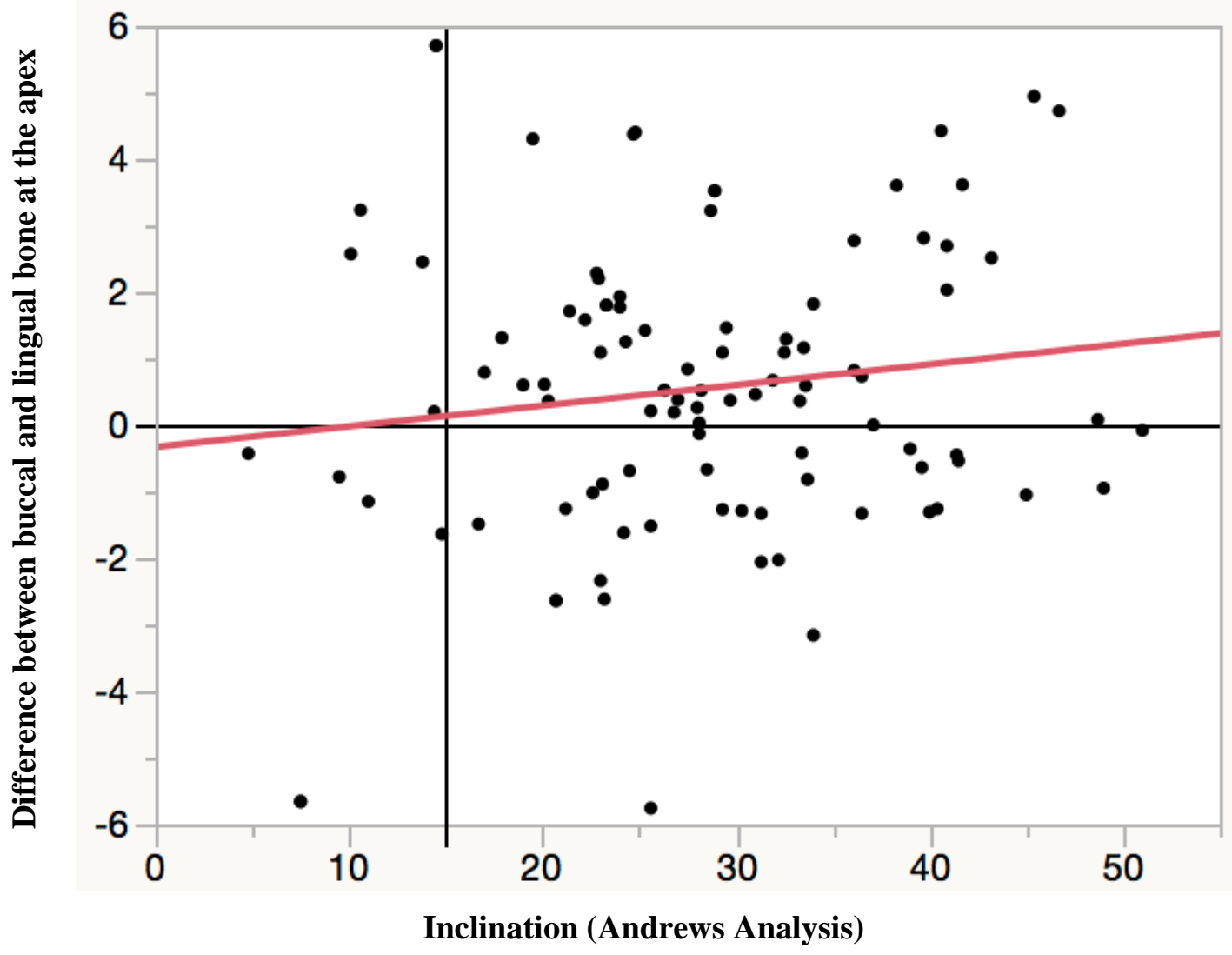

Figure 47. Md Andrews: Difference in bone distribution at the apex

Fig 47. The difference between buccal and lingual bone at the apex of the maxillary incisors at various inclinations with a line of best-fit (red) and optimal range of inclination (Andrews analysis) indicated by a black line. 


\section{DOWNS ANALYSIS: RATIO ANALYSIS AT APEX}

The Downs analysis measures the mandibular incisor inclination relative to the mandibular plane, with a mean of $1.4^{\circ}$ and a range of $-8.5^{\circ}$ to $7^{\circ}$ (a negative value indicated proclined incisors).

Bivariate fit analysis showed a significant correlation between the ratio of buccal and lingual bone thickness and incisal inclination at the apex, with an $\mathrm{r}$-value $=.365 \mathrm{p}=.0002$ (Figure 48). Incisors inclined in the optimal range as indicated by the Downs analysis were significantly more likely to result in equal distribution of buccal and lingual bone at the apex (Figure 48).

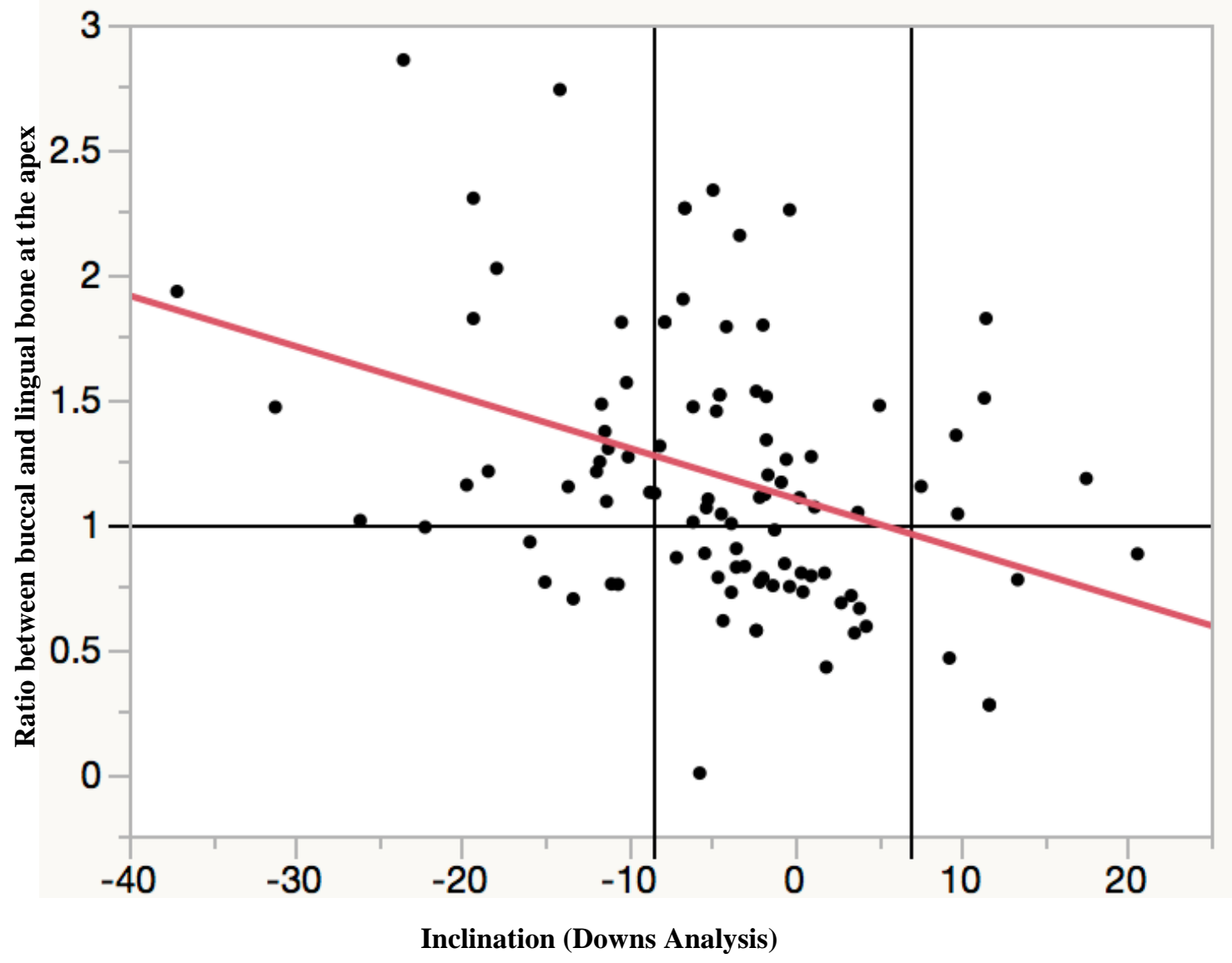

Figure 48. Md Downs: Bone distribution at the apex 
Fig 48. The ratio between buccal and lingual bone at the apex of the maxillary incisors at various inclinations with a line of best-fit (red) and optimal range of inclination (Downs analysis) indicated by a black line.

\section{DOWNS ANALYSIS: DIFFERENCE ANALYSIS AT APEX}

Bivariate fit analysis revealed a significant correlation between the difference of buccal and lingual bone thickness and incisal inclination at the apex, with an r-value $=.387 \mathrm{p}<.0001$.

Optimally inclined incisors as indicated by the Downs analysis were significantly more likely to result in equal distribution of bone at the apex (Figure 49).

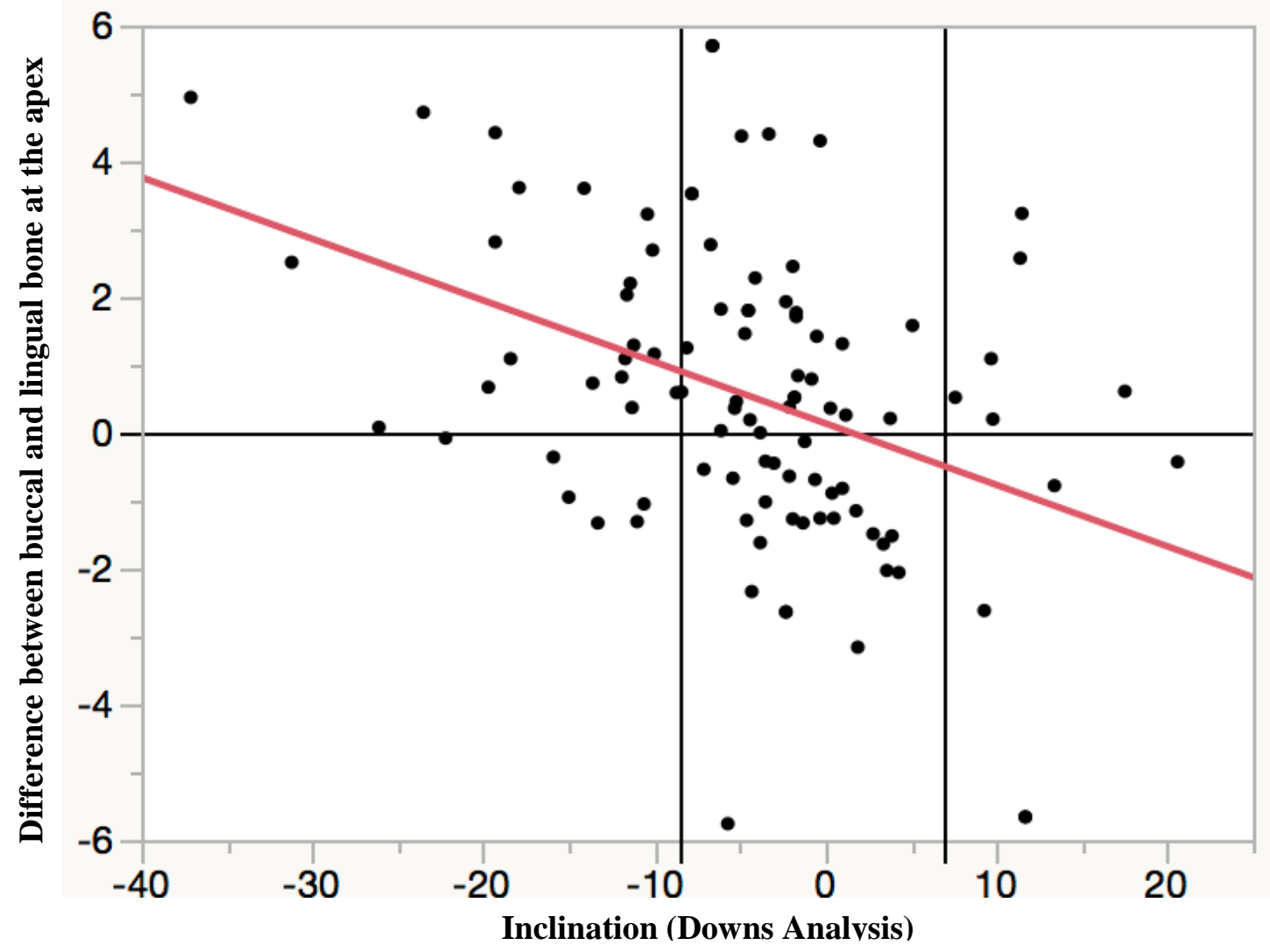

Figure 49. Md Downs: Difference in bone distribution at the apex 
Fig 49. The difference between buccal and lingual bone at the apex of the maxillary incisors at various inclinations with a line of best-fit (red) and optimal range of inclination (Downs analysis) indicated by a black line.

\section{TWEED ANALYSIS: RATIO ANALYSIS AT APEX}

The Tweed analysis measures the mandibular incisor inclination relative to the mandibular plane, with an optimal inclination of 87 degrees.

Bivariate fit analysis did show a significant correlation between the ratio of buccal and lingual bone thickness and incisal inclination at the apex, with an $r$-value $=.365 \mathrm{p}=.0002$ (Figure 50). Incisors inclined in the optimal range as indicated by the Tweed analysis were significantly more likely to result in equal distribution of buccal and lingual bone at the apex (Figure 50).

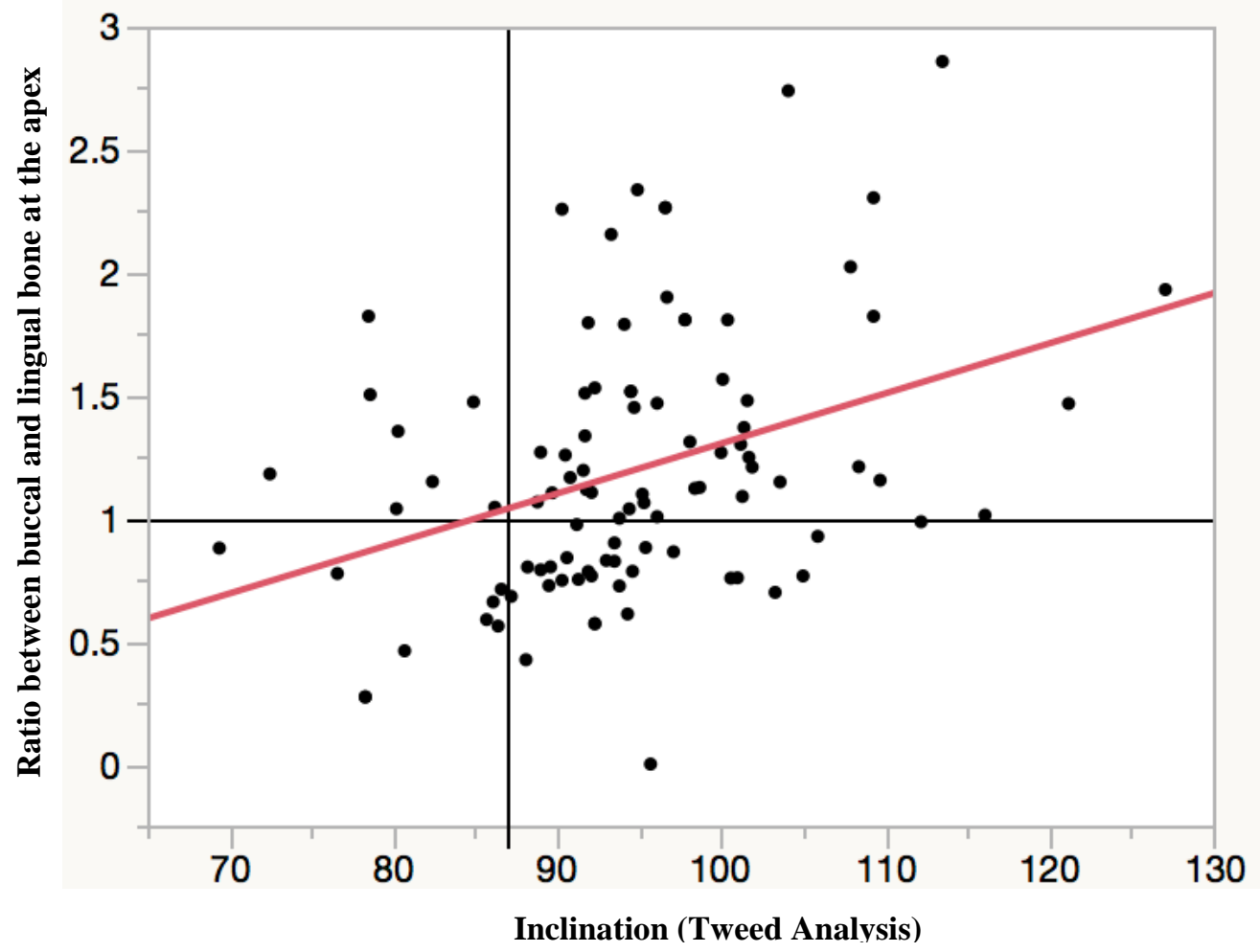

Figure 50. Md Tweed: Bone distribution at the apex 
Fig 50. The ratio between buccal and lingual bone at the apex of the maxillary incisors at various inclinations with a line of best-fit (red) and optimal range of inclination (Tweed analysis) indicated by a black line.

\section{TWEED ANALYSIS: DIFFERENCE ANALYSIS AT APEX}

Bivariate fit analysis revealed A significant correlation between the difference of buccal and lingual bone thickness and incisal inclination at the apex, with an r-value $=.388 \mathrm{p}<.0001$. Optimally inclined incisors as indicated by the Tweed analysis were significantly more likely to result in equal distribution of bone at the apex (Figure 51).

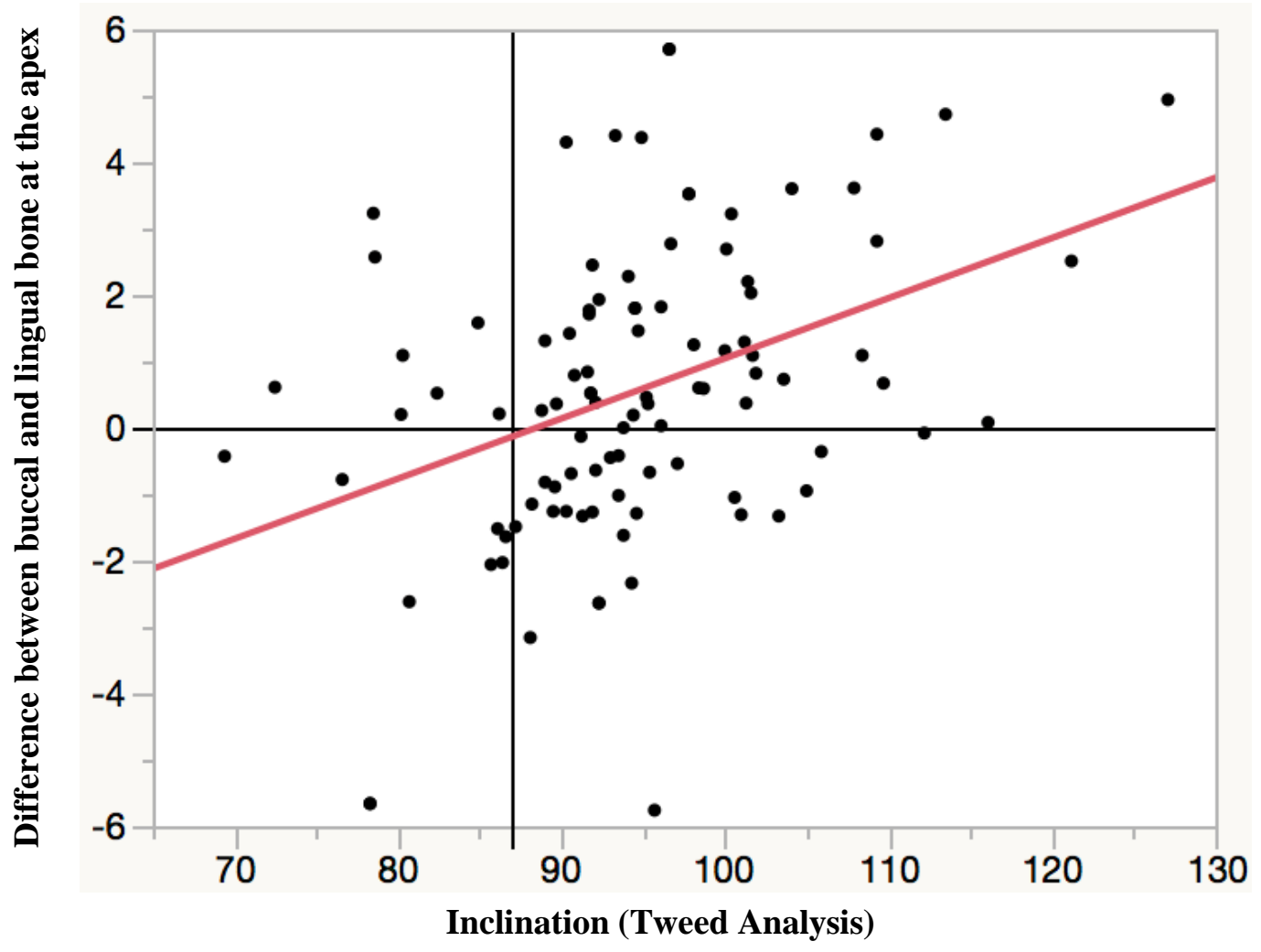

Figure 51. Md Tweed: Difference in bone distribution at the apex

Fig 51. The difference between buccal and lingual bone at the apex of the maxillary incisors at various inclinations with a line of best-fit (red) and optimal range of inclination (Tweed analysis) indicated by a black line. 


\section{RICKETTS ANALYSIS: RATIO ANALYSIS AT APEX}

The Ricketts analysis measures the mandibular incisor inclination relative to the line A-Po (A point-Pogonion), with a mean of $22^{\circ}$ and a range of range of $18^{\circ}$ to $26^{\circ}$.

Bivariate fit analysis did not show a significant correlation between the ratio of buccal and lingual bone thickness and incisal inclination at the apex, with an $\mathrm{r}$-value=.171 $\mathrm{p}=.089$. Incisors inclined in the optimal range as indicated by the Ricketts analysis were not significantly more likely to result in equal distribution of buccal and lingual bone at the apex (Figure 52).

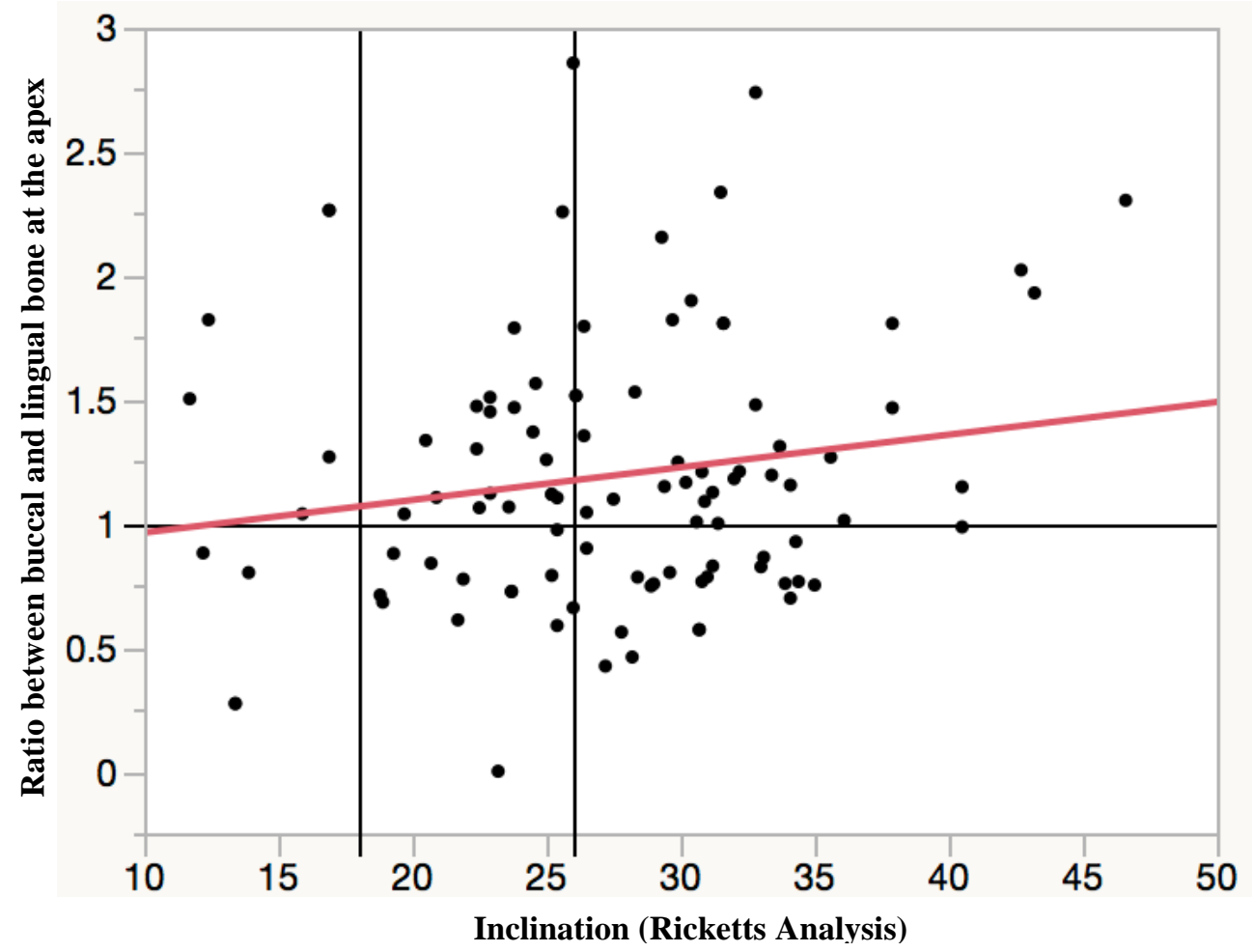

Figure 52. Md Ricketts: Bone distribution at the apex

Fig 52. The ratio between buccal and lingual bone at the apex of the maxillary incisors at various inclinations with a line of best-fit (red) and optimal range of inclination (Ricketts analysis) indicated by a black line. 


\section{RICKETTS ANALYSIS: DIFFERENCE ANALYSIS AT APEX}

Bivariate fit analysis revealed a significant correlation between the difference of buccal and lingual bone thickness and incisal inclination at the apex, with an r-value=.199 $p=.047$.

Optimally inclined incisors as indicated by the Ricketts analysis were not significantly more likely to result in equal distribution of bone at the apex (Figure 53).

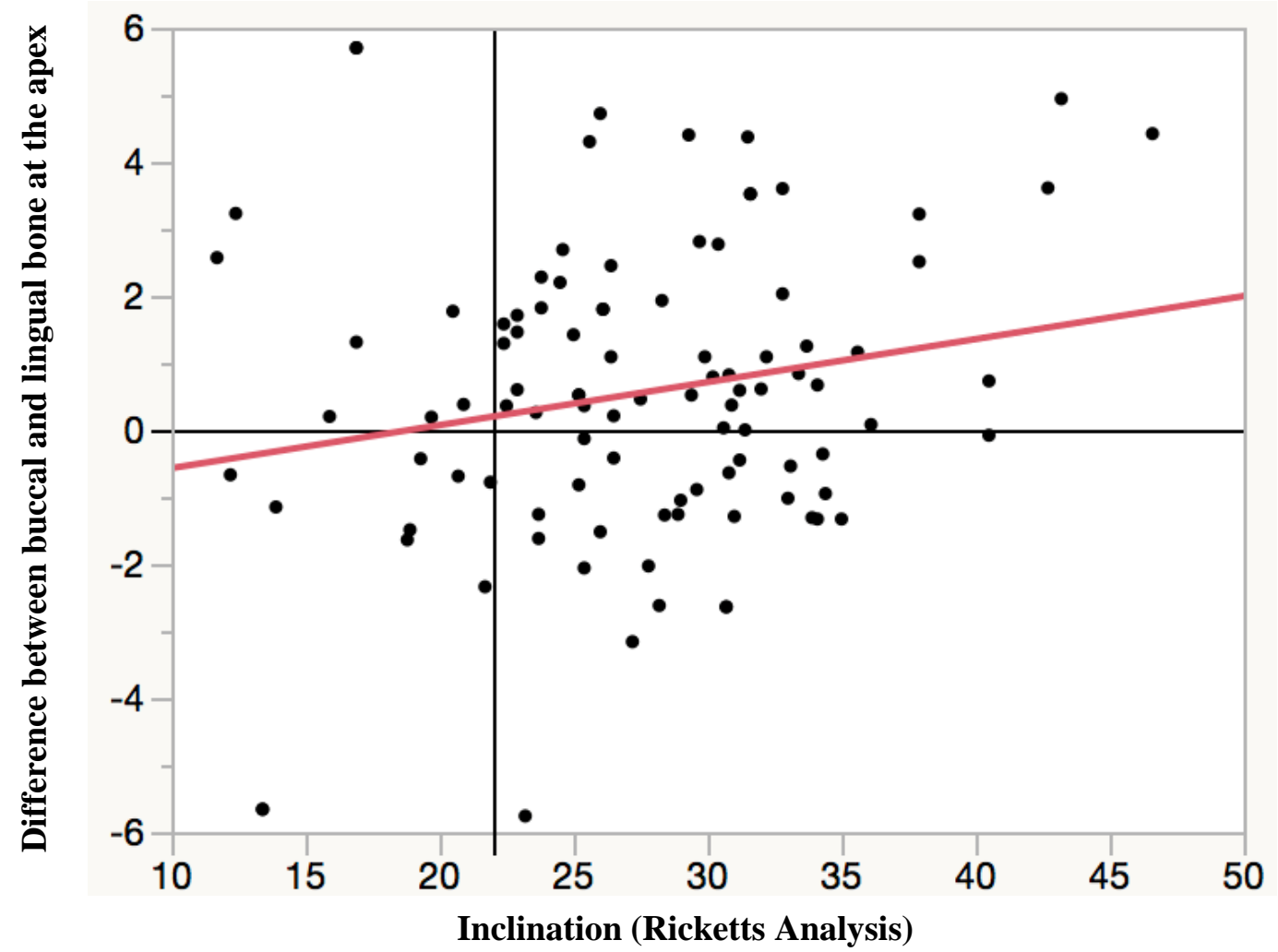

Figure 53. Md Ricketts: Difference in bone distribution at the apex

Fig 53. The difference between buccal and lingual bone at the apex of the maxillary incisors at various inclinations with a line of best-fit (red) and optimal range of inclination (Ricketts analysis) indicated by a black line. 


\section{MAXILLA}

$\mathrm{H}_{0}$ : Maxillary incisors inclined in the optimal range according to the Steiner, Andrews, Burstone analyses do not have less dehiscences than incisors with more positive or negative inclination.

$\mathrm{H}_{0}$ : Maxillary incisors inclined in the optimal range according to the Steiner, Andrews, Burstone analyses do not have less fenestrations than incisors with more positive or negative inclination.

The maxillary incisors were analyzed for the presence of dehiscences and fenestrations at various inclinations. Overall, out of a sample of 100 only $11 \%$ of the sample presented with fenestrations at the maxillary incisors. Additionally, $25 \%$ of the sample had a dehiscence noted at the maxillary incisors. There was no statistically significant difference in the presence of dehiscences or fenestrations at various inclinations regardless of the analysis utilized: Steiner, Andrews, and Burstone. Although, the data lacked statistical significance there was a trend in the presence of fenestrations and inclination that maybe of clinical importance, as follows:

\section{$\underline{\text { STEINER ANALYSIS }}$}

The Steiner analysis measures the maxillary incisor inclination relative to line NA (Nasion-A point) with an optimal inclination of 22 degrees.

Contingency analysis (chi-square) did not show a significant relationship, with $\mathrm{x}^{2}=.274 \mathrm{p}<.060$. The trend was for maxillary incisors deemed as retroclined by the Steiner analysis to present with more fenestrations compared to normoinclined or proclined maxillary incisors (Figure 54). 


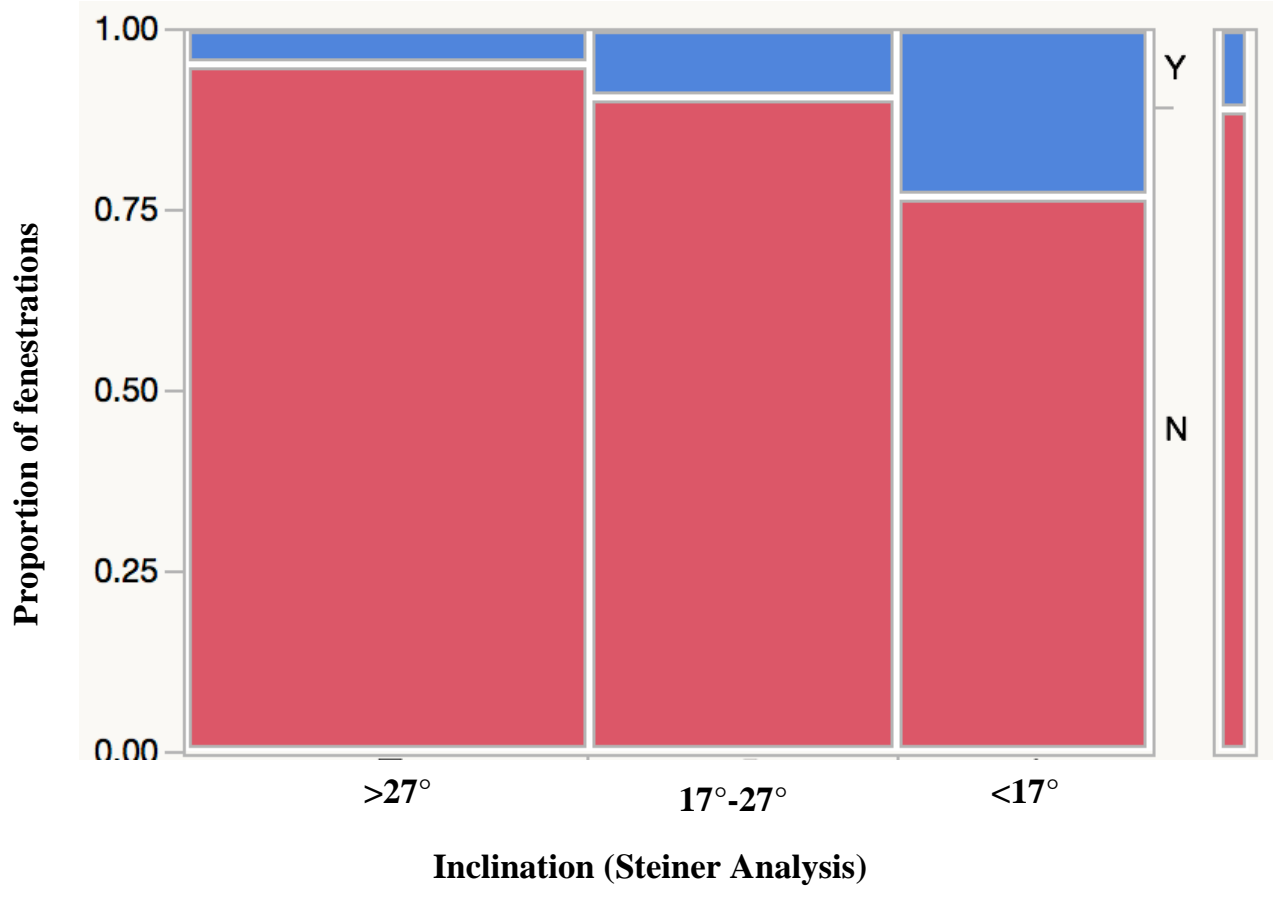

Figure 54. Mx Steiner: Fenestrations

Fig 54. Chi square analysis of the proportion of fenestrations, indicated in blue (Y), absence of fenestrations, indicated in red $(\mathrm{N})$, at various inclinations (Steiner analysis).

\section{ANDREWS ANALYSIS}

The Andrews analysis measures the maxillary incisor inclination relative to the occlusal plane with an optimal inclination of 25 degrees.

Contingency analysis (chi-square) did not show a significant relationship, with $x^{2}=.283 p<.069$. The trend was for maxillary incisors deemed as retroclined by the Andrews analysis to present with more fenestrations compared to normoinclined or proclined maxillary incisors (Figure 55). 


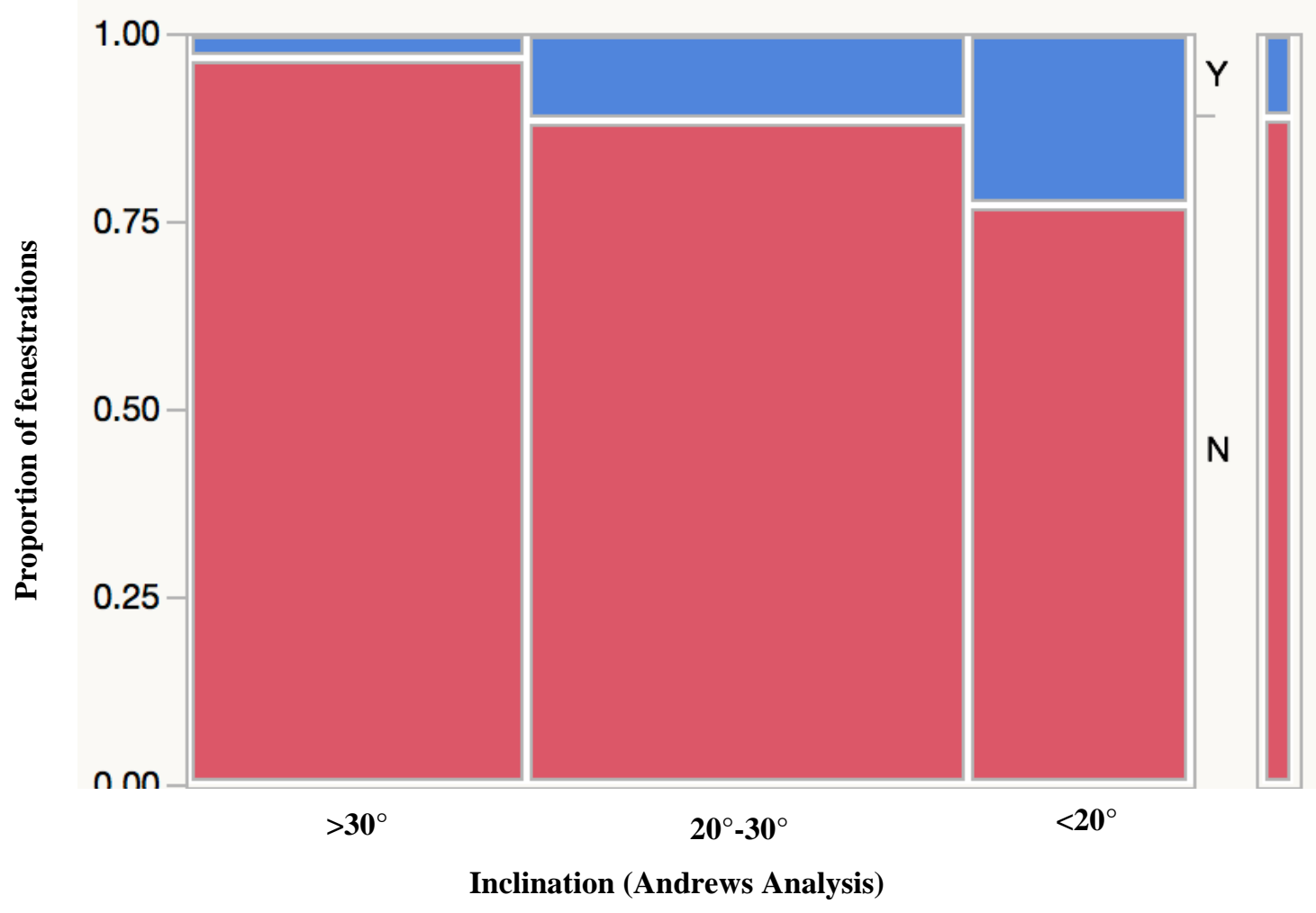

Figure 55. Mx Andrews: Fenestrations

Fig 55. Chi square analysis of the proportion of fenestrations, indicated in blue (Y), absence of fenestrations, indicated in red (N), at various inclinations (Andrews analysis).

\section{BURSTONE ANALYSIS}

The Burstone analysis measures the maxillary incisor inclination relative to the palatal plane with an optimal inclination of 110 degrees.

Contingency analysis (chi-square) did not show a significant relationship, with $\mathrm{x}^{2}=.098 \mathrm{p}<.730$. The trend was for maxillary incisors deemed as retroclined by the Burstone analysis to present with more fenestrations compared to normoinclined or proclined maxillary incisors (Figure 56). 


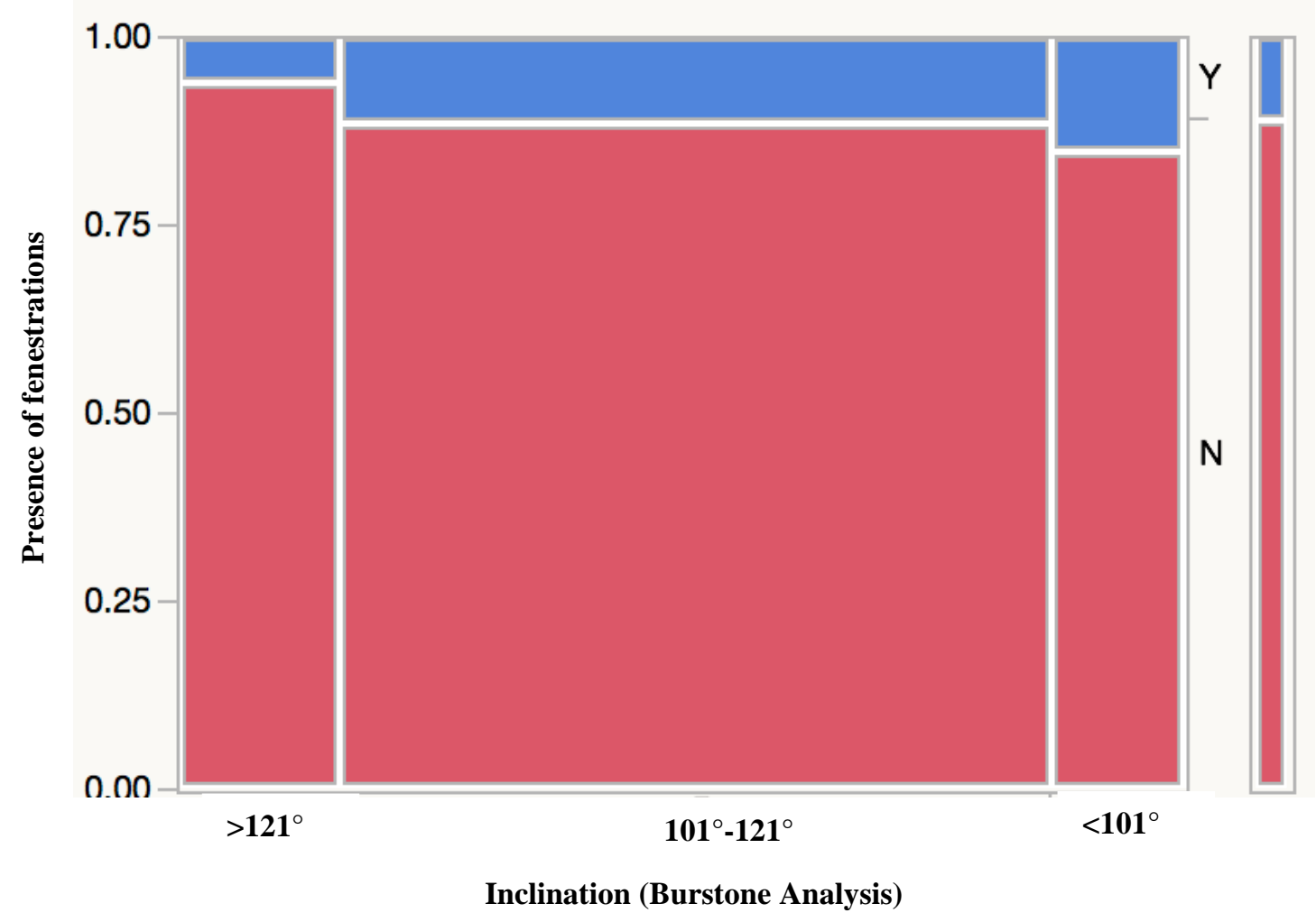

Figure 56. Mx Burstone: Fenestrations

Fig 56. Chi square analysis of the proportion of fenestrations, indicated in blue (Y), absence of fenestrations, indicated in red $(\mathrm{N})$, at various inclinations (Burstone analysis).

\section{MANDIBLE}

The mandibular incisors were analyzed for the presence of dehiscences and fenestrations at various inclinations Overall, out of a sample of 100 there were no fenestrations noted at the root surface of the mandibular incisors regardless of the type of analysis or incisal inclination.

However, $91 \%$ of the sample had a dehiscence present. Only the Downs, Tweed, and Ricketts analysis revealed a significant association between inclination and the presence of dehiscences. 
$\mathrm{H}_{0}$ : Mandibular incisors inclined in the optimal range according to the Downs, Steiner, Tweed, Andrews, Ricketts analyses do not have less dehiscences than incisors with more positive or negative inclination.

$\mathrm{H}_{0}$ : Mandibular incisors inclined in the optimal range according to the Downs, Steiner, Tweed, Andrews, Ricketts analyses do not have less fenestrations than incisors with more positive or negative inclination.

\section{DOWNS ANALYSIS}

The Downs analysis measures the mandibular incisor inclination relative to the mandibular plane, with a mean of $1.4^{\circ}$ and a range of $-8.5^{\circ}$ to $7^{\circ}$ (a negative value indicates proclined incisors).

Contingency analysis (chi-square) shows a significant relationship, with $x^{2}=.130 \mathrm{p}<.017$. Mandibular incisors at inclinations greater than $7^{\circ}$ (retroclined incisors) had dehiscences present $100 \%$ of the time, followed by incisors inclined in the optimal range, followed by incisors at inclinations less than $-8.5^{\circ}$ (proclined incisors) (Figure 57).

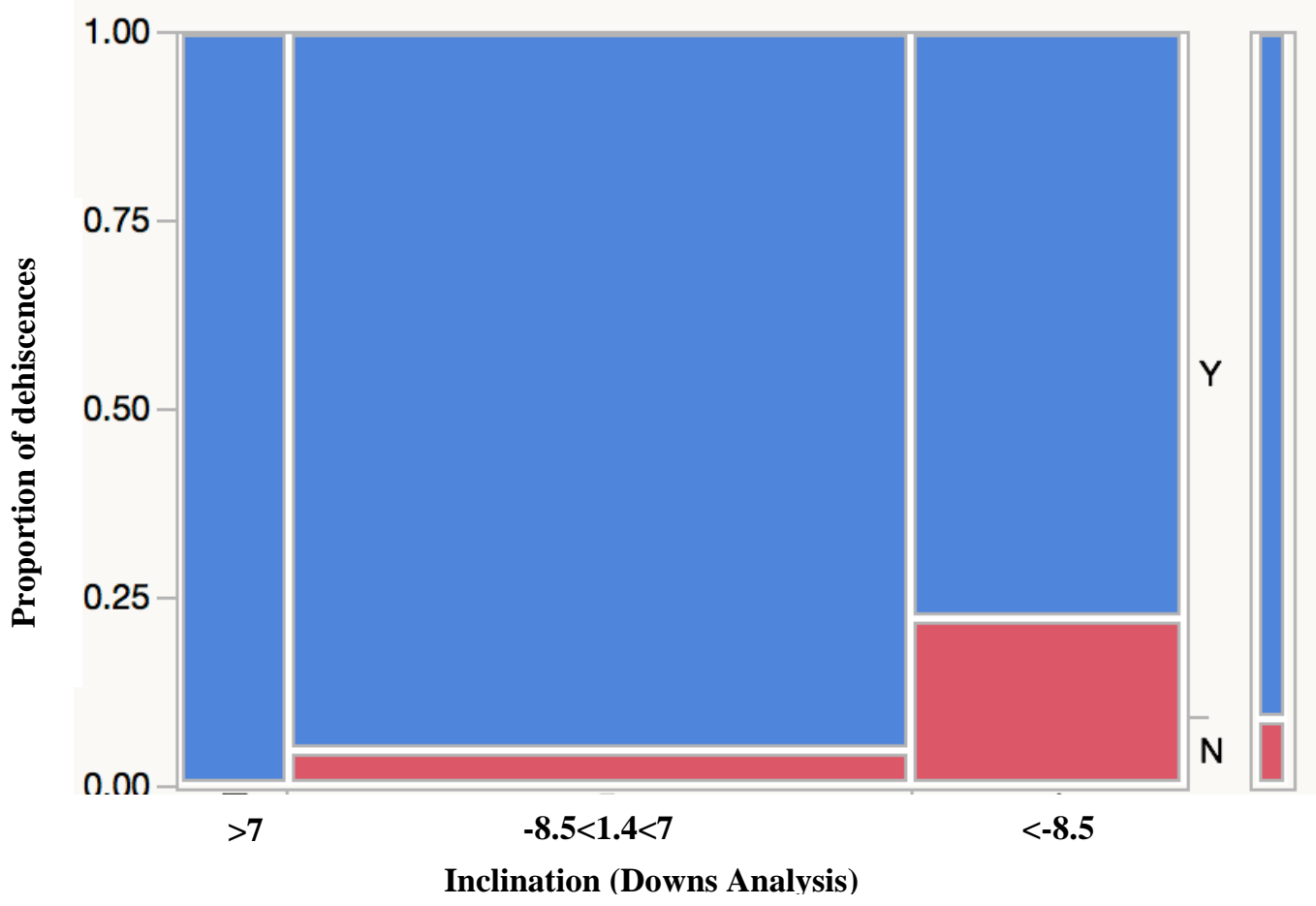

Figure 57. Md Downs: Dehiscences 
Fig 57. Chi square analysis of the proportion of dehiscences, indicated in blue (Y), absence of dehiscences, indicated in red $(\mathrm{N})$, at various inclinations (Downs analysis).

\section{TWEED ANALYSIS}

The Tweed analysis measures the mandibular incisor inclination relative to the mandibular plane, with an optimal inclination of 87 degrees.

Contingency analysis (chi-square) shows a significant relationship, with $\mathrm{x}^{2}=.162 \mathrm{p}<.037$. Mandibular incisors at inclinations $82^{\circ}$ to $92^{\circ}$ (optimal range) and mandibular incisors at inclinations less than $82^{\circ}$ (retroclined incisors) had dehiscences present $100 \%$ of the time, followed by incisors at inclinations greater than $92^{\circ}$ (Figure 58).

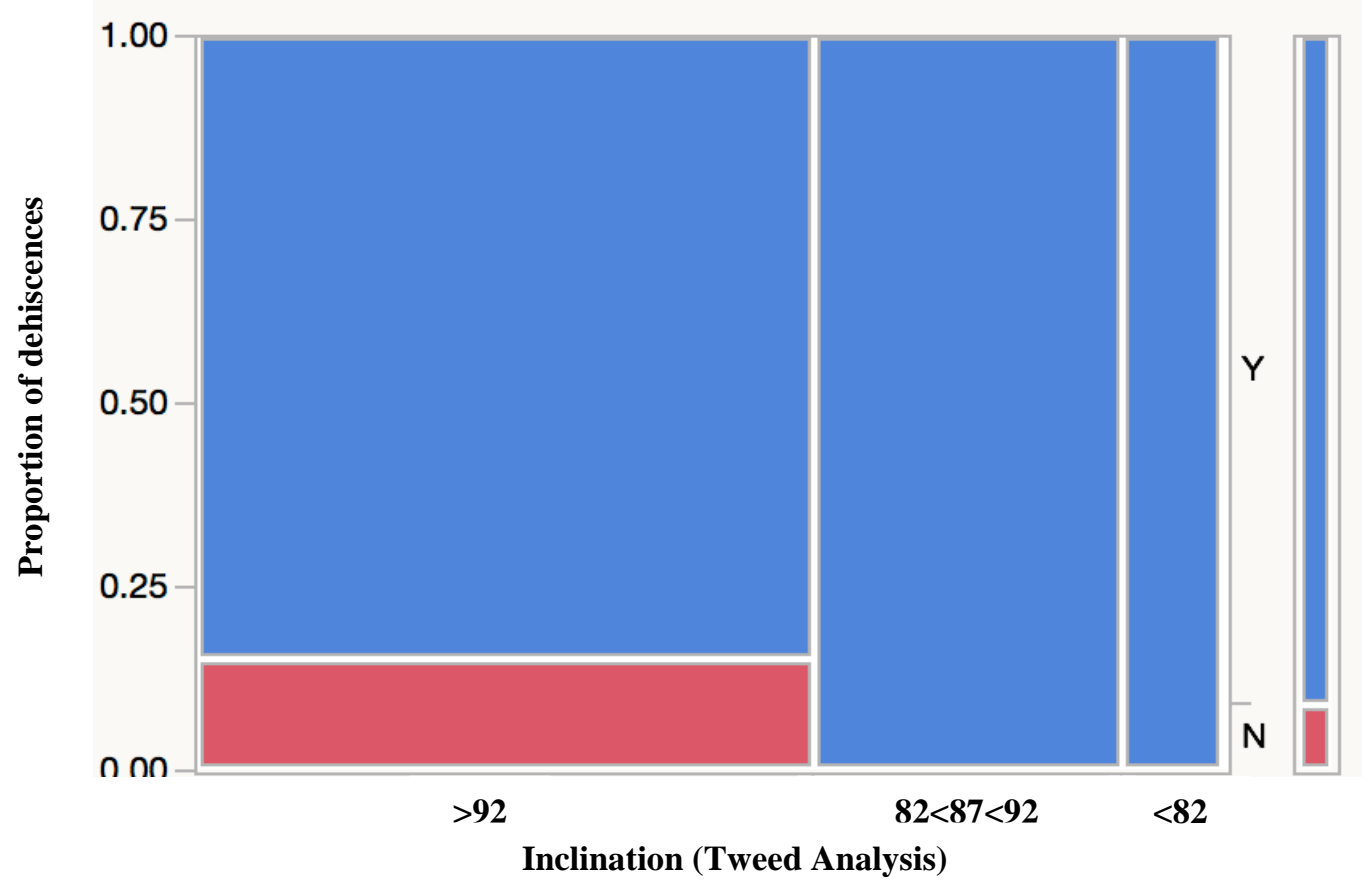

Figure 58. Md Tweed: Dehiscences 
Fig 58. Chi square analysis of the proportion of dehiscences, indicated in blue (Y), absence of dehiscences, indicated in red $(\mathrm{N})$, at various inclinations (Tweed analysis).

\section{$\underline{\text { RICKETTS ANALYSIS }}$}

The Ricketts analysis measures the mandibular incisor inclination relative to the line A-Po (A point-Pogonion), with a mean of $22^{\circ}$ and a range of range of $18^{\circ}$ to $26^{\circ}$.

Contingency analysis (chi-square) shows a significant relationship, with $x^{2}=.178 \mathrm{p}<.024$. Mandibular incisors at inclinations $18^{\circ}$ to $26^{\circ}$ (optimal range) and mandibular incisors at inclinations less than $18^{\circ}$ (retroclined incisors) had dehiscences present $100 \%$ of the time, followed by incisors at inclinations greater than $26^{\circ}$ (Figure 59).

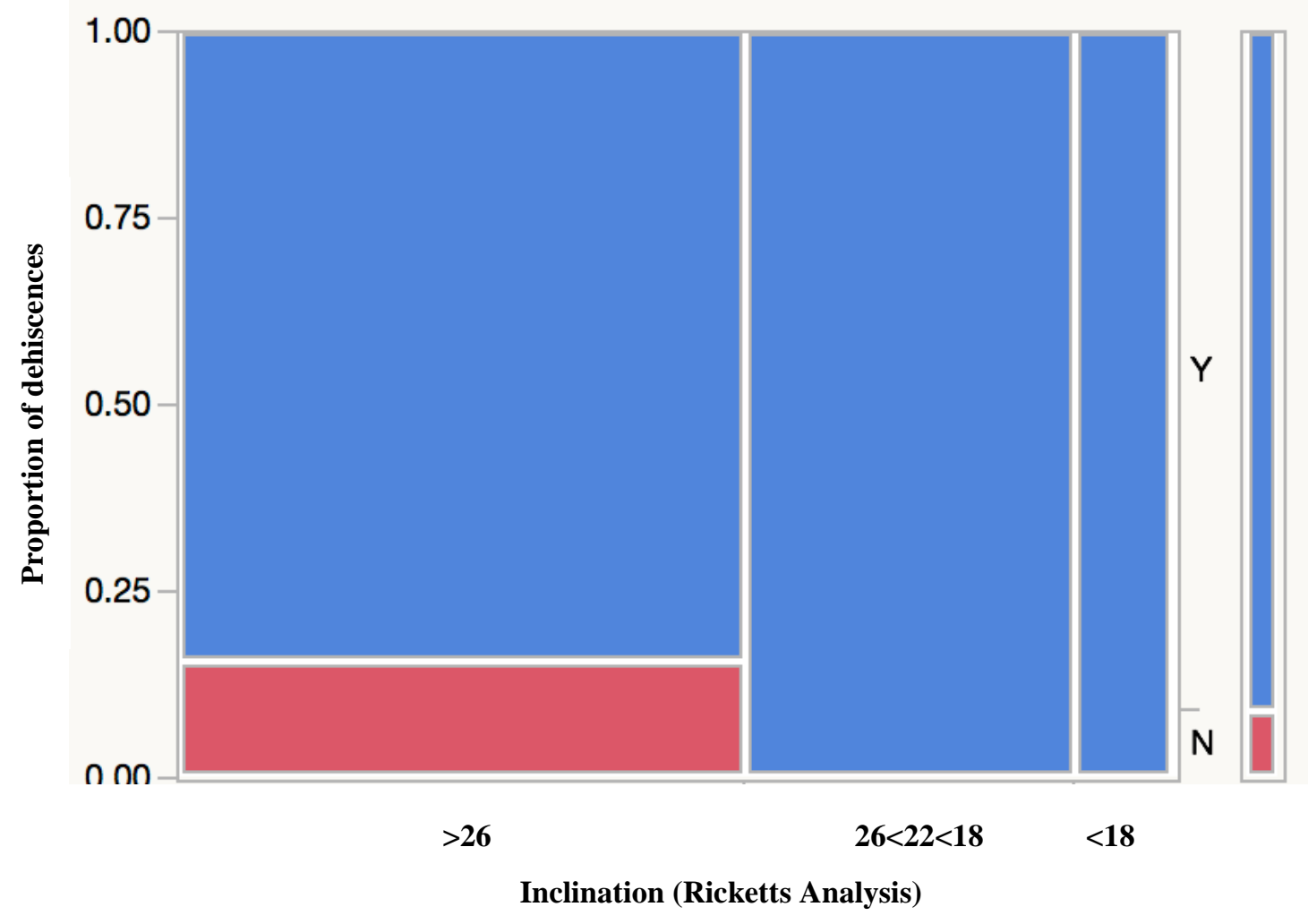

Figure 59. Md Ricketts: Dehiscences 
Fig 59. Chi square analysis of the proportion of dehiscences, indicated in blue (Y), absence of dehiscences, indicated in red $(\mathrm{N})$, at various inclinations (Ricketts analysis).

\section{$\underline{\text { SKELETAL CLASS AND PERIODONTAL DEFECTS }}$}

The maxillary and mandibular incisors were analyzed for the presence of dehiscences based on skeletal classification.

$\mathrm{H}_{0}$ : Patients classified with skeletal Class I occlusion do not have less dehiscences present in the maxilla or mandible than patients classified with skeletal Class II or III occlusions.

A contingency analysis of skeletal class and the presence of dehiscences did not reveal any significant differences. Skeletal class was not predictive of the presence or absence of dehiscences in the maxilla, $x^{2}=.133 \mathrm{p}<.379$. Skeletal class was also not predictive of the presence or absence of dehiscences in the mandible, $x^{2}=.113 \mathrm{p}<.064$.

The maxillary and mandibular incisors were analyzed for the presence of fenestrations based on skeletal classification.

$\mathrm{H}_{0}$ : Patients classified with skeletal Class I occlusion do not have less fenestrations present in the maxilla or mandible than patients classified with skeletal Class II or III occlusions.

A contingency analysis of skeletal class and the presence of fenestrations did not reveal any significant differences. Skeletal class was not predictive of the presence or absence of fenestrations in the maxilla, $\mathrm{x}^{2}=.257 \mathrm{p}<.088$. Out of a sample of 100 no fenestrations were noted regardless of skeletal classification in the mandible. 


\section{VERTICAL FACE HEIGHT AND PERIODONTAL DEFECTS}

The maxillary and mandibular incisors were analyzed for the presence of dehiscences based on vertical face height.

$\mathrm{H}_{0}$ : Maxillary and mandibular incisors in patients with normal vertical dimension do not have less dehiscences than incisors in patients with increased or decreased vertical dimension.

Overall, there was no significant difference in the presence of dehiscences based on vertical face height in the maxilla or mandible

The maxillary and mandibular incisors were analyzed for the presence of fenestrations based on vertical face height.

$\mathrm{H}_{0}$ : Maxillary and mandibular incisors in patients with normal vertical dimension do not have less fenestrations than incisors in patients with increased or decreased vertical dimension.

Overall, there was no significant difference in the presence of fenestrations based on vertical face height in the maxilla or mandible

\section{RELIABILITY OF MEASUREMENTS}

Because one examiner conducted all measurement in this study, a reliability test was performed to determine the repeatability of the measures made for the airway variables in this study. A random sample of five subjects had the data collection process repeated four weeks after the first assessment. The results for each variable is listed in Table 1, with only significant differences 
noted in the SNA and ANB values. Nevertheless, the mean difference for SNB and ANB, .0047 and .027 , respectively, are not clinically significant and therefore the data collected in this study is considered reliable and consistent across all variables.

Table 13. Intra-rater reliability. Intra-rater reliability of a random sample of five subjects measured four weeks apart for all tested variables.

\begin{tabular}{|l|l|l|l|l|l|}
\hline Variable & Mean 1 & Mean 2 & Mean Diff & P-Value & Sig Diff \\
\hline SNA & 82.23 & 82.17 & & .59 & NS \\
\hline SNB & 80.97 & 80.6 & & .0047 & $* *$ \\
\hline ANB & 1.27 & 1.57 & & .027 & $*$ \\
\hline UFH & 50.04 & 50.07 & & .85 & NS \\
\hline LFH & 61.55 & 61.63 & & .84 & NS \\
\hline Mx Steiner & 20.43 & 20.33 & & .77 & NS \\
\hline Mx Andrews & 25.8 & 25.53 & & .24 & NS \\
\hline Mx Burstone & 112.65 & 112.55 & & .71 & NS \\
\hline Mx Buccal Bone CR & .87 & .84 & & .08 & NS \\
\hline Mx Buccal Bone Apex & 2.86 & 2.86 & & .82 & NS \\
\hline Mx Lingual Bone CR & 4.22 & 4.23 & & .17 & NS \\
\hline Mx Lingual Apex & 10.71 & 10.73 & & .25 & NS \\
\hline Md Downs & -.32 & -.35 & & .83 & NS \\
\hline Md Steiner & 19.82 & 19.57 & & .098 & NS \\
\hline Md Tweed & 90.32 & 90.22 & & .30 & NS \\
\hline Md Andrews & 17.65 & 17.75 & & & \\
\hline
\end{tabular}




\begin{tabular}{|l|l|l|l|l|l|}
\hline Md Ricketts & 22.83 & 22.97 & & .19 & NS \\
\hline Md Buccal Bone CR & .31 & .32 & & .26 & NS \\
\hline Md Buccal Bone Apex & 5.92 & 5.91 & & .60 & NS \\
\hline Md Lingual Bone CR & 1.52 & 1.54 & & .29 & NS \\
\hline Md Lingual Bone Apex & 5.32 & 5.43 & & .29 & NS \\
$* \mathrm{p}<0.05$ & & & & \\
$* * \mathrm{p}<0.01$
\end{tabular}

\section{CHAPTER 5: DISCUSSION}

\section{DATA COLLECTION AND SAMPLE ANALYSIS}

The sample size in this study was limited to ages 17-20 with the goal of having healthy periodontium and alveolar bone levels prior to orthodontic therapy with the intention of eliminating the confounding variables of decreased periodontal support and increased periodontal defects with age. Research has shown that age is an important factor related to periodontal disease and periodontal breakdown. Teeth in the incisor region consistently show the highest frequency of advanced alveolar bone loss and lowest frequency of adequate tissue support [59]. The distribution of males and females in the sample were almost equal and therefore should not serve as confounding variable during analysis. Variable analysis revealed a normal distribution across all the values of interest.

\section{MAXILLARY INCISOR INCLINATION}

The current study analyzed maxillary incisor inclination as it relates to alveolar bone thickness in the bucco-lingual dimension. An important difference between bucco-lingual dimension of the alveolus in the maxilla and the mandible is the overall thickness. The maxillary alveolus, due to normal growth and development, results in a thicker lingual dimension. Taking normal development and anatomy into consideration the data was analyzed with the assumption that the lingual bone thickness would be twice as thick as buccal bone thickness in the maxillary incisor 
region. In this sample, the presence of equal amount of bucco-lingual bone at the center of resistance of optimally inclined maxillary incisors as described by Steiner, Andrews and Burstone did not exist. The maxillary incisors consistently showed a trend of having more bone on the lingual aspect rather than buccal. Previous research has shown that thin facial bone $(<2$ $\mathrm{mm}$ ) on maxillary incisors is a contributing factor to facial bone fenestration, dehiscence, and soft-tissue recession [61]. Additionally, retrospective studies analyzing maxillary incisor facial bone thickness utilizing tomographic scans revealed minimal facial bone thickness, varying from 1.41-1.45 $\mathrm{mm}$ measured $3 \mathrm{~mm}$ from the cemento-enamel junction [61]. Therefore, it is not uncommon to see minimal facial bone thickness on the maxillary incisors. It was noted however, that for all analyses, the line of best fit crossed the area of optimal bucco-lingual bone thickness at greater inclinations. Therefore, based on the results of this study it can be concluded that regardless of the analyses being utilized to center the teeth in the alveolus, the maxillary incisors should be inclined a few degrees beyond what has been described to be optimal. Interestingly, analysis of bucco-lingual bone thickness of maxillary central incisors at the apex revealed a statistically significant difference utilizing either the Steiner, Andrews or Burstone analysis. Although each analysis uses different reference points to assess maxillary incisor inclination, optimally inclined incisors specified by each analysis resulted in incisors with more bone on the lingual aspect compared to the buccal. Therefore, utilizing any of the three analyses to establish optimally inclined maxillary incisors will not result in optimal amount of buccolingual bone but instead more bone on the lingual aspect as compared to the buccal aspect. Additionally, for roots to be centered at the apex, the inclination of the maxillary incisors, regardless of analysis would have to be several degrees more than what has been described to be optimal. Although the trend for centeredness for both CR and apex requires more inclined incisors, if the maxillary incisors were inclined to be centered at the apex they would in fact not be centered at CR, and the opposite statement is also true, centering maxillary incisors at CR based on the results of this study would not result in centered incisors at the apex.

\section{MANDIBULAR INCISOR INCLINATION}

The current study was looking to identify various mandibular incisor inclinations as they relate to alveolar bone thickness in the bucco-lingual dimension. Incisor inclination varies greatly in the 
general population. Additionally there are a vast number of analyses that dictate the ideal inclination of incisors. Therefore, this study was looking to analyze various methods of assessing incisor inclination to reveal if any one method would result in an inclination, in the optimal range, as identified by the analysis, with a corresponding presence of equal amount of buccolingual bone.

Overall, it can be concluded that in this sample the presence of equal amount of bucco-lingual bone at the center of resistance regardless of inclination or the analysis utilized to assess the inclination, did not exist. The mandibular incisors consistently showed the presence of more bone on the lingual aspect rather than buccal. It is interesting to note that although the sample ranged from retroclined, normoinclined, and proclined incisors, more bone was consistently found on the lingual aspect at center of resistance regardless of inclination, although this finding was not significant, the trend was consistent across all analyses and inclinations. This is consistent with previous findings by $\mathrm{Nahm}^{61}$, who conducted a CBCT study of buco-lingual bone thickness of maxillary and mandibular incisors, and found significant differences between alveolar bone thickness on the lingual and buccal aspects of mandibular incisors, with greater bone thickness in the mandibular lingual region spacing from the CEJ to the root apex. Furthermore, the researchers were able to conclude that the buccal aspect of pre-treatment mandibular incisors had less alveolar bone thickness, which is consistent with the findings of the current study.

Interestingly, utilizing the Downs and Tweed analysis, incisors inclined in the optimal range were significantly more likely to result in equal amount of bucco-lingual bone at the apex. Both analyses utilize the mandibular plane as a reference to measure incisor inclination, and both analyses suggest that optimal inclination approximates 90 degrees. The other analyses: Steiner, Andrews, Ricketts, did not show any significant association between mandibular incisor inclination and the presence of equal amount of bucco-lingual bone at the apex. Overall, it can be concluded that utilizing the Downs and Tweed analysis to establish optimally inclined incisors will likely result in equal amount of bucco-lingual bone at the apex. Nevertheless, centerdness of the incisor roots at the apex does not indicate the dentition is free of periodontal defects. As previously stated, regardless of inclination, the roots of the mandibular incisors did not result in equal amount of bucco-lingual bone at the center of resistance. 


\section{MAXILLARY PERIODONTAL DEFECTS}

Analysis of periodontal defects of maxillary central incisors indicated a greater prevalence of dehiscences as compared to fenestrations. Overall, the sample had 25\% prevalence of dehiscences and $11 \%$ prevalence of fenestrations. It is worthy to note the $25 \%$ dehiscence prevalence in the maxillary incisors as compared to $91 \%$ dehiscence prevalence in the mandibular incisors. Although, the maxillary incisors presented with both dehiscences and fenestrations, the observed rate of these periodontal defects was much less compared to the mandibular incisors. It has been shown that the prevalence of fenestrations is indeed greater in the maxilla compared to the mandible [23]. A study conducted by Rupprecht ${ }^{64}$ analyzing the prevalence of dehiscences and fenestrations in modern skulls found that out of the entire sample $40.4 \%$ of the skulls had a dehiscence and $61.6 \%$ of the skulls had a fenestrations. However, out of the $40.4 \%$ of the skulls that had a dehiscence $67 \%$ of them were found in the mandible, while out of the $61.6 \%$ of the skulls that had a fenestration $58 \%$ of them were found in the maxilla. The current study adds to these findings by drawing similar conclusions, the presence of dehiscences are seen more in mandibular incisors compared to maxillary incisors, while the presence of fenestrations are seen more in maxillary incisors compared to mandibular incisors.

Although the prevalence of fenestrations based on inclination of maxillary incisors did not yield any statistically significant results, the trends based on all three analyses yielded an interesting finding. Maxillary incisors deemed as retroclined by the Steiner, Andrews, and Burstone analyses were more likely to present with a fenestration compared to incisors deemed as normoinclined or proclined by the aforementioned analyses. A possible explanation for the lack of statistical significance is the insignificant number of periodontal defect seen in the maxilla in this sample.

\section{MANDIBULAR PERIODONTAL DEFECTS}

One of the more salient findings of the current study was the significant number of periodontal defects that were observed in the sample. Ninety one percent of the mandibular incisors in this study were identified to have a dehiscence. While, none were found to have fenestrations, regardless of inclination. This is a significant finding, demonstrating that pretreatment mandibular incisors, regardless of inclination, exhibit a significant number of periodontal defects. This finding is consistent with previous research by Evangelista ${ }^{65}$, reporting a 
dehiscence rate of $51.09 \%$ of all the teeth studied in their sample, $75.65 \%$ of those defects were found on the buccal root surface and prevalence was greatest for the mandible. Interestingly, the teeth most affected were the mandibular central and lateral incisors, which is consistent with the findings of the current study. Yagci ${ }^{23}$ also found greater prevalence of fenestrations in the maxilla and more dehiscences in the mandible, with the greatest frequency of dehiscences seen in the mandibular incisor region, which is consistent with the findings of this study. Although the percentage of periodontal defects identified in the current sample were higher than reported elsewhere it is not uncommon to see false positive identifications of these defects on CT scans. Alveolar defect identification depends on length, thickness of the alveolar cortical plate, and visualization of the periodontal ligament space [62]. Due to these limitations, false positive identification of alveolar defects when the alveolar cortical plate is less than $.5 \mathrm{~mm}$ may occur [62]. Therefore, although a significant portion of the sample was identified to have an alveolar defect, the results are presented with caution. It can be conclusively stated that pre-treatment mandibular incisors, regardless of inclination, are at a high risk of exhibiting periodontal defects. This is of great clinical significance because it has bearing on orthodontic treatment plans. Mandibular incisors are often compromised to accommodate a skeletal malocclusion, starting with an already compromised position of the incisor may influence the proposed treatment plan to avoid further compromise and periodontal breakdown.

Another significant trend found when analyzing periodontal defects of mandibular incisors, was the relationship between incisor inclination and dehiscences. Relative to the Downs, Tweed, and Ricketts analyses retroclined incisors were likely to have a dehiscence present $100 \%$ of the time. Although most of the sample exhibited a dehiscence, incisors deemed as retroclined by the Downs, Tweed, and Ricketts analyses showed a statistically significant relationship between inclination and the presence of periodontal defects. Previous research has focused on analyzing the relationship between skeletal classification and the presence of dehiscences in mandibular incisors. The findings of these studies supports the conclusion that patients classified with a skeletal class III malocclusion were significantly more likely to present with periodontal defects in the mandibular incisors [23]. Drawing parallels between these previous findings, skeletal class III malocclusion is often accompanied with retroclined mandibular incisors, therefore, the 
current study is in agreement with previous research that retroclined incisors are more likely to result in periodontal defects.

\section{SKELETAL CLASSIFICATION AND PERIODONTAL DEFECTS}

Although analysis of the skeletal classification and the presence of periodontal defects did not reveal any statistical significance there was a trend, in this study, consistent with previous research. The current study found that patients classified with a Class III malocclusion were more likely to present with dehiscences on the mandibular incisors as compared to individuals classified with a Class I or Class II malocclusion. A Class III skeletal classification is often accompanied by retroclined mandibular incisors and proclined maxillary incisors, and as previously stated retroclined incisors were significantly more likely to present with a dehiscence than incisors classified as normo-inclined or proclined. Furthermore, multiple studies have found that Class III individuals are significantly more likely to present with dehiscences compared to those classified as Class I or Class II [23, 63]. A possible explanation for why the data, in this study, failed to reach significance is due to the distribution of the sample size, with a significant portion of the sample presenting with a Class I and Class II malocclusion.

\section{VERTICAL DIMENSION AND PERIODONTAL DEFECTS}

The vertical dimension was also considered in the current research, however it failed to produce any significant findings. Regardless of vertical face height in the maxilla, this study failed to find statistically significant results in terms of the presence of dehiscences or fenestrations. This finding is presented with caution due to the lack of diversity in the sample. The sample predominantly consisted of normo-divergent patients with normal LFH. Therefore, it is difficult to draw a conclusion regarding the influence of the vertical dimension on the presence or absence of periodontal defects.

Regardless of the vertical face height in the mandible this study failed to find statistically significant results in terms of the presence of dehiscences or fenestrations. This finding is presented with caution due to the lack of diversity in the sample. The sample predominantly consisted of normo-divergent patients with normal LFH. Therefore, it is difficult to draw a conclusion regarding the influence of the vertical dimension on the presence or absence of 
periodontal defects. Previous research has shown that the vertical dimension does have an effect on the prevalence of periodontal defects in the incisor region. Enhos et al. was able to conclude that patients classified as hyperdivergent presented with statistically more dehiscences compared to normodivergent and hypodivergent patients. Additionally, the authors were able to conclude that the prevalence of fenestrations did not differ for varying vertical patterns while the prevalence of dehiscences were statistically different for the different vertical patterns [50].

\section{HYPOTHESIS TESTING}

1. ACCEPTED: Maxillary incisors inclined in the optimal range according to the Steiner, Andrews, and Burstone analyses are not more centered in alveolar bone, as measured at the CR and apex, than incisors with more positive or negative inclination.

2. Mandibular incisors inclined in the optimal range according to the Downs, Steiner, Tweed, Andrews, and Ricketts analyses are not more centered in alveolar bone than incisors with more positive or negative inclination.

a. ACCEPTED: CR

b. REJECTED: Mandibular incisors inclined in the optimal range according to the Downs, and Tweed are more centered in alveolar bone than incisors with more positive or negative inclination at the apex

3. ACCEPTED: Maxillary incisors inclined in the optimal range according to the Steiner, Andrews, Burstone analyses do not have less dehiscences than incisors with more positive or negative inclination.

4. ACCEPTED: Maxillary incisors inclined in the optimal range according to the Steiner, Andrews, Burstone analyses do not have less fenestrations than incisors with more positive or negative inclination. 
5. Mandibular incisors inclined in the optimal range according to the Downs, Steiner, Tweed, Andrews, Ricketts analyses do not have less dehiscences than incisors with more positive or negative inclination.

a. ACCEPTED: Steiner and Andrews

b. REJECTED: Downs, Tweed, and Ricketts

6. ACCEPTED: Mandibular incisors inclined in the optimal range according to the Downs, Steiner, Tweed, Andrews, Ricketts analyses do not have less fenestrations than incisors with more positive or negative inclination.

7. ACCEPTED: Patients classified with skeletal Class I occlusion do not have less dehiscences present in the maxilla or mandible than patients classified with skeletal Class II or III occlusions.

8. ACCEPTED: Patients classified with skeletal Class I occlusion do not have less fenestrations present in the maxilla or mandible than patients classified with skeletal Class II or III occlusions.

9. ACCEPTED: Maxillary and mandibular incisors in patients with normal vertical dimension do not have less dehiscences than incisors in patients with increased or decreased vertical dimension.

10. ACCEPTED: Maxillary and mandibular incisors in patients with normal vertical dimension do not have less fenestrations than incisors in patients with increased or decreased vertical dimension.

\section{CLINICAL IMPLICATIONS}

It is evident that pre-treatment incisor position is often compromised and is accompanied by preexisting periodontal defects, especially in the mandible. Although the current study was looking 
to identify an analysis that could identify a more optimal inclination of maxillary and mandibular incisors in the alveolus. It seems such an analysis may not exist or may not be applicable across all subjects. It is therefore prudent to look at the starting conditions of the maxillary and mandibular incisors on an individual basis prior to the start of treatment. A few important trends did emerge during the study that should be emphasized and utilized to achieve the best clinical results. In the maxilla, it seems prudent to err on the side of proclining the maxillary incisors a few degrees more than prescribed by the Steiner, Andrews, and Burstone analyses as it will more likely result in roots centered in the alveolus at CR and apex. Furthermore, it was observed that maxillary incisors categorized as retroclined were more likely to present with periodontal defects, fenestrations. Similarly, if one was to err it would be more prudent to err on the side of proclining maxillary incisors as opposed to retroclining.

Mandibular incisors on the other hand do not show a trend for centeredness at the center of resistance regardless of inclination or analyses and presented with a statistically and clinically significant number of periodontal defects, namely dehiscences. Although this study was able to conclude that utilizing the Downs and Tweed analyses, which use the mandibular plane as reference to center the mandibular incisors, produced centered roots at the apex, this may not be of clinical importance. Regardless of centeredness at the apex a large majority of mandibular incisors presented with a periodontal defect, therefore, it seems that centeredness at the center of resistance is what is clinically significant.

\section{CHAPTER 6: SUMMARY AND CONCLUSIONS}

\section{SUMMARY}

The specific aims of this study was to utilize cone-beam computed tomography to investigate optimal maxillary and mandibular incisor inclination that would result in roots centered in bone in the maxillary and mandibular alveolus. Furthermore, the study was looking to analyze the presence of dehiscences and fenestrations, and draw specific conclusions regarding incisor inclination and the presence of such defects. The final 100 subjects used in this study represent an unbiased sample that met the inclusion and exclusion criteria collected from the private practice of Dr. Thomas Shipley. CBCT radiographs were oriented in three dimensions using a standardized method. Incisor inclination based on landmarks of various analyses were recorded 
along with mm measurements of buccal and lingual bone, and the presence or absence of dehiscences and fenestrations. Statistical analysis was performed for all the variables, with several variables showing statistical significance.

\section{CONCLUSIONS}

Based on the results of this study, the following conclusions have been reached:

1. The existing landmarks for ideal maxillary incisor inclination (as defined by Steiner, Andrews, and Burstone) do not result in roots centered in bone at $\mathrm{CR}$ and apex.

2. The existing landmarks for ideal mandibular incisor inclination (as defined by Steiner, Andrews, Downs, Tweed, and Ricketts) do not result in roots centered in bone at CR.

3. Mandibular incisors inclined in the optimal range according to the Downs and Tweed analyses are significantly more likely to result in roots centered in the mandibular alveolus at the apex.

4. Mandibular incisors deemed as retroclined and normo inclined according to the Downs, Tweed, and Ricketts analyses have more dehiscences than incisors with more positive inclinations.

\section{CHAPTER 7: RECOMMENDATIONS FOR FUTURE RESEARCH}

\section{LARGE-SCALE REPRODUCTION OF THIS STUDY}

There is clear the need for more research in this subject matter. There are many experts that have established orthodontic norms but this project has shown that they may not be applicable on the grand scale. This study should be repeated with a larger sample in order to see if some of the trends that were observed are significant and failed to reach significance due to small sample size. Furthermore, it seems that periodontal defects are present regardless of incisor inclination and so our attention should be focused on identifying pre-treatment periodontal conditions which will then dictate the proper incisor inclination. Additionally, other factors such as the age of the patient is certainly to produce interesting results. It may be prudent to look at younger patients at the time of incisor eruption to assess if natural eruption results in optimal bone and the conditions of the periodontium worsen during development and growth. 


\section{PRE AND POST TREATMENT CHANGES}

Another area that should be explored are the changes that occur in the dimensions of the buccal and lingual bone as incisors are moved orthodontically. Therefore, future studies should undertake pre and post treatment analyses of the incisors and their relation to the alveolus along with the changes that occur in the sagittal dimension as a result of orthodontic tooth movement. It seems future research should also focus on identifying what specific conditions lead to periodontal defects and how they can be addressed either prior to or after treatment. 


\section{REFERENCES}

1. Davidovitch, Z. (1991). Tooth Movement. Critical Reviews in Oral Biology and Medicine, 2(4), 411-450.

2. Garib, DG., Yatabe, MS., Ozawa, TO., \& Filho, OG. (2010). Dental press J Orthod, 15(5), 192-205.

3. Brunetto, M., Andriani Jda, D., Ribeiro, GL., Locks, A., Correa, M., Correa, LR. (2013). Three-dimensional assessment of buccal alveolar bone after rapid and slow maxillary expansion: a clinical trial study. Am J Orthod Dentofacial Orthop, 143(5), 633-44.

4. Yared, K., Zenobio, E., \& Pacheco, W. (2006). Periodontal status of mandibular incisors after orthodontic proclination in adults. American Journal Orthodontic and Dentofacial Orthopoedics, 130(6), 6e1-6e8.

5. Nanci, A. (2013). Ten Carte's Oral Histology: development, Structure, and Function. Mosby, 2013.

6. Cahill, DR., \& Marks, SC. (1980). Tooth eruption: evidence for the central role of the dental follicle. Journal of Oral Pathology, 9(4), 189-200.

7. Wise, GE., \& King, GJ. (2008). Mechanisms of tooth eruption and orthodontic tooth movement. Journal of Dental Research, 87(5), 414-34.

8. Feller, L., Khammissa, RAG., Schechter, I., Moodley, A., Thomadakis, G., \& Lemmer, J. (2015). Periodontal biological events associated with orthodontic tooth movement: the biomechanics of the cytoskeleton and the extracellular matrix. The Scientific World Journal, 2015, 1-7.

9. Proffit, WR., Fields, RP., \& Sarver, DM. (2003). Contemporary Orthodontics. Mosby, 2003.

10. Hazenberg, JG., Lee, TC., \& Taylor, D. (2006). The role of osteocytes in functional bone adaptation. International Bone \& Mineral Society, 3, 10-16.

11. Miyoshi, K., Igarashi, K., Saeki, S., Shinoda, H., \& Mitani, H. (2001). Tooth movement and changes in periodontal tissue in response to orthodontic force in rats vary depending on the time of day the force is applied. European Journal of Orthodontics, 23, 329-338.

12. Esashika, M., Kaneko, S., Yanagishita, M., \& Soma, K. (2003). Influence of orthodontic forces on the distribution of proteoglycans in rat hypofunctional periodontal ligament. Journal of Medical Dental Science, 50, 183-194.

13. Tweed, CH. (1954). The Frankfort-mandibular incisor anlge (FMIA) in orthodontic diagnosis, treatment prognosis. The Angle Orthodontist, 24(3), 121-169.

14. Steiner, C. (1954). Cephalometrics in clinical practice. The Angle Orthodontist, 29(1), 8-29.

15. Jacobson, A., \& Jacobson, R. (2006). Radiographic Cephalometry: From Basics to 3-D Imaging. Quintessence Publishing Co, 2006.

16. Andrews, LF. (1989). Straight Wire: The Concept and Appliance. L.A Wells Co, 2003.

17. Sedek, J., \& McKee, MD. (2000). Molecular and cellular biology of alveolar bone. Periodontology, 24, 99-126.

18. Sarikaya, S., Haydar, B., Ciger, S., \& Ariyurek, M. (2002). Changes in alveolar bone thickness due to retraction of anterior teeth. American Journal of Orthodontics and Dentofacial Orthopoedics, 122, 15-26. 
19. Lund, H., Gröndahl, K., \& Gröndahl, H. G. (2012). Cone beam computed tomography evaluations of marginal alveolar bone before and after orthodontic treatment combined with premolar extractions. European journal of oral sciences, 120(3), 201-211.

20. Batenhorst, KF., Bowers, GM., \& Williams, IE. (1974). Tissue changes resulting from facial tipping and extrusion in monkeys. Periodontology, 46, 660-668.

21. Garlock, DT., Buschang, PH., Araujo, EA., Behrents, RG., \& Kim, KB. (2016). Evaluation of marginal alveolar bone in the anterior mandible with retreatment and posttreatment computed tomography in nonextraction patients. AJODO; 149: 192-201.

22. Handelman, CS. (1996). The anterior alveolus: its importance in limiting orthodontic treatment and its influence on the occurrence of iatrogenic sequelae. Angle Orthodontist, 66(2), 95-110.

23. Yagci, A., Veli, I., Tancan, U., Ucar, FI., Ozer, T., Enhos, S. (2012). Dehiscence and fenestration in skeletal Class I, II, and III malocclusions assessed with cone-beam computed tomography. Angle Orthodontist; 82(1): 67-74.

24. Edwards, JG. (1976). A study of the anterior portion of the palate as it relates to orthodontic therapy. American Journal of Orthodontics, 69(3), 249-273.

25. Shaw, A. (2015). Dimensional changes in height of labial alveolar bone of proclined lower incisor after lingual positioning by orthodontic treatment: A cephalometric study on adult Bengali population. Contemp Clin Dent, 6(1), 31-4.

26. Cattaneo P., Treccani M., \& Carlsson K. (2011). Transversal maxillary dento-alveolar changes in patients treated with active and passive self-ligating brackets: A randomized clinical trial using CBCT-scans and digital models. Orthodontics \& Craniofacial Research, 14(4), 222-233.

27. Damon DH. (1998). The rationale, evolution and clinical application of the self-ligating bracket. Clin Orthod Res, 1(1), 52-61.

28. Damon DH. (1998) The damon low-friction bracket: A biologically compatible straightwire system. J Clin Orthod, 32(11), 670-680.

29. 29. Nisha, N., Saranyan, RR., Joseph, AA., Akhilesh, S., Rasila, S., \& Rajan, KS. (2015). Wilkodontics: A magical wand for rapid success. Annals of International Medical and Dental Research, 1(3), 110-114.

30. Gracco, A., Lombardo, L., Mancuso, G., Gravina, V., Siciliani, G. (2009). Upper incisor position and bony support in untreated patients as seen on CBCT. Angle Orthod, 79(4), 692-702.

31. Tsunori, M., Masamitsu, M., Kasai, K. (1998). Relationship between facial types and tooth and bone characteristics of the mandible obtained by CT scanning. Angle Orthodontist, 68(6), 557-562.

32. Nahas-Scocate, AC., De Siqueira, BA., Patel, MP., Lipiec-Ximenez, ME., Chilvarquer, I., \& Do Valle-Corotti, KM. (2014). Bone tissue amount related to upper incisor inclination. Angle Orthodontist, 84(2), 279-85.

33. Nayak Krishna, US., Shetty, A., Girija, MP., \& Nayak, R. (2013). Changes in alveolar bone thickness due to retraction of anterior teeth during orthodontic treatment: a cephalometric and computed tomography comparative study. Indian J Dent Res, 24(6), 736-41. 
34. Sadek, MM., Sabet, NE., \& Hassan, IT. (2015). Alveolar bone mapping in subjects with differential vertical facial dimensions. Eur J Orthod, 37(2), 194-201.

35. Al-Khateeb, SN., Al-Maaitah, EF., Abu Alhaija, WS., \& Badran, SA. (2014). Mandibular symphasis morphology and dimensions in different anteroposterior jaw relationships. Angle Orthodontist, 84(2), 304-309.

36. Arriola-Guillen, LE., \& Flores-mir, C. (2014). Molar heights and incisor inclinations in adult with Class II and Class III skeletal open-bite malocclusions. Am J Orthod Dentofacial Orthop, 145(3), 325-32.

37. Nauert, K., \& Berg, R. (1999). Evaluation of bony-lingual support of lower incisors in orthodontically untreated adults with the help of computed tomography. Journal of Orofacial Orthopoedics, 60(5), 321-34.

38. Dayoub, NS., \& Al-Sabbagh, R. (2015). Assessment of supporting bone thickness related to lower incisor, a CBCT study. International Journal of PharmTech Research, 8(1), 5362.

39. Papapanou, PN., \& Wennström, JL. (1991). The angular bony defect as indicator of further alveolar bone loss. Journal of clinical periodontology, 18(5), 317-322.

40. Glickman, I., \& Carranza, FA. (1979). Clinical Periodontology. Saunders, 1979.

41. Gorbunkova, A., Pagni, G., Brizhak, A., Farronato, G., \& Rasperini, G. (2015). Impact of orthodontic treatment on periodontal tissues: A narrative review of multidisciplinary literature. International Jounral of Dentistry, 1-9.

42. Yang, Y., Yang, H., Pan, H., Xu, J., \& Hu, T. (2015). Evaluation and new classification of alveolar bone dehiscences using cone-beam computed tomography in vivo. International Journal of Morphology, 33(1), 361-368.

43. Wennstrom, JL. (1996). Mucogingival considerations in orthodontic treatment. Seminars in Orthodontics, 2(1), 46-54.

44. Mostafa, YA., El Sharaby, FA., \& El Beialy, AR. (2009). Do alveolar bone defects merit orthodontists' respect? World Journal of Orthodontics, 10(1), 16-20.

45. Rasperini, G., Acunzo, R., \& Farronato, G. (2015). Influence of periodontal biotype on root surface exposure during orthodontic treatment: A preliminary study. The International Journal of Periodontics \& Restorative Dentistry, 35(5), 665-675.

46. Zawawi, KH., Al-Harthi, SM., \& Al-Zahrani, MS. (2012). Prevalence of gingival biotype and its relationship to dental malocclusion. Saudi Medical Journal, 33(6), 671-5.

47. Artun, J., \& Grobety, D. (2001). Periodontal status of mandibular incisors after pronounced orthodontic advancement during adolescence: A follow-up evaluation, 119(1), 2-10.

48. Ruf, S., Hansen, K., \& Pancherz, H. (1998). Does orthodontic proclination of lower incisors in children and adolescents cause gingival recession? American Journal of Orthodontics and Dentofacial Orthopoedics, 11, 100-6.

49. Melsen, B., \& Allais, D. (2005). Factors of importance for the development of dehiscences during labial movement of mandibular incisors: A retrospective study of adult orthodontic patients. American Journal of Orthodontics and Dentofacial Orthopoedics, 127, 552-61. 
50. Enhos, S., Uysal, T., Yagci, A., Veli, I., Ucar, FI., Ozer, T. (2012). Dehiscence and feneration in patients with different vertical growth patterns assessed with cone-beam comuted tomography. Angle Orthodontist, 82(5): 868-874.

51. de-Azeved0-Vaz, SL., Vasconcelos, KF., Neves, FS., Melo, SL., Campos, PS., \& HaiterNeto, F. (2013). Detection of periimplant fenestration and dehiscence with the use of two scan modes and the smallest voxel sizes of cone-beam computed tomography device. Oral and Maxillofacial Radiology, 115, 121-127.

52. Sun, L., Zhang, L., Shen, G., Wang, B., \& Fang, B. (2015). Accuracy of cone-beam computed tomography in detecting alveolar bone dehiscences and fenestrations. American Journal of Orthodontics and Dentofacial Orthopoedics, 147, 313-23.

53. Tian, Y., Liu, F., Sun, H., Lv, P., Cao, Y., Yu, M., \& Yue, Y. (2015). Alveolar bone thickness around maxillary central incisors of different inclination assessed with conebeam computed tomography. The Korean Journal of Orthodontics, 45(5), 245-252.

54. Kapila, S. (2014). Cone beam computed tomography in orthodontics: Indications, insights, and innovations. John Wiley \& Sons, Inc, 2014.

55. Kheir, NA., \& Kau, CH. (2014). Measuring mandibular asymmetry in Class I normal subjects using 3D novel coordinate system. Annals of Maxillofacial Surgery, 4(1), 34-38.

56. Ricketts, RM., Bench, RW., Hilgers, JJ., \& Schulhof, R. (1972). An overview of computerized cephalometrics. American Journal of Orthodontics, 61(1), 1-28.

57. Park, JU., Kook, Y., \& Kim, Y. (2012). Assessment of asymmetry in a normal occlusion sample and asymmetric patients with three-dimensional cone beam computed tomography. The Angle Orthodontist, 82(5), 860-867.

58. Tong, H., Kwon, D., Shi, J., Sakai, N., Enciso, R., \& Sameshima, G. (2012). Mesiodistal angulation and faciolingual inclination of each whole tooth in 3-dimensional space in patients with near-normal occlusion. American Journal of Orthodontics and Dentofacial Orthopoedics, 141(5), 604-617.

59. Papapanou, PN., Wennstrom, JL., Grondahi, K. (1988). Periodontal status in relation to age and tooth type. Journal of Clinical Periodontology, 15(7): 469-478.

60. Ghassemian, M., Nowzari, H., Lajolo, C., Verdugo, F., Pirronti, T., D’Addona, A. (2012). The thickness of facial alveolar bone overlying healthy maxillary anterior teeth. Journal of Periodontology, 83(2): 187-197.

61. Nahm, KY., Kang, JH., Moon, SC., Choi, YS., Kook, YA., Kim, SH., \& Huang, JC. (2012). Alveolar bone loss around incisors in Class I bidentoalveolar protrusion patients: a retrospective three-dimensional cone beam CT study. Dentomaxillofacial Radiology, 41: 481-488.

62. Fuhrmann, R. (1996). Three-dimensional interpretation of alveolar bone dehiscences. An anatomical-radiological study. Part I. Journal of Orofacial Orthopedics, 57: 62-74.

63. Kim, Y., Park, J. U, Kook, Y. (2009). Alveolar bone loss around incisors in surgical skeletal Class III patients. Angle Orthodontist, 79(4): 676-682.

64. Rupprecht, RD., Horning, GM., Nicoll, BK., Cohen, ME. (2001). Prevalence of dehiscences and fenestrations in modern American skulls. Journal of Periodontology, 72(6): 722-729. 
65. Evangelista, K., Vasconcelos, K., Bumann, A., Hirsch, E., Nitka, M., Silva, MG. (2010). Dehiscence and fenestration in patients with Class I and Class II division 1 malocclusion assessed with cone-beam computed tomography. AJODO, 138(2): 133e1-133e7. 


\section{APPENDICES}

\section{APPENDIX A- IRB EXEMPTION}

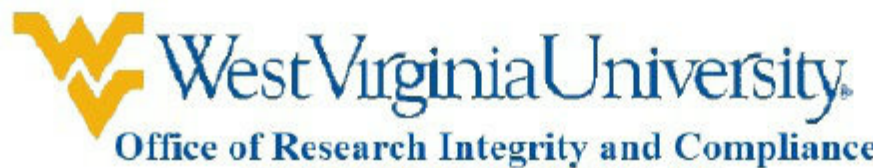

886 CHESNUT RIDGE ROAD MORGANTOWN, WV 26506

\section{Approval Letter Expedited}

Action Date

To

From

Approval Date

Expiration Date

Subject

Protocol Number

Title
$03 / 07 / 2017$

Timothy Tremont

WVU Office of Research Integrity and Compliance

03/06/2017

$03 / 05 / 2018$

Protocol Approval Letter

1701425459

A CBCT Analysis of Optimal Maxillary and Mandibular Incisor Inclination

The above-referenced research study was reviewed by the West Virginia University Institutional Review Board IRB and was approved in accordance with $46 \mathrm{CFR} 46.101 \mathrm{~b}$.

It has been determined that this study is of minimal risk and meets the criteria as defined by the expedited categories listed below:

- Category 5. Research involving materials (data, documents, records, or specimens) that have been collected, or will be collected solely for nonresearch purposes (such as medical treatment or diagnosis).

- Category 7. Research on individual or group characteristics or behavior (including, but not limited to, research on perception, cognition, motivation, identity, language, communication, cultural beliefs or practices, and social behavior) or research employing survey, interview, oral history, focus group, program evaluation, human factors evaluation, or quality assurance methodologies. [NOTE: Some research in this category may be exempt from the DHHS regulations for the protection of human subjects. See Exempt Categories and 45 CFR 46.101(b)(2) and (b)(3). This listing refers only to research that is not exempt.]

Documents reviewed and/or approved as part of this submission:

Specific Minor Revisions.docx: 2017-02-15-05:00

Methods and Materials.docx: 2017-01-23-05:00

HIPAA Waiver Form 2-MG.docx: 2017-02-22-05:00

Response to SMR-Feb 21, 2017.docx: 2017-02-22-05:00 
Limited Data Set Agreement.pdf: 2017-03-02-05:00

Documents for use in this study are available in the WVUkc system in the Notes and Attachments section of your protocol.

The Office of Research Integrity and Compliance is here to provide assistance to you from the initial submission of an IRB protocol and all subsequent activity. Please feel free to contact us by phone at 304.293 .7073 with any question you may have. Thank you.

WVU Office of Research Integrity and Compliance

Date:03/07/2017

Signed:

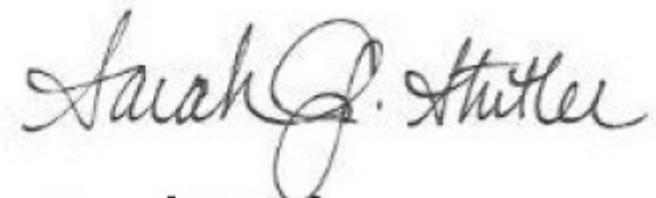

\section{Sarah Stutler}

IRB Administrator

ving regulations apply:

1. Unanticipated or serious adverse events/side effects encountered in this research study must be reported to the IRB within five (5) days via the Notify IRB action.

2. Any modifications to the study protocol or informed consent form must be reviewed and approved by the IRB prior to implementation via submission of an amendment.

3. You may not use a modified informed consent form until it has been approved and validated by the IRB. 


\section{APPENDIX B-RAW DATA}

ID

SNA

SNB

ANB

$\begin{array}{rll} & \text { Sex Age } \\ 1 & \mathrm{M} \\ 2 & \mathrm{M} \\ 3 & \mathrm{~F} \\ 4 & \mathrm{~F} \\ 5 & \mathrm{M} \\ 6 & \mathrm{M} \\ 7 & \mathrm{~F} \\ 8 & \mathrm{~F} \\ 9 & \mathrm{M} \\ 10 & \mathrm{M} \\ 11 & \mathrm{M} \\ 12 & \mathrm{M} \\ 13 & \mathrm{~F} \\ 14 & \mathrm{~F} \\ 15 & \mathrm{M}\end{array}$

17

17

17

17

17

17

17

17

17

17

17

17

17

17

17

$16 \mathrm{M}$

$17 \mathrm{M}$

$18 \mathrm{M}$

$19 \mathrm{M}$

$20 \mathrm{M}$

$21 \mathrm{M}$

$22 \mathrm{M}$

$23 \mathrm{M}$

$24 \mathrm{M}$

$25 \mathrm{~F}$

$26 \mathrm{~F}$

$27 \mathrm{M}$

$28 \mathrm{M}$

$29 \mathrm{~F}$

$30 \mathrm{~F}$

$31 \mathrm{M}$

$32 \mathrm{M}$

$33 \mathrm{~F}$

$34 \mathrm{~F}$

$35 \mathrm{M}$

$36 \mathrm{M}$

$37 \mathrm{M}$
86.5

86.5

76.3

76.3

83.9

83.9

87.4

87.4

79.3

79.3

81.6

81.6

86.2

86.2

81.8

81.8

75

75

78.4

78.4

82.6

82.6

77.3

77.3

77.8

77.8

77.4

77.4

81.4

81.4

77.6

77.6

81.5

81.5

83.6

83.6

82.5
85.7

85.7

74.2

74.2

83

83

83.6

83.6

77.6

77.6

77.2

77.2

78.7

78.7

79.2

79.2

70.7

70.7

78.3

78.3

81.4

81.4

80.6

80.6

81.7

81.7

81.5

81.5

80.4

80.4

74.2

74.2

82.2

82.2

80.1

80.1

82.9
0.8

0.8

2.1

2.1

0.9

0.9

3.8

3.8

1.7

1.7

4.4

4.4

7.5

7.5

2.6

2.6

4.3

4.3

0.1

0.1

1.2

1.2

$-3.3$

$-3.3$

$-3.9$

$-3.9$

$-4.1$

$-4.1$

1

1

3.4

3.4

$-0.7$

$-0.7$

3.5

3.5

$-0.4$ 


\begin{tabular}{|c|c|c|c|c|c|}
\hline 38 & $M$ & 18 & 82.5 & 82.9 & -0.4 \\
\hline 39 & $M$ & 18 & 76.4 & 72.1 & 4.3 \\
\hline 40 & $M$ & 18 & 76.4 & 72.1 & 4.3 \\
\hline 41 & $M$ & 18 & 81.9 & 78.1 & 3.8 \\
\hline 42 & $M$ & 18 & 81.9 & 78.1 & 3.8 \\
\hline 43 & $\mathrm{~F}$ & 18 & 85.5 & 82.2 & 3.3 \\
\hline 44 & $\mathrm{~F}$ & 18 & 85.5 & 82.2 & 3.3 \\
\hline 45 & $M$ & 18 & 80.9 & 72 & 8.9 \\
\hline 46 & $M$ & 18 & 80.9 & 72 & 8.9 \\
\hline 47 & $M$ & 18 & 81 & 75.8 & 5.2 \\
\hline 48 & $M$ & 18 & 81 & 75.8 & 5.2 \\
\hline 49 & $\mathrm{~F}$ & 18 & 80.5 & 76.9 & 3.6 \\
\hline 50 & $\mathrm{~F}$ & 18 & 80.5 & 76.9 & 3.6 \\
\hline 51 & $F$ & 18 & 81.2 & 75.5 & 5.7 \\
\hline 52 & $\mathrm{~F}$ & 18 & 81.2 & 75.5 & 5.7 \\
\hline 53 & $\mathrm{~F}$ & 18 & 86.5 & 79.2 & 7.3 \\
\hline 54 & $\mathrm{~F}$ & 18 & 86.5 & 79.2 & 7.3 \\
\hline 55 & $\mathrm{~F}$ & 18 & 89.8 & 87.9 & 1.9 \\
\hline 56 & $\mathrm{~F}$ & 18 & 89.8 & 87.9 & 1.9 \\
\hline 57 & $\mathrm{~F}$ & 18 & 84.3 & 80.8 & 3.5 \\
\hline 58 & $\mathrm{~F}$ & 18 & 84.3 & 80.8 & 3.5 \\
\hline 59 & $M$ & 18 & 88 & 78.6 & 9.4 \\
\hline 60 & $M$ & 18 & 88 & 78.6 & 9.4 \\
\hline 61 & $M$ & 18 & 76.2 & 71.6 & 4.6 \\
\hline 62 & $M$ & 18 & 76.2 & 71.6 & 4.6 \\
\hline 63 & $\mathrm{~F}$ & 18 & 82.6 & 79.7 & 2.9 \\
\hline 64 & $\mathrm{~F}$ & 18 & 82.6 & 79.7 & 2.9 \\
\hline 65 & $F$ & 18 & 86.6 & 77.2 & 9.4 \\
\hline 66 & $\mathrm{~F}$ & 18 & 86.6 & 77.2 & 9.4 \\
\hline 67 & $\mathrm{~F}$ & 20 & 83 & 82.3 & 0.7 \\
\hline 68 & $\mathrm{~F}$ & 20 & 83 & 82.3 & 0.7 \\
\hline 69 & $\mathrm{~F}$ & 20 & 84.3 & 80.6 & 3.7 \\
\hline 70 & $\mathrm{~F}$ & 20 & 84.3 & 80.6 & 3.7 \\
\hline 71 & $\mathrm{~F}$ & 20 & 84.5 & 77.1 & 7.4 \\
\hline 72 & $\mathrm{~F}$ & 20 & 84.5 & 77.1 & 7.4 \\
\hline 73 & $M$ & 20 & 78.2 & 75.8 & 2.4 \\
\hline 74 & $M$ & 20 & 78.2 & 75.8 & 2.4 \\
\hline 75 & $M$ & 20 & 77.9 & 79.4 & -1.5 \\
\hline 76 & $M$ & 20 & 77.9 & 79.4 & -1.5 \\
\hline
\end{tabular}




\begin{tabular}{|c|c|c|c|c|c|}
\hline 77 & 20 & 81.3 & & 77.8 & 3.5 \\
\hline 78 & 20 & 81.3 & & 77.8 & 3.5 \\
\hline 79 & 20 & 84.8 & & 80.3 & 4.5 \\
\hline 80 & 20 & 84.8 & & 80.3 & 4.5 \\
\hline 81 & 20 & 83.1 & & 73.5 & 9.6 \\
\hline 82 & 20 & 83.1 & & 73.5 & 9.6 \\
\hline 83 & 20 & 84.3 & & 81.8 & 2.5 \\
\hline 84 & 20 & 84.3 & & 81.8 & 2.5 \\
\hline 85 & 20 & 81.2 & & 72.5 & 8.7 \\
\hline 86 & 20 & 81.2 & & 72.5 & 8.7 \\
\hline 87 & 20 & 83.6 & & 78.8 & 4.8 \\
\hline 88 & 20 & 83.6 & & 78.8 & 4.8 \\
\hline 89 & 20 & 79.9 & & 77.5 & 2.4 \\
\hline 90 & 20 & 79.9 & & 77.5 & 2.4 \\
\hline 91 & 20 & 89.4 & & 84.9 & 4.5 \\
\hline 92 & 20 & 89.4 & & 84.9 & 4.5 \\
\hline 93 & 20 & 77.1 & & 76.4 & 0.7 \\
\hline 94 & 20 & 77.1 & & 76.4 & 0.7 \\
\hline 95 & 20 & 82.5 & & 79.9 & 2.6 \\
\hline 96 & 20 & 82.5 & & 79.9 & 2.6 \\
\hline 97 & 20 & 83.4 & & 85.9 & -2.5 \\
\hline 98 & 20 & 83.4 & & 85.9 & -2.5 \\
\hline 99 & 20 & 82.1 & & 78.4 & 3.7 \\
\hline 100 & 20 & 82.1 & & 78.4 & 3.7 \\
\hline & Mean & 82.002 & & 78.874 & 3.128 \\
\hline & Min & 75 & & 70.7 & -4.1 \\
\hline & Max & 89.8 & & 87.9 & 9.6 \\
\hline & 1.15889184 & 3.56784121 & & 496575 & 3.28879579 \\
\hline $\begin{array}{l}\text { UFH ( } N \text { to PP in } \\
\mathrm{mm} \text { ) }\end{array}$ & LFH (PP to menton in $\mathrm{mm}$ ) & Mx Steiner (NA) & & MxAndrews & MxBurstone \\
\hline 49.18 & 57.5 & & 17 & 28.1 & 115.4 \\
\hline 49.18 & 57.5 & & 18 & 27.7 & 112 \\
\hline 47.6 & 60.31 & & 28.1 & 28.2 & 117.6 \\
\hline 47.6 & 60.31 & & 19.8 & 22 & 111.1 \\
\hline 53.33 & 66.85 & & 22.8 & 29 & 113.3 \\
\hline 53.33 & 66.85 & & 16.9 & 19.8 & 106.5 \\
\hline 48.42 & 55.12 & & 22.7 & 26 & 103.6 \\
\hline 48.42 & 55.12 & & 28.5 & 35.3 & 112.6 \\
\hline 47.6 & 60.31 & & 28.1 & 28.2 & 117.6 \\
\hline 47.6 & 60.31 & & 19.8 & 22 & 111.1 \\
\hline
\end{tabular}




\begin{tabular}{|c|c|c|c|c|}
\hline 53.05 & 63.29 & 11.5 & 14.5 & 101.3 \\
\hline 53.05 & 63.29 & 19.4 & 20.9 & 107.4 \\
\hline 46.78 & 63.3 & 1 & 17 & 95.6 \\
\hline 46.78 & 63.3 & 5.3 & 14 & 91.7 \\
\hline 50.33 & 77.69 & 40.6 & 40.2 & 118.9 \\
\hline 50.33 & 77.69 & 33.1 & 31.3 & 114 \\
\hline 53.03 & 59.77 & 10.6 & 12.6 & 100.6 \\
\hline 53.03 & 59.77 & 22.3 & 22.3 & 109.1 \\
\hline 50.5 & 72.37 & 30.3 & 29.7 & 120.5 \\
\hline 50.3 & 72.37 & 25.1 & 28 & 115.9 \\
\hline 49.68 & 67.8 & 27.1 & 36 & 110.6 \\
\hline 49.68 & 67.8 & 27.6 & 34.7 & 107.7 \\
\hline 48.43 & 67.1 & 31.4 & 26.8 & 117.3 \\
\hline 48.43 & 67.1 & 30.7 & 29.1 & 120.7 \\
\hline 51.22 & 60.17 & 35 & 37.2 & 125.8 \\
\hline 51.22 & 60.17 & 35 & 35.5 & 128.4 \\
\hline 54.96 & 65.47 & 36.3 & 35.4 & 117.1 \\
\hline 54.96 & 65.47 & 39.4 & 34.5 & 121.2 \\
\hline 46.5 & 65.2 & 34.4 & 34.1 & 118.6 \\
\hline 46.5 & 65.2 & 30.5 & 31 & 122.4 \\
\hline 51.16 & 68.45 & 17.3 & 17.2 & 98.6 \\
\hline 51.16 & 68.45 & 19.9 & 20.1 & 101.8 \\
\hline 45.72 & 67.1 & 36.5 & 46.1 & 120.9 \\
\hline 45.72 & 67.1 & 41.2 & 44 & 119.9 \\
\hline 47.06 & 64.11 & 8.9 & 12.9 & 92.4 \\
\hline 47.06 & 64.11 & 14.4 & 15.6 & 93.5 \\
\hline 55.49 & 61.94 & 37.2 & 43.3 & 132.3 \\
\hline 55.49 & 61.94 & 43.3 & 50 & 136.1 \\
\hline 51.14 & 70.63 & 17.8 & 9.1 & 98 \\
\hline 51.14 & 70.63 & 17.2 & 13.5 & 101.3 \\
\hline 50.31 & 60.31 & 15.7 & 18.2 & 104.2 \\
\hline 50.31 & 60.31 & 16.9 & 20.1 & 112.9 \\
\hline 47.6 & 66.55 & 28.7 & 29.9 & 118.9 \\
\hline 47.6 & 66.55 & 25.1 & 31.1 & 117.1 \\
\hline 54.96 & 63.02 & 6.9 & 2.3 & 90.3 \\
\hline 54.96 & 63.02 & 4.6 & 3.5 & 89.8 \\
\hline 50.86 & 58.67 & 28.2 & 27.9 & 117.3 \\
\hline 50.86 & 58.67 & 27.1 & 29 & 116.7 \\
\hline 51.16 & 66.28 & 23.4 & 31.8 & 110.6 \\
\hline
\end{tabular}




\begin{tabular}{|c|c|c|c|c|}
\hline 51.16 & 66.28 & 26.2 & 29 & 110.1 \\
\hline 52.76 & 59.76 & 8.2 & 13.6 & 103.7 \\
\hline 52.76 & 59.76 & 8 & 12.7 & 97.1 \\
\hline 47.6 & 55.69 & 30.4 & 34.6 & 123.4 \\
\hline 47.6 & 55.69 & 31.2 & 42.7 & 131.3 \\
\hline 43.53 & 67.64 & 27.8 & 37.4 & 113.4 \\
\hline 43.53 & 67.64 & 29.6 & 40.5 & 114.9 \\
\hline 49.5 & 55.97 & 16.4 & 22 & 109.5 \\
\hline 49.5 & 55.97 & 19.2 & 25.9 & 102.5 \\
\hline 54.94 & 65.74 & 13.5 & 20.8 & 107 \\
\hline 54.94 & 65.74 & 23.5 & 29.7 & 120.9 \\
\hline 49.51 & 69.54 & 23.7 & 23.4 & 104.1 \\
\hline 49.51 & 69.54 & 18.5 & 24 & 99.8 \\
\hline 48.43 & 61.4 & 27.6 & 25.6 & 115.3 \\
\hline 48.43 & 61.4 & 28.1 & 28.5 & 119 \\
\hline 47.62 & 69 & 12.1 & 24 & 111.2 \\
\hline 47.62 & 69 & 15.8 & 25 & 105.7 \\
\hline 46.24 & 60.31 & 18.2 & 20.7 & 102.5 \\
\hline 46.24 & 60.31 & 16 & 20.7 & 107.8 \\
\hline 46.79 & 66.01 & 32.6 & 33.5 & 124.1 \\
\hline 46.79 & 66.01 & 28.1 & 30.6 & 119 \\
\hline 49.77 & 64.11 & 26.8 & 30.2 & 120.7 \\
\hline 49.77 & 64.11 & 35.1 & 38.4 & 124.1 \\
\hline 54.96 & 69 & 16.1 & 23.9 & 112.5 \\
\hline 54.96 & 69 & 17.6 & 22.4 & 113.3 \\
\hline 52.5 & 60.86 & 25.7 & 29.4 & 121.4 \\
\hline 52.5 & 60.86 & 28.5 & 30.1 & 118.1 \\
\hline 47.32 & 57.05 & 28.6 & 32.3 & 120.4 \\
\hline 47.32 & 57.05 & 29.2 & 36.3 & 120.4 \\
\hline 55.79 & 65.47 & 13.5 & 17.2 & 108.2 \\
\hline 55.79 & 65.47 & 17.5 & 24.7 & 110.2 \\
\hline 52.77 & 57.59 & 7.6 & 14.4 & 104 \\
\hline 52.77 & 57.59 & 6.2 & 13.5 & 98.2 \\
\hline 48.42 & 60.3 & 27.7 & 28.1 & 116.7 \\
\hline 48.42 & 60.3 & 31.3 & 32 & 118.9 \\
\hline 56.58 & 63.84 & 12.5 & 15.7 & 105.4 \\
\hline 56.58 & 63.84 & 11.9 & 16.2 & 102.7 \\
\hline 47.08 & 59.5 & 40.6 & 54.6 & 138.6 \\
\hline 47.08 & 59.5 & 45.7 & 53.5 & 141.9 \\
\hline
\end{tabular}




\begin{tabular}{|c|c|c|c|c|c|c|}
\hline \multicolumn{2}{|c|}{48.14} & \multicolumn{2}{|c|}{58.95} & 25.3 & 26.3 & 120.1 \\
\hline \multicolumn{2}{|c|}{48.14} & \multicolumn{2}{|c|}{58.95} & 21.8 & 25 & 119.5 \\
\hline \multicolumn{2}{|c|}{44.61} & \multicolumn{2}{|c|}{51.07} & 14 & 22.5 & 111.3 \\
\hline \multicolumn{2}{|c|}{44.61} & \multicolumn{2}{|c|}{51.07} & 18.7 & 22.3 & 101.9 \\
\hline \multicolumn{2}{|c|}{51.14} & \multicolumn{2}{|c|}{55.96} & 11.7 & 6.4 & 94.9 \\
\hline \multicolumn{2}{|c|}{51.14} & \multicolumn{2}{|c|}{55.96} & 18.2 & 15.2 & 104.6 \\
\hline \multicolumn{2}{|c|}{49.76} & \multicolumn{2}{|c|}{66.01} & 26.4 & 27.6 & 118.5 \\
\hline \multicolumn{2}{|c|}{49.76} & \multicolumn{2}{|c|}{66.01} & 29.4 & 34.1 & 123.1 \\
\hline \multicolumn{2}{|c|}{50.59} & \multicolumn{2}{|c|}{60.04} & 36.8 & 39.6 & 127.9 \\
\hline \multicolumn{2}{|c|}{50.59} & \multicolumn{2}{|c|}{60.04} & 36.8 & 37 & 124.9 \\
\hline \multicolumn{2}{|c|}{55.19} & \multicolumn{2}{|c|}{60.31} & 21.1 & 21.1 & 112.9 \\
\hline \multicolumn{2}{|c|}{55.19} & \multicolumn{2}{|c|}{60.31} & 26 & 26.9 & 116.2 \\
\hline \multicolumn{2}{|c|}{50.1502} & \multicolumn{2}{|c|}{63.0086} & 23.416 & 26.785 & 112.72 \\
\hline 43. & & 51 & & 1 & 2.3 & 89.8 \\
\hline 56. & & 77 & & 45.7 & 54.6 & 141.9 \\
\hline 3.1604797 & & 5.039764 & & 9.62283396 & 10.054351 & 10.5576149 \\
\hline Mx Buccal Bone & Mx Buccal & Mx Lingual & Mx Lingual & $\mathrm{Mx}$ & My Dehicrence & \\
\hline & Dolic माpex & & Dolic मार्र & N & $\begin{array}{l}y \\
y\end{array}$ & \\
\hline 0 & 2.2 & 4.48 & 11.02 & $\mathrm{~N}$ & $Y$ & \\
\hline 0 & 2.53 & 6.94 & 12.27 & $\mathrm{~N}$ & $Y$ & \\
\hline 1.05 & 3.14 & 3.01 & 11.21 & $N$ & $N$ & \\
\hline 1.15 & 3.79 & 4.81 & 11.52 & $\mathrm{~N}$ & $N$ & \\
\hline 1.74 & 3.58 & 2.82 & 8.6 & $N$ & $N$ & \\
\hline 1.25 & 1.91 & 3.25 & 9.66 & Y & $N$ & \\
\hline 1.42 & 3.92 & 2.27 & 6.12 & $N$ & $N$ & \\
\hline 1.41 & 2.85 & 1.86 & 4.15 & $N$ & $N$ & \\
\hline 1.05 & 3.14 & 3.01 & 11.21 & $N$ & $N$ & \\
\hline 1.15 & 3.79 & 4.81 & 11.52 & $\mathrm{~N}$ & $\mathrm{~N}$ & \\
\hline 0 & 0 & 2.03 & 8.51 & $Y$ & $N$ & \\
\hline 0 & 0 & 2.55 & 8.28 & $Y$ & $\mathrm{~N}$ & \\
\hline 0 & 0 & 4.92 & 11.18 & $N$ & $Y$ & \\
\hline 0 & 2.39 & 4.81 & 8.67 & $N$ & $Y$ & \\
\hline 1.75 & 4.01 & 1.63 & 5.03 & $N$ & $\mathrm{~N}$ & \\
\hline 2.18 & 4.54 & 1.55 & 5.14 & $N$ & $N$ & \\
\hline 0 & 0 & 3.61 & 12.58 & $N$ & $Y$ & \\
\hline 0 & 0 & 2.82 & 5.4 & $N$ & $Y$ & \\
\hline 1.01 & 3.05 & 1.63 & 9.83 & $Y$ & $N$ & \\
\hline 0.89 & 3.29 & 2.04 & 8.85 & $\mathrm{~N}$ & $\mathrm{~N}$ & \\
\hline 1.34 & 2.88 & 2.09 & 9.54 & $N$ & $N$ & \\
\hline 1.49 & 2.39 & 2.74 & 9.99 & $\mathrm{~N}$ & $\mathrm{~N}$ & \\
\hline
\end{tabular}




\begin{tabular}{|c|c|c|c|c|c|}
\hline 1.01 & 3.01 & 2.25 & 6.98 & $\mathrm{~N}$ & $\mathrm{~N}$ \\
\hline 1.01 & 2.04 & 3.01 & 6.23 & $\mathrm{~N}$ & $\mathrm{~N}$ \\
\hline 0 & 2.44 & 21.12 & 4.91 & $\mathrm{~N}$ & $Y$ \\
\hline 0 & 4.42 & 2.14 & 8.72 & $\mathrm{~N}$ & $Y$ \\
\hline 1.56 & 2.49 & 2.27 & 6.09 & $\mathrm{~N}$ & $\mathrm{~N}$ \\
\hline 1.5 & 4.18 & 2.74 & 6.17 & $N$ & $\mathrm{~N}$ \\
\hline 0.87 & 2.16 & 1.9 & 7.21 & $\mathrm{~N}$ & $\mathrm{~N}$ \\
\hline 0 & 1.64 & 2.36 & 8.92 & $N$ & $\mathrm{~N}$ \\
\hline 0 & 1.72 & 2.8 & 9.42 & $\mathrm{~N}$ & $Y$ \\
\hline 1.73 & 2.03 & 3.16 & 10.29 & $\mathrm{~N}$ & $Y$ \\
\hline 1.15 & 1.96 & 1.47 & 5.68 & $\mathrm{~N}$ & $\mathrm{~N}$ \\
\hline 1.49 & 2.58 & 1.68 & 5.71 & $\mathrm{~N}$ & $\mathrm{~N}$ \\
\hline 1.41 & 2.17 & 3.88 & 17.25 & $\mathrm{~N}$ & $\mathrm{~N}$ \\
\hline 0.9 & 2.42 & 4.42 & 14.74 & $\mathrm{~N}$ & $\mathrm{~N}$ \\
\hline 1.43 & 4.65 & 2 & 4.69 & $\mathrm{~N}$ & $\mathrm{~N}$ \\
\hline 0 & 3.69 & 2.49 & 6.47 & $Y$ & $\mathrm{~N}$ \\
\hline 1.36 & 2.62 & 2.06 & 7.96 & $\mathrm{~N}$ & $\mathrm{~N}$ \\
\hline 0 & 2.5 & 2.74 & 8.63 & $Y$ & $\mathrm{~N}$ \\
\hline 1.4 & 1.97 & 2.58 & 9.02 & $\mathrm{~N}$ & $\mathrm{~N}$ \\
\hline 1.27 & 3.23 & 2.52 & 8.84 & $N$ & $\mathrm{~N}$ \\
\hline 1.42 & 3.03 & 1.95 & 6.12 & $N$ & $\mathrm{~N}$ \\
\hline 1.49 & 2.68 & 2 & 7.04 & $N$ & $\mathrm{~N}$ \\
\hline 1.41 & 2.5 & 3.7 & 16.09 & $Y$ & $\mathrm{~N}$ \\
\hline 0.54 & 2.3 & 5 & 15.46 & $Y$ & $\mathrm{~N}$ \\
\hline 0.98 & 4.41 & 3.57 & 11.17 & $\mathrm{~N}$ & $\mathrm{~N}$ \\
\hline 0.95 & 3.43 & 3.84 & 12.85 & $\mathrm{~N}$ & $\mathrm{~N}$ \\
\hline 0 & 3.94 & 0 & 6.03 & $N$ & $Y$ \\
\hline 1.48 & 1.8 & 1.89 & 6.6 & $\mathrm{~N}$ & $\mathrm{~N}$ \\
\hline 0 & 0.63 & 2.15 & 11.35 & $\mathrm{~N}$ & $Y$ \\
\hline 0 & 1 & 1.97 & 14.67 & $N$ & $Y$ \\
\hline 1.51 & 1.67 & 2.21 & 7.72 & $\mathrm{~N}$ & $\mathrm{~N}$ \\
\hline 1.39 & 3.26 & 2.27 & 7.45 & $\mathrm{~N}$ & $\mathrm{~N}$ \\
\hline 1.75 & 4.01 & 1.63 & 5.03 & $N$ & $\mathrm{~N}$ \\
\hline 2.18 & 4.54 & 1.55 & 5.14 & $N$ & $\mathrm{~N}$ \\
\hline 0.56 & 4.04 & 3.83 & 14.7 & $\mathrm{~N}$ & $\mathrm{~N}$ \\
\hline 0 & 4.79 & 3.34 & 10.65 & $\mathrm{~N}$ & $Y$ \\
\hline 0.87 & 0.83 & 2.33 & 10.65 & $Y$ & $\mathrm{~N}$ \\
\hline 1.14 & 2.42 & 2.32 & 9.4 & $Y$ & $\mathrm{~N}$ \\
\hline 1.73 & 3.24 & 2.74 & 8.13 & $\mathrm{~N}$ & $\mathrm{~N}$ \\
\hline
\end{tabular}




\begin{tabular}{|c|c|c|c|c|c|}
\hline 1.6 & 3.92 & 2.78 & 9.72 & $\mathrm{~N}$ & $\mathrm{~N}$ \\
\hline 1.48 & 3.75 & 1.64 & 9.62 & $\mathrm{~N}$ & $\mathrm{~N}$ \\
\hline 1.3 & 3.26 & 1.91 & 8.3 & $\mathrm{~N}$ & $\mathrm{~N}$ \\
\hline 1.3 & 2.25 & 2.21 & 6.02 & $\mathrm{~N}$ & $\mathrm{~N}$ \\
\hline 0 & 2.33 & 2.22 & 6.59 & $\mathrm{~N}$ & $Y$ \\
\hline 0 & 2.1 & 1.56 & 7.96 & $\mathrm{~N}$ & $Y$ \\
\hline 0 & 1.94 & 1.77 & 7.8 & $\mathrm{~N}$ & $Y$ \\
\hline 1.35 & 1.33 & 1.34 & 5.11 & $\mathrm{~N}$ & $\mathrm{~N}$ \\
\hline 1.45 & 3.01 & 1.38 & 5.26 & $\mathrm{~N}$ & $Y$ \\
\hline 1.22 & 3.1 & 1.57 & 4.16 & $\mathrm{~N}$ & $\mathrm{~N}$ \\
\hline 1.05 & 3.75 & 1.2 & 4.03 & $\mathrm{~N}$ & $\mathrm{~N}$ \\
\hline 1.58 & 1.28 & 3.21 & 9.67 & Y & $\mathrm{N}$ \\
\hline 0 & 2.79 & 3.16 & 10.87 & $\mathrm{~N}$ & $Y$ \\
\hline 1.57 & 4.23 & 1.97 & 7.05 & $\mathrm{~N}$ & $\mathrm{~N}$ \\
\hline 1.41 & 4.19 & 2.39 & 7.54 & $\mathrm{~N}$ & $\mathrm{~N}$ \\
\hline 1.67 & 3.36 & 1.55 & 4.11 & $\mathrm{~N}$ & $Y$ \\
\hline 1.26 & 2.88 & 1.51 & 3.53 & $\mathrm{~N}$ & $\mathrm{~N}$ \\
\hline 0 & 1.47 & 3.64 & 13.74 & $\mathrm{~N}$ & $Y$ \\
\hline 0 & 1.83 & 4.49 & 11.97 & $\mathrm{~N}$ & $Y$ \\
\hline 0 & 1.91 & 2.85 & 12.92 & $\mathrm{~N}$ & $Y$ \\
\hline 0 & 1.32 & 4.24 & 14.01 & $\mathrm{~N}$ & $Y$ \\
\hline 1.5 & 4.55 & 3.26 & 9.41 & $\mathrm{~N}$ & $\mathrm{~N}$ \\
\hline 0.64 & 4.95 & 3.18 & 8.68 & $\mathrm{~N}$ & $\mathrm{~N}$ \\
\hline 1.25 & 2.11 & 1.75 & 8.97 & $\mathrm{~N}$ & $\mathrm{~N}$ \\
\hline 1.07 & 2.27 & 1.84 & 9.05 & $\mathrm{~N}$ & $\mathrm{~N}$ \\
\hline 0.9 & 3.36 & 3.7 & 7.36 & $\mathrm{~N}$ & $\mathrm{~N}$ \\
\hline 0.99 & 2.68 & 2.72 & 6.7 & $\mathrm{~N}$ & $\mathrm{~N}$ \\
\hline 1.24 & 1.26 & 2.36 & 5.29 & $\mathrm{~N}$ & $\mathrm{~N}$ \\
\hline 1.6 & 1.28 & 1.73 & 5.95 & $\mathrm{~N}$ & $\mathrm{~N}$ \\
\hline 1.21 & 3.16 & 3.91 & 11.7 & $\mathrm{~N}$ & $\mathrm{~N}$ \\
\hline 1.17 & 4.25 & 2.61 & 9.92 & $\mathrm{~N}$ & $\mathrm{~N}$ \\
\hline 1.57 & 3.32 & 4.15 & 15.53 & $\mathrm{~N}$ & $\mathrm{~N}$ \\
\hline 1.28 & 2.84 & 4.32 & 16.43 & $\mathrm{~N}$ & $\mathrm{~N}$ \\
\hline 1.44 & 1.6 & 2.71 & 7.22 & $\mathrm{~N}$ & $\mathrm{~N}$ \\
\hline 1.64 & 3.08 & 1.75 & 8.31 & $\mathrm{~N}$ & $\mathrm{~N}$ \\
\hline 0.98 & 2.61 & 1.87 & 8.3 & $\mathrm{~N}$ & $\mathrm{~N}$ \\
\hline 0.93 & 2.45 & 1.67 & 7.36 & $\mathrm{~N}$ & $\mathrm{~N}$ \\
\hline 0 & 3.15 & 4 & 14.29 & $\mathrm{~N}$ & $Y$ \\
\hline 0.92 & 3.36 & 3.42 & 11.36 & $\mathrm{~N}$ & $\mathrm{~N}$ \\
\hline
\end{tabular}




\begin{tabular}{|c|c|c|c|c|c|}
\hline 0.9494 & 2.7012 & 2.871 & 8.9227 & \#DIV/0! & \#DIV/0! \\
\hline 0 & 0 & 0 & 3.53 & & \\
\hline 2.18 & 4.95 & 21.12 & 17.25 & & \\
\hline 0.64189401 & 1.15062063 & 2.13859318 & 3.16344776 & \#DIV/0! & \#DIV/0! \\
\hline MdDowns (90- & & & & & \\
\hline$Y)$ & MdDowns & MdSteiner & MdTweed & MdAndrews & MdRicketts \\
\hline 78.3 & 11.7 & 11.7 & 78.3 & 7.5 & 13.4 \\
\hline 92.3 & -2.3 & 27.1 & 92.3 & 20.7 & 30.7 \\
\hline 96.6 & -6.6 & 14.8 & 96.6 & 14.5 & 16.9 \\
\hline 97.8 & -7.8 & 27.8 & 97.8 & 28.9 & 31.6 \\
\hline 90.3 & -0.3 & 22 & 90.3 & 19.5 & 25.6 \\
\hline 86.6 & 3.4 & 15.5 & 86.6 & 14.8 & 18.8 \\
\hline 89.5 & 0.5 & 27 & 89.5 & 21.2 & 23.7 \\
\hline 90.6 & -0.6 & 27.7 & 90.6 & 24.5 & 20.7 \\
\hline 96.6 & -6.6 & 14.8 & 96.6 & 14.5 & 16.9 \\
\hline 97.8 & -7.8 & 27.8 & 97.8 & 28.9 & 31.6 \\
\hline 94.3 & -4.3 & 24 & 94.3 & 23 & 21.7 \\
\hline 101.3 & -11.3 & 27.9 & 101.3 & 29.7 & 30.9 \\
\hline 87.2 & 2.8 & 26.9 & 87.2 & 16.7 & 18.9 \\
\hline 88.2 & 1.8 & 19.8 & 88.2 & 11 & 13.9 \\
\hline 91.8 & -1.8 & 27.7 & 91.8 & 26.3 & 25.2 \\
\hline 94.5 & -4.5 & 26.9 & 94.5 & 23.3 & 26.1 \\
\hline 80.2 & 9.8 & 15.1 & 80.2 & 14.4 & 15.9 \\
\hline 95.7 & -5.7 & 22.4 & 95.7 & 25.6 & 23.2 \\
\hline 84.9 & 5.1 & 24.6 & 84.9 & 22.2 & 22.4 \\
\hline 92.3 & -2.3 & 22.2 & 92.3 & 24 & 28.3 \\
\hline 90.8 & -0.8 & 27.3 & 90.8 & 17 & 30.2 \\
\hline 91.9 & -1.9 & 24.7 & 91.9 & 13.8 & 26.4 \\
\hline 80.3 & 9.7 & 21.4 & 80.3 & 23 & 26.4 \\
\hline 82.4 & 7.6 & 22 & 82.4 & 28.2 & 29.4 \\
\hline 76.6 & 13.4 & 15.4 & 76.6 & 9.5 & 21.9 \\
\hline 69.4 & 20.6 & 8 & 69.4 & 4.8 & 19.3 \\
\hline 72.48 & 17.52 & 22.5 & 72.48 & 20.1 & 32 \\
\hline 89.6 & 0.4 & 22.5 & 89.6 & 23.1 & 29.6 \\
\hline 103.6 & -13.6 & 34.5 & 103.6 & 36.5 & 40.5 \\
\hline 100 & -10 & 33.2 & 100 & 33.5 & 35.6 \\
\hline 95.2 & -5.2 & 31 & 95.2 & 31 & 27.5 \\
\hline 93.8 & -3.8 & 24.9 & 93.8 & 24.2 & 23.7 \\
\hline 93.5 & -3.5 & 31.7 & 93.5 & 22.6 & 33 \\
\hline 98.1 & -8.1 & 32.8 & 98.1 & 24.3 & 33.7 \\
\hline
\end{tabular}




\begin{tabular}{|c|c|c|c|c|c|}
\hline 89 & 1 & 18.5 & 89 & 17.9 & 16.9 \\
\hline 93.3 & -3.3 & 29.4 & 93.3 & 24.8 & 29.3 \\
\hline 78.3 & 11.7 & 11.7 & 78.3 & 7.5 & 13.4 \\
\hline 92.3 & -2.3 & 27.1 & 92.3 & 20.7 & 30.7 \\
\hline 89 & 1 & 30.3 & 89 & 33.7 & 25.2 \\
\hline 93.5 & -3.5 & 25.7 & 93.5 & 33.4 & 26.5 \\
\hline 94.4 & -4.4 & 18.7 & 94.4 & 26.8 & 19.7 \\
\hline 98.4 & -8.4 & 27.3 & 98.4 & 19 & 22.9 \\
\hline 86.4 & 3.6 & 29.8 & 86.4 & 32.2 & 27.8 \\
\hline 85.7 & 4.3 & 27.8 & 85.7 & 31.3 & 25.4 \\
\hline 101.2 & -11.2 & 24.6 & 101.2 & 32.6 & 22.4 \\
\hline 95.4 & -5.4 & 22.5 & 95.4 & 28.5 & 12.2 \\
\hline 104.1 & -14.1 & 36.4 & 104.1 & 38.3 & 32.8 \\
\hline 96.7 & -6.7 & 31 & 96.7 & 36.1 & 30.4 \\
\hline 91.3 & -1.3 & 32.9 & 91.3 & 31.3 & 35 \\
\hline 91.6 & -1.6 & 35.4 & 91.6 & 27.5 & 33.4 \\
\hline 88.8 & 1.2 & 23.2 & 88.8 & 28 & 23.6 \\
\hline 92.1 & -2.1 & 24.2 & 92.1 & 27 & 20.9 \\
\hline 101.9 & -11.9 & 40.8 & 101.9 & 36.1 & 30.8 \\
\hline 105.9 & -15.9 & 36.6 & 105.9 & 39 & 34.3 \\
\hline 91.8 & -1.8 & 27.7 & 91.8 & 26.3 & 25.2 \\
\hline 94.5 & -4.5 & 26.9 & 94.5 & 23.3 & 26.1 \\
\hline 91.7 & -1.7 & 24.7 & 91.7 & 24 & 20.5 \\
\hline 90.5 & -0.5 & 27.6 & 90.5 & 25.3 & 25 \\
\hline 112.2 & -22.2 & 44.9 & 112.2 & 51 & 40.5 \\
\hline 116.1 & -26.1 & 45.3 & 116.1 & 48.7 & 36.1 \\
\hline 94.7 & -4.7 & 24.5 & 94.7 & 29.5 & 22.9 \\
\hline 89.7 & 0.3 & 28.1 & 89.7 & 33.3 & 25.4 \\
\hline 107.9 & -17.9 & 41.6 & 107.9 & 41.7 & 42.7 \\
\hline 109.3 & -19.3 & 42.8 & 109.3 & 40.6 & 46.6 \\
\hline 90.3 & -0.3 & 30.4 & 90.3 & 40.4 & 28.9 \\
\hline 88.1 & 1.9 & 34.4 & 88.1 & 34 & 27.2 \\
\hline 91.7 & -1.7 & 18.6 & 91.7 & 21.4 & 22.9 \\
\hline 94.1 & -4.1 & 24.7 & 94.1 & 22.8 & 23.8 \\
\hline 101 & -11 & 40.5 & 101 & 40 & 33.9 \\
\hline 103.3 & -13.3 & 35.3 & 103.3 & 36.5 & 34.1 \\
\hline 100.6 & -10.6 & 38.3 & 100.6 & 45 & 29 \\
\hline 105 & -15 & 41.4 & 105 & 49 & 34.4 \\
\hline 96.1 & -6.1 & 27 & 96.1 & 28.1 & 30.6 \\
\hline
\end{tabular}




\begin{tabular}{|c|c|c|c|c|c|}
\hline 98.7 & -8.7 & 31.7 & 98.7 & 33.6 & 31.2 \\
\hline 86.1 & 3.9 & 23.3 & 86.1 & 25.6 & 26 \\
\hline 80.7 & 9.3 & 24.5 & 80.7 & 23.2 & 28.2 \\
\hline 97.1 & -7.1 & 37.1 & 97.1 & 41.5 & 33.1 \\
\hline 93.8 & -3.8 & 34.3 & 93.8 & 37.1 & 31.4 \\
\hline 91.2 & -1.2 & 27.6 & 91.2 & 28.1 & 25.4 \\
\hline 86.2 & 3.8 & 26.8 & 86.2 & 25.6 & 26.5 \\
\hline 109.3 & -19.3 & 32.5 & 109.3 & 39.7 & 29.7 \\
\hline 113.5 & -23.5 & 36.2 & 113.5 & 46.7 & 26 \\
\hline 127.1 & -37.1 & 40.4 & 127.1 & 45.4 & 43.2 \\
\hline 121.2 & -31.2 & 34.2 & 121.2 & 43.2 & 37.9 \\
\hline 101.6 & -11.6 & 41.4 & 101.6 & 40.9 & 32.8 \\
\hline 100.1 & -10.1 & 36.1 & 100.1 & 40.9 & 24.6 \\
\hline 108.4 & -18.4 & 31.6 & 108.4 & 32.5 & 32.2 \\
\hline 109.7 & -19.7 & 36 & 109.7 & 31.9 & 34.1 \\
\hline 94.6 & -4.6 & 29.7 & 94.6 & 30.3 & 31 \\
\hline 91.9 & -1.9 & 32.2 & 91.9 & 29.3 & 28.4 \\
\hline 95.3 & -5.3 & 26.2 & 95.3 & 20.3 & 22.5 \\
\hline 101.4 & -11.4 & 22.9 & 101.4 & 22.9 & 24.5 \\
\hline 78.6 & 11.4 & 4.1 & 78.6 & 10.1 & 11.7 \\
\hline 78.5 & 11.5 & 6.5 & 78.5 & 10.6 & 12.4 \\
\hline 93 & -3 & 31.3 & 93 & 41.4 & 31.2 \\
\hline 92.1 & -2.1 & 36.7 & 92.1 & 39.6 & 30.8 \\
\hline 100.4 & -10.4 & 30.6 & 100.4 & 28.7 & 37.9 \\
\hline 94.9 & -4.9 & 28.2 & 94.9 & 24.7 & 31.5 \\
\hline 96.1 & -6.1 & 32.2 & 96.1 & 34 & 23.8 \\
\hline 101.7 & -11.7 & 28.3 & 101.7 & 29.3 & 29.9 \\
\hline 94.4558 & -4.4558 & 27.868 & 94.4558 & 28.125 & 27.329 \\
\hline 69.4 & -37.1 & 4.1 & 69.4 & 4.8 & 11.7 \\
\hline 127.1 & 20.6 & 45.3 & 127.1 & 51 & 46.6 \\
\hline 9.615646464 & 9.61564646 & 8.12102745 & 9.61564646 & 9.98691442 & 6.9658662 \\
\hline Md Buccal Bone & Md Buccal & Md Lingual & Md Lingual & Md & \\
\hline $\mathrm{CR}$ & Bone Apex & Bone CR & Bone Apex & Fenestrations & Md Dehiscences \\
\hline 0 & 2.13 & 3.23 & 7.79 & $\mathrm{~N}$ & $\mathrm{Y}$ \\
\hline 0 & 3.52 & 1.71 & 6.16 & $\mathrm{~N}$ & $Y$ \\
\hline 1.41 & 10.21 & 1.52 & 4.51 & $\mathrm{~N}$ & $\mathrm{Y}$ \\
\hline 0.45 & 7.88 & 1.29 & 4.36 & $\mathrm{~N}$ & $\mathrm{Y}$ \\
\hline 0 & 7.72 & 0 & 3.42 & $\mathrm{~N}$ & $Y$ \\
\hline 0 & 4.04 & 1.35 & 5.68 & $\mathrm{~N}$ & $\mathrm{Y}$ \\
\hline 0.87 & 3.34 & 1.31 & 4.6 & $\mathrm{~N}$ & $\mathrm{Y}$ \\
\hline
\end{tabular}




\begin{tabular}{|c|c|c|c|c|c|}
\hline 0 & 3.61 & 1.01 & 4.3 & $\mathrm{~N}$ & Y \\
\hline 1.41 & 10.21 & 1.52 & 4.51 & $\mathrm{~N}$ & $Y$ \\
\hline 0.45 & 7.88 & 1.29 & 4.36 & $\mathrm{~N}$ & Y \\
\hline 0 & 3.67 & 0 & 6.01 & $\mathrm{~N}$ & Y \\
\hline 0 & 4.54 & 0 & 4.17 & $\mathrm{~N}$ & Y \\
\hline 0 & 3.2 & 1.7 & 4.69 & $N$ & Y \\
\hline 0 & 4.65 & 1.96 & 5.8 & $\mathrm{~N}$ & Y \\
\hline 0 & 4.95 & 0 & 4.43 & $\mathrm{~N}$ & Y \\
\hline 0 & 5.29 & 0 & 3.49 & $\mathrm{~N}$ & Y \\
\hline 0 & 5.37 & 1.24 & 5.17 & $\mathrm{~N}$ & Y \\
\hline 0 & 0 & 4.3 & 5.76 & $\mathrm{~N}$ & Y \\
\hline 0 & 4.92 & 0 & 3.34 & $\mathrm{~N}$ & Y \\
\hline 0.99 & 5.57 & 1.15 & 3.64 & $\mathrm{~N}$ & $\mathrm{~N}$ \\
\hline 0 & 5.56 & 0 & 4.77 & $\mathrm{~N}$ & Y \\
\hline 0 & 5.53 & 0 & 3.08 & $\mathrm{~N}$ & Y \\
\hline 0 & 4.17 & 0 & 3.08 & $\mathrm{~N}$ & Y \\
\hline 0 & 4.01 & 0 & 3.49 & $\mathrm{~N}$ & Y \\
\hline 0 & 2.69 & 0 & 3.47 & $\mathrm{~N}$ & Y \\
\hline 0 & 3.11 & 0 & 3.54 & $\mathrm{~N}$ & $Y$ \\
\hline 0 & 3.99 & 0 & 3.38 & $\mathrm{~N}$ & Y \\
\hline 0 & 3.61 & 0 & 4.5 & $\mathrm{~N}$ & Y \\
\hline 0 & 5.67 & 0 & 4.94 & $\mathrm{~N}$ & $Y$ \\
\hline 0 & 5.5 & 1.35 & 4.34 & $\mathrm{~N}$ & Y \\
\hline 0 & 5.15 & 0 & 4.69 & $\mathrm{~N}$ & $Y$ \\
\hline 0 & 4.26 & 0 & 5.88 & $\mathrm{~N}$ & Y \\
\hline 0 & 4.81 & 1.79 & 5.83 & $\mathrm{~N}$ & $Y$ \\
\hline 0 & 5.27 & 2.11 & 4.02 & $\mathrm{~N}$ & $Y$ \\
\hline 0 & 6.19 & 2.29 & 4.88 & $\mathrm{~N}$ & Y \\
\hline 1.47 & 8.21 & 1.79 & 3.81 & $\mathrm{~N}$ & $N$ \\
\hline 0 & 2.13 & 3.23 & 7.79 & $\mathrm{~N}$ & Y \\
\hline 0 & 3.52 & 1.71 & 6.16 & $\mathrm{~N}$ & Y \\
\hline 0 & 3.09 & 0 & 3.91 & $\mathrm{~N}$ & Y \\
\hline 0 & 3.77 & 0 & 4.19 & $\mathrm{~N}$ & Y \\
\hline 0 & 5.16 & 0 & 4.97 & $\mathrm{~N}$ & Y \\
\hline 0 & 5.54 & 0 & 4.94 & $\mathrm{~N}$ & Y \\
\hline 0 & 2.6 & 1.53 & 4.63 & $\mathrm{~N}$ & Y \\
\hline 0 & 2.94 & 1.67 & 5 & $\mathrm{~N}$ & Y \\
\hline 0 & 5.58 & 1.72 & 4.29 & $\mathrm{~N}$ & Y \\
\hline 0 & 4.95 & 1.66 & 5.62 & $\mathrm{~N}$ & $Y$ \\
\hline
\end{tabular}




\begin{tabular}{|c|c|c|c|c|c|}
\hline 0 & 5.67 & 1.27 & 2.07 & $\mathrm{~N}$ & $Y$ \\
\hline 0 & 5.85 & 1.34 & 3.08 & $\mathrm{~N}$ & $Y$ \\
\hline 0 & 4.02 & 0 & 5.35 & $\mathrm{~N}$ & Y \\
\hline 0 & 5.15 & 0 & 4.31 & $\mathrm{~N}$ & $Y$ \\
\hline 0 & 4.18 & 0 & 3.92 & $\mathrm{~N}$ & $Y$ \\
\hline 0 & 4 & 0 & 3.62 & $\mathrm{~N}$ & Y \\
\hline 0 & 4.76 & 0 & 3.94 & $\mathrm{~N}$ & $Y$ \\
\hline 0 & 4.53 & 0 & 4.89 & $\mathrm{~N}$ & Y \\
\hline 0 & 4.95 & 0 & 4.43 & $\mathrm{~N}$ & Y \\
\hline 0 & 5.29 & 0 & 3.49 & $\mathrm{~N}$ & Y \\
\hline 0 & 7.05 & 1.98 & 5.28 & $\mathrm{~N}$ & $Y$ \\
\hline 0 & 6.94 & 3 & 5.52 & $\mathrm{~N}$ & Y \\
\hline 0 & 5.51 & 1.69 & 5.59 & $N$ & $Y$ \\
\hline 0 & 6.48 & 1.76 & 6.4 & $\mathrm{~N}$ & $Y$ \\
\hline 0 & 4.7 & 0 & 3.24 & $N$ & $Y$ \\
\hline 0 & 3.84 & 0 & 3.48 & $\mathrm{~N}$ & $Y$ \\
\hline 0 & 7.14 & 0 & 3.53 & $\mathrm{~N}$ & $Y$ \\
\hline 0 & 7.81 & 0 & 3.39 & $N$ & $Y$ \\
\hline 0 & 3.73 & 1.7 & 4.99 & $N$ & $Y$ \\
\hline 0 & 2.33 & 1.33 & 5.49 & $N$ & $Y$ \\
\hline 0 & 5.07 & 1.21 & 3.36 & $\mathrm{~N}$ & $Y$ \\
\hline 0 & 5.17 & 0 & 2.89 & $\mathrm{~N}$ & $Y$ \\
\hline 1.02 & 4.1 & 1.19 & 5.41 & $N$ & $N$ \\
\hline 0.51 & 3.08 & 1.24 & 4.41 & $\mathrm{~N}$ & $\mathrm{~N}$ \\
\hline 0 & 3.26 & 0 & 4.31 & $\mathrm{~N}$ & $Y$ \\
\hline 0 & 3.1 & 0 & 4.05 & $\mathrm{~N}$ & $Y$ \\
\hline 0.89 & 4.78 & 1.95 & 4.75 & $N$ & $\mathrm{~N}$ \\
\hline 0.78 & 5.29 & 1.69 & 4.7 & $\mathrm{~N}$ & $\mathrm{~N}$ \\
\hline 0 & 2.95 & 1.56 & 4.47 & $\mathrm{~N}$ & $Y$ \\
\hline 0 & 2.24 & 1.56 & 4.86 & $\mathrm{~N}$ & $Y$ \\
\hline 0 & 3.42 & 1.57 & 3.96 & $\mathrm{~N}$ & $Y$ \\
\hline 0 & 4.29 & 1.7 & 4.29 & $\mathrm{~N}$ & Y \\
\hline 0 & 4.97 & 1.98 & 5.1 & $\mathrm{~N}$ & $Y$ \\
\hline 0 & 4.9 & 1.73 & 4.69 & $\mathrm{~N}$ & Y \\
\hline 0 & 6.23 & 1.9 & 3.42 & $\mathrm{~N}$ & $Y$ \\
\hline 0 & 7.26 & 1.7 & 2.54 & $\mathrm{~N}$ & $Y$ \\
\hline 0.8 & 10.25 & 1.74 & 5.31 & $\mathrm{~N}$ & $\mathrm{~N}$ \\
\hline 0.88 & 7.89 & 1.89 & 5.38 & $\mathrm{~N}$ & $\mathrm{~N}$ \\
\hline 0.41 & 6.27 & 1.45 & 4.24 & $\mathrm{~N}$ & $\mathrm{~N}$ \\
\hline
\end{tabular}




\begin{tabular}{|c|c|c|c|}
\hline 0 & 7.45 & 0 & 4.76 \\
\hline 0 & 6.29 & 1.49 & 5.2 \\
\hline 0 & 5 & 0 & 4.33 \\
\hline 0 & 4.69 & 1.43 & 5.98 \\
\hline 0 & 4.59 & 0 & 5.86 \\
\hline 0 & 6.05 & 1.71 & 5.69 \\
\hline 0 & 8.16 & 1.79 & 5.96 \\
\hline 0 & 7.68 & 1.27 & 5.11 \\
\hline 0 & 7.16 & 0 & 3.93 \\
\hline 0 & 2.17 & 0 & 2.62 \\
\hline 0 & 2.09 & 1.11 & 2.73 \\
\hline 0 & 7.21 & 1.56 & 3.99 \\
\hline 0 & 7.64 & 1.47 & 3.27 \\
\hline 0 & 5.71 & 0 & 3.89 \\
\hline 0 & 5.49 & 0 & 4.4 \\
\hline 0.1234 & 5.0554 & 0.9739 & 4.5126 \\
\hline 0 & 0 & 0 & 2.07 \\
\hline 1.47 & 10.25 & 4.3 & 7.79 \\
\hline 0.33393648 & 1.86908956 & 0.95035442 & 1.04688245 \\
\hline
\end{tabular}

N $\quad Y$

$\mathrm{N} \quad \mathrm{Y}$

N Y

N Y

N Y

$\mathrm{N} \quad \mathrm{Y}$

N Y

$\mathrm{N} Y \mathrm{Y}$

N Y

$\mathrm{N} Y$

N $\quad Y$

$\mathrm{N} Y$

N Y

$\mathrm{N} \quad \mathrm{Y}$

N $\quad Y$ 


\section{APPENDIX B-RAW STATISTICS}

Bivariate Fit of md CR/md lingual CR By MdDowns

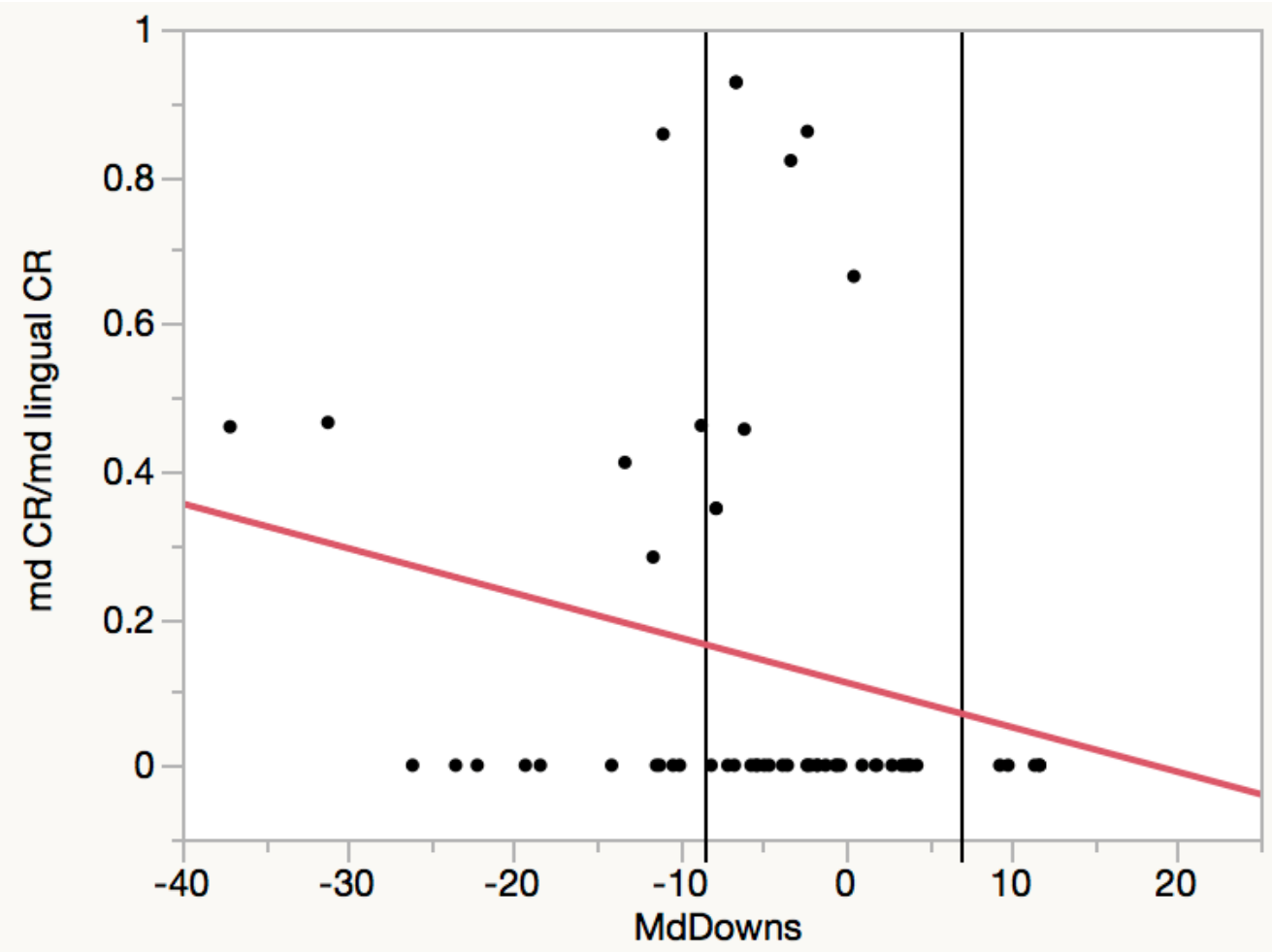

\section{Linear Fit}

Linear Fit

md $\mathrm{CR} / \mathrm{md}$ lingual $\mathrm{CR}=0.1127877-0.0060762 *$ MdDowns

Summary of Fit

RSquare

0.046386

RSquare Adj

0.029047

Root Mean Square Error

0.277692

Mean of Response

0.145503

Observations (or Sum Wgts)

Analysis of Variance

$\begin{array}{lrrrr}\text { Source } & \text { DF } & \text { Sum of Squares } & \text { Mean Square } & \text { F Ratio } \\ \text { Model } & 1 & 0.2063008 & 0.206301 & 2.6753 \\ & & & & \\ & & & 118 & \end{array}$




$\begin{array}{lrrrr}\text { Source } & \text { DF } & \text { Sum of Squares } & \text { Mean Square } & \text { F Ratio } \\ \text { Error } & 55 & 4.2412045 & 0.077113 & \text { Prob > F } \\ \text { C. Total } & 56 & 4.4475053 & & 0.1076\end{array}$

Parameter Estimates

$\begin{array}{lccrr}\text { Term } & \text { Estimate } & \text { Std Error } & \text { t Ratio } & \text { Prob }>|\mathbf{t}| \\ \text { Intercept } & 0.1127877 & 0.041868 & 2.69 & 0.0093^{*} \\ \text { MdDowns } & -0.006076 & 0.003715 & -1.64 & 0.1076\end{array}$

Bivariate Fit of md APEX/md lingual APEX By MdDowns

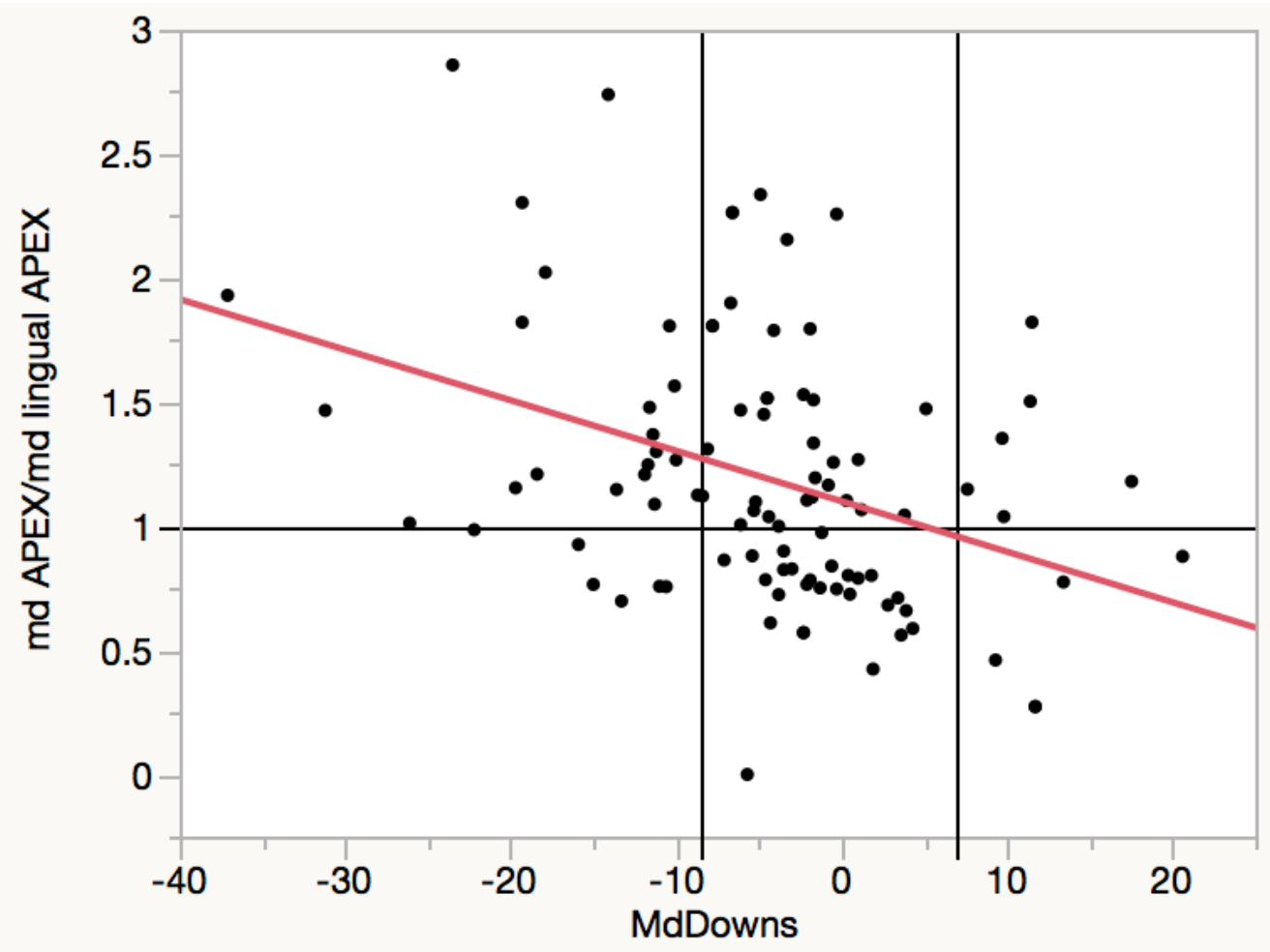

\section{Linear Fit}

Linear Fit

md APEX/md lingual APEX $=1.1007547-0.020352 *$ MdDowns

Summary of Fit

RSquare

0.133071

RSquare Adj

0.124224

Root Mean Square Error

0.502043 
Analysis of Variance

$\begin{array}{lrrrr}\text { Source } & \text { DF } & \text { Sum of Squares } & \text { Mean Square } & \text { F Ratio } \\ \text { Model } & 1 & 3.791462 & 3.79146 & 15.0427 \\ \text { Error } & 98 & 24.700637 & 0.25205 & \text { Prob > F } \\ \text { C. Total } & 99 & 28.492099 & & 0.0002 *\end{array}$

Parameter Estimates

$\begin{array}{lcccr}\text { Term } & \text { Estimate } & \text { Std Error } & \text { t Ratio } & \text { Prob }>|\mathbf{t}| \\ \text { Intercept } & 1.1007547 & 0.055382 & 19.88 & <.0001^{*} \\ \text { MdDowns } & -0.020352 & 0.005247 & -3.88 & 0.0002 *\end{array}$

Bivariate Fit of md CR/md lingual CR By MdSteiner

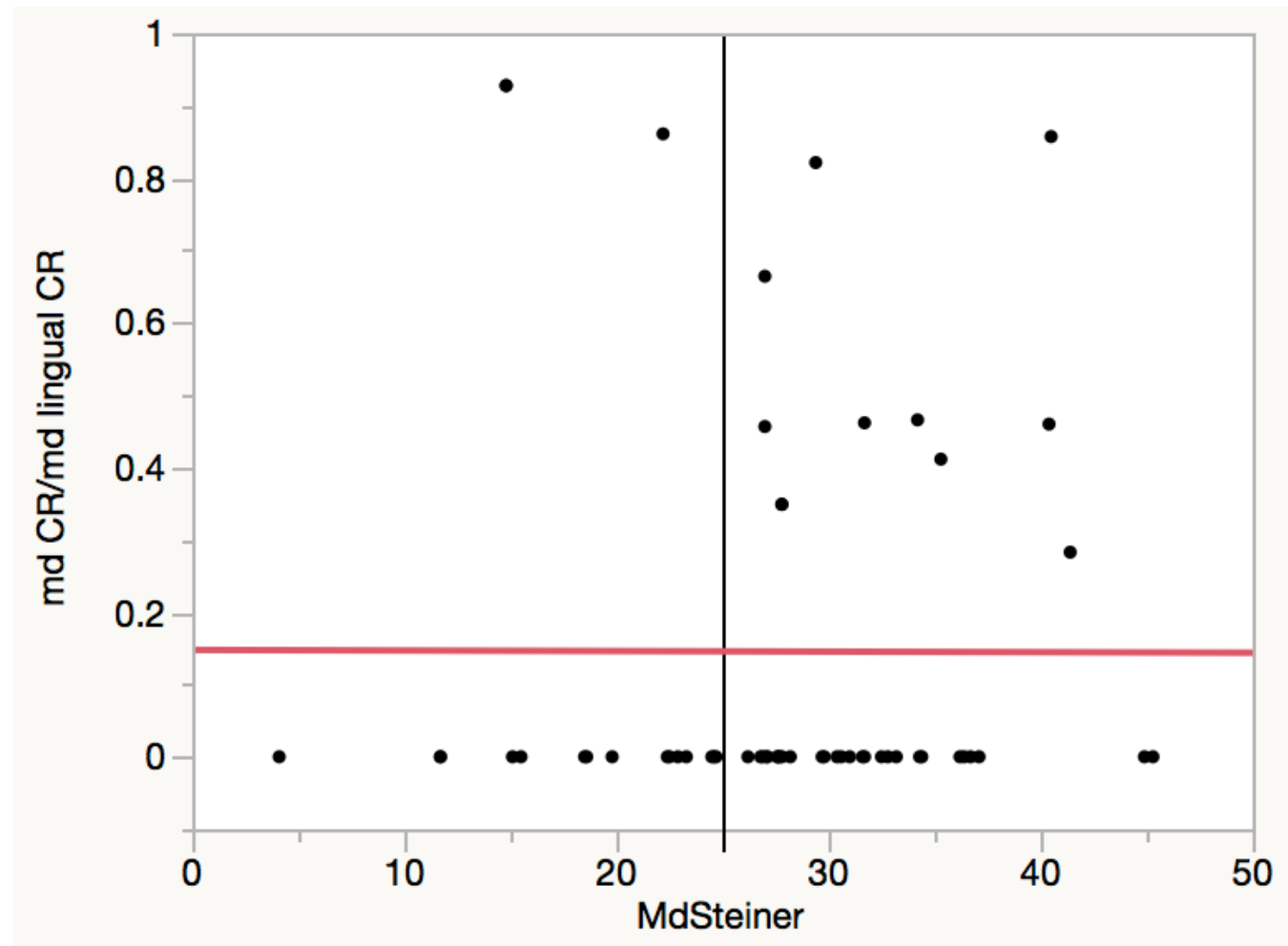

Linear Fit 
Linear Fit

md CR/md lingual CR $=0.1477023-7.9049 \mathrm{e}-5 *$ MdSteiner

Summary of Fit

RSquare

$5.465 \mathrm{e}-6$

RSquare Adj

$-0.01818$

Root Mean Square Error

0.284365

Mean of Response

0.145503

Observations (or Sum Wgts)

Analysis of Variance

\begin{tabular}{lrrrr} 
Source & DF & Sum of Squares & Mean Square & F Ratio \\
\hline Model & 1 & 0.0000243 & 0.000024 & 0.0003 \\
\hline Error & 55 & 4.4474810 & 0.080863 & Prob > F \\
C. Total & 56 & 4.4475053 & & 0.9862
\end{tabular}

Parameter Estimates

$\begin{array}{lcrrr}\text { Term } & \text { Estimate } & \text { Std Error } & \text { t Ratio } & \text { Prob>|t| } \\ \text { Intercept } & 0.1477023 & 0.13233 & 1.12 & 0.2692 \\ \text { MdSteiner } & -0.000079 & 0.00456 & -0.02 & 0.9862\end{array}$


Bivariate Fit of md APEX/md lingual APEX By MdSteiner

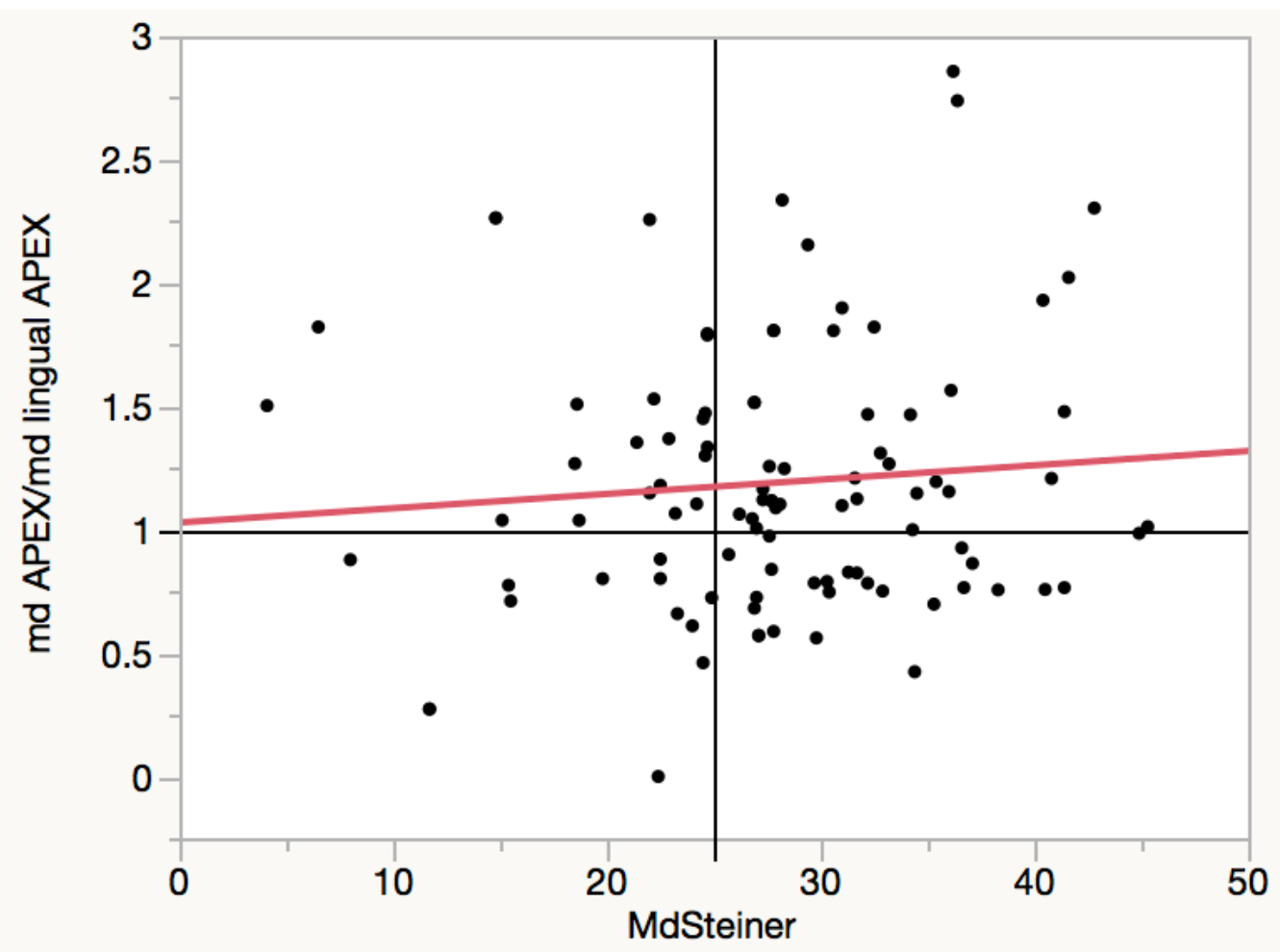

\section{Linear Fit}

Linear Fit

md APEX/md lingual APEX $=1.0293211+0.0058174 *$ MdSteiner

Summary of Fit

RSquare

RSquare Adj

Root Mean Square Error

Mean of Response

Observations (or Sum Wgts)
0.007755

$-0.00237$

0.537104

1.191439

100

Analysis of Variance

$\begin{array}{lrrrr}\text { Source } & \text { DF } & \text { Sum of Squares } & \text { Mean Square } & \text { F Ratio } \\ \text { Model } & 1 & 0.220957 & 0.220957 & 0.7659 \\ \text { Error } & 98 & 28.271141 & 0.288481 & \text { Prob > F } \\ \text { C. Total } & 99 & 28.492099 & & 0.3836\end{array}$


Parameter Estimates

$\begin{array}{lcrrr}\text { Term } & \text { Estimate } & \text { Std Error } & \text { t Ratio } & \text { Prob>|t| } \\ \text { Intercept } & 1.0293211 & 0.19287 & 5.34 & <.0001 * \\ \text { MdSteiner } & 0.0058174 & 0.006647 & 0.88 & 0.3836\end{array}$

Bivariate Fit of md CR/md lingual CR By MdTweed

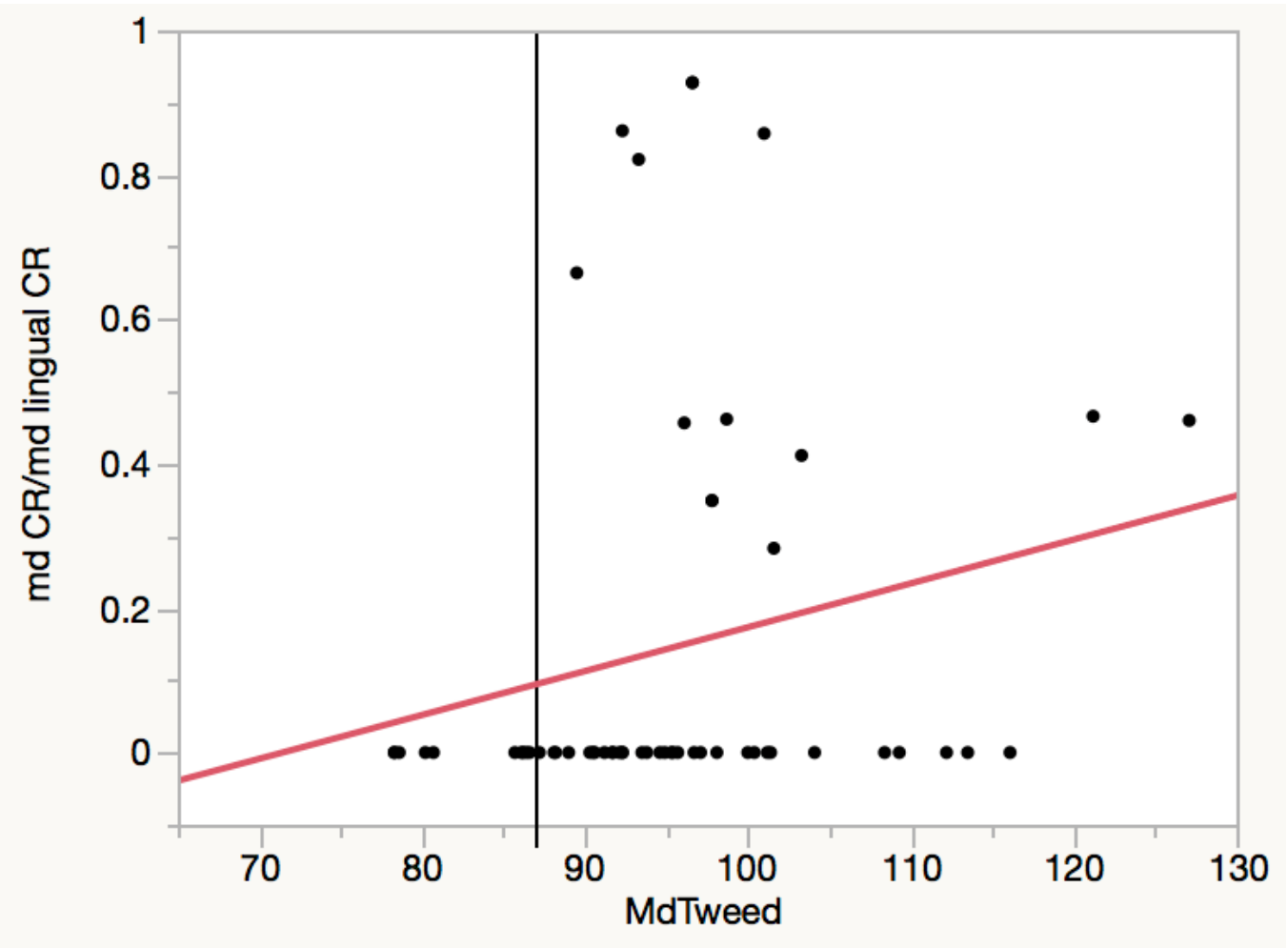

\section{Linear Fit}

Linear Fit

md CR/md lingual CR $=-0.434069+0.0060762 *$ MdTweed

Summary of Fit

RSquare

0.046386

RSquare Adj

0.029047

Root Mean Square Error

0.277692

Mean of Response

0.145503

Observations (or Sum Wgts) 
Analysis of Variance

$\begin{array}{lrrrr}\text { Source } & \text { DF } & \text { Sum of Squares } & \text { Mean Square } & \text { F Ratio } \\ \text { Model } & 1 & 0.2063008 & 0.206301 & 2.6753 \\ \text { Error } & 55 & 4.2412045 & 0.077113 & \text { Prob > F } \\ \text { C. Total } & 56 & 4.4475053 & & 0.1076\end{array}$

Parameter Estimates

$\begin{array}{lccrr}\text { Term } & \text { Estimate } & \text { Std Error } & \text { t Ratio } & \text { Prob }>|\mathbf{t}| \\ \text { Intercept } & -0.434069 & 0.356244 & -1.22 & 0.2282 \\ \text { MdTweed } & 0.0060762 & 0.003715 & 1.64 & 0.1076\end{array}$

Bivariate Fit of md APEX/md lingual APEX By MdTweed

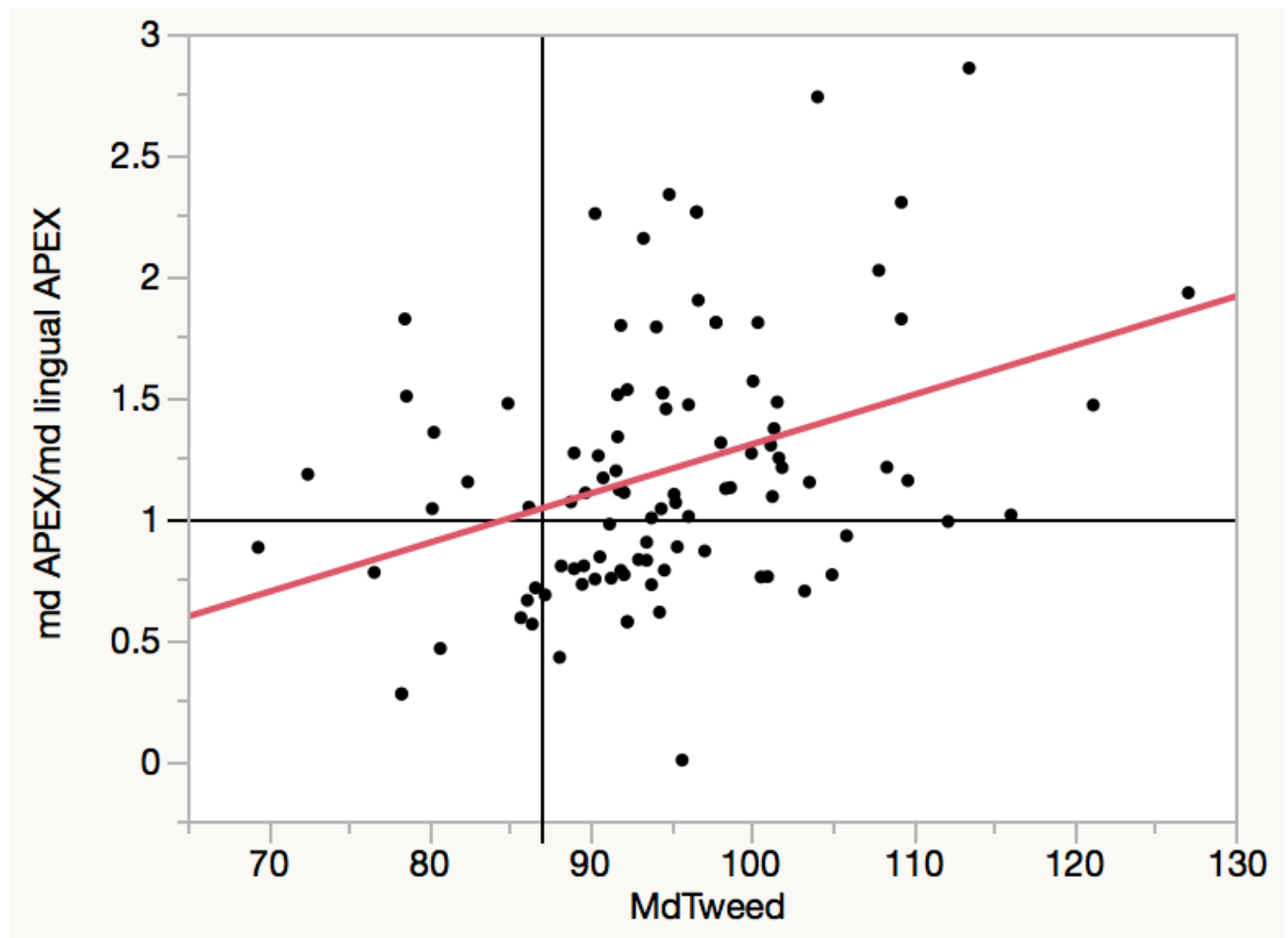

\section{Linear Fit}

Linear Fit

md APEX/md lingual APEX $=-0.730926+0.020352 *$ MdTweed

Summary of Fit

RSquare

0.133071 
RSquare Adj

Root Mean Square Error

Mean of Response

Observations (or Sum Wgts)
0.124224

0.502043

1.191439

100

Analysis of Variance

$\begin{array}{lrrrr}\text { Source } & \text { DF } & \text { Sum of Squares } & \text { Mean Square } & \text { F Ratio } \\ \text { Model } & 1 & 3.791462 & 3.79146 & 15.0427 \\ \text { Error } & 98 & 24.700637 & 0.25205 & \text { Prob > F } \\ \text { C. Total } & 99 & 28.492099 & & 0.0002^{*}\end{array}$

Parameter Estimates

$\begin{array}{lcrrr}\text { Term } & \text { Estimate } & \text { Std Error } & \text { t Ratio } & 0.1455 \\ \text { Intercept } & -0.730926 & 0.498184 & -1.47 & 3.88\end{array}$

Bivariate Fit of md CR/md lingual CR By MdAndrews

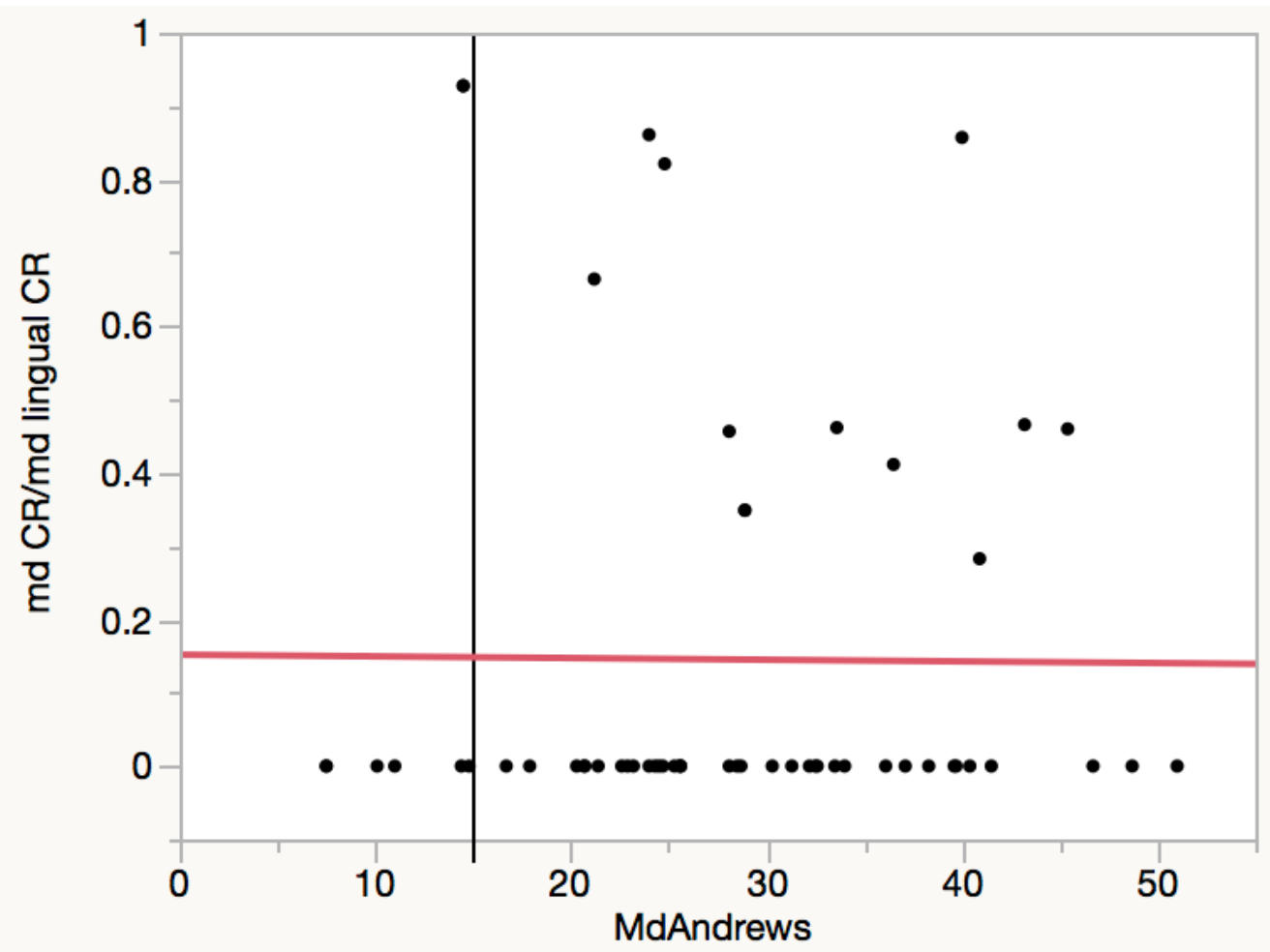




\section{- Linear Fit}

Linear Fit

$\mathrm{md} \mathrm{CR} / \mathrm{md}$ lingual $\mathrm{CR}=0.1520239-0.0002313 *$ MdAndrews

Summary of Fit

RSquare

$7.34 \mathrm{e}-5$

RSquare Adj

$-0.01811$

Root Mean Square Error

0.284355

Mean of Response

0.145503

57

Analysis of Variance

$\begin{array}{lrrrr}\text { Source } & \text { DF } & \text { Sum of Squares } & \text { Mean Square } & \text { F Ratio } \\ \text { Model } & 1 & 0.0003265 & 0.000326 & 0.0040 \\ \text { Error } & 55 & 4.4471788 & 0.080858 & \text { Prob > F } \\ \text { C. Total } & 56 & 4.4475053 & & 0.9496\end{array}$

Parameter Estimates

$\begin{array}{lcccr}\text { Term } & \text { Estimate } & \text { Std Error } & \text { t Ratio } & \text { Prob }>|\mathbf{t}| \\ \text { Intercept } & 0.1520239 & 0.109315 & 1.39 & 0.1699 \\ \text { MdAndrews } & -0.000231 & 0.003641 & -0.06 & 0.9496\end{array}$


Bivariate Fit of md APEX/md lingual APEX By MdAndrews

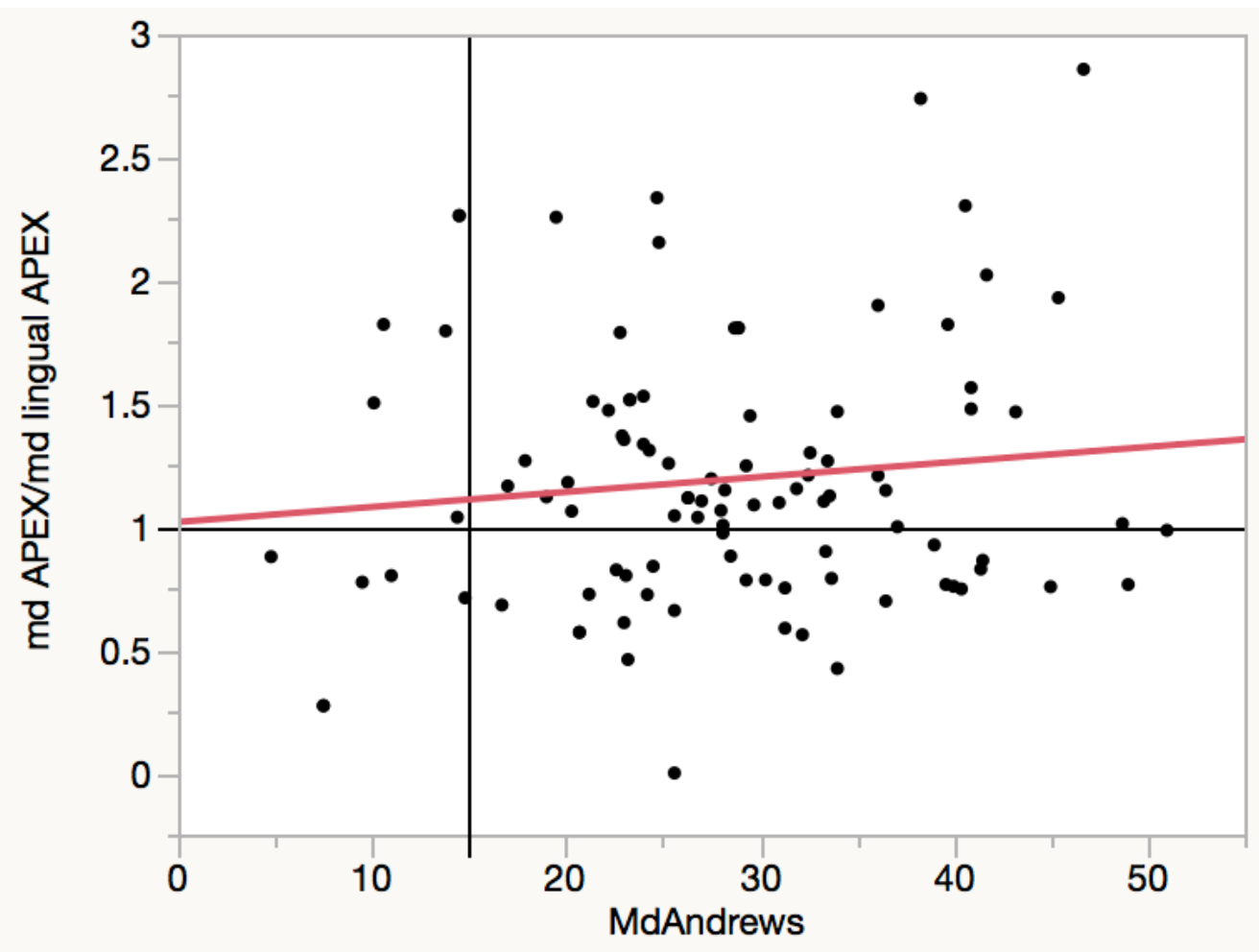

\section{Linear Fit}

Linear Fit

md APEX/md lingual APEX $=1.0194983+0.0061135 *$ MdAndrews

Summary of Fit

RSquare

0.012952

RSquare Adj

0.00288

Root Mean Square Error

0.535696

Mean of Response

1.191439

Observations (or Sum Wgts)

Analysis of Variance

$\begin{array}{lrrrr}\text { Source } & \text { DF } & \text { Sum of Squares } & \text { Mean Square } & \text { F Ratio } \\ \text { Model } & 1 & 0.369038 & 0.369038 & 1.2860 \\ \text { Error } & 98 & 28.123060 & 0.286970 & \text { Prob > F } \\ \text { C. Total } & 99 & 28.492099 & & 0.2596\end{array}$


Parameter Estimates

$\begin{array}{lcrrr}\text { Term } & \text { Estimate } & \text { Std Error } & \text { t Ratio } & \text { Prob>|t| } \\ \text { Intercept } & 1.0194983 & 0.160807 & 6.34 & <.0001^{*} \\ \text { MdAndrews } & 0.0061135 & 0.005391 & 1.13\end{array}$

Bivariate Fit of md CR/md lingual CR By MdRicketts

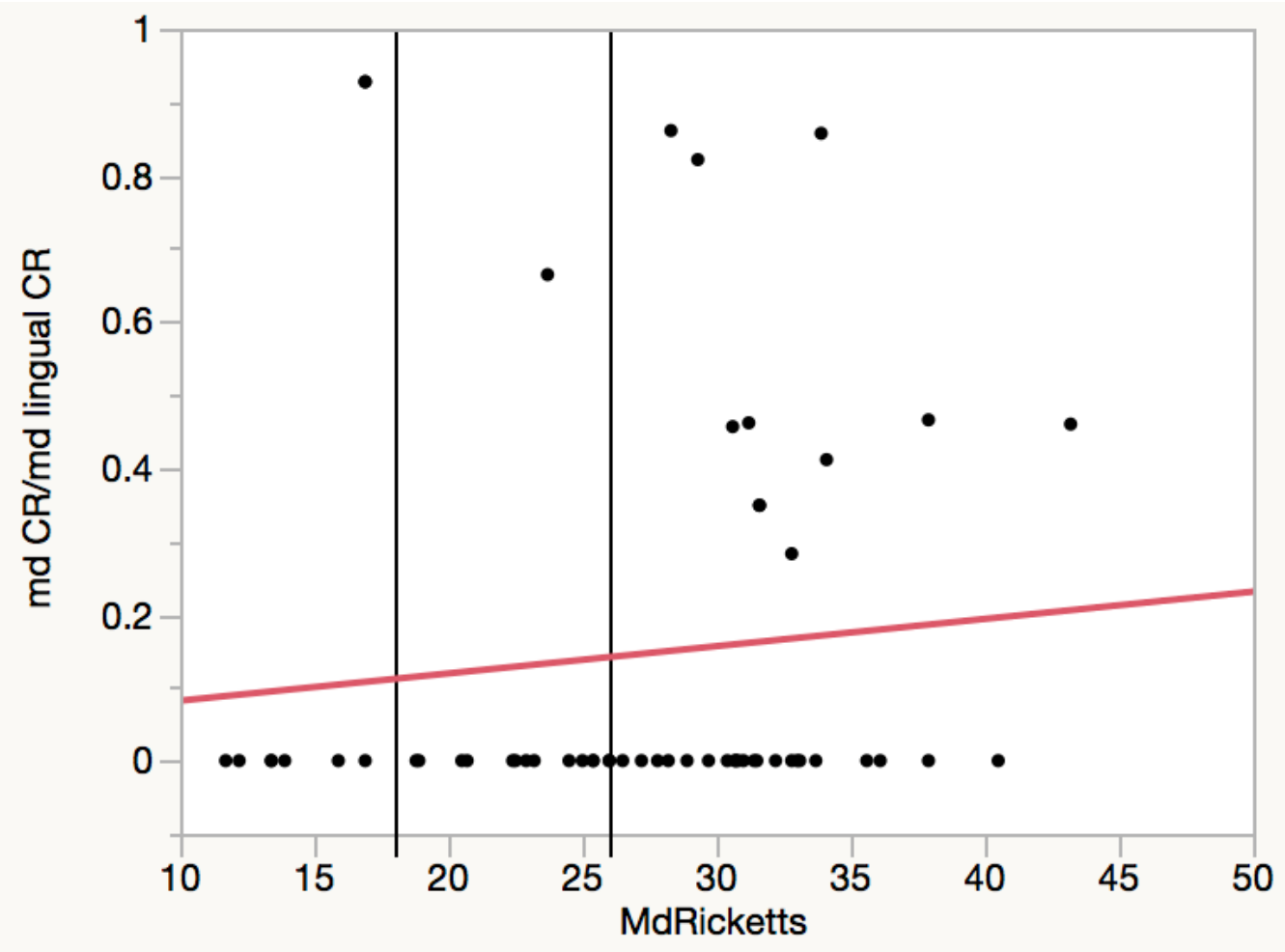

\section{Linear Fit}

Linear Fit

md CR/md lingual CR $=0.0446245+0.0037307 *$ MdRicketts

Summary of Fit

RSquare

0.009674

RSquare Adj

$-0.00833$

Root Mean Square Error

0.282987

Mean of Response

0.145503

Observations (or Sum Wgts) 
Analysis of Variance

$\begin{array}{lrrrr}\text { Source } & \text { DF } & \text { Sum of Squares } & \text { Mean Square } & \text { F Ratio } \\ \text { Model } & 1 & 0.0430230 & 0.043023 & 0.5372 \\ \text { Error } & 55 & 4.4044823 & 0.080081 & \text { Prob > F } \\ \text { C. Total } & 56 & 4.4475053 & & 0.4667\end{array}$

Parameter Estimates

$\begin{array}{lrrrr}\text { Term } & \text { Estimate } & \text { Std Error } & \text { t Ratio } & \text { Prob }>|\mathbf{t}| \\ \text { Intercept } & 0.0446245 & 0.142643 & 0.31 & 0.7556 \\ \text { MdRicketts } & 0.0037307 & 0.00509 & 0.73 & 0.4667\end{array}$

Bivariate Fit of md APEX/md lingual APEX By MdRicketts

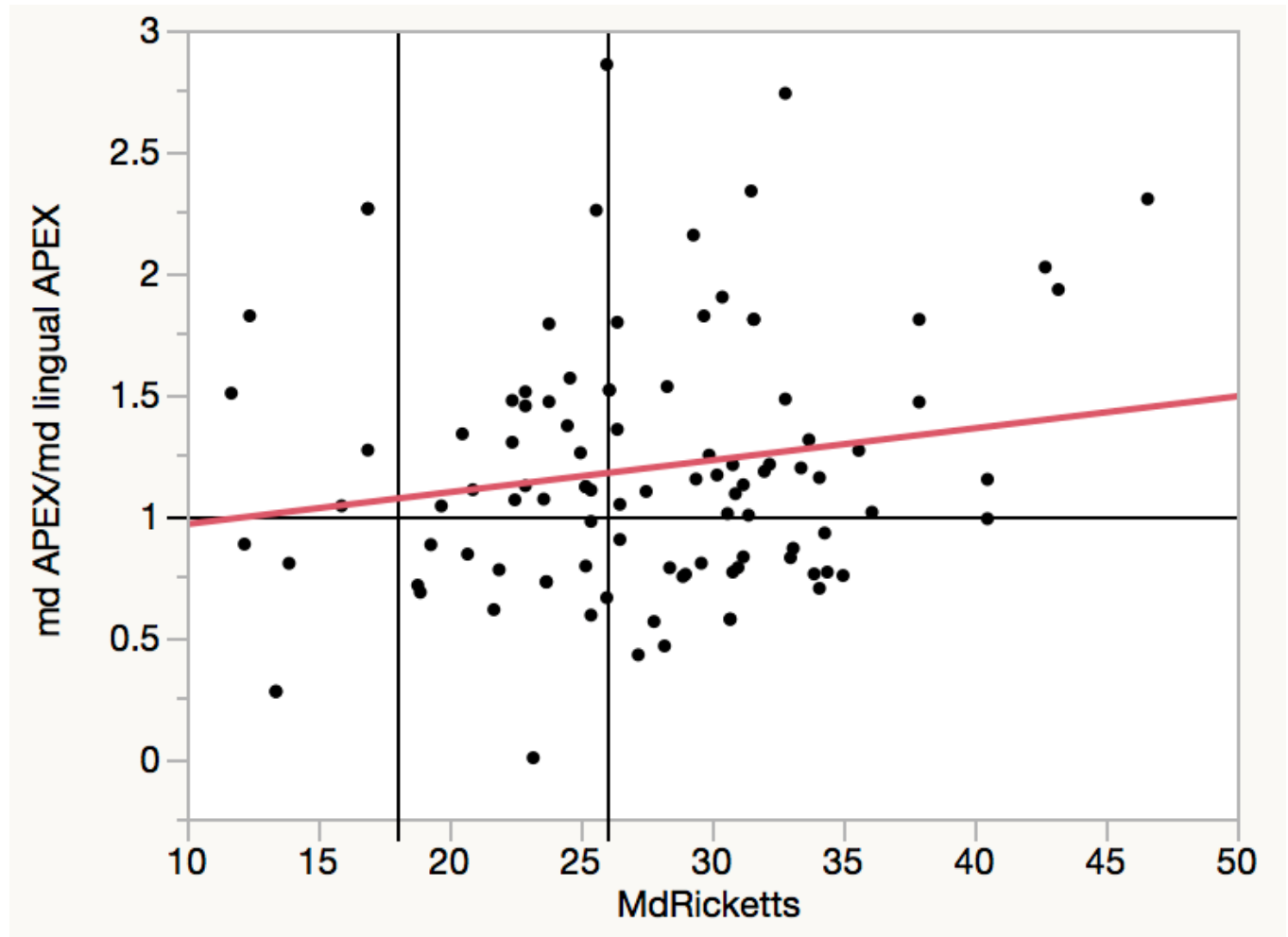

\section{Linear Fit}

Linear Fit

md APEX/md lingual APEX $=0.8310637+0.0131866 *$ MdRicketts

Summary of Fit

RSquare

0.029317 
RSquare Adj

Root Mean Square Error

Mean of Response

Observations (or Sum Wgts)
0.019412

0.531236

1.191439

100

Analysis of Variance

$\begin{array}{lrrrr}\text { Source } & \text { DF } & \text { Sum of Squares } & \text { Mean Square } & \text { F Ratio } \\ \text { Model } & 1 & 0.835311 & 0.835311 & 2.9599 \\ \text { Error } & 98 & 27.656787 & 0.282212 & \text { Prob > F } \\ \text { C. Total } & 99 & 28.492099 & & 0.0885\end{array}$

\section{Parameter Estimates}

\begin{tabular}{|c|c|c|c|c|}
\hline Term & Estimate & Std Error & t Ratio & Prob $>|t|$ \\
\hline Intercept & 0.8310637 & 0.2161 & 3.85 & $0.0002 *$ \\
\hline
\end{tabular}


Fit Group

Bivariate Fit of Md L Bone CR - Md B Bone CR By MdDowns

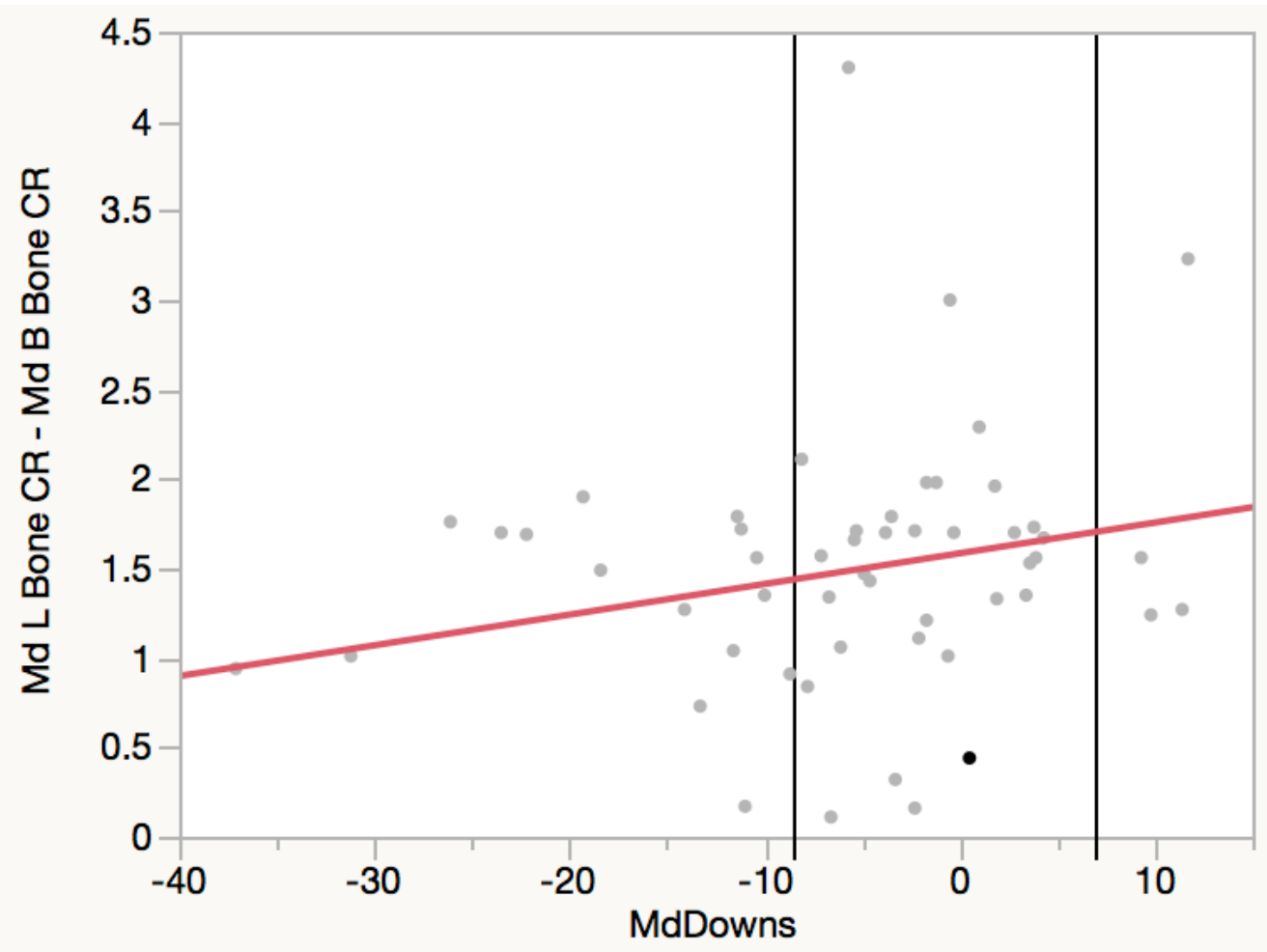

\section{Linear Fit}

Linear Fit

Md L Bone CR - Md B Bone CR $=1.5844683+0.0171544 *$ MdDowns

Summary of Fit

RSquare

0.051212

RSquare Adj

0.033962

Root Mean Square Error

0.744239

Mean of Response

1.492105

Observations (or Sum Wgts)

Analysis of Variance

$\begin{array}{lrrrr}\text { Source } & \text { DF } & \text { Sum of Squares } & \text { Mean Square } & \text { F Ratio } \\ \text { Model } & 1 & 1.644340 & 1.64434 & 2.9687 \\ \text { Error } & 55 & 30.464008 & 0.55389 & \text { Prob > F }\end{array}$




$\begin{array}{lrrrr}\text { Source } & \text { DF } & \text { Sum of Squares } & \text { Mean Square } & \text { F Ratio } \\ \text { C. Total } & 56 & 32.108347 & 0.0905\end{array}$

Parameter Estimates

$\begin{array}{lrrrr}\text { Term } & \text { Estimate } & \text { Std Error } & \text { t Ratio } & \text { Prob }>|\mathbf{t}| \\ \text { Intercept } & 1.5844683 & 0.11221 & 14.12 & <.0001^{*} \\ \text { MdDowns } & 0.0171544 & 0.009956 & 1.72 & 0.0905\end{array}$

Bivariate Fit of Md L Bone CR - Md B Bone CR By MdSteiner

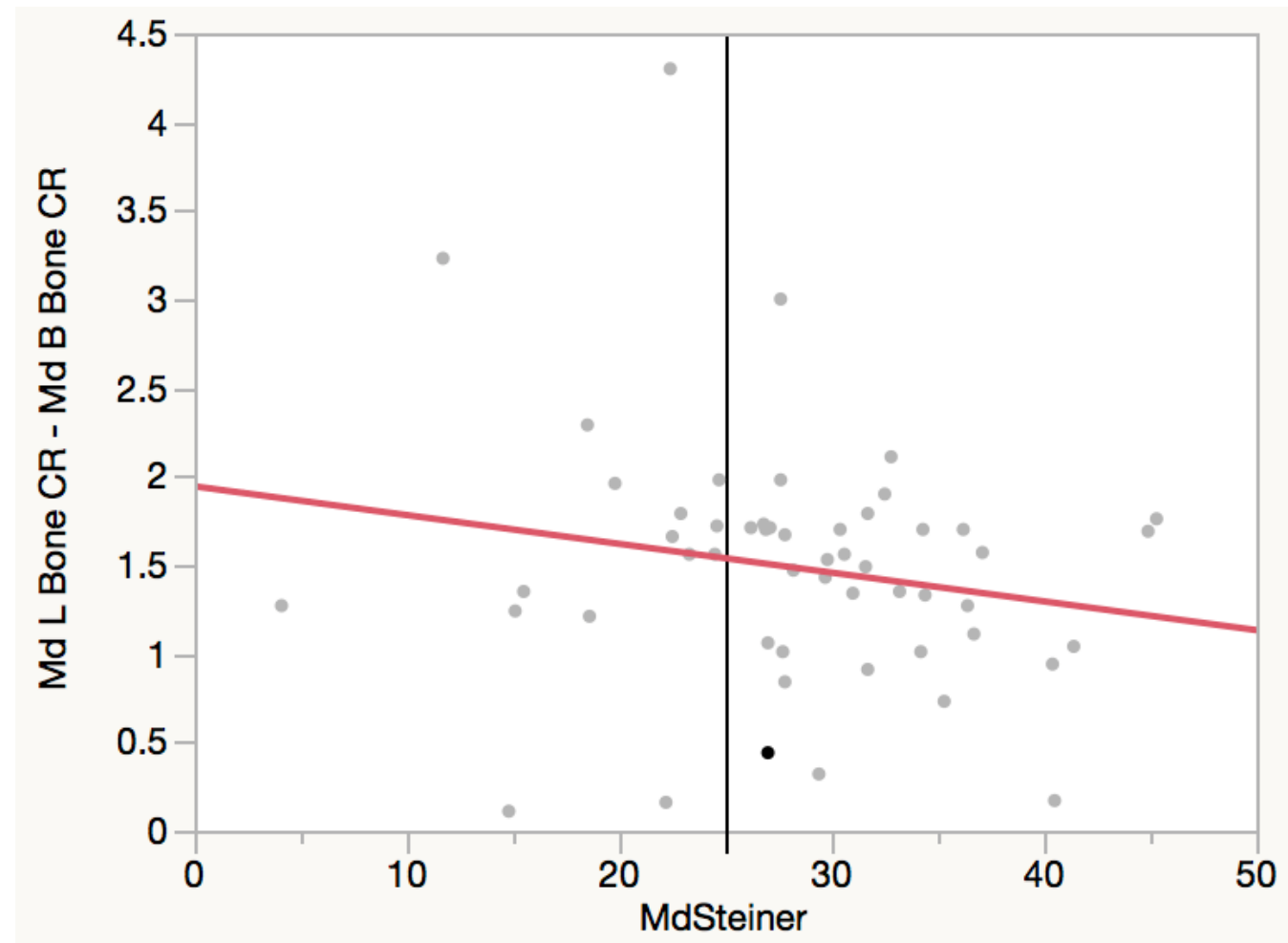

\section{LLinear Fit}

Linear Fit

Md L Bone CR - Md B Bone CR = 1.9441127 - 0.016247*MdSteiner

Summary of Fit

RSquare

0.031974

RSquare Adj

0.014374

Root Mean Square Error

0.751746

Mean of Response

1.492105

Observations (or Sum Wgts) 
Analysis of Variance

$\begin{array}{lrrrr}\text { Source } & \text { DF } & \text { Sum of Squares } & \text { Mean Square } & \text { F Ratio } \\ \text { Model } & 1 & 1.026637 & 1.02664 & 1.8167 \\ \text { Error } & 55 & 31.081710 & 0.56512 & \text { Prob > F } \\ \text { C. Total } & 56 & 32.108347 & & 0.1832\end{array}$

Parameter Estimates

$\begin{array}{lrrrr}\text { Term } & \text { Estimate } & \text { Std Error } & \text { t Ratio } & \text { Prob }>|\mathbf{t}| \\ \text { Intercept } & 1.9441127 & 0.349827 & 5.56 & <.0001^{*} \\ \text { MdSteiner } & -0.016247 & 0.012054 & -1.35 & 0.1832\end{array}$

Bivariate Fit of Md L Bone CR - Md B Bone CR By MdTweed

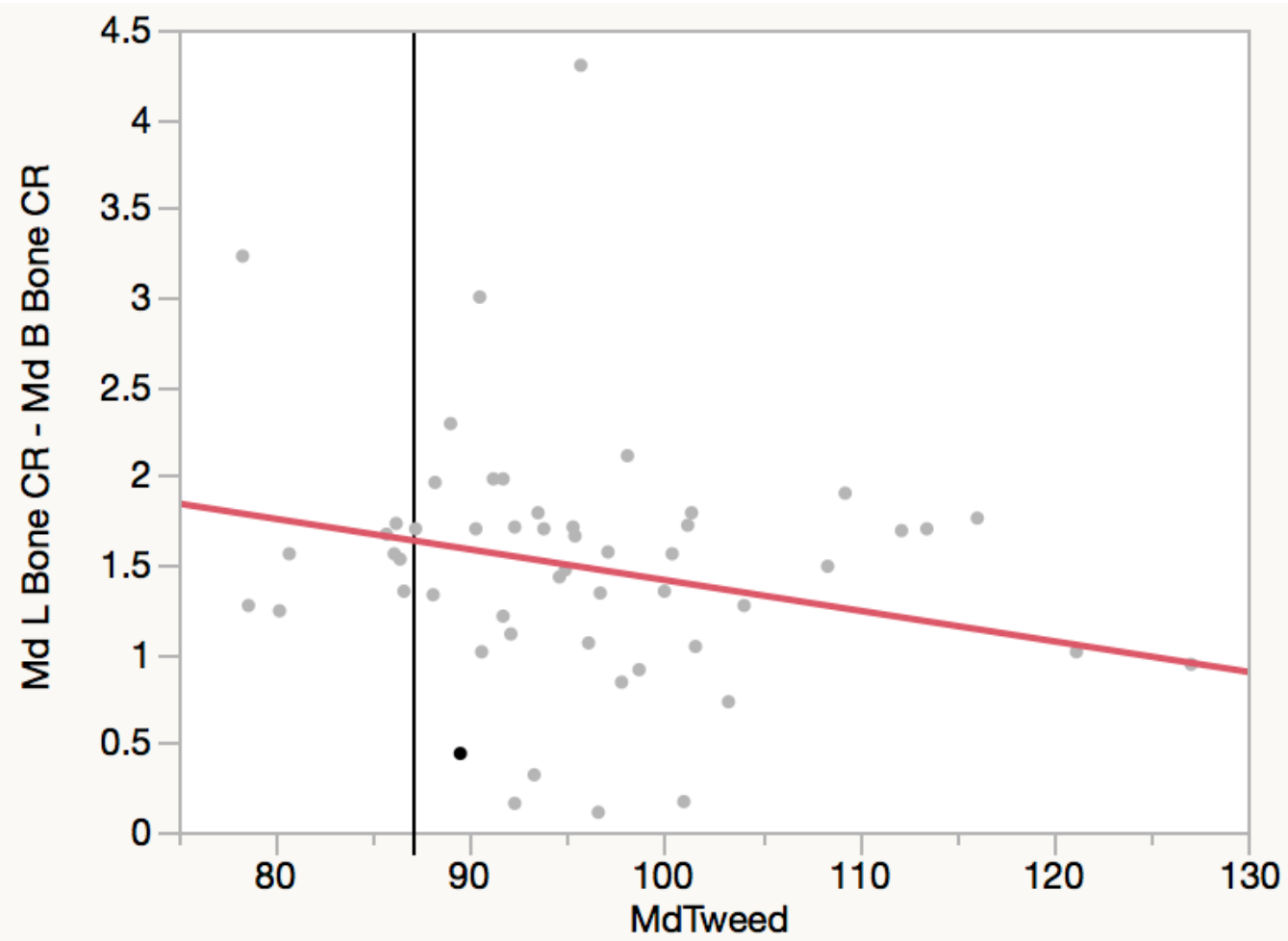

\section{Linear Fit}

Linear Fit

Md L Bone CR - Md B Bone CR = $3.128367-0.0171544 *$ MdTweed 
Summary of Fit

RSquare

RSquare Adj

Root Mean Square Error

Mean of Response

Observations (or Sum Wgts)
0.051212

0.033962

0.744239

1.492105

57

Analysis of Variance

$\begin{array}{lrrrr}\text { Source } & \text { DF } & \text { Sum of Squares } & \text { Mean Square } & \text { F Ratio } \\ \text { Model } & 1 & 1.644340 & 1.64434 & 2.9687 \\ \text { Error } & 55 & 30.464008 & 0.55389 & \text { Prob > F } \\ \text { C. Total } & 56 & 32.108347 & & 0.0905\end{array}$

Parameter Estimates

$\begin{array}{lcrrr}\text { Term } & \text { Estimate } & \text { Std Error } & \text { t Ratio } & \text { Prob }>|\mathbf{t}| \\ \text { Intercept } & 3.128367 & 0.954765 & 3.28 & 0.0018^{*} \\ \text { MdTweed } & -0.017154 & 0.009956 & -1.72 & 0.0905\end{array}$


Bivariate Fit of Md L Bone CR - Md B Bone CR By MdAndrews

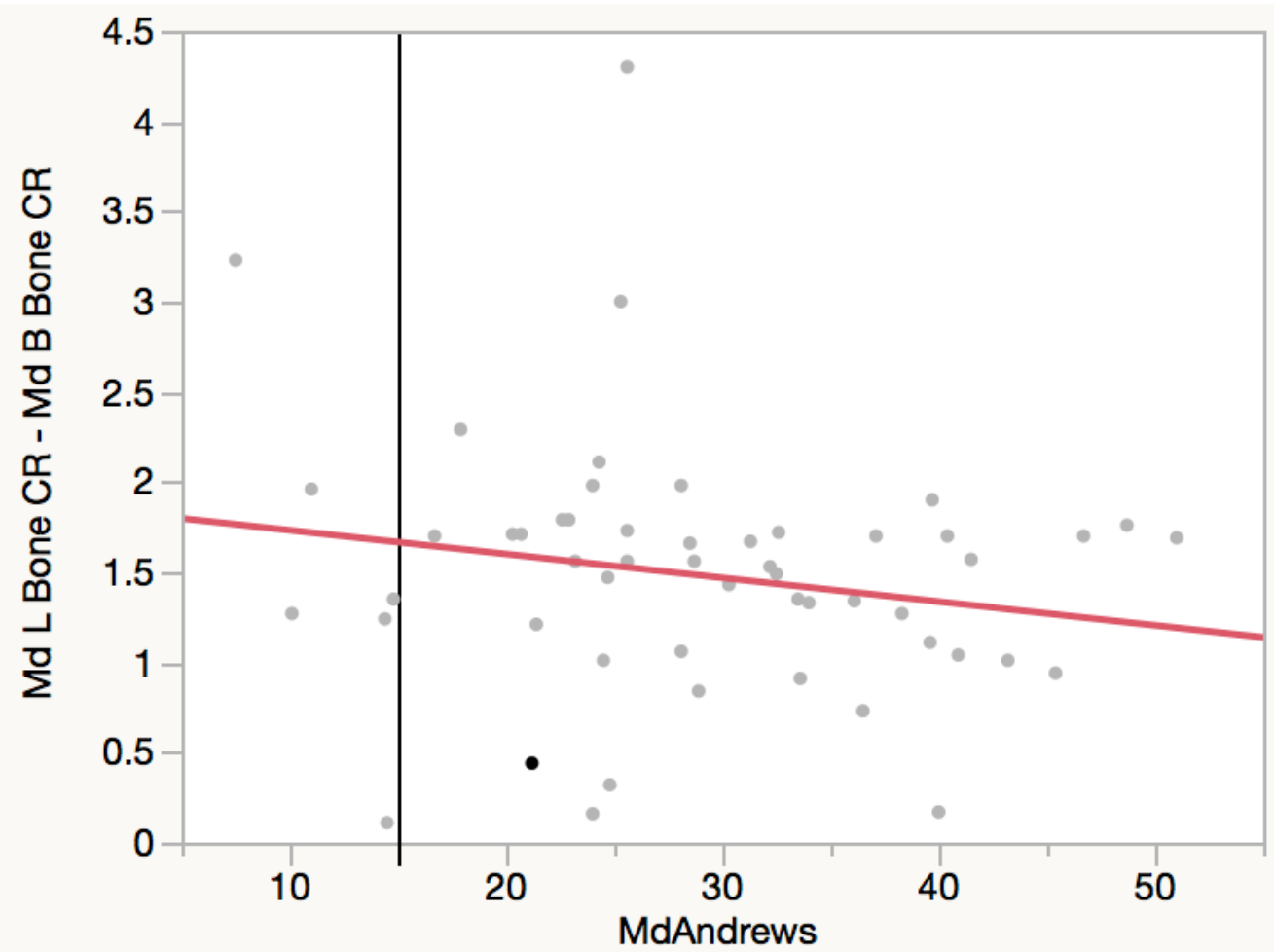

Linear Fit

Linear Fit

Md L Bone CR - Md B Bone CR = 1.863857 - 0.0131892*MdAndrews

Summary of Fit

$\begin{array}{ll}\text { RSquare } & 0.033047\end{array}$

RSquare Adj

0.015466

Root Mean Square Error

0.751329

Mean of Response

1.492105

Observations (or Sum Wgts)

Analysis of Variance

$\begin{array}{lrrrr}\text { Source } & \text { DF } & \text { Sum of Squares } & \text { Mean Square } & \text { F Ratio } \\ \text { Model } & 1 & 1.061079 & 1.06108 & 1.8797 \\ \text { Error } & 55 & 31.047268 & 0.56450 & \text { Prob > F } \\ \text { C. Total } & 56 & 32.108347 & & 0.1759\end{array}$


Parameter Estimates

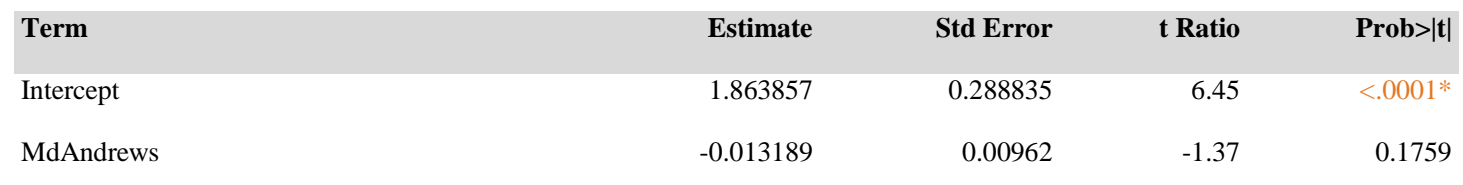

Bivariate Fit of Md L Bone CR - Md B Bone CR By MdRicketts

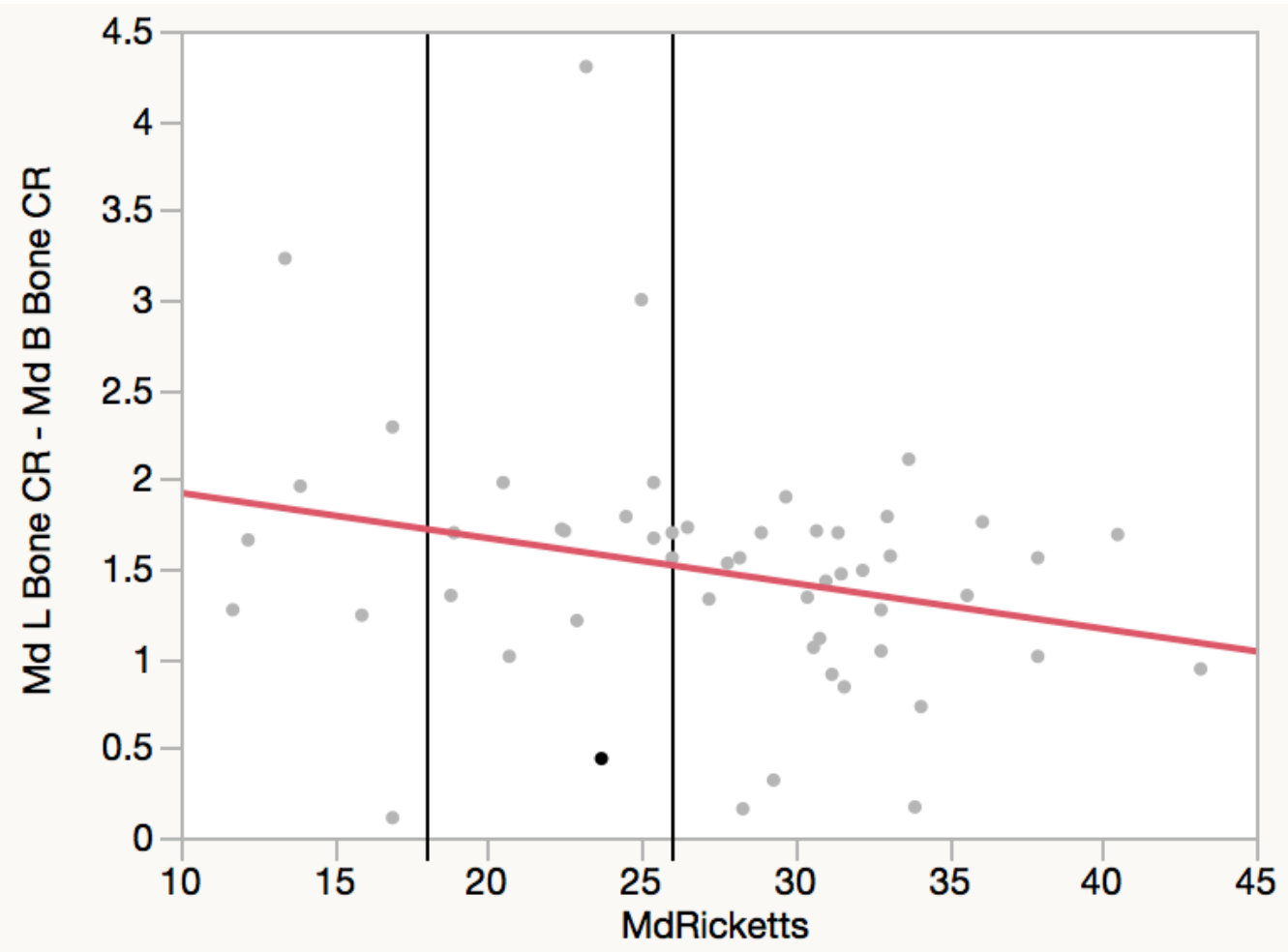

\section{Linear Fit}

Linear Fit

Md L Bone CR - Md B Bone CR = 2.1747439 - 0.0252452*MdRicketts

Summary of Fit

RSquare

0.061357

RSquare Adj

0.044291

Root Mean Square Error

0.740249

Mean of Response

1.492105

Observations (or Sum Wgts) 
Analysis of Variance

$\begin{array}{lrrrr}\text { Source } & \text { DF } & \text { Sum of Squares } & \text { Mean Square } & \text { F Ratio } \\ \text { Model } & 1 & 1.970080 & 1.97008 & 3.5952 \\ \text { Error } & 55 & 30.138268 & 0.54797 & \text { Prob > F } \\ \text { C. Total } & 56 & 32.108347 & & 0.0632\end{array}$

Parameter Estimates

$\begin{array}{lcccr}\text { Term } & \text { Estimate } & \text { Std Error } & \text { t Ratio } & \text { Prob }>|\mathbf{t}| \\ \text { Intercept } & 2.1747439 & 0.373133 & 5.83 & <.0001^{*} \\ \text { MdRicketts } & -0.025245 & 0.013314 & -1.90 & 0.0632\end{array}$

Fit Group

Bivariate Fit of Md L Bone Apex-Md B Bone Apex By MdDowns

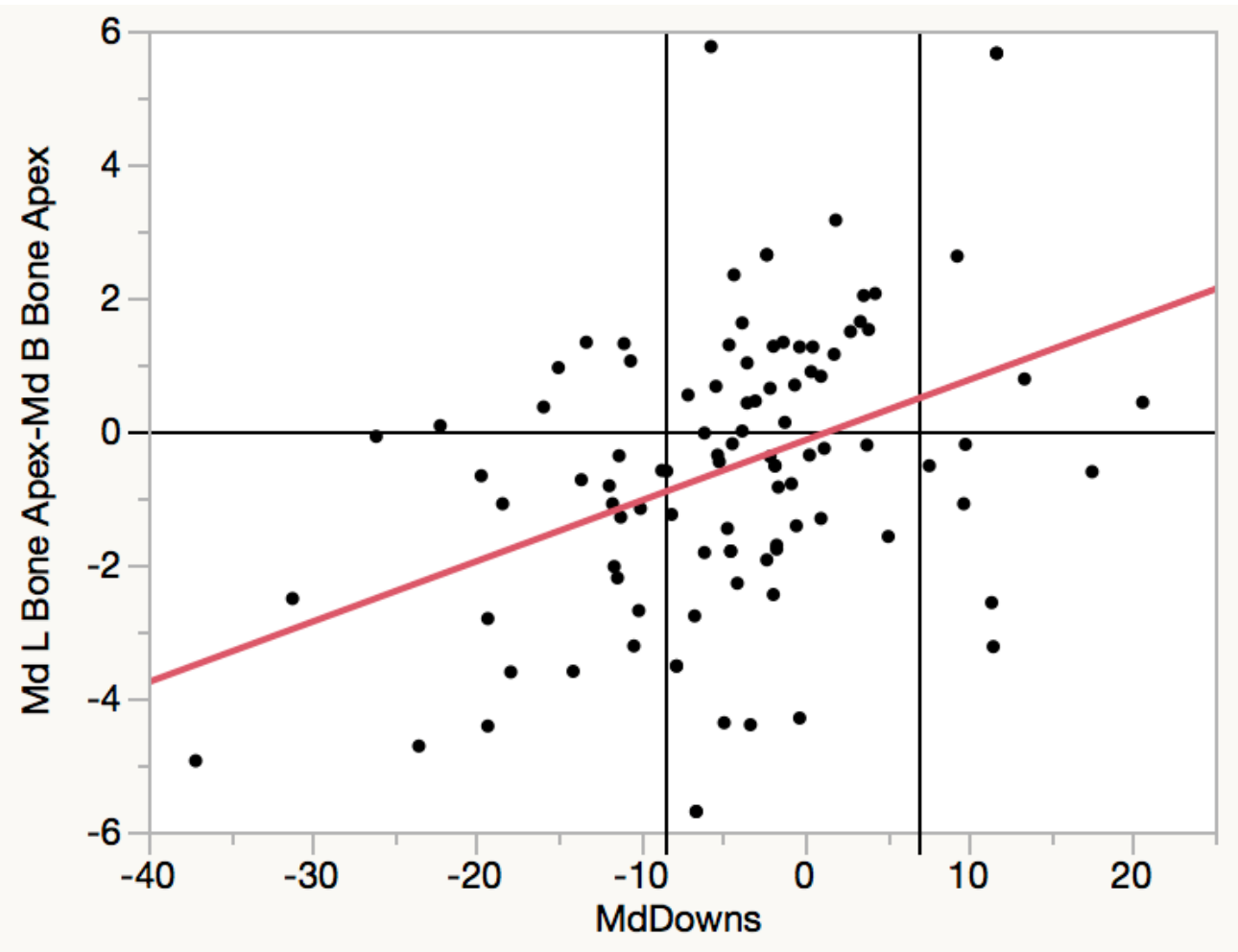

\section{Linear Fit}

Linear Fit

Md L Bone Apex-Md B Bone Apex $=-0.138993+0.0906251 *$ MdDowns

Summary of Fit

RSquare

0.150285 
RSquare Adj

Root Mean Square Error

Mean of Response

Observations (or Sum Wgts)
0.141614

2.082622

$-0.5428$

100

Analysis of Variance

$\begin{array}{lrrrr}\text { Source } & \text { DF } & \text { Sum of Squares } & \text { Mean Square } & \text { F Ratio } \\ \text { Model } & 1 & 75.17765 & 75.1777 & 17.3328 \\ \text { Error } & 98 & 425.05676 & 4.3373 & \text { Prob > F } \\ \text { C. Total } & 99 & 500.23442 & & <.0001 *\end{array}$

Parameter Estimates

$\begin{array}{lccrr}\text { Term } & \text { Estimate } & \text { Std Error } & \text { t Ratio } & \text { Prob>|t| } \\ \text { Intercept } & -0.138993 & 0.229741 & -0.60 & 0.5466 \\ \text { MdDowns } & 0.0906251 & 0.021768 & 4.16 & <.0001 *\end{array}$

Bivariate Fit of Md L Bone Apex-Md B Bone Apex By MdSteiner

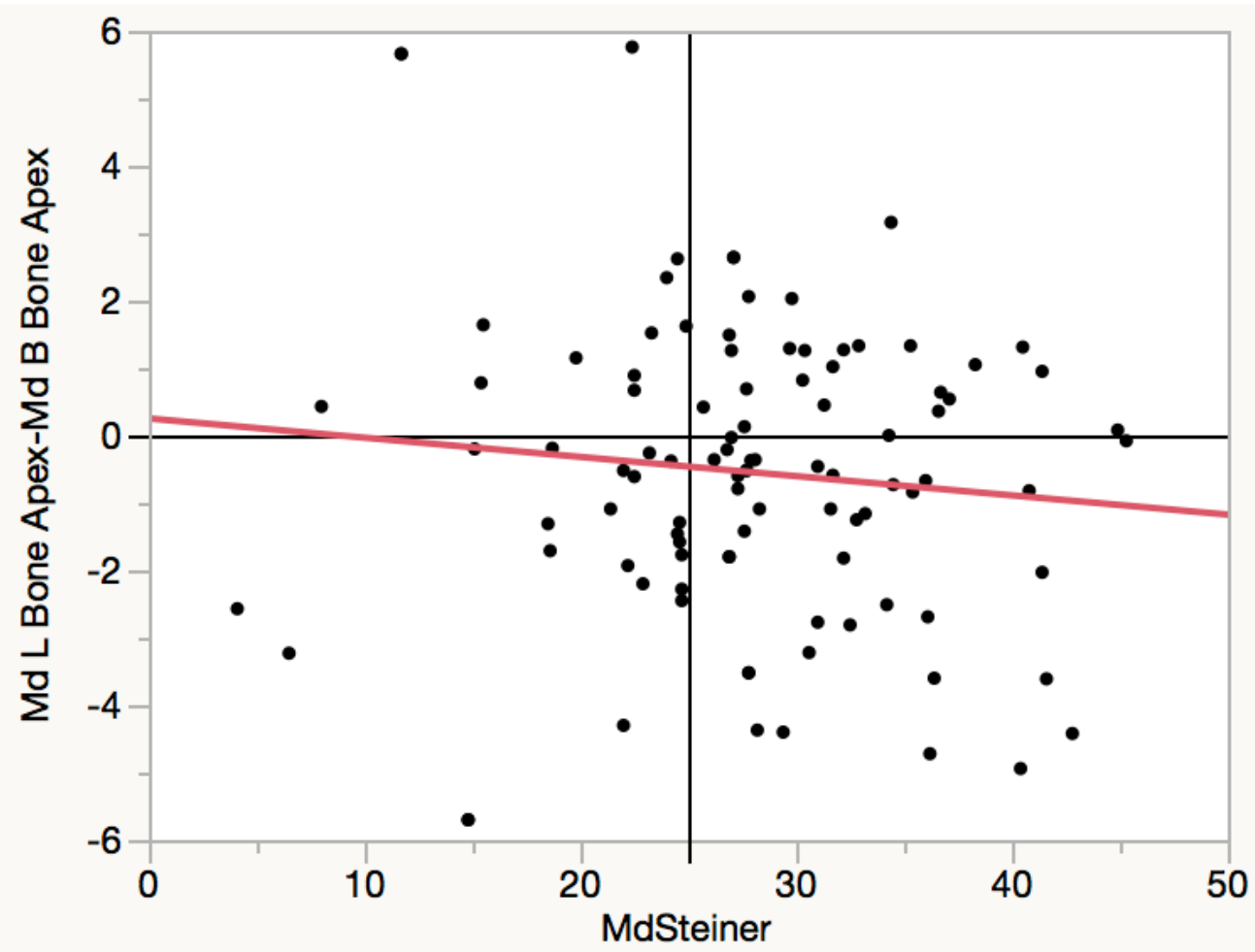




\section{_Linear Fit}

Linear Fit

Md L Bone Apex-Md B Bone Apex = $0.2522318-0.0285285^{*}$ MdSteiner

Summary of Fit

RSquare

0.010623

RSquare Adj

0.000527

Root Mean Square Error

2.247267

Mean of Response

$-0.5428$

Observations (or Sum Wgts)

100

Analysis of Variance

$\begin{array}{lrrrr}\text { Source } & \text { DF } & \text { Sum of Squares } & \text { Mean Square } & \text { F Ratio } \\ \text { Model } & 1 & 5.31391 & 5.31391 & 1.0522 \\ \text { Error } & 98 & 494.92050 & 5.05021 & \text { Prob > F } \\ \text { C. Total } & 99 & 500.23442 & & 0.3075\end{array}$

Parameter Estimates

$\begin{array}{lccrr}\text { Term } & \text { Estimate } & \text { Std Error } & \text { t Ratio } & \text { Prob }>|\mathbf{t}| \\ \text { Intercept } & 0.2522318 & 0.806976 & 0.31 & 0.7553 \\ \text { MdSteiner } & -0.028528 & 0.027812 & -1.03 & 0.3075\end{array}$


Bivariate Fit of Md L Bone Apex-Md B Bone Apex By MdTweed

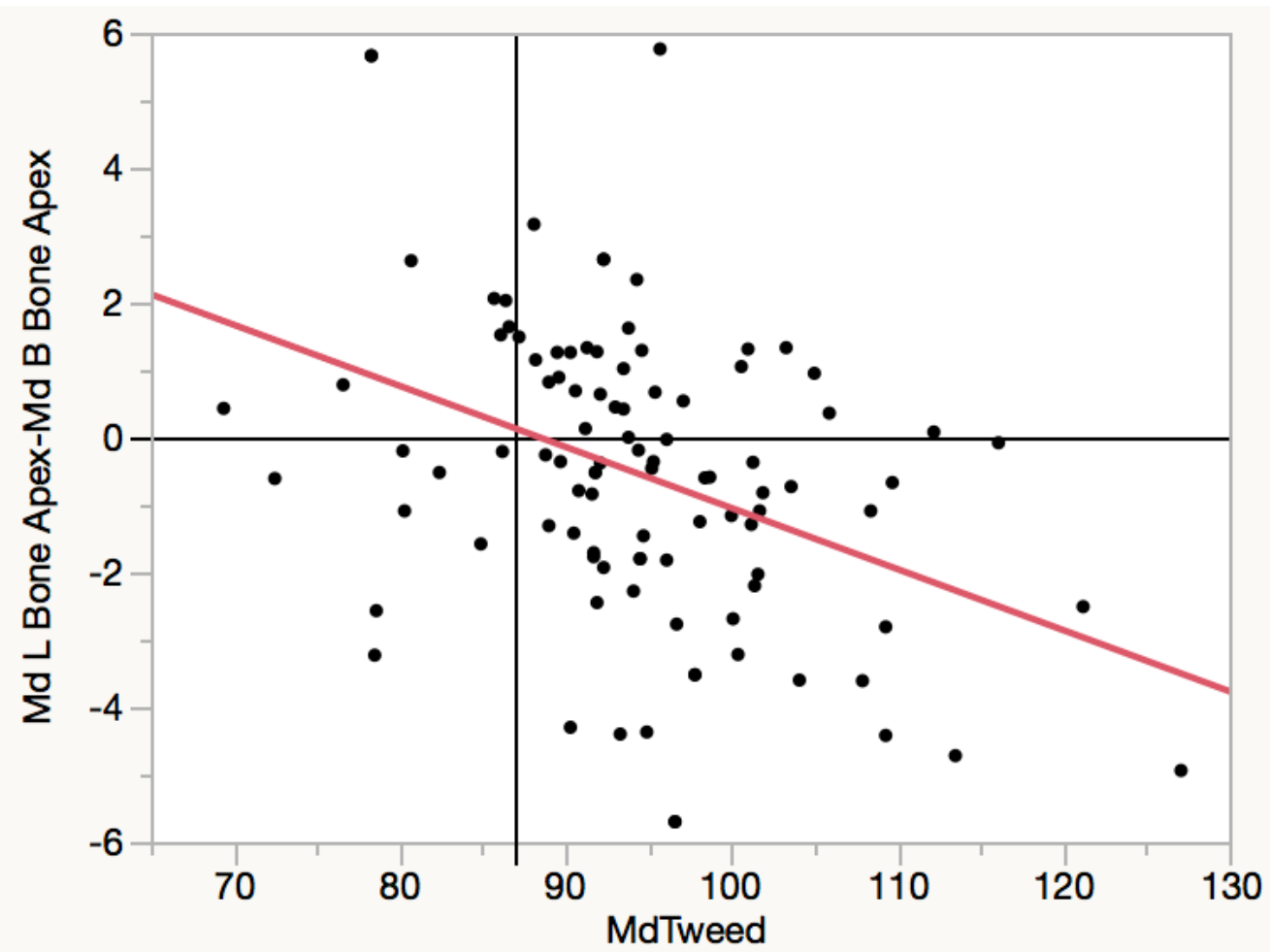

\section{Linear Fit}

Linear Fit

Md L Bone Apex-Md B Bone Apex = 8.0172622 - 0.0906251*MdTweed

Summary of Fit

RSquare

0.150285

RSquare Adj

0.141614

Root Mean Square Error

2.082622

Mean of Response

$-0.5428$

Observations (or Sum Wgts)

Analysis of Variance

$\begin{array}{lrrrr}\text { Source } & \text { DF } & \text { Sum of Squares } & \text { Mean Square } & \text { F Ratio } \\ \text { Model } & 1 & 75.17765 & 75.1777 & 17.3328 \\ \text { Error } & 98 & 425.05676 & 4.3373 & \text { Prob > F } \\ \text { C. Total } & 99 & 500.23442 & & <.0001^{*}\end{array}$


Parameter Estimates

$\begin{array}{lccrr}\text { Term } & \text { Estimate } & \text { Std Error } & \text { t Ratio } & \text { Prob>|t| } \\ \text { Intercept } & 8.0172622 & 2.066615 & 3.88 & 0.0002 * \\ \text { MdTweed } & -0.090625 & 0.021768 & -4.16 & <.0001 *\end{array}$

Bivariate Fit of Md L Bone Apex-Md B Bone Apex By MdAndrews

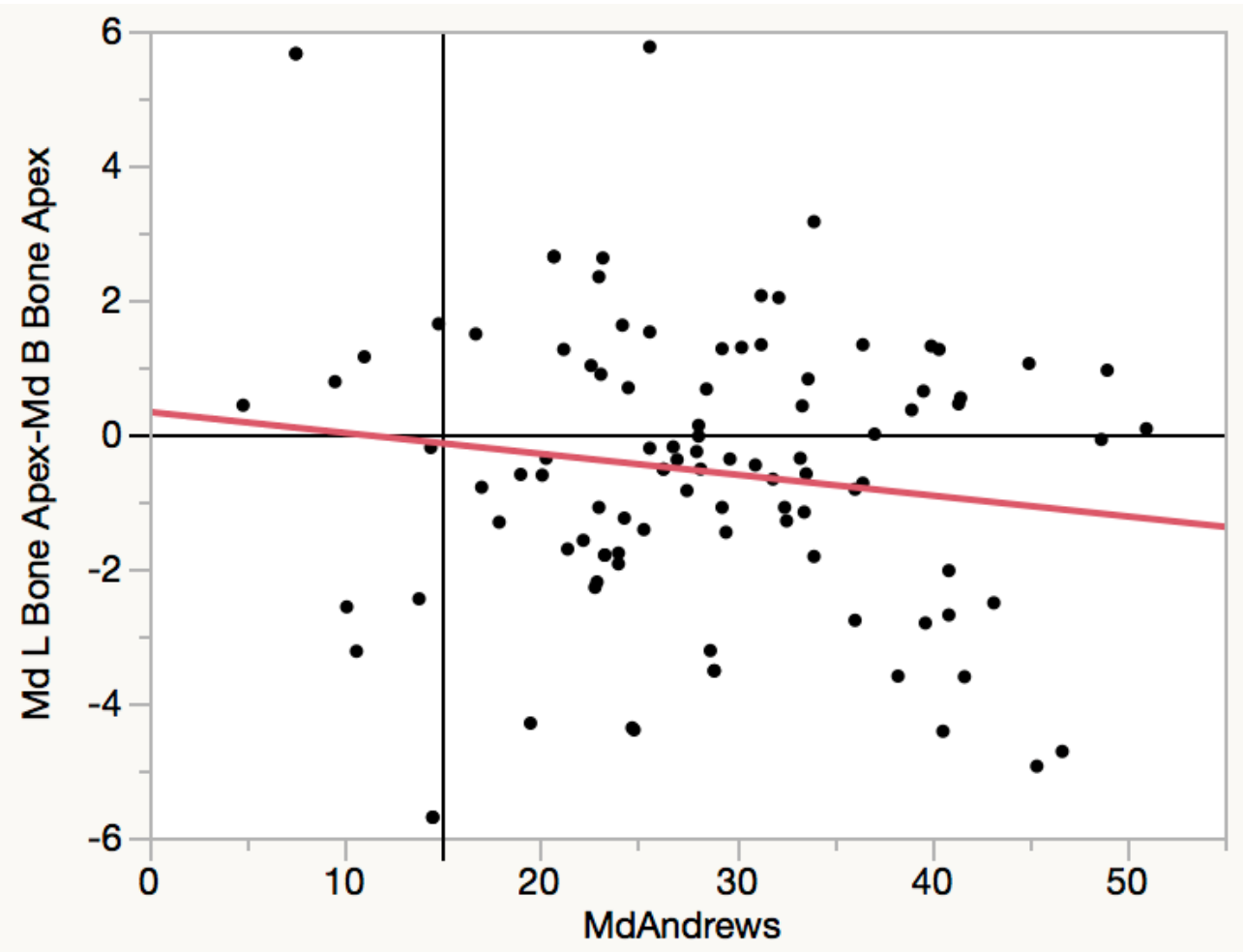

\section{Linear Fit}

Linear Fit

Md L Bone Apex-Md B Bone Apex = 0.3316233 - 0.0310906*MdAndrews

Summary of Fit

RSquare

0.01908

RSquare Adj

0.009071

Root Mean Square Error

2.237641

Mean of Response

$-0.5428$

Observations (or Sum Wgts)

100 
Analysis of Variance

$\begin{array}{lrrrr}\text { Source } & \text { DF } & \text { Sum of Squares } & \text { Mean Square } & \text { F Ratio } \\ \text { Model } & 1 & 9.54457 & 9.54457 & 1.9062 \\ \text { Error } & 98 & 490.68985 & 5.00704 & \text { Prob > F } \\ \text { C. Total } & 99 & 500.23442 & & 0.1705\end{array}$

Parameter Estimates

$\begin{array}{lrrrr}\text { Term } & \text { Estimate } & \text { Std Error } & \text { t Ratio } & \text { Prob }>|\mathbf{t}| \\ \text { Intercept } & 0.3316233 & 0.671703 & 0.49 & 0.6226 \\ \text { MdAndrews } & -0.031091 & 0.022519 & -1.38 & 0.1705\end{array}$

Bivariate Fit of Md L Bone Apex-Md B Bone Apex By MdRicketts

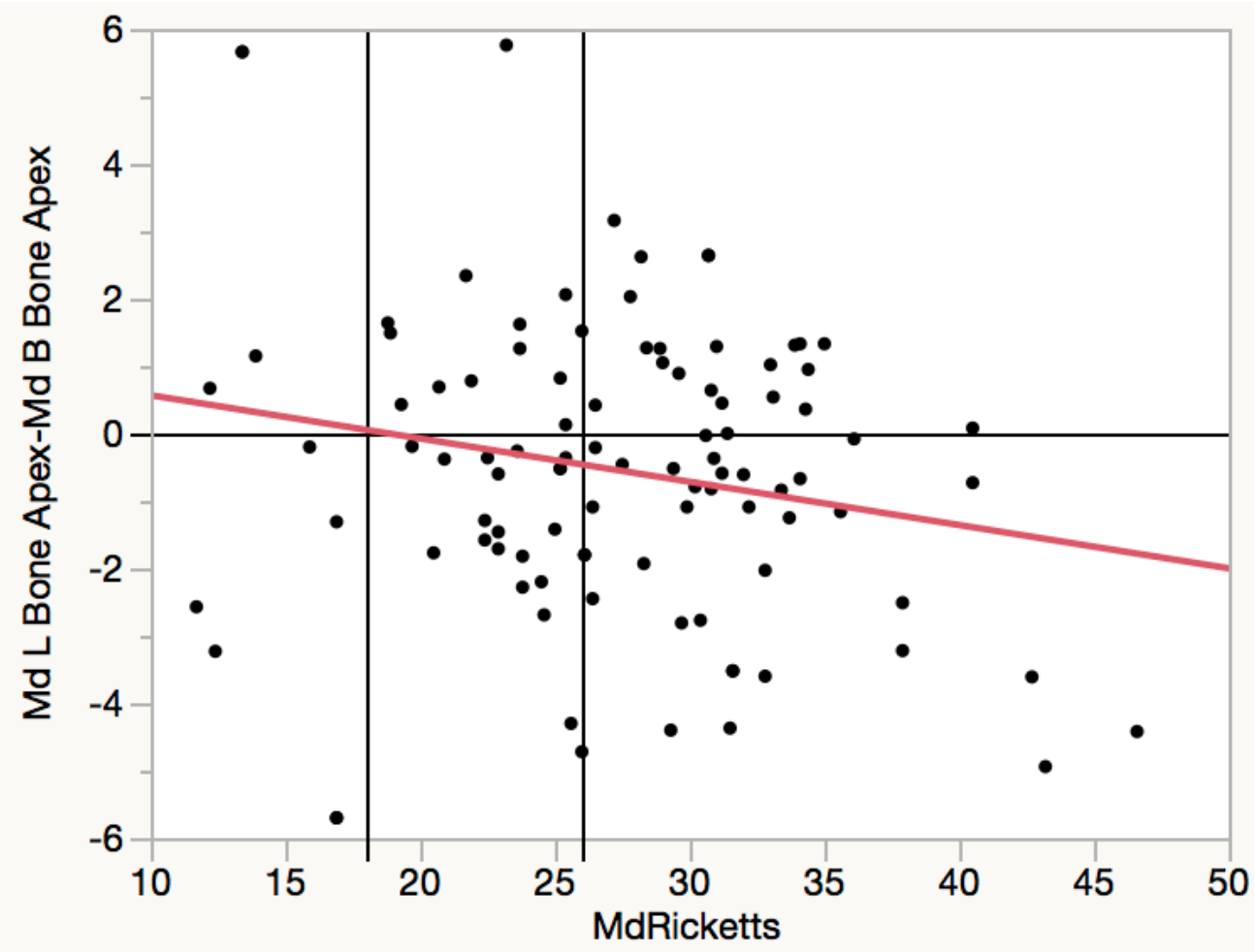

\section{Linear Fit}

Linear Fit

Md L Bone Apex-Md B Bone Apex = 1.2132097 - 0.0642544*MdRicketts

Summary of Fit

RSquare

0.039648

RSquare Adj

0.029848 
Root Mean Square Error

Mean of Response

Observations (or Sum Wgts)
2.214058

$-0.5428$

100

Analysis of Variance

$\begin{array}{lrrrr}\text { Source } & \text { DF } & \text { Sum of Squares } & \text { Mean Square } & \text { F Ratio } \\ \text { Model } & 1 & 19.83315 & 19.8332 & 4.0459 \\ \text { Error } & 98 & 480.40126 & 4.9021 & \text { Prob > F } \\ \text { C. Total } & 99 & 500.23442 & & 0.0470^{*}\end{array}$

Parameter Estimates

\begin{tabular}{|c|c|c|c|c|}
\hline Term & Estimate & Std Error & t Ratio & Prob $>|t|$ \\
\hline
\end{tabular}

Fit Group

Contingency Analysis of Md Dehiscences By Range Downs

Mosaic Plot

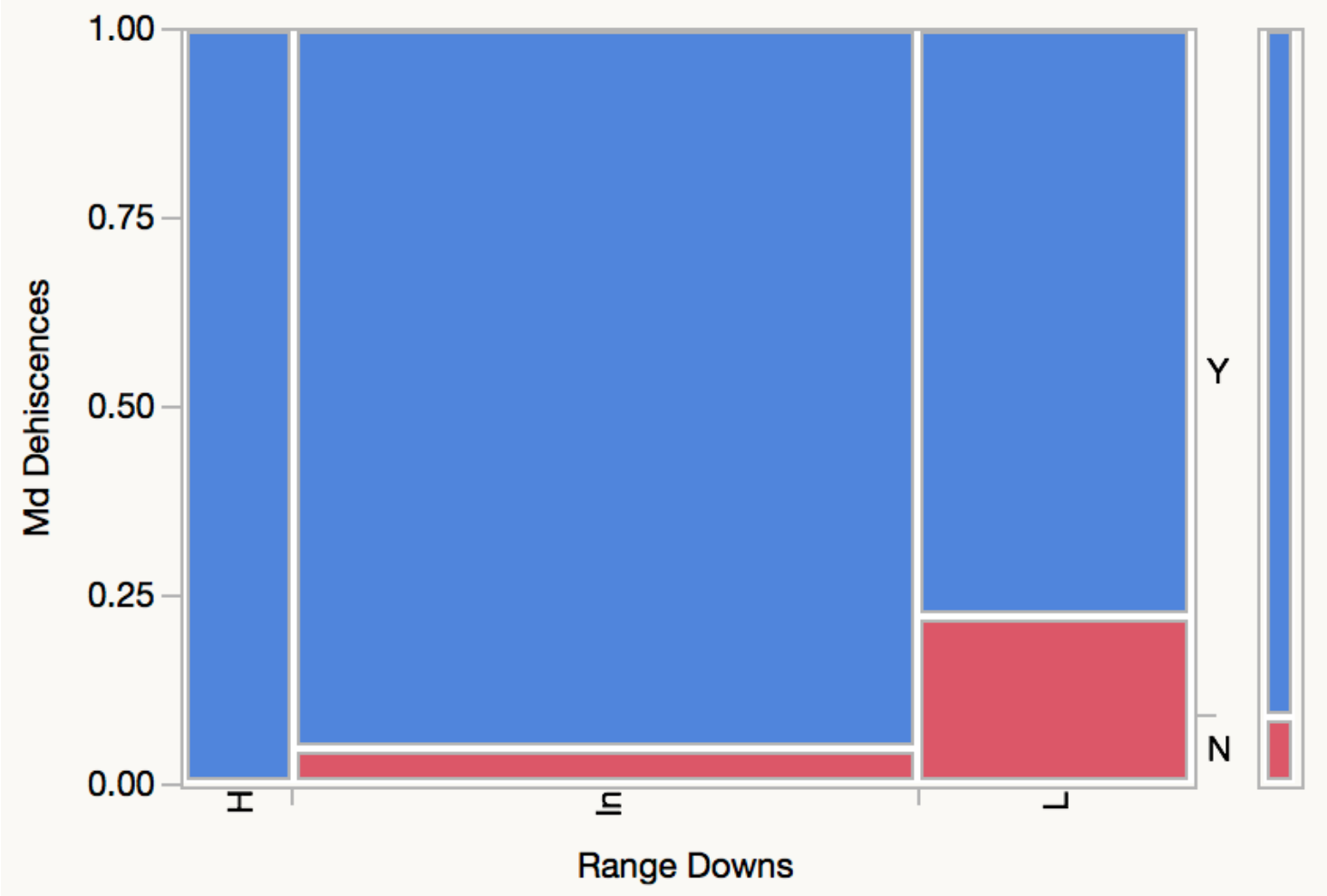




\section{Contingency Table}

Range Downs By Md Dehiscences

\begin{tabular}{|c|c|c|c|}
\hline $\begin{array}{l}\text { Count } \\
\text { Total \% } \\
\text { Col \% } \\
\text { Row \% }\end{array}$ & $\mathrm{N}$ & $\mathrm{Y}$ & Total \\
\hline $\mathrm{H}$ & $\begin{array}{r}0 \\
0.00 \\
0.00 \\
0.00\end{array}$ & $\begin{array}{r}11 \\
11.00 \\
12.09 \\
100.00\end{array}$ & $\begin{array}{r}11 \\
11.00\end{array}$ \\
\hline In & \begin{tabular}{r|}
3 \\
3.00 \\
33.33 \\
4.84
\end{tabular} & $\begin{array}{r}59 \\
59.00 \\
64.84 \\
95.16\end{array}$ & $\begin{array}{r}62 \\
62.00\end{array}$ \\
\hline $\mathrm{L}$ & \begin{tabular}{r|}
6 \\
6.00 \\
66.67 \\
22.22
\end{tabular} & $\begin{array}{r}21 \\
21.00 \\
23.08 \\
77.78\end{array}$ & $\begin{array}{r}27 \\
27.00\end{array}$ \\
\hline Total & $\begin{array}{r}9 \\
9.00\end{array}$ & $\begin{array}{r}91 \\
91.00\end{array}$ & 100 \\
\hline
\end{tabular}

Tests

\begin{tabular}{rrrr}
$\mathbf{N}$ & DF & -LogLike & RSquare (U) \\
\hline 100 & 2 & 3.9399291 & 0.1302
\end{tabular}

$\begin{array}{lrr}\text { Test } & \text { ChiSquare } & \text { Prob }>\text { ChiSq } \\ \text { Likelihood Ratio } & 7.880 & 0.0194^{*} \\ \text { Pearson } & 8.162 & 0.0169^{*}\end{array}$



Mosaic Plot

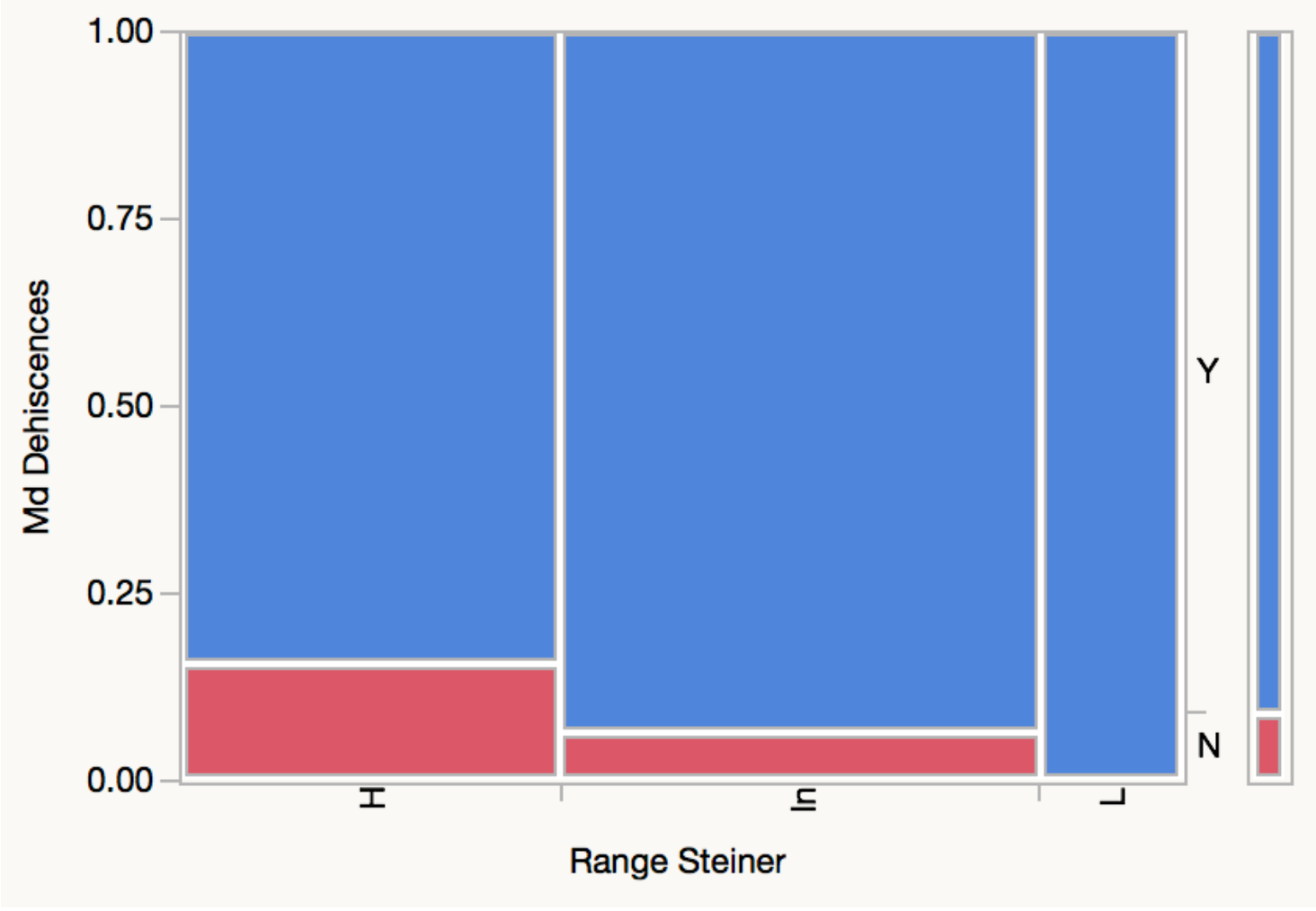

\section{Contingency Table}

Range Steiner By Md Dehiscences

\begin{tabular}{|c|c|c|c|}
\hline $\begin{array}{l}\text { Count } \\
\text { Total \% } \\
\text { Col \% } \\
\text { Row \% }\end{array}$ & $\mathrm{N}$ & $\mathrm{Y}$ & Total \\
\hline $\mathrm{H}$ & $\begin{array}{r}6 \\
6.00 \\
66.67 \\
15.79\end{array}$ & $\begin{array}{r}32 \\
32.00 \\
35.16 \\
84.21\end{array}$ & $\begin{array}{r}38 \\
38.00\end{array}$ \\
\hline In & $\begin{array}{r}3 \\
3.00 \\
33.33 \\
6.25\end{array}$ & $\begin{array}{r}45 \\
45.00 \\
49.45 \\
93.75\end{array}$ & $\begin{array}{r}48 \\
48.00\end{array}$ \\
\hline $\mathrm{L}$ & $\begin{array}{r}0 \\
0.00\end{array}$ & $\begin{array}{r}14 \\
14.00\end{array}$ & $\begin{array}{r}14 \\
14.00\end{array}$ \\
\hline
\end{tabular}




\begin{tabular}{|l|r|r|r|}
\hline & 0.00 & 15.38 & \\
& 0.00 & 100.00 & \\
\hline Total & 9 & 91 & 100 \\
& 9.00 & 91.00 & \\
\hline
\end{tabular}

\section{Tests}

$\begin{array}{rrrr}\mathbf{N} & \text { DF } & \text {-LogLike } & \text { RSquare (U) } \\ 100 & 2 & 2.4576143 & 0.0812\end{array}$

$\begin{array}{lrr}\text { Test } & \text { ChiSquare } & \text { Prob>ChiSq } \\ \text { Likelihood Ratio } & 4.915 & 0.0856 \\ \text { Pearson } & 3.967 & 0.1376\end{array}$

Warning: 20\% of cells have expected count less than 5, ChiSquare suspect. Contingency Analysis of Md Dehiscences By Range Tweed Mosaic Plot

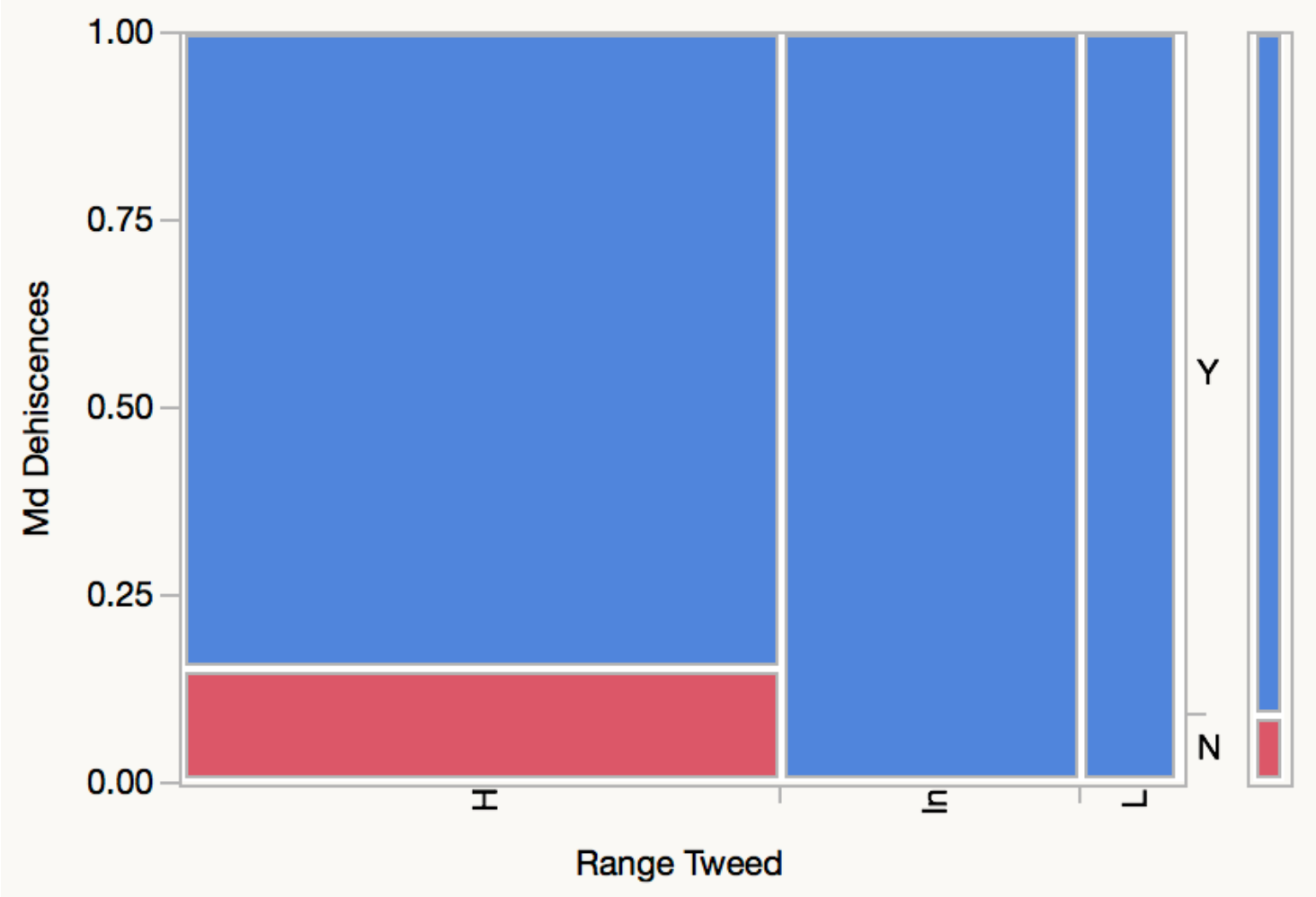

Contingency Table

Range Tweed By Md Dehiscences

\begin{tabular}{|l|l|l|l|}
\hline Count & $\mathrm{N}$ & $\mathrm{Y}$ & Total \\
\hline
\end{tabular}




\begin{tabular}{|c|c|c|c|}
\hline $\begin{array}{l}\text { Total \% } \\
\text { Col \% } \\
\text { Row \% }\end{array}$ & & & \\
\hline $\mathrm{H}$ & $\begin{array}{r}9 \\
9.00 \\
100.00 \\
15.00\end{array}$ & $\begin{array}{r}51 \\
51.00 \\
56.04 \\
85.00\end{array}$ & $\begin{array}{r}60 \\
60.00\end{array}$ \\
\hline In & $\begin{array}{r}0 \\
0.00 \\
0.00 \\
0.00\end{array}$ & $\begin{array}{r}30 \\
30.00 \\
32.97 \\
100.00\end{array}$ & $\begin{array}{r}30 \\
30.00\end{array}$ \\
\hline $\mathrm{L}$ & $\begin{array}{r}0 \\
0.00 \\
0.00 \\
0.00\end{array}$ & $\begin{array}{r}10 \\
10.00 \\
10.99 \\
100.00\end{array}$ & $\begin{array}{r}10 \\
10.00\end{array}$ \\
\hline Total & $\begin{array}{r}9 \\
9.00\end{array}$ & $\begin{array}{r}91 \\
91.00\end{array}$ & 100 \\
\hline
\end{tabular}

Tests

\begin{tabular}{rrrr}
$\mathbf{N}$ & DF & -LogLike & RSquare (U) \\
\hline 100 & 2 & 4.8912370 & 0.1617
\end{tabular}

\begin{tabular}{lrr} 
Test & ChiSquare & Prob>ChiSq \\
\hline Likelihood Ratio & 9.782 & $0.0075^{*}$ \\
Pearson & 6.593 & $0.0370^{*}$
\end{tabular}


Mosaic Plot

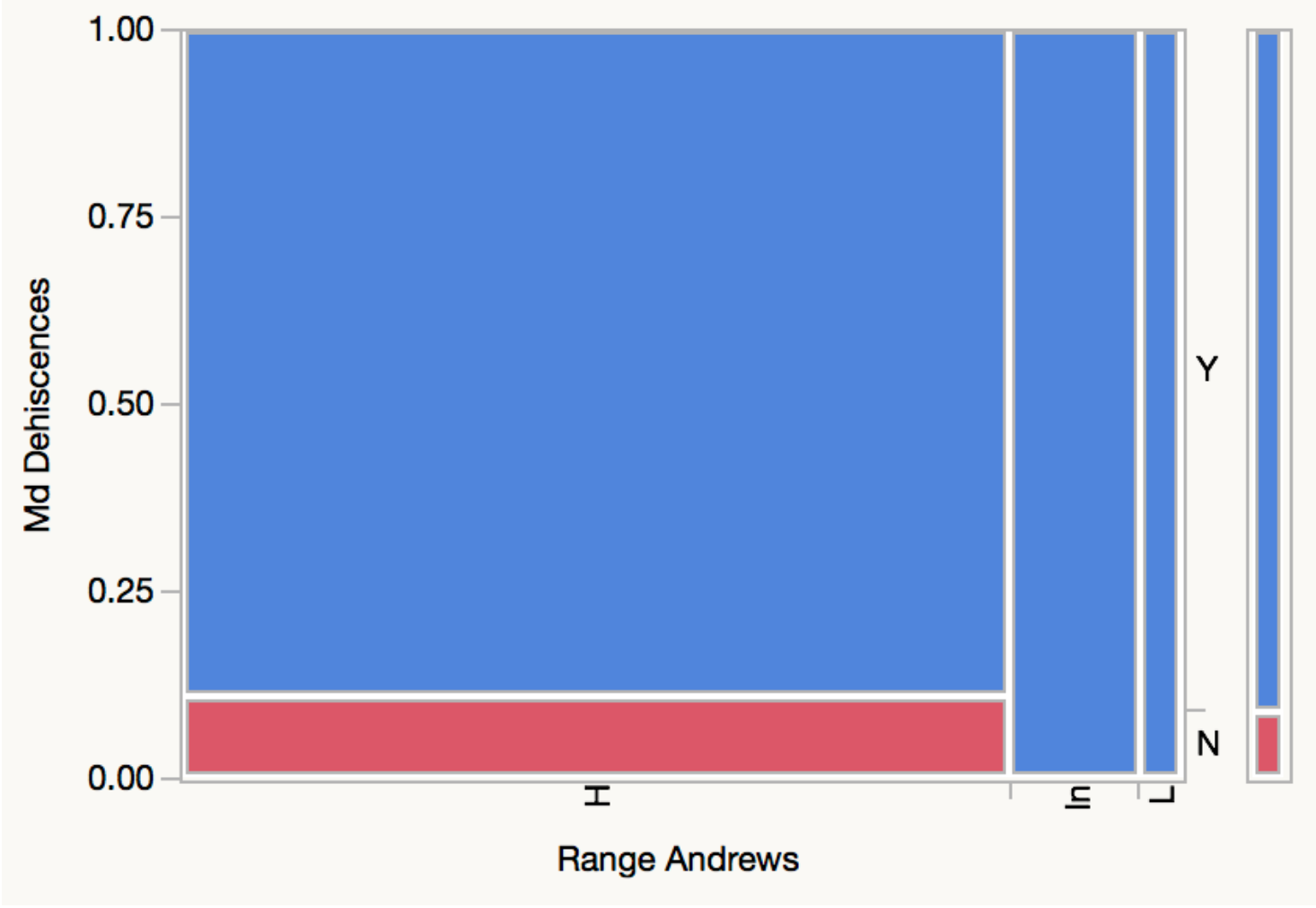

\section{Contingency Table}

Range Andrews By Md Dehiscences

\begin{tabular}{|c|c|c|c|}
\hline $\begin{array}{l}\text { Count } \\
\text { Total \% } \\
\text { Col \% } \\
\text { Row \% }\end{array}$ & $\mathrm{N}$ & $\mathrm{Y}$ & Total \\
\hline $\mathrm{H}$ & $\begin{array}{r}9 \\
9.00 \\
100.00 \\
10.84\end{array}$ & $\begin{array}{r}74 \\
74.00 \\
81.32 \\
89.16\end{array}$ & $\begin{array}{r}83 \\
83.00\end{array}$ \\
\hline In & $\begin{array}{r}0 \\
0.00 \\
0.00 \\
0.00\end{array}$ & $\begin{array}{r}13 \\
13.00 \\
14.29 \\
100.00\end{array}$ & $\begin{array}{r}13 \\
13.00\end{array}$ \\
\hline $\mathrm{L}$ & $\begin{array}{r}0 \\
0.00\end{array}$ & $\begin{array}{r}4 \\
4.00\end{array}$ & $\begin{array}{r}4 \\
4.00\end{array}$ \\
\hline
\end{tabular}




\begin{tabular}{|l|r|r|r|}
\hline & 0.00 & 4.40 & \\
& 0.00 & 100.00 & \\
\hline Total & 9 & 91 & 100 \\
& 9.00 & 91.00 & \\
\hline
\end{tabular}

\section{Tests}

$\begin{array}{rrrr}\mathbf{N} & \text { DF } & \text {-LogLike } & \text { RSquare (U) } \\ 100 & 2 & 1.7658500 & 0.0584\end{array}$

$\begin{array}{lrr}\text { Test } & \text { ChiSquare } & \text { Prob }>\text { ChiSq } \\ \text { Likelihood Ratio } & 3.532 & 0.1710 \\ \text { Pearson } & 2.026 & 0.3632\end{array}$

Warning: 20\% of cells have expected count less than 5, ChiSquare suspect. Contingency Analysis of Md Dehiscences By Range Ricketts Mosaic Plot

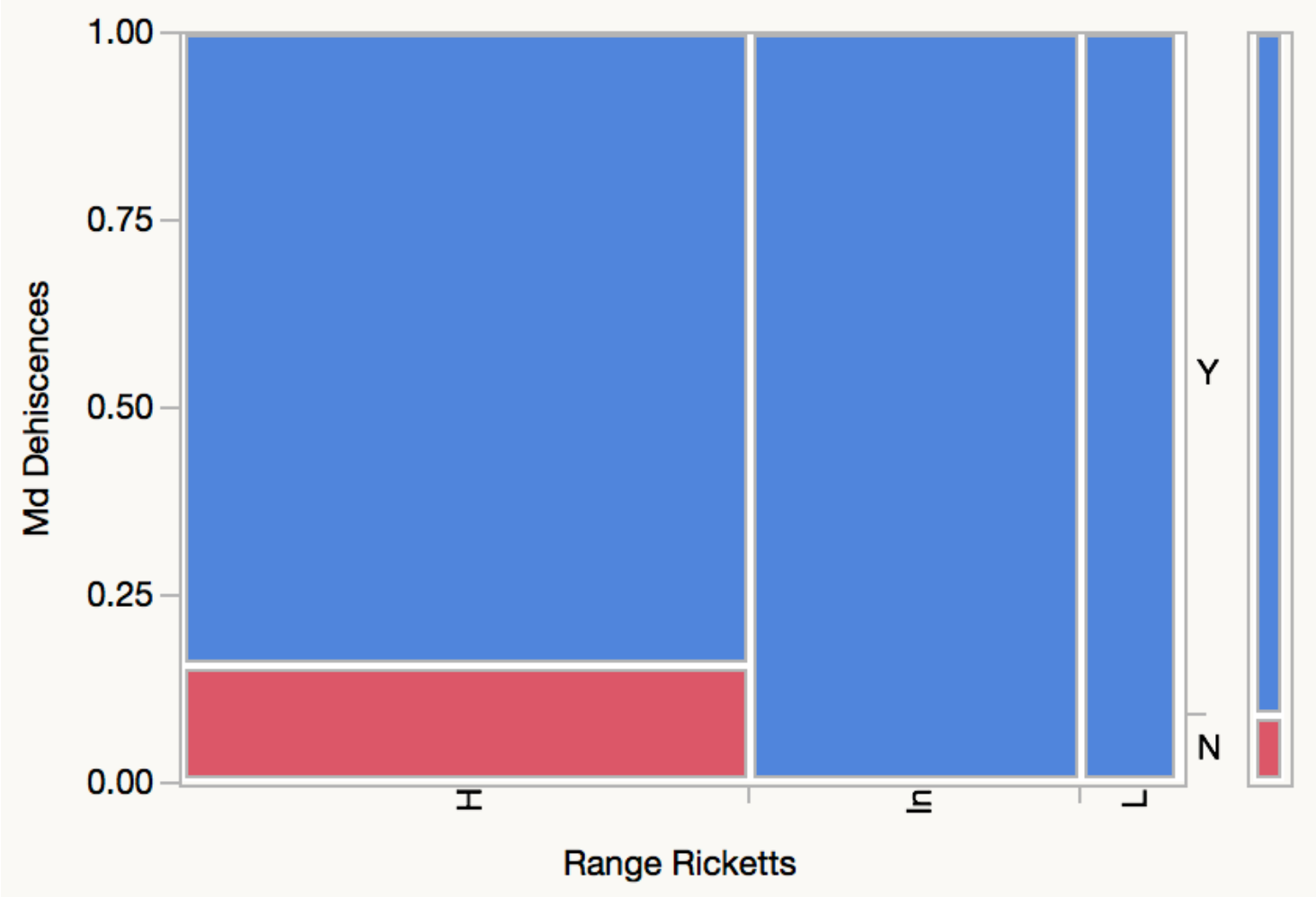

Contingency Table

Range Ricketts By Md Dehiscences

\begin{tabular}{|l|r|r|r|}
\hline Count & $\mathrm{N}$ & $\mathrm{Y}$ & Total \\
\hline
\end{tabular}




\begin{tabular}{|c|c|c|c|}
\hline $\begin{array}{l}\text { Total \% } \\
\text { Col \% } \\
\text { Row \% }\end{array}$ & & & \\
\hline $\mathrm{H}$ & $\begin{array}{r}9 \\
9.00 \\
100.00 \\
15.79\end{array}$ & $\begin{array}{r}48 \\
48.00 \\
52.75 \\
84.21\end{array}$ & $\begin{array}{r}57 \\
57.00\end{array}$ \\
\hline In & $\begin{array}{r}0 \\
0.00 \\
0.00 \\
0.00\end{array}$ & $\begin{array}{r}33 \\
33.00 \\
36.26 \\
100.00\end{array}$ & $\begin{array}{r}33 \\
33.00\end{array}$ \\
\hline $\mathrm{L}$ & $\begin{array}{r}0 \\
0.00 \\
0.00 \\
0.00\end{array}$ & $\begin{array}{r}10 \\
10.00 \\
10.99 \\
100.00\end{array}$ & $\begin{array}{r}10 \\
10.00\end{array}$ \\
\hline Total & $\begin{array}{r}9 \\
9.00\end{array}$ & $\begin{array}{r}91 \\
91.00\end{array}$ & 100 \\
\hline
\end{tabular}

Tests

\begin{tabular}{rrrr}
$\mathbf{N}$ & DF & -LogLike & RSquare (U) \\
\hline 100 & 2 & 5.3925298 & 0.1782
\end{tabular}

\begin{tabular}{lrr} 
Test & ChiSquare & Prob>ChiSq \\
\hline Likelihood Ratio & 10.785 & $0.0046^{*}$ \\
Pearson & 7.461 & $0.0240^{*}$
\end{tabular}

Warning: $20 \%$ of cells have expected count less than 5, ChiSquare suspect. 
Contingency Analysis of Md Dehiscences By Range ANB

Mosaic Plot

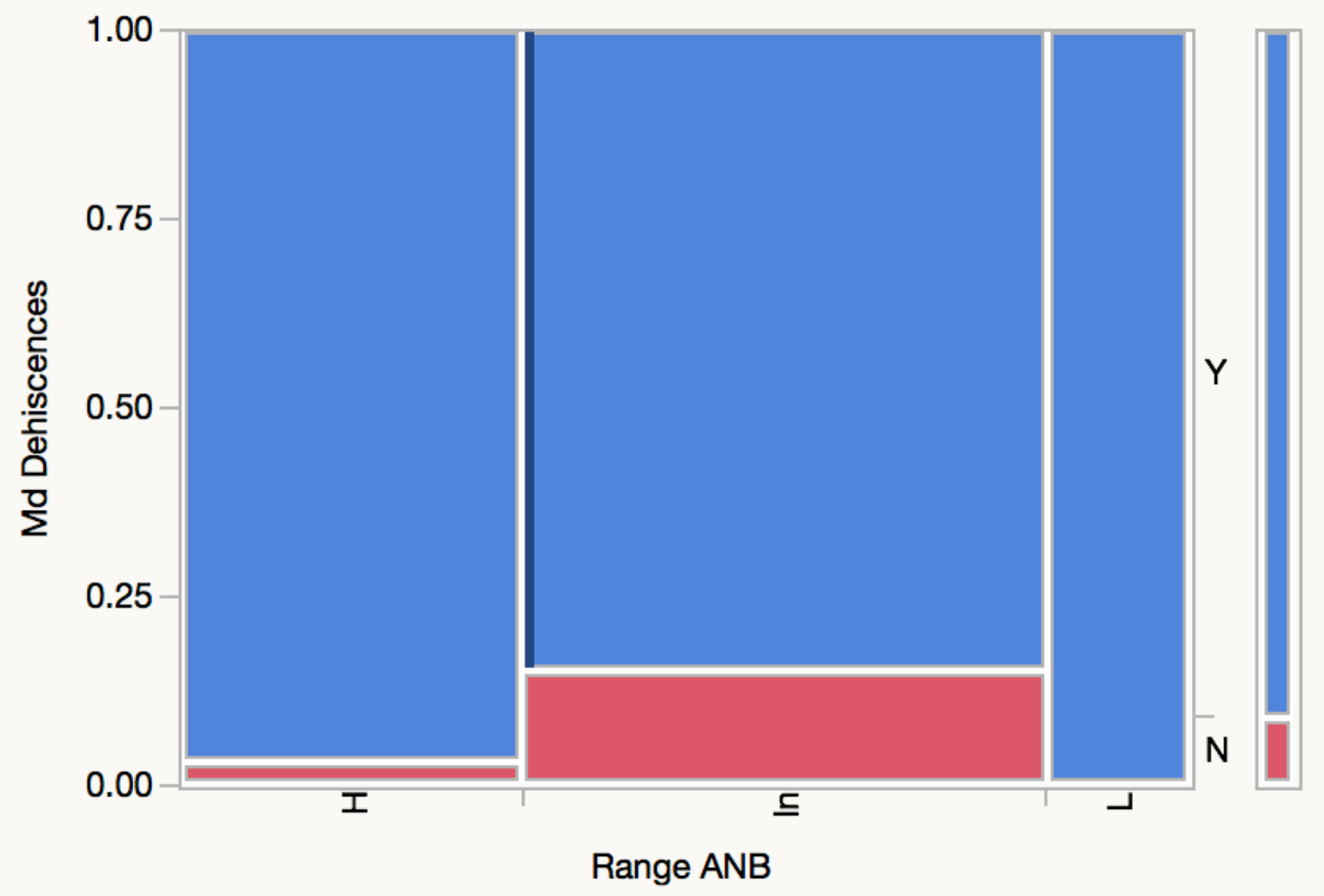

Contingency Table

Range ANB By Md Dehiscences

\begin{tabular}{|c|c|c|c|}
\hline $\begin{array}{l}\text { Count } \\
\text { Total \% } \\
\text { Col \% } \\
\text { Row \% }\end{array}$ & $\mathrm{N}$ & $\mathrm{Y}$ & Total \\
\hline $\mathrm{H}$ & $\begin{array}{r}1 \\
1.00 \\
11.11 \\
2.94\end{array}$ & $\begin{array}{r}33 \\
33.00 \\
36.26 \\
97.06\end{array}$ & $\begin{array}{r}34 \\
34.00\end{array}$ \\
\hline In & $\begin{array}{r}8 \\
8.00 \\
88.89 \\
15.38\end{array}$ & $\begin{array}{r}44 \\
44.00 \\
48.35 \\
84.62\end{array}$ & $\begin{array}{r}52 \\
52.00\end{array}$ \\
\hline $\mathrm{L}$ & $\begin{array}{r}0 \\
0.00\end{array}$ & $\begin{array}{r}14 \\
14.00\end{array}$ & $\begin{array}{r}14 \\
14.00\end{array}$ \\
\hline
\end{tabular}




\begin{tabular}{|l|r|r|r|}
\hline & 0.00 & 15.38 & \\
& 0.00 & 100.00 & \\
\hline Total & 9 & 91 & 100 \\
& 9.00 & 91.00 & \\
\hline
\end{tabular}

\section{Tests}

$\begin{array}{rrrr}\mathbf{N} & \text { DF } & \text {-LogLike } & \text { RSquare (U) } \\ 100 & 2 & 3.4174769 & 0.1130\end{array}$

$\begin{array}{lrr}\text { Test } & \text { ChiSquare } & \text { Prob>ChiSq } \\ \text { Likelihood Ratio } & 6.835 & 0.0328^{*} \\ \text { Pearson } & 5.497 & 0.0640\end{array}$

Warning: 20\% of cells have expected count less than 5, ChiSquare suspect.

Fit Group

Contingency Analysis of Range Downs By Range ANB

Mosaic Plot 


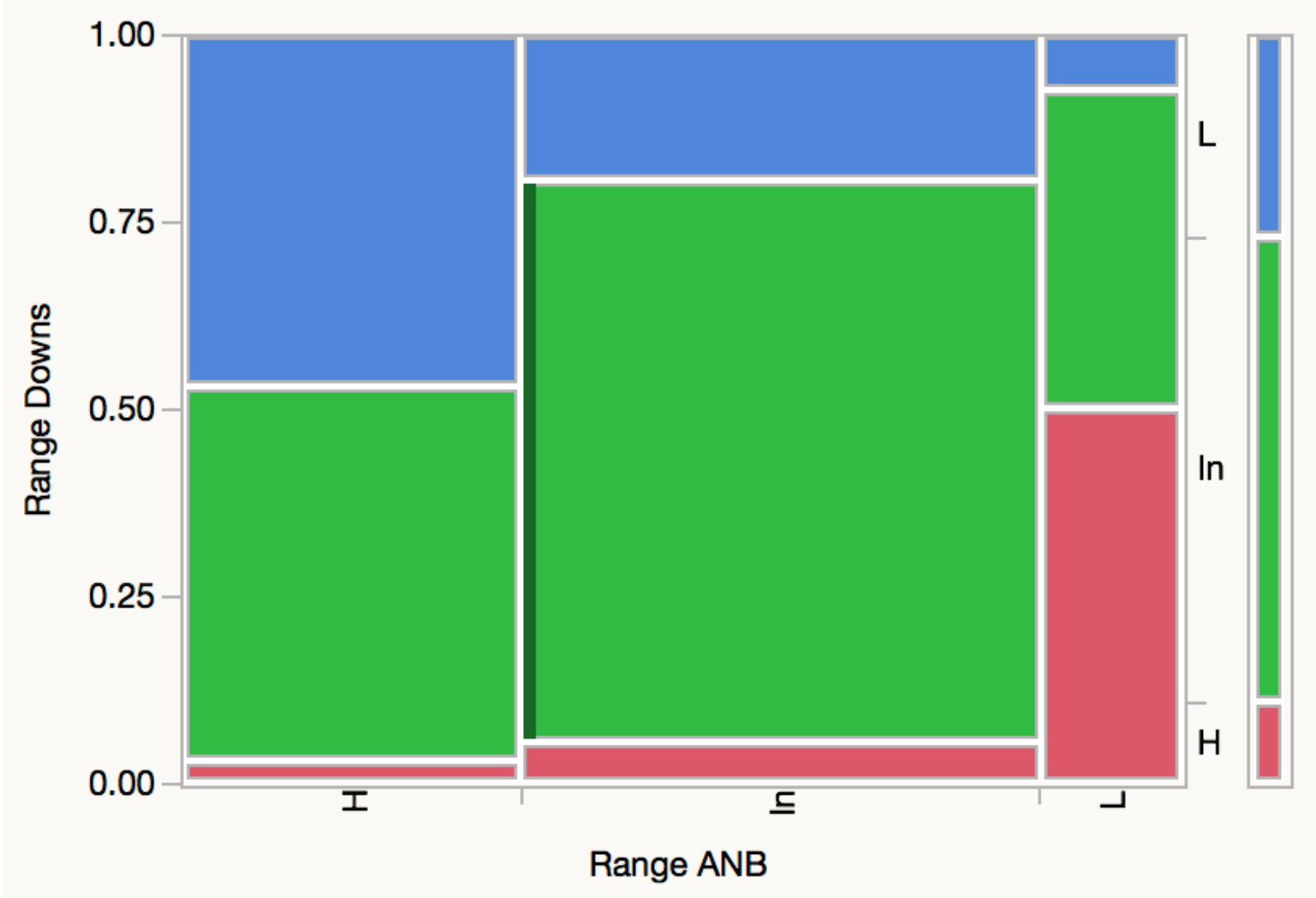

Contingency Table

Range ANB By Range Downs

\begin{tabular}{|c|c|c|c|c|}
\hline \begin{tabular}{|l} 
Count \\
Total \% \\
Col \% \\
Row \%
\end{tabular} & $\mathrm{H}$ & $\mathrm{In}$ & $\mathrm{L}$ & Total \\
\hline $\mathrm{H}$ & $\begin{array}{r}1 \\
1.00 \\
9.09 \\
2.94\end{array}$ & $\begin{array}{r}17 \\
17.00 \\
27.42 \\
50.00\end{array}$ & $\begin{array}{r}16 \\
16.00 \\
59.26 \\
47.06\end{array}$ & $\begin{array}{r}34 \\
34.00\end{array}$ \\
\hline In & $\begin{array}{r}3 \\
3.00 \\
27.27 \\
5.77\end{array}$ & $\begin{array}{r}39 \\
39.00 \\
62.90 \\
75.00\end{array}$ & $\begin{array}{r}10 \\
10.00 \\
37.04 \\
19.23\end{array}$ & $\begin{array}{r}52 \\
52.00\end{array}$ \\
\hline $\mathrm{L}$ & 7.00 & $\begin{array}{r}6 \\
6.00\end{array}$ & 1 & $\begin{array}{r}14 \\
14.00\end{array}$ \\
\hline
\end{tabular}




\begin{tabular}{|l|r|r|r|r|}
\hline & 63.64 & 9.68 & 3.70 & \\
& 50.00 & 42.86 & 7.14 & \\
\hline Total & 11 & 62 & 27 & 100 \\
& 11.00 & 62.00 & 27.00 & \\
\hline
\end{tabular}

Tests

\begin{tabular}{rrrr}
$\mathbf{N}$ & DF & -LogLike & RSquare (U) \\
\hline 100 & 4 & 13.061076 & 0.1463
\end{tabular}

$\begin{array}{lrr}\text { Test } & \text { ChiSquare } & \text { Prob }>\text { ChiSq } \\ \text { Likelihood Ratio } & 26.122 & <.0001^{*} \\ \text { Pearson } & 33.967 & <.0001^{*}\end{array}$

Warning: 20\% of cells have expected count less than 5, ChiSquare suspect.

Contingency Analysis of Range Steiner By Range ANB

Mosaic Plot 


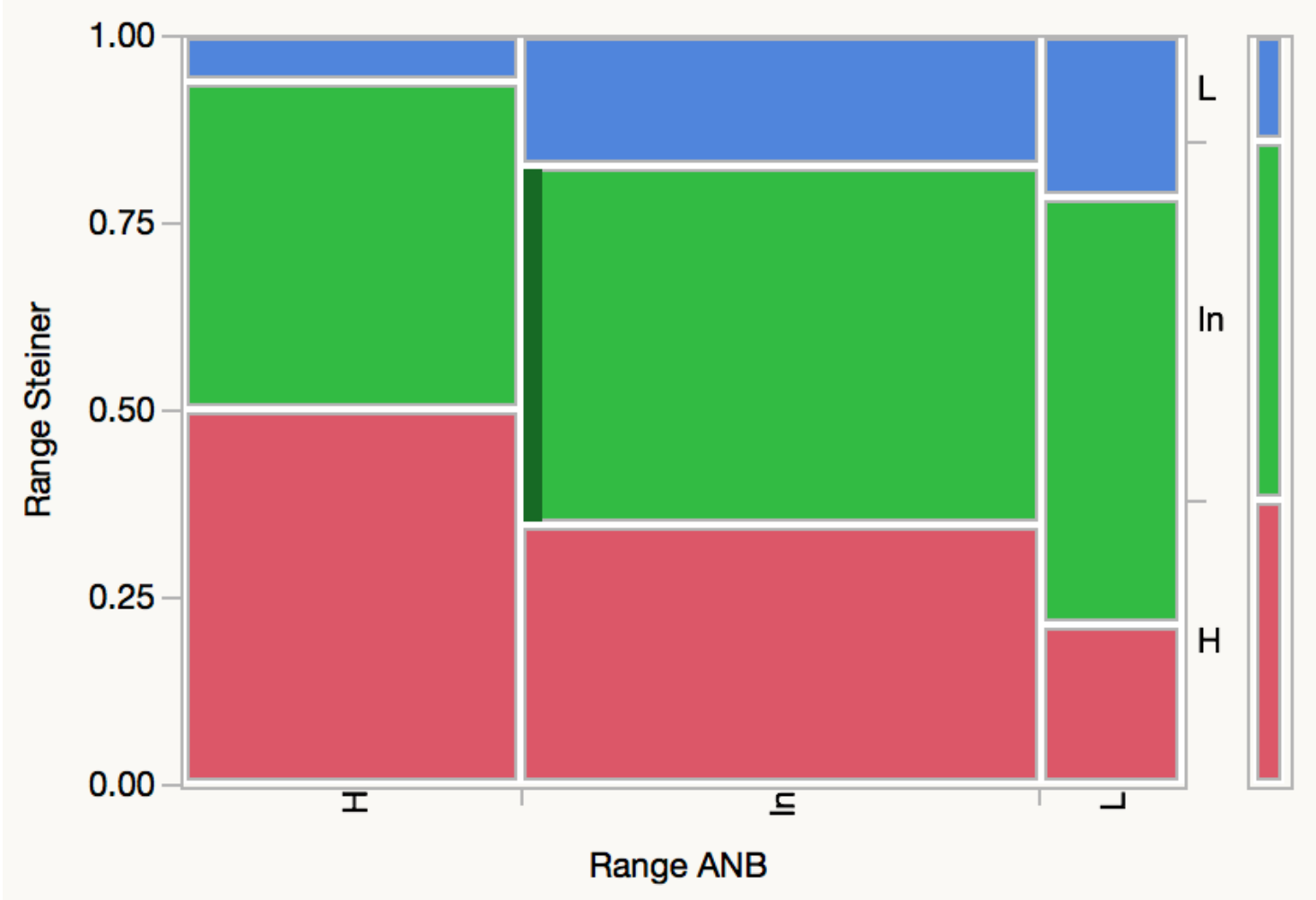

Contingency Table

Range ANB By Range Steiner

\begin{tabular}{|c|c|c|c|c|}
\hline $\begin{array}{l}\text { Count } \\
\text { Total \% } \\
\text { Col \% } \\
\text { Row \% }\end{array}$ & $\begin{array}{ll}\mathrm{H} \\
\end{array}$ & $\mathrm{In}$ & $\mathrm{L}$ & Total \\
\hline $\mathrm{H}$ & $\begin{array}{r}17 \\
17.00 \\
44.74 \\
50.00\end{array}$ & $\begin{array}{r}15 \\
15.00 \\
31.25 \\
44.12\end{array}$ & $\begin{array}{r}2 \\
2.00 \\
14.29 \\
5.88\end{array}$ & $\begin{array}{r}34 \\
34.00\end{array}$ \\
\hline In & $\begin{array}{r}18 \\
18.00 \\
47.37 \\
34.62\end{array}$ & $\begin{array}{r}25 \\
25.00 \\
52.08 \\
48.08\end{array}$ & $\begin{array}{r}9 \\
9.00 \\
64.29 \\
17.31\end{array}$ & $\begin{array}{r}52 \\
52.00\end{array}$ \\
\hline $\mathrm{L}$ & 3.00 & 8 & $\begin{array}{r}3 \\
3.00 \\
\end{array}$ & $\begin{array}{r}14 \\
14.00\end{array}$ \\
\hline
\end{tabular}




\begin{tabular}{|l|r|r|r|r|}
\hline & 7.89 & 16.67 & 21.43 & \\
& 21.43 & 57.14 & 21.43 & \\
\hline Total & 38 & 48 & 14 & 100 \\
& 38.00 & 48.00 & 14.00 & \\
\hline
\end{tabular}

Tests

\begin{tabular}{rrrr}
$\mathbf{N}$ & DF & -LogLike & RSquare (U) \\
\hline 100 & 4 & 2.8890483 & 0.0290
\end{tabular}

$\begin{array}{lrr}\text { Test } & \text { ChiSquare } & \text { Prob>ChiSq } \\ \text { Likelihood Ratio } & 5.778 & 0.2163 \\ \text { Pearson } & 5.366 & 0.2518\end{array}$

Warning: $20 \%$ of cells have expected count less than 5, ChiSquare suspect.

Contingency Analysis of Range Tweed By Range ANB

Mosaic Plot 


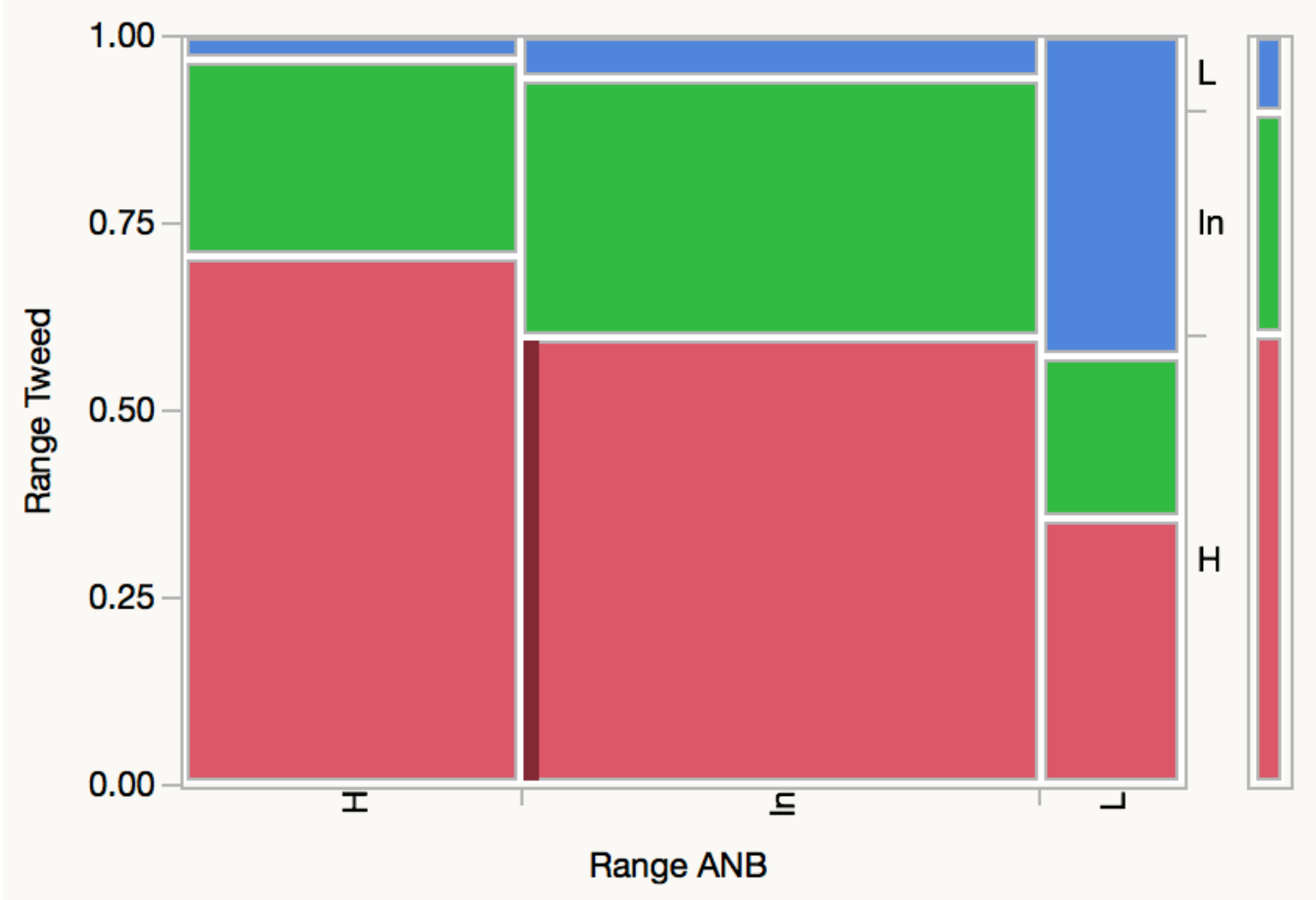

Contingency Table

Range ANB By Range Tweed

\begin{tabular}{|c|c|c|c|c|}
\hline \begin{tabular}{|l} 
Count \\
Total \% \\
Col \% \\
Row \%
\end{tabular} & $\mathrm{H}$ & In & $\mathrm{L}$ & Total \\
\hline $\mathrm{H}$ & $\begin{array}{r}24 \\
24.00 \\
40.00 \\
70.59\end{array}$ & $\begin{array}{r}9 \\
9.00 \\
30.00 \\
26.47\end{array}$ & $\begin{array}{r}1 \\
1.00 \\
10.00 \\
2.94\end{array}$ & $\begin{array}{r}34 \\
34.00\end{array}$ \\
\hline In & $\begin{array}{r}31 \\
31.00 \\
51.67 \\
59.62\end{array}$ & $\begin{array}{r}18 \\
18.00 \\
60.00 \\
34.62\end{array}$ & $\begin{array}{r}3 \\
3.00 \\
30.00 \\
5.77\end{array}$ & $\begin{array}{r}52 \\
52.00\end{array}$ \\
\hline $\mathrm{L}$ & 5 & 3 & 6 & $\begin{array}{r}14 \\
14.00\end{array}$ \\
\hline
\end{tabular}




\begin{tabular}{|l|r|r|r|r|}
\hline & 8.33 & 10.00 & 60.00 & \\
& 35.71 & 21.43 & 42.86 & \\
\hline Total & 60 & 30 & 10 & 100 \\
& 60.00 & 30.00 & 10.00 & \\
\hline
\end{tabular}

Tests

$\begin{array}{rrrr}\mathbf{N} & \text { DF } & \text {-LogLike } & \text { RSquare (U) } \\ 100 & 4 & 7.4048669 & 0.0825\end{array}$

$\begin{array}{lrr}\text { Test } & \text { ChiSquare } & \text { Prob>ChiSq } \\ \text { Likelihood Ratio } & 14.810 & 0.0051^{*} \\ \text { Pearson } & 20.605 & 0.0004^{*}\end{array}$

Warning: $20 \%$ of cells have expected count less than 5, ChiSquare suspect.

Contingency Analysis of Range Andrews By Range ANB

Mosaic Plot 


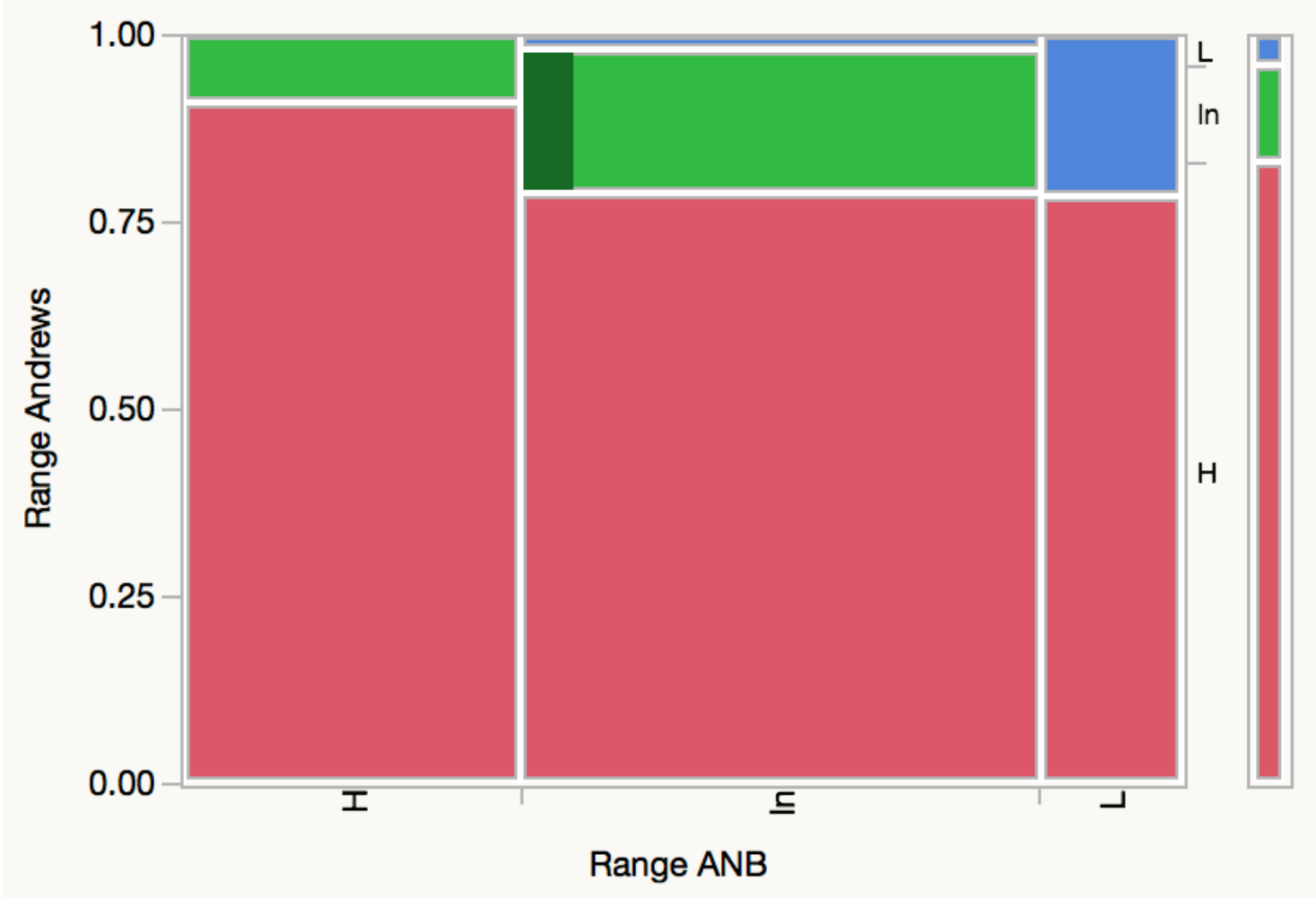

Contingency Table

Range ANB By Range Andrews

\begin{tabular}{|c|c|c|c|c|}
\hline $\begin{array}{l}\text { Count } \\
\text { Total \% } \\
\text { Col \% } \\
\text { Row \% }\end{array}$ & $\mathrm{H}$ & $\mathrm{In}$ & $\mathrm{L}$ & Total \\
\hline $\mathrm{H}$ & $\begin{array}{r}31 \\
31.00 \\
37.35 \\
91.18\end{array}$ & $\begin{array}{r}3 \\
3.00 \\
23.08 \\
8.82\end{array}$ & $\begin{array}{r}0 \\
0.00 \\
0.00 \\
0.00\end{array}$ & $\begin{array}{r}34 \\
34.00\end{array}$ \\
\hline In & $\begin{array}{r}41 \\
41.00 \\
49.40 \\
78.85\end{array}$ & $\begin{array}{r}10 \\
10.00 \\
76.92 \\
19.23\end{array}$ & $\begin{array}{r}1 \\
1.00 \\
25.00 \\
1.92\end{array}$ & $\begin{array}{r}52 \\
52.00\end{array}$ \\
\hline $\mathrm{L}$ & $\begin{array}{r}11 \\
11.00\end{array}$ & $\begin{array}{r}0 \\
0.00\end{array}$ & $\begin{array}{r}3 \\
3.00 \\
\end{array}$ & $\begin{array}{r}14 \\
14.00\end{array}$ \\
\hline
\end{tabular}




\begin{tabular}{|l|r|r|r|r|}
\hline & 13.25 & 0.00 & 75.00 & \\
& 78.57 & 0.00 & 21.43 & \\
\hline Total & 83 & 13 & 4 & 100 \\
& 83.00 & 13.00 & 4.00 & \\
\hline
\end{tabular}

Tests

\begin{tabular}{rrrr}
$\mathbf{N}$ & DF & -LogLike & RSquare (U) \\
\hline 100 & 4 & 7.2604260 & 0.1323
\end{tabular}

$\begin{array}{lrr}\text { Test } & \text { ChiSquare } & \text { Prob>ChiSq } \\ \text { Likelihood Ratio } & 14.521 & 0.0058^{*} \\ \text { Pearson } & 16.796 & 0.0021^{*}\end{array}$

Warning: $20 \%$ of cells have expected count less than 5, ChiSquare suspect.

Contingency Analysis of Range Ricketts By Range ANB

Mosaic Plot 


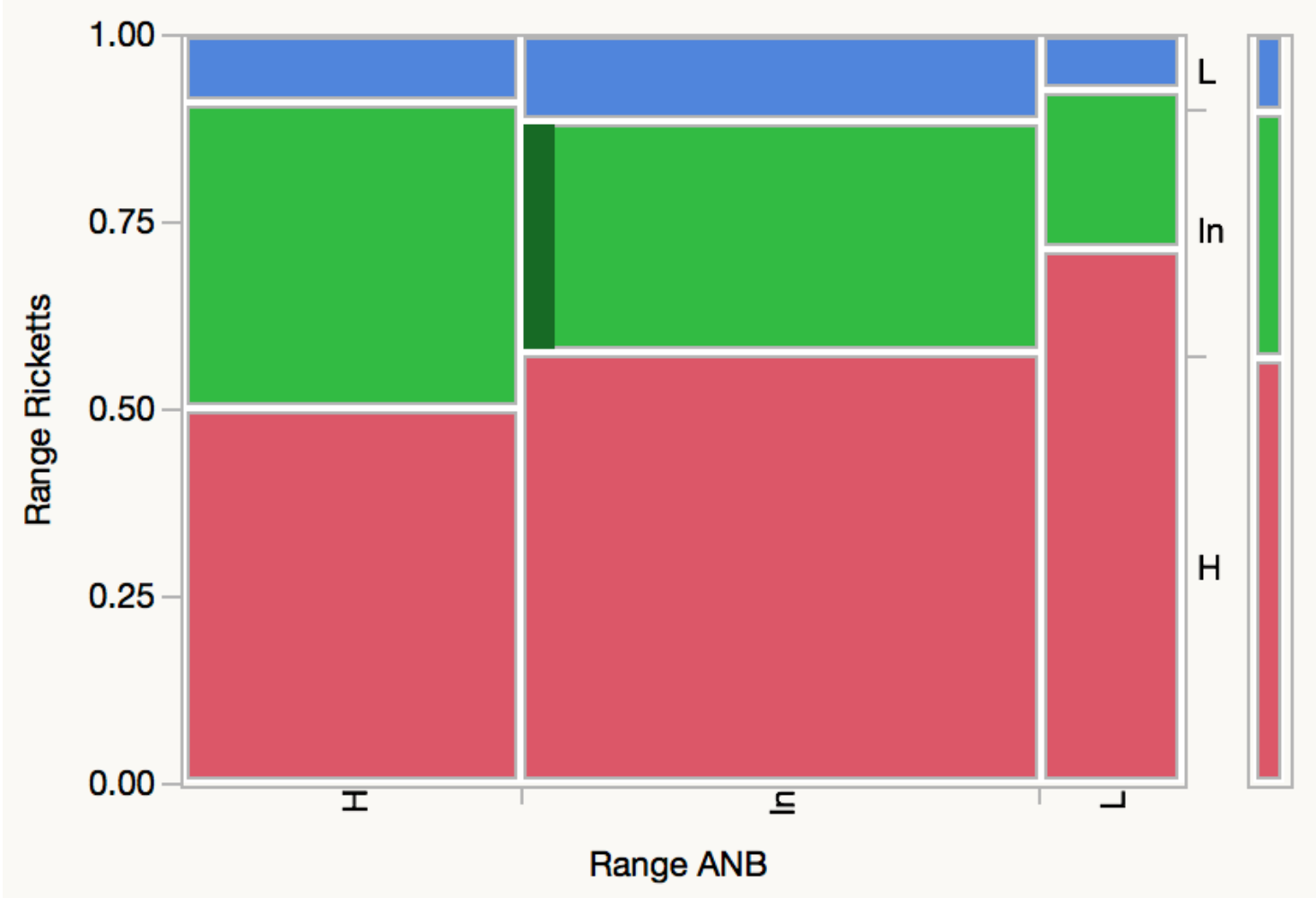

Contingency Table

Range ANB By Range Ricketts

\begin{tabular}{|c|c|c|c|c|}
\hline \begin{tabular}{|l} 
Count \\
Total \% \\
Col \% \\
Row \%
\end{tabular} & $\mathrm{H}$ & In & $\mathrm{L}$ & Total \\
\hline $\mathrm{H}$ & $\begin{array}{r}17 \\
17.00 \\
29.82 \\
50.00\end{array}$ & $\begin{array}{r}14 \\
14.00 \\
42.42 \\
41.18\end{array}$ & $\begin{array}{r}3 \\
3.00 \\
30.00 \\
8.82\end{array}$ & $\begin{array}{r}34 \\
34.00\end{array}$ \\
\hline In & $\begin{array}{r}30 \\
30.00 \\
52.63 \\
57.69\end{array}$ & $\begin{array}{r}16 \\
16.00 \\
48.48 \\
30.77\end{array}$ & $\begin{array}{r}6 \\
6.00 \\
60.00 \\
11.54\end{array}$ & $\begin{array}{r}52 \\
52.00\end{array}$ \\
\hline $\mathrm{L}$ & $\begin{array}{r}10 \\
10.00\end{array}$ & 3 & 1 & $\begin{array}{r}14 \\
14.00\end{array}$ \\
\hline
\end{tabular}




\begin{tabular}{|l|r|r|r|r|}
\hline & 17.54 & 9.09 & 10.00 & \\
& 71.43 & 21.43 & 7.14 & \\
\hline Total & 57 & 33 & 10 & 100 \\
& 57.00 & 33.00 & 10.00 & \\
\hline
\end{tabular}

Tests

$\begin{array}{rrrr}\mathbf{N} & \text { DF } & \text {-LogLike } & \text { RSquare (U) } \\ 100 & 4 & 1.2216140 & 0.0133\end{array}$

$\begin{array}{lrr}\text { Test } & \text { ChiSquare } & \text { Prob }>\text { ChiSq } \\ \text { Likelihood Ratio } & 2.443 & 0.6548 \\ \text { Pearson } & 2.428 & 0.6576\end{array}$

Warning: $20 \%$ of cells have expected count less than 5, ChiSquare suspect.

Contingency Analysis of Md Dehiscences By Range \% lower

Mosaic Plot

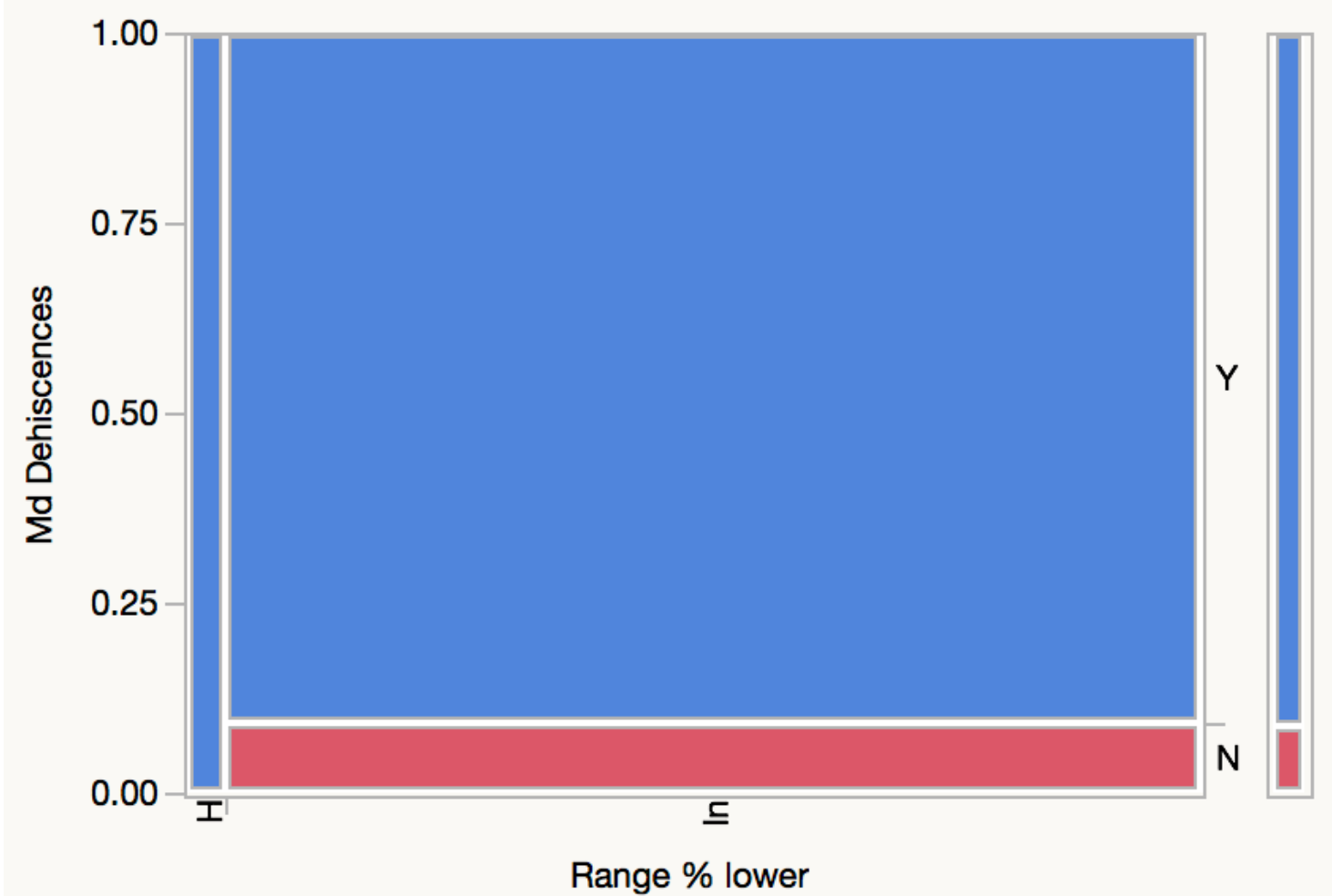




\section{Contingency Table}

Range \% lower By Md Dehiscences

\begin{tabular}{|c|c|c|c|}
\hline $\begin{array}{l}\text { Count } \\
\text { Total \% } \\
\text { Col \% } \\
\text { Row \% }\end{array}$ & $\mathrm{N}$ & $\mathrm{Y}$ & Total \\
\hline $\mathrm{H}$ & $\begin{array}{r}0 \\
0.00 \\
0.00 \\
0.00\end{array}$ & $\begin{array}{r}4 \\
4.00 \\
4.40 \\
100.00\end{array}$ & $\begin{array}{r}4 \\
4.00\end{array}$ \\
\hline In & $\begin{array}{r}9 \\
9.00 \\
100.00 \\
9.38\end{array}$ & $\begin{array}{r}87 \\
87.00 \\
95.60 \\
90.63\end{array}$ & $\begin{array}{r}96 \\
96.00\end{array}$ \\
\hline Total & $\begin{array}{r}9 \\
9.00\end{array}$ & $\begin{array}{r}91 \\
91.00\end{array}$ & 100 \\
\hline
\end{tabular}

Tests

\begin{tabular}{rrrr}
$\mathbf{N}$ & DF & -LogLike & RSquare (U) \\
\hline 100 & 1 & 0.38538345 & 0.0127
\end{tabular}

$\begin{array}{lrr}\text { Test } & \text { ChiSquare } & \text { Prob>ChiSq } \\ \text { Likelihood Ratio } & 0.771 & 0.3800 \\ \text { Pearson } & 0.412 & 0.5209\end{array}$

Fisher's Exact Test

Left

Right

2-Tail
Prob Alternative Hypothesis

0.6816 Prob(Md Dehiscences=Y) is greater for Range \% lower=H than In

$1.0000 \operatorname{Prob}(\mathrm{Md}$ Dehiscences=Y) is greater for Range \% lower=In than $\mathrm{H}$

1.0000 Prob(Md Dehiscences=Y) is different across Range \% lower 
Bivariate Fit of $2 \mathrm{mx}$ CR/mx lingual CR By Mx Steiner (NA)

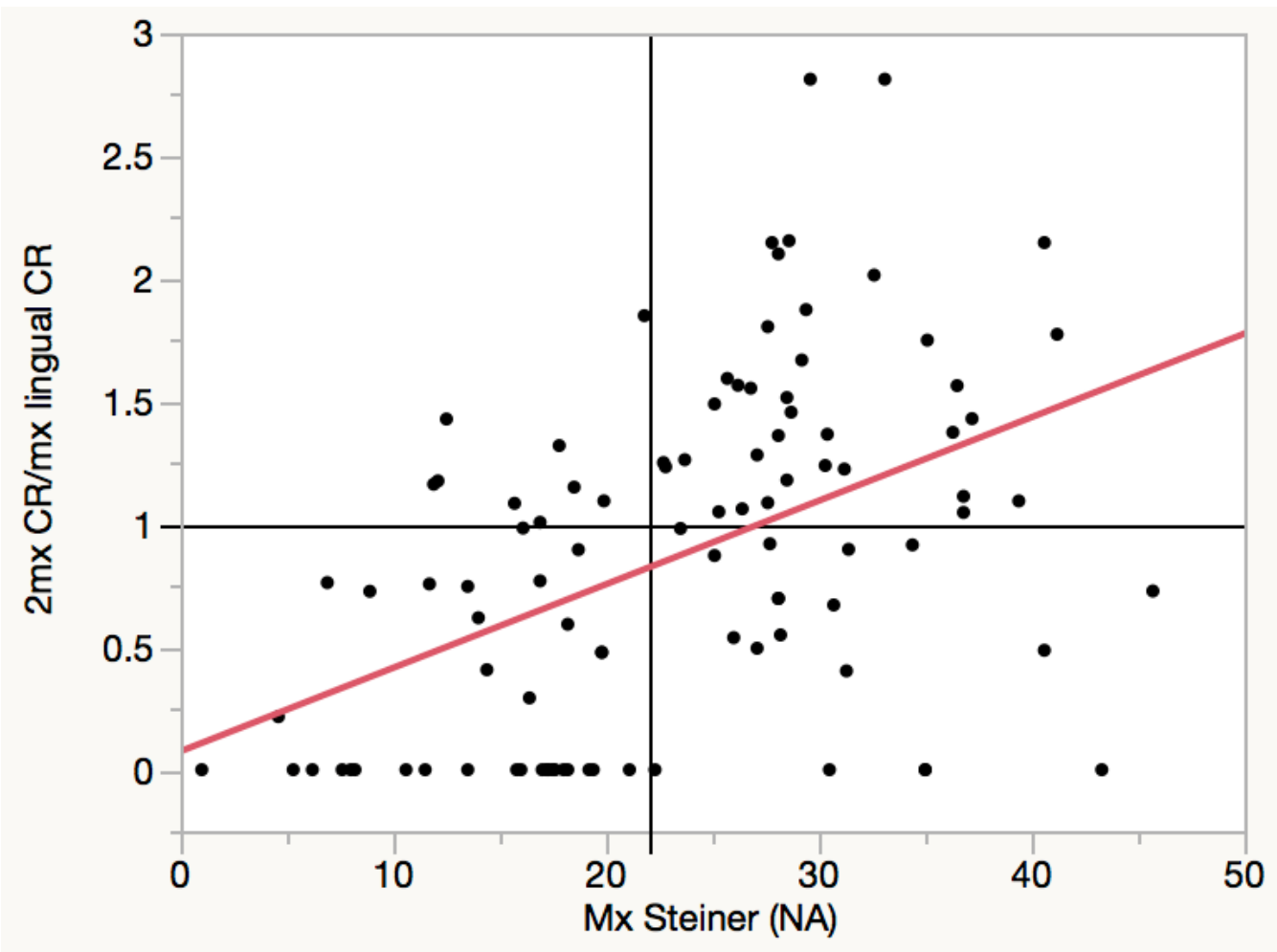

- Linear Fit

Linear Fit

$2 \mathrm{mx} C R / \mathrm{mx}$ lingual $\mathrm{CR}=0.0749305+0.0340388 * \mathrm{Mx}$ Steiner $(\mathrm{NA})$

Summary of Fit

RSquare

0.218216

RSquare Adj

0.210156

Root Mean Square Error

0.626338

Mean of Response

0.871988

Observations (or Sum Wgts)

99

Parameter Estimates

$\begin{array}{lcccr}\text { Term } & \text { Estimate } & \text { Std Error } & \text { t Ratio } & \text { Prob }>|\mathbf{t}| \\ \text { Intercept } & 0.0749305 & 0.165611 & 0.45 & 0.6520 \\ \text { Mx Steiner (NA) } & 0.0340388 & 0.006542 & 5.20 & <.0001 *\end{array}$


Bivariate Fit of 2 mx APEX/mx lingual APEX By Mx Steiner (NA)

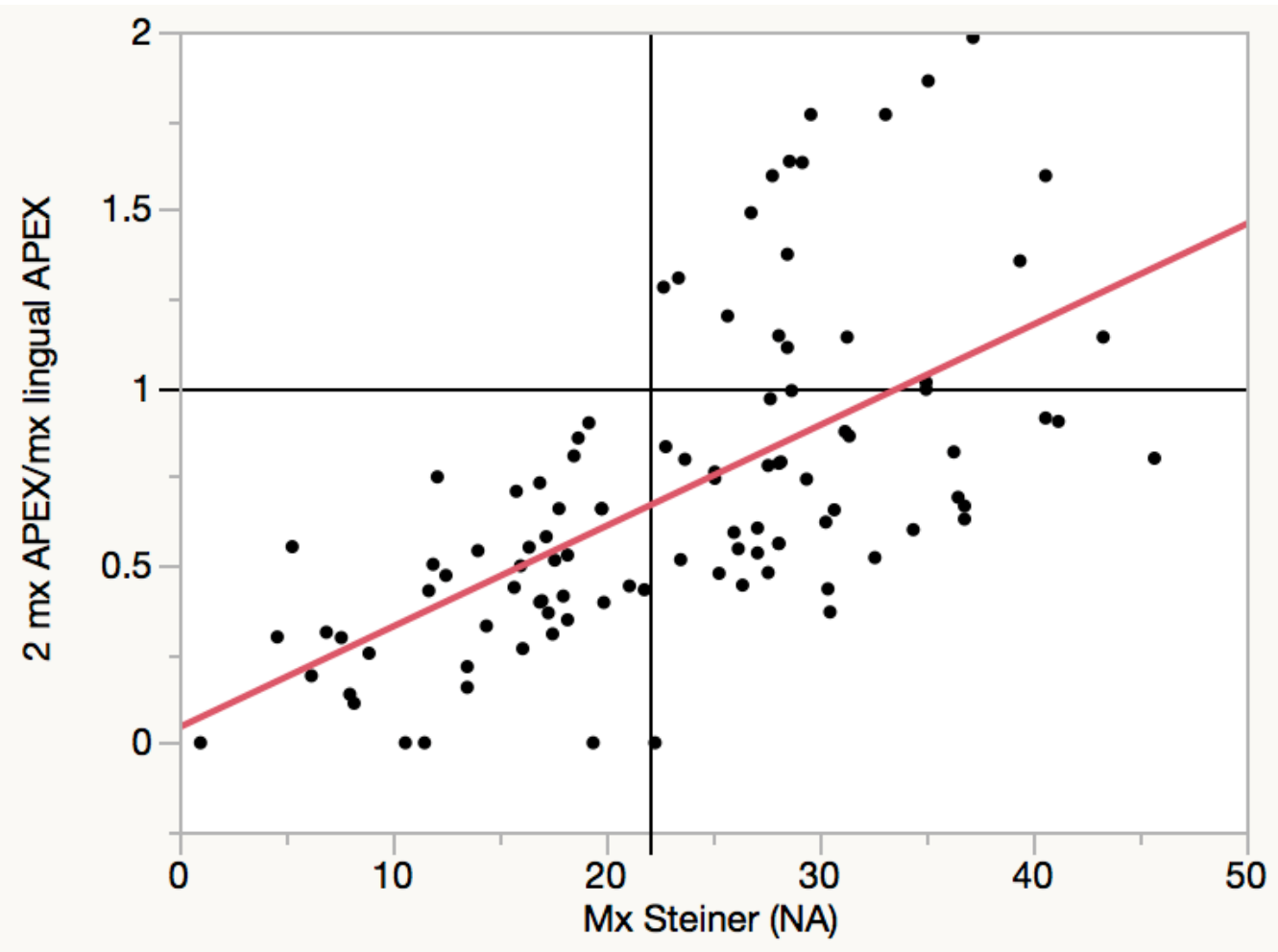

\section{Linear Fit}

Linear Fit

$2 \mathrm{mx}$ APEX/mx lingual APEX $=0.0431355+0.0283057 * \mathrm{Mx}$ Steiner $(\mathrm{NA})$

Summary of Fit

RSquare

0.381423

RSquare Adj

0.375111

Root Mean Square Error

0.348637

Mean of Response

0.705941

Observations (or Sum Wgts)

100

Parameter Estimates

$\begin{array}{lrrrr}\text { Term } & \text { Estimate } & \text { Std Error } & \text { t Ratio } & \text { Prob }>|\mathbf{t}| \\ \text { Intercept } & 0.0431355 & 0.092116 & 0.47 & 0.6406\end{array}$




$\begin{array}{lrrrr}\text { Term } & \text { Estimate } & \text { Std Error } & \text { t Ratio } & \text { Prob>|t| } \\ \text { Mx Steiner (NA) } & & & & \\ & 0.0283057 & 0.003641 & 7.77 & <.0001^{*}\end{array}$

Bivariate Fit of 2mx CR/mx lingual CR By MxAndrews

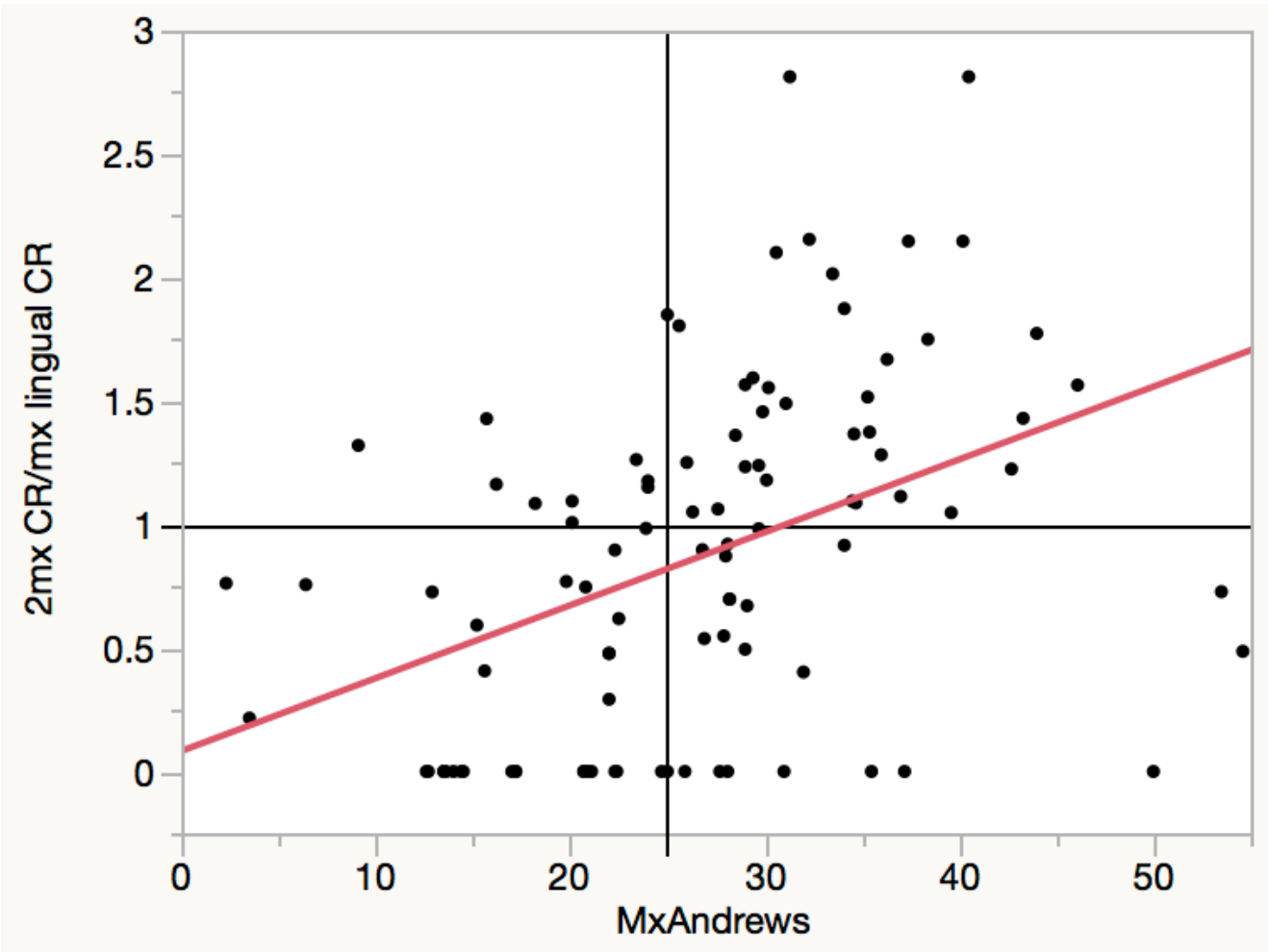

\section{Linear Fit}

Linear Fit

$2 \mathrm{mx} \mathrm{CR} / \mathrm{mx}$ lingual $\mathrm{CR}=0.082894+0.0295161 *$ MxAndrews

Summary of Fit

RSquare

0.178671

RSquare Adj

0.170204

Root Mean Square Error

0.641984

Mean of Response

0.871988

Observations (or Sum Wgts) 
Parameter Estimates

$\begin{array}{lcrrr}\text { Term } & \text { Estimate } & \text { Std Error } & \text { t Ratio } & \text { Prob>|t| } \\ \text { Intercept } & 0.082894 & 0.183498 & 0.45 & 0.6525 \\ \text { MxAndrews } & 0.0295161 & 0.006425 & 4.59\end{array}$

Bivariate Fit of 2 mx APEX/mx lingual APEX By MxAndrews

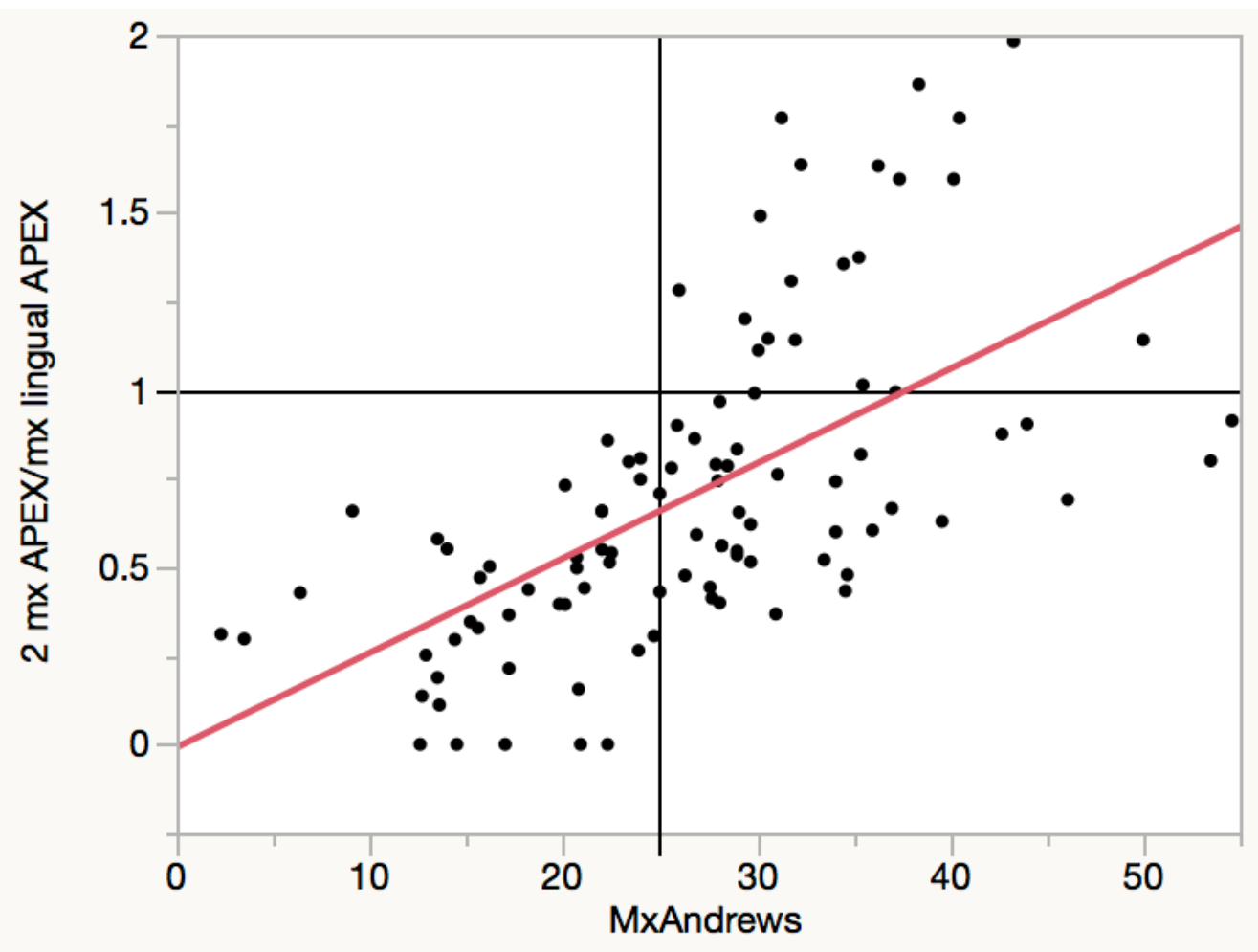

\section{Linear Fit}

Linear Fit

$2 \mathrm{mx}$ APEX/mx lingual APEX $=-0.008536+0.0266745^{*} \mathrm{Mx}$ Andrews

Summary of Fit

RSquare

0.369791

RSquare Adj

0.36336

Root Mean Square Error

0.3519

Mean of Response

0.705941

Observations (or Sum Wgts)

100 
Parameter Estimates

$\begin{array}{lcrrr}\text { Term } & \text { Estimate } & \text { Std Error } & \text { t Ratio } & \text { Prob }>|\mathbf{t}| \\ \text { Intercept } & -0.008536 & 0.100576 & -0.08 & 0.9325 \\ \text { MxAndrews } & 0.0266745 & 0.003518 & 7.58 & <.0001 *\end{array}$

Bivariate Fit of $2 \mathrm{mx} \mathrm{CR} / \mathrm{mx}$ lingual CR By MxBurstone

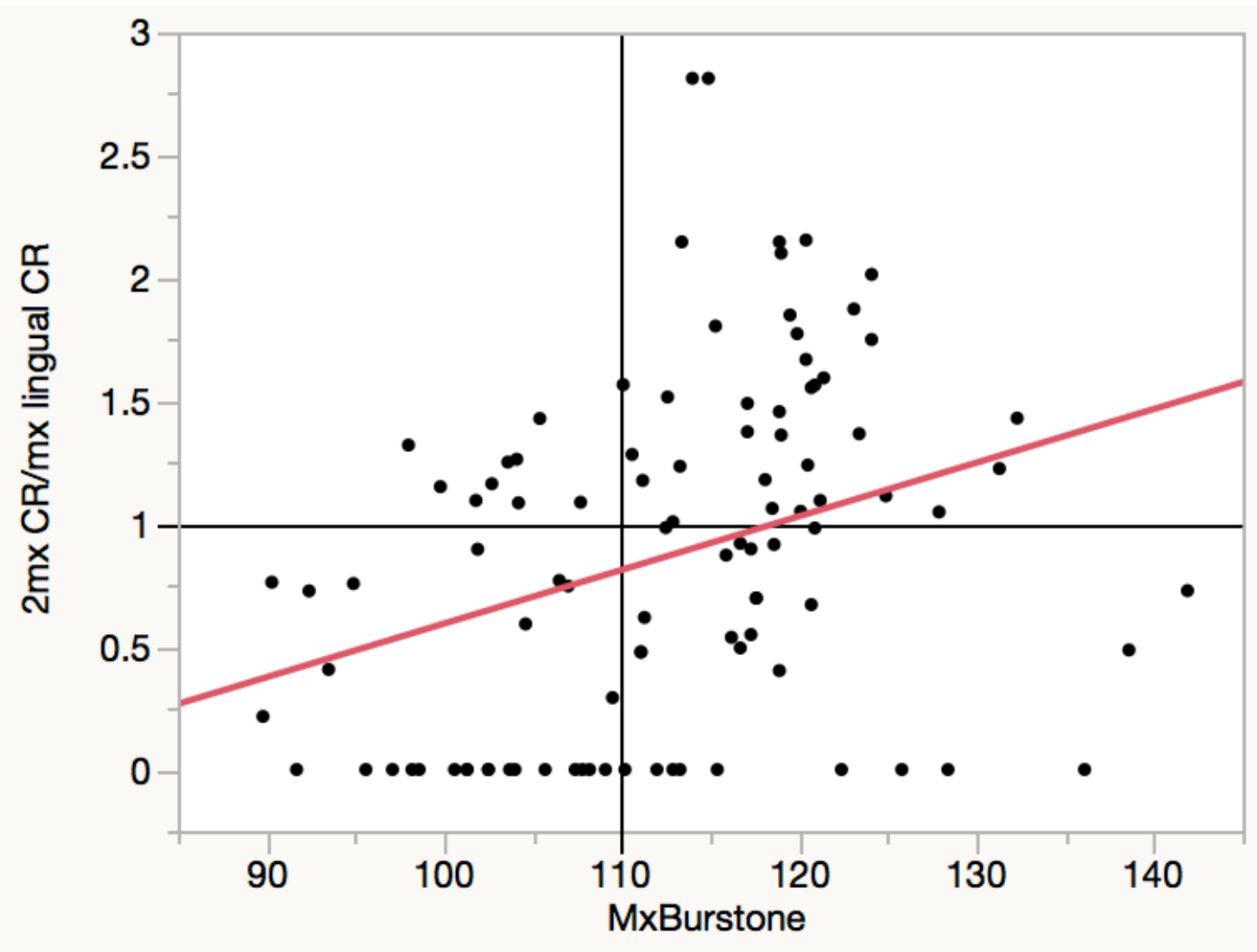

\section{Linear Fit}

Linear Fit

$2 \mathrm{mx} \mathrm{CR} / \mathrm{mx}$ lingual $\mathrm{CR}=-1.589315+0.0218314 * \mathrm{MxBurstone}$

Summary of Fit

RSquare

0.108006

RSquare Adj

0.09881

Root Mean Square Error

0.669031

Mean of Response

0.871988

Observations (or Sum Wgts)

99 
Parameter Estimates

\begin{tabular}{|c|c|c|c|c|}
\hline Term & Estimate & Std Error & t Ratio & Prob $>|t|$ \\
\hline Intercept & -1.589315 & 0.721325 & -2.20 & $0.0299 *$ \\
\hline
\end{tabular}

Bivariate Fit of $2 \mathrm{mx}$ APEX/mx lingual APEX By MxBurstone

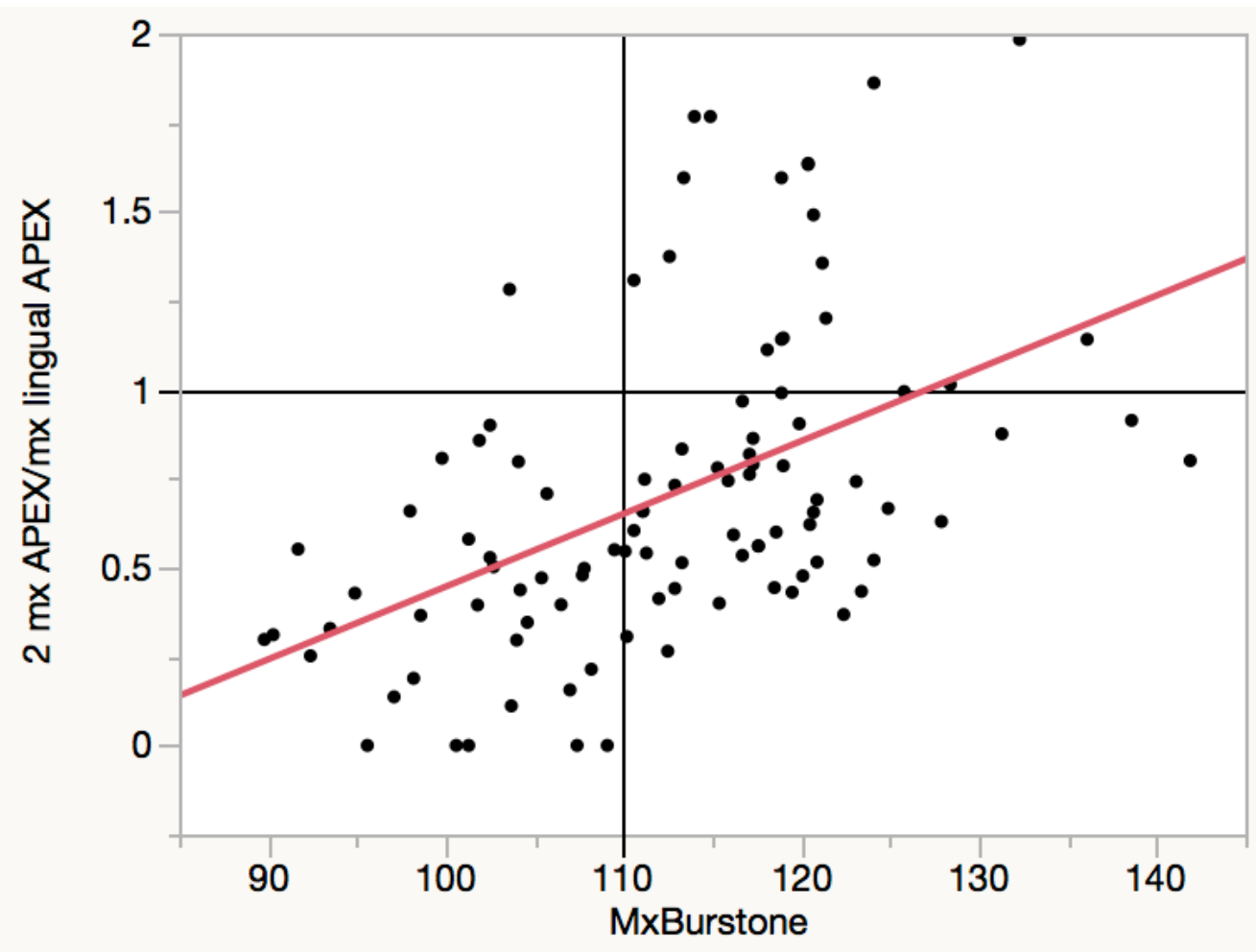

\section{Linear Fit}

Linear Fit

$2 \mathrm{mx}$ APEX/mx lingual APEX $=-1.59883+0.0204469 * \mathrm{MxBurstone}$

Summary of Fit

RSquare

0.239574

RSquare Adj

0.231815

Root Mean Square Error

0.38655

Mean of Response

0.705941

Observations (or Sum Wgts)

100 
Parameter Estimates

$\begin{array}{lcccr}\text { Term } & \text { Estimate } & \text { Std Error } & \text { t Ratio } & \text { Prob }>|\mathbf{t}| \\ \text { Intercept } & -1.59883 & 0.416583 & -3.84 & 0.0002 * \\ \text { MxBurstone } & 0.0204469 & 0.00368 & 5.56 & <.0001 *\end{array}$

Bivariate Fit of diff CR By Mx Steiner (NA)

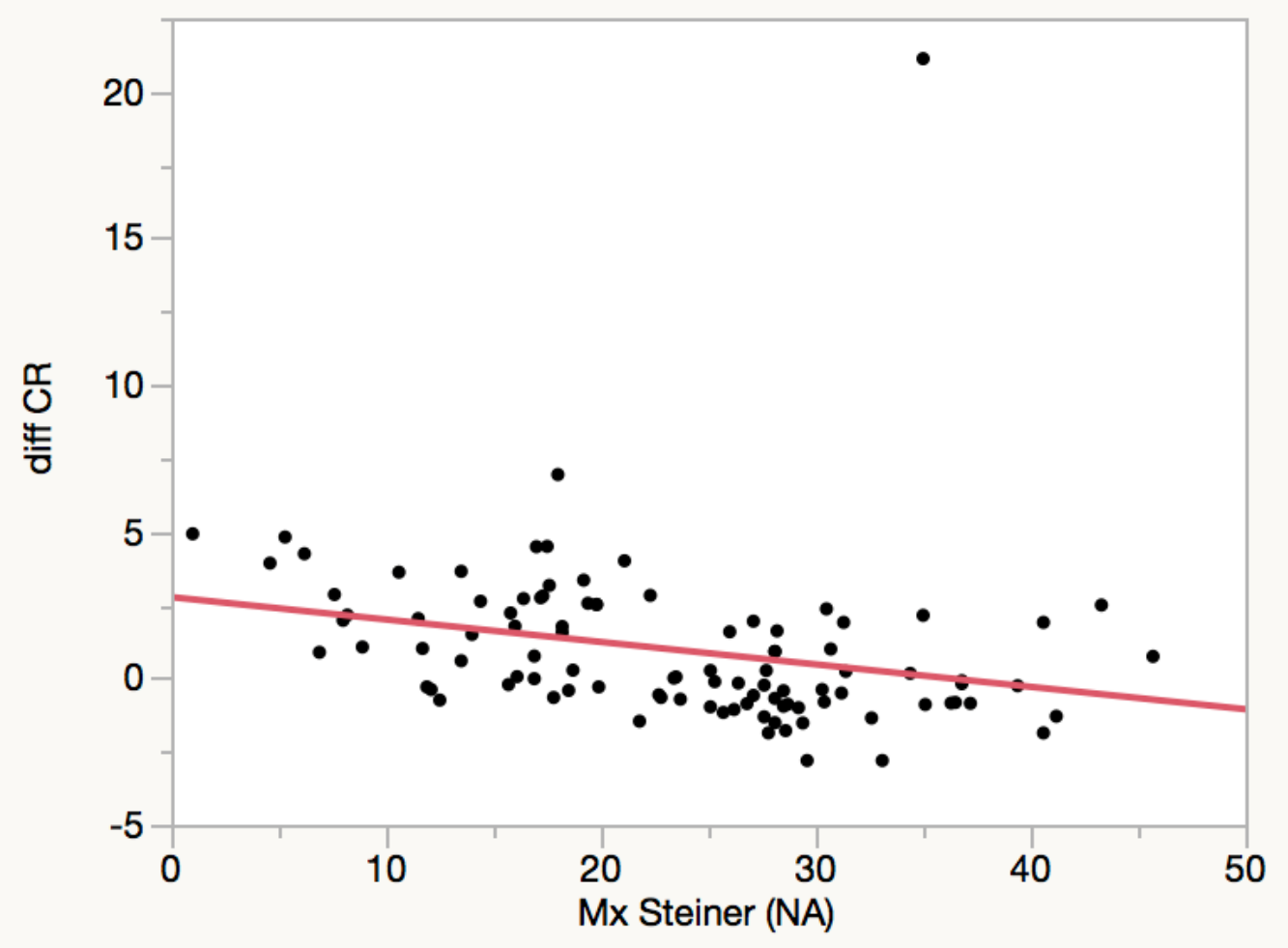

\section{_Linear Fit}

Linear Fit

diff $\mathrm{CR}=2.7628893-0.0764729 * \mathrm{Mx}$ Steiner (NA)

Summary of Fit

RSquare

0.069619

RSquare Adj

0.060125

Root Mean Square Error

2.703851

Mean of Response

0.9722

Observations (or Sum Wgts)

100 
Analysis of Variance

$\begin{array}{lrrrr}\text { Source } & \text { DF } & \text { Sum of Squares } & \text { Mean Square } & \text { F Ratio } \\ \text { Model } & 1 & 53.61128 & 53.6113 & 7.3332 \\ \text { Error } & 98 & 716.45923 & 7.3108 & \text { Prob > F } \\ \text { C. Total } & 99 & 770.07052 & & 0.0080^{*}\end{array}$

Parameter Estimates

$\begin{array}{lcccc}\text { Term } & \text { Estimate } & \text { Std Error } & \text { t Ratio } & \text { Prob>|t| } \\ \text { Intercept } & 2.7628893 & 0.714407 & 3.87 & 0.0002 * \\ \text { Mx Steiner (NA) } & -0.076473 & 0.02824 & -2.71 & 0.0080 *\end{array}$

Bivariate Fit of diff CR apex By Mx Steiner (NA)

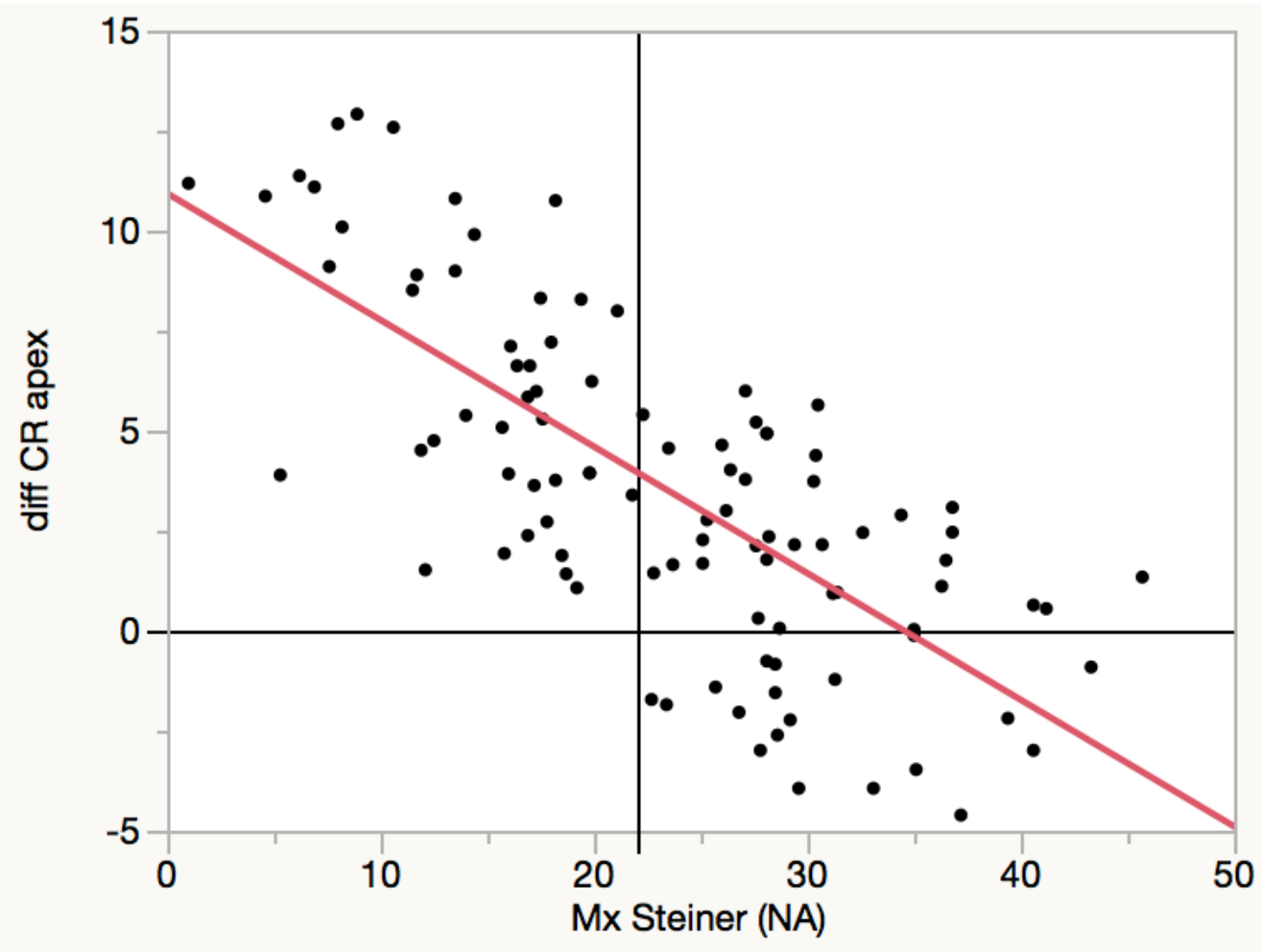

\section{Linear Fit}

Linear Fit

diff CR apex $=10.929532-0.3164175^{*}$ Mx Steiner (NA) 
Summary of Fit

RSquare

RSquare Adj

Root Mean Square Error

Mean of Response

Observations (or Sum Wgts)
0.531485

0.526704

2.873325

3.5203

100

Analysis of Variance

$\begin{array}{lrrrr}\text { Source } & \text { DF } & \text { Sum of Squares } & \text { Mean Square } & \text { F Ratio } \\ \text { Model } & 1 & 917.8299 & 917.830 & 111.1713 \\ \text { Error } & 98 & 809.0876 & 8.256 & \text { Prob }>\text { F } \\ \text { C. Total } & 99 & 1726.9175 & & <.0001 *\end{array}$

Parameter Estimates

\begin{tabular}{|c|c|c|c|c|}
\hline Term & Estimate & Std Error & t Ratio & Prob $>|t|$ \\
\hline Intercept & 10.929532 & 0.759186 & 14.40 & $<.0001 *$ \\
\hline Mx Steiner (NA) & -0.316418 & 0.03001 & -10.54 & $<.0001 *$ \\
\hline
\end{tabular}


Bivariate Fit of diff CR By MxAndrews

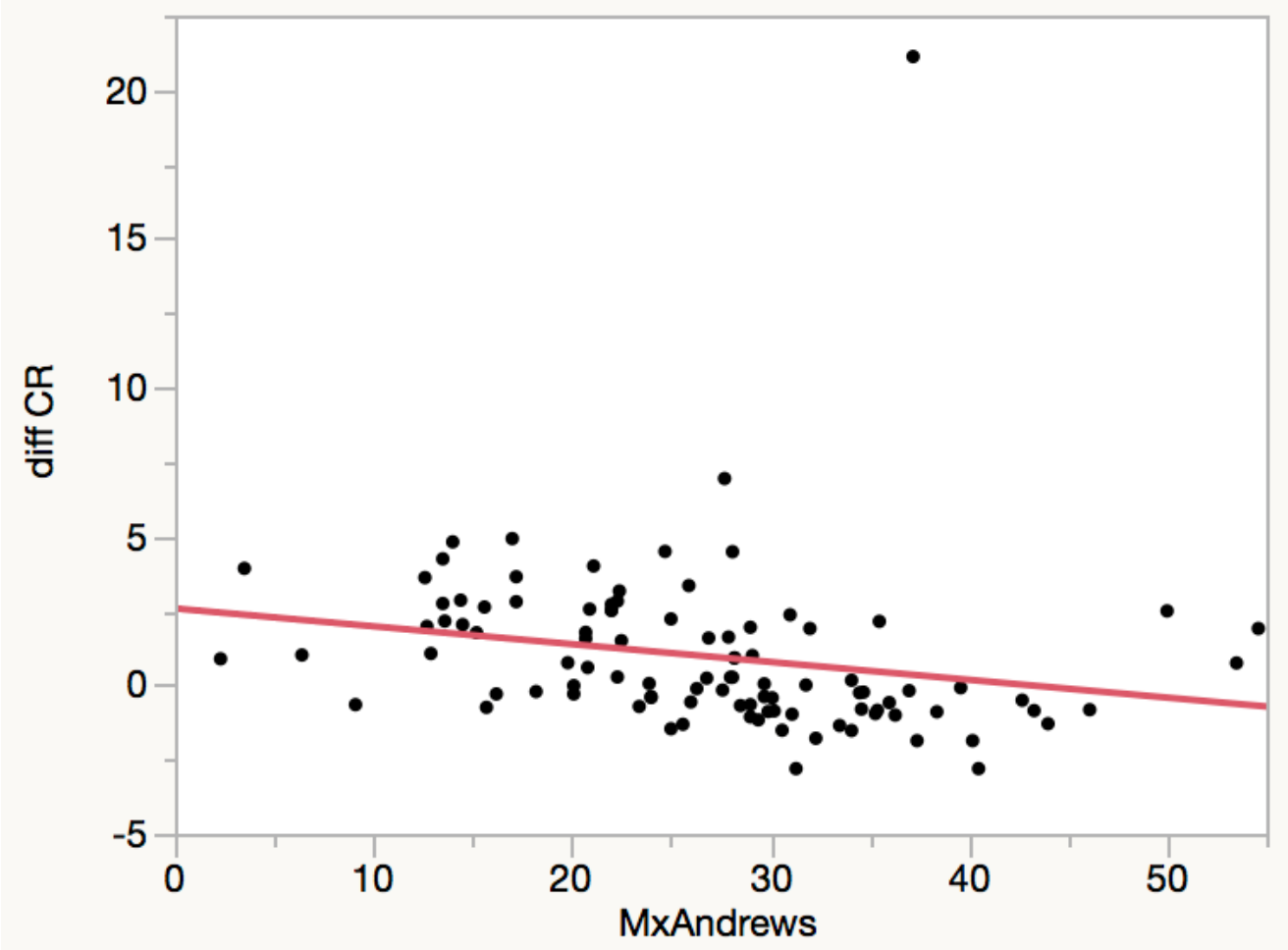

\section{Linear Fit}

Linear Fit

diff $\mathrm{CR}=2.5804756-0.0600439 *$ MxAndrews

Summary of Fit

\section{RSquare}

RSquare Adj

Root Mean Square Error

Mean of Response

Observations (or Sum Wgts)
0.046854

0.037128

2.736729

0.9722

100

Analysis of Variance

$\begin{array}{lrrrr}\text { Source } & \text { DF } & \text { Sum of Squares } & \text { Mean Square } & \text { F Ratio } \\ \text { Model } & 1 & 36.08120 & 36.0812 & 4.8175 \\ \text { Error } & 98 & 733.98932 & 7.4897 & \text { Prob > F } \\ \text { C. Total } & 99 & 770.07052 & & 0.0305^{*}\end{array}$


Parameter Estimates

$\begin{array}{lcrrr}\text { Term } & \text { Estimate } & \text { Std Error } & \text { t Ratio } & \text { Prob>|t| } \\ \text { Intercept } & 2.5804756 & 0.782183 & 3.30 & 0.0014 * \\ \text { MxAndrews } & -0.060044 & 0.027356 & -2.19 & 0.0305^{*}\end{array}$

Bivariate Fit of diff CR apex By MxAndrews

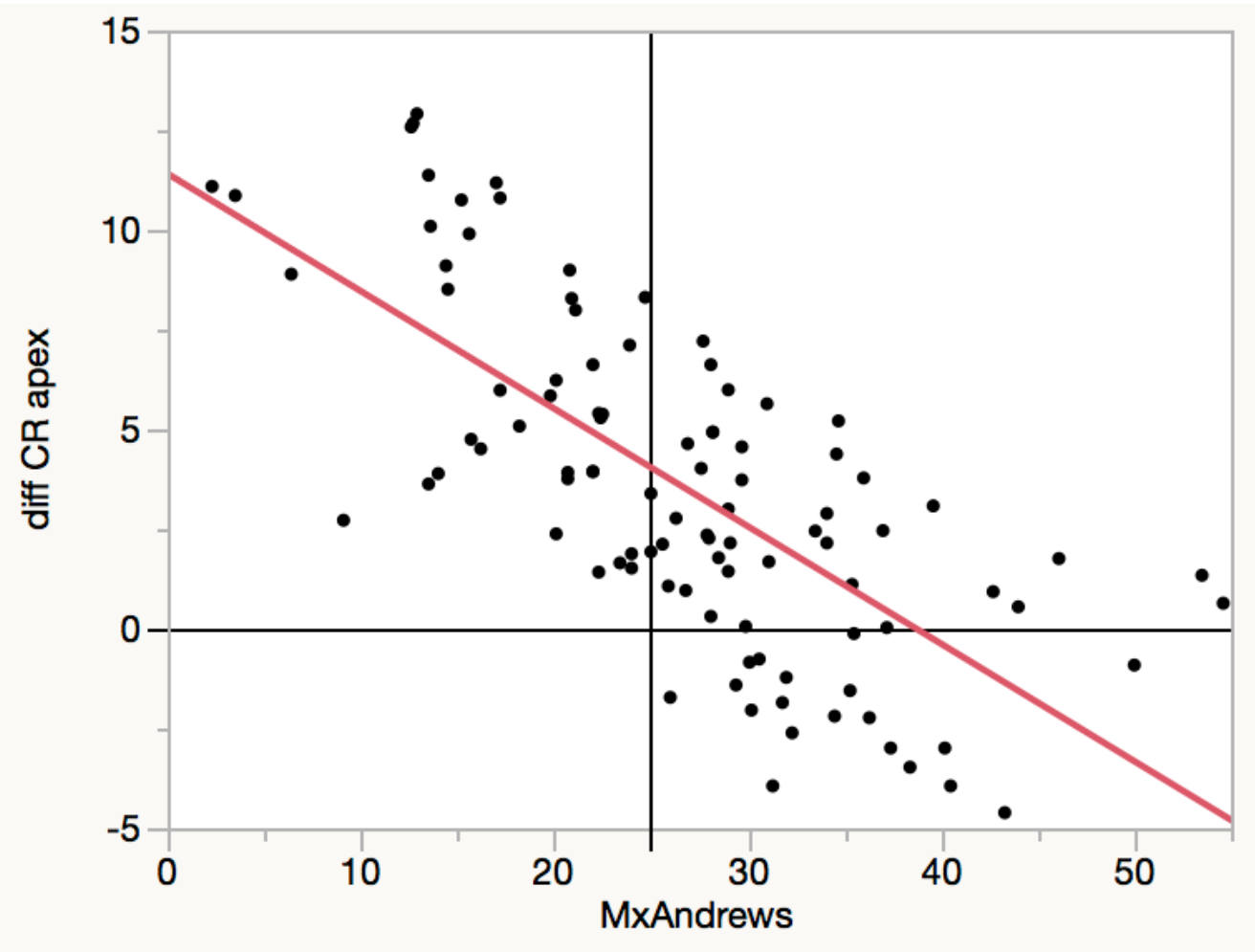

\section{Linear Fit}

Linear Fit

diff CR apex $=11.411466-0.2946114 *$ MxAndrews

Summary of Fit

RSquare

0.503003

RSquare Adj

0.497932

Root Mean Square Error

2.959372

Mean of Response

3.5203

Observations (or Sum Wgts) 
Analysis of Variance

$\begin{array}{lrrrr}\text { Source } & \text { DF } & \text { Sum of Squares } & \text { Mean Square } & \text { F Ratio } \\ \text { Model } & 1 & 868.6451 & 868.645 & 99.1844 \\ \text { Error } & 98 & 858.2724 & 8.758 & \text { Prob }>\text { F } \\ \text { C. Total } & 99 & 1726.9175 & & <.0001^{*}\end{array}$

Parameter Estimates

$\begin{array}{lcccr}\text { Term } & \text { Estimate } & \text { Std Error } & \text { t Ratio } & \text { Prob }>|\mathbf{t}| \\ \text { Intercept } & 11.411466 & 0.845816 & 13.49 & <.0001 * \\ \text { MxAndrews } & -0.294611 & 0.029582 & -9.96 & <.0001 *\end{array}$

Bivariate Fit of diff CR By MxBurstone

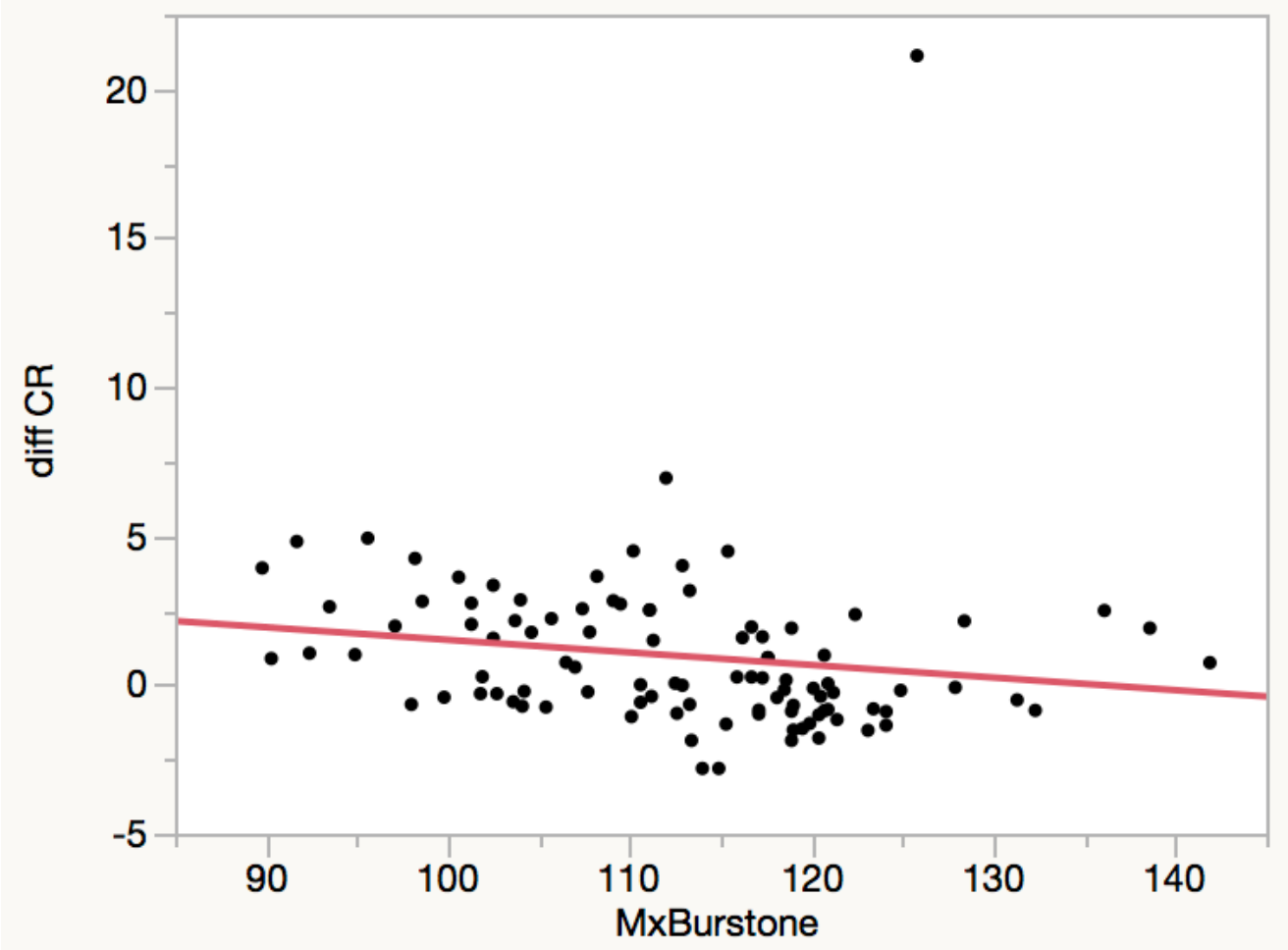

\section{Linear Fit}

Linear Fit

diff $\mathrm{CR}=5.7399375-0.0422972 *$ MxBurstone

Summary of Fit

RSquare

0.025637

RSquare Adj

0.015694 
Root Mean Square Error

Mean of Response

Observations (or Sum Wgts)
2.767023

0.9722

100

Analysis of Variance

$\begin{array}{lrrrr}\text { Source } & \text { DF } & \text { Sum of Squares } & \text { Mean Square } & \text { F Ratio } \\ \text { Model } & 1 & 19.74193 & 19.7419 & 2.5785 \\ \text { Error } & 98 & 750.32859 & 7.6564 & \text { Prob > F } \\ \text { C. Total } & 99 & 770.07052 & & 0.1115\end{array}$

Parameter Estimates

$\begin{array}{lcccr}\text { Term } & \text { Estimate } & \text { Std Error } & \text { t Ratio } & \text { Prob }>|\mathbf{t}| \\ \text { Intercept } & 5.7399375 & 2.982003 & 1.92 & 0.0571 \\ \text { MxBurstone } & -0.042297 & 0.026341 & -1.61 & 0.1115\end{array}$

Bivariate Fit of diff CR apex By MxBurstone

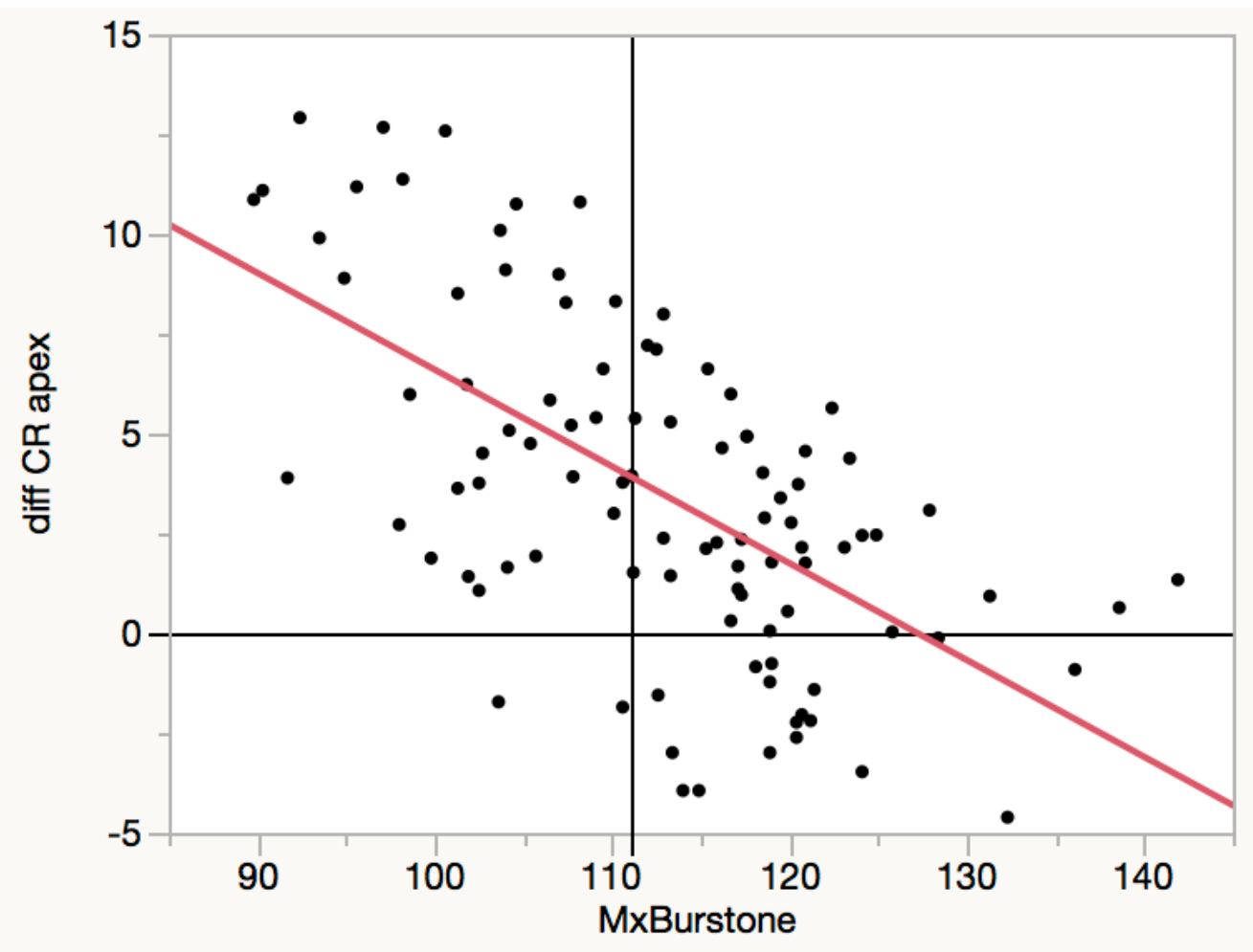

Linear Fit 
Linear Fit

diff CR apex $=30.855677-0.2425069 *$ MxBurstone

Summary of Fit

0.375788

RSquare Adj

0.369419

Root Mean Square Error

3.316566

Mean of Response

3.5203

Observations (or Sum Wgts)

100

Analysis of Variance

$\begin{array}{lrrrr}\text { Source } & \text { DF } & \text { Sum of Squares } & \text { Mean Square } & \text { F Ratio } \\ \text { Model } & 1 & 648.9556 & 648.956 & 58.9981 \\ \text { Error } & 98 & 1077.9619 & 11.000 & \text { Prob }>\text { F } \\ \text { C. Total } & 99 & 1726.9175 & & <.0001^{*}\end{array}$

Parameter Estimates

\begin{tabular}{|c|c|c|c|c|}
\hline Term & Estimate & Std Error & t Ratio & Prob $>|t|$ \\
\hline Intercept & 30.855677 & 3.574242 & 8.63 & $<.0001 *$ \\
\hline
\end{tabular}


Contingency Analysis of Mx Fenestrations By Range Mx Andrews

Mosaic Plot

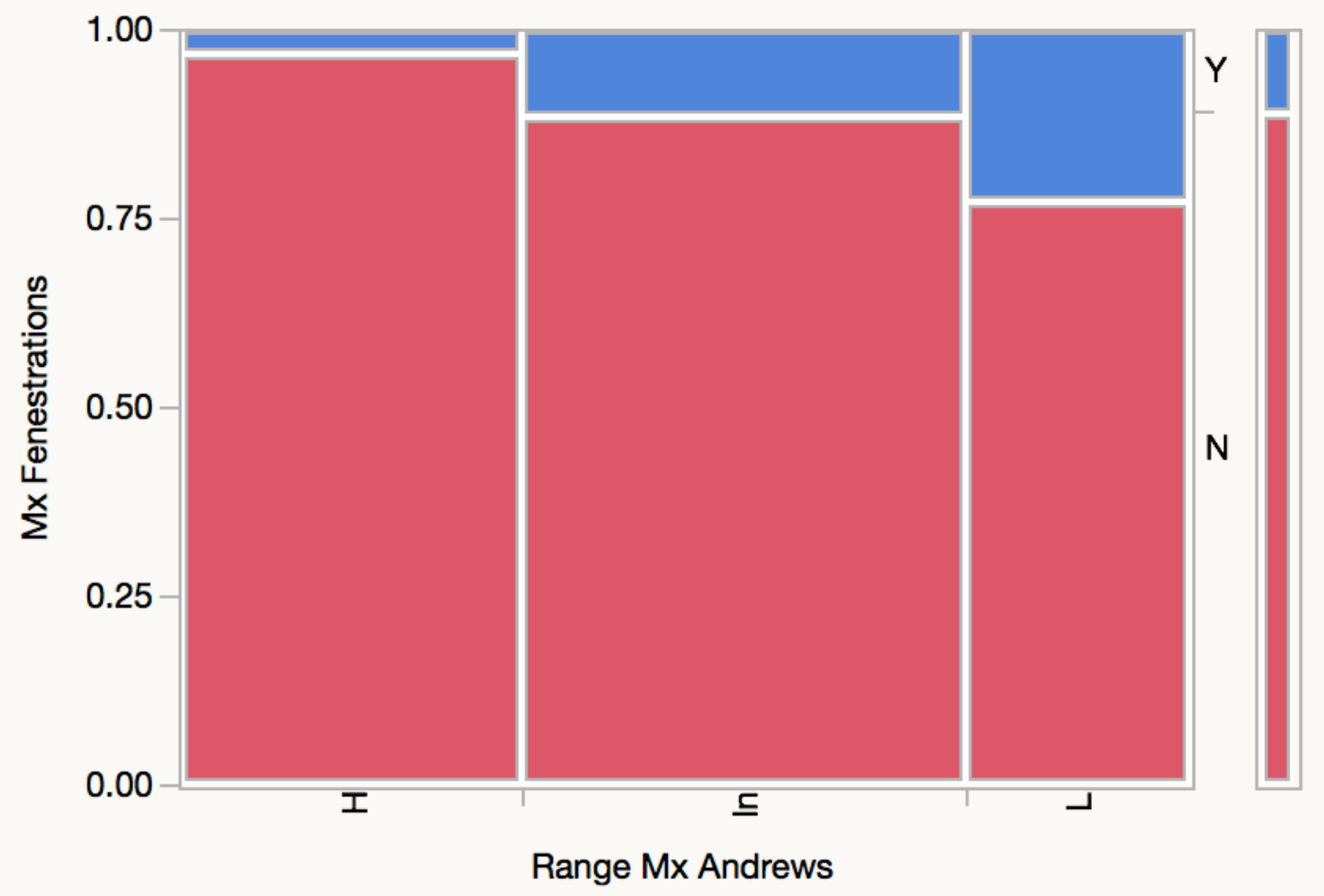

Contingency Table

Range Mx Andrews By Mx Fenestrations

\begin{tabular}{|c|c|c|c|}
\hline $\begin{array}{l}\text { Count } \\
\text { Total \% } \\
\text { Col \% } \\
\text { Row \% }\end{array}$ & $\mathrm{N}$ & $\mathrm{Y}$ & Total \\
\hline $\mathrm{H}$ & $\begin{array}{r}33 \\
33.00 \\
37.08 \\
97.06\end{array}$ & $\begin{array}{r}1 \\
1.00 \\
9.09 \\
2.94\end{array}$ & $\begin{array}{r}34 \\
34.00\end{array}$ \\
\hline In & $\begin{array}{r}39 \\
39.00 \\
43.82 \\
88.64\end{array}$ & $\begin{array}{r}5 \\
5.00 \\
45.45 \\
11.36\end{array}$ & $\begin{array}{r}44 \\
44.00\end{array}$ \\
\hline $\mathrm{L}$ & $\begin{array}{r}17 \\
17.00\end{array}$ & $\begin{array}{r}5 \\
5.00\end{array}$ & $\begin{array}{r}22 \\
22.00\end{array}$ \\
\hline
\end{tabular}




\begin{tabular}{|l|r|r|r|}
\hline & 19.10 & 45.45 & \\
& 77.27 & 22.73 & \\
\hline Total & 89 & 11 & 100 \\
& 89.00 & 11.00 & \\
\hline
\end{tabular}

\section{Tests}

$\begin{array}{rrrr}\mathbf{N} & \text { DF } & \text {-LogLike } & \text { RSquare (U) } \\ 100 & 2 & 2.7706577 & 0.0800\end{array}$

$\begin{array}{lrr}\text { Test } & \text { ChiSquare } & \text { Prob }>\text { ChiSq } \\ \text { Likelihood Ratio } & 5.541 & 0.0626 \\ \text { Pearson } & 5.352 & 0.0688\end{array}$

Warning: $20 \%$ of cells have expected count less than 5, ChiSquare suspect.

Contingency Analysis of Mx Dehiscences By Range Mx Andrews

Mosaic Plot

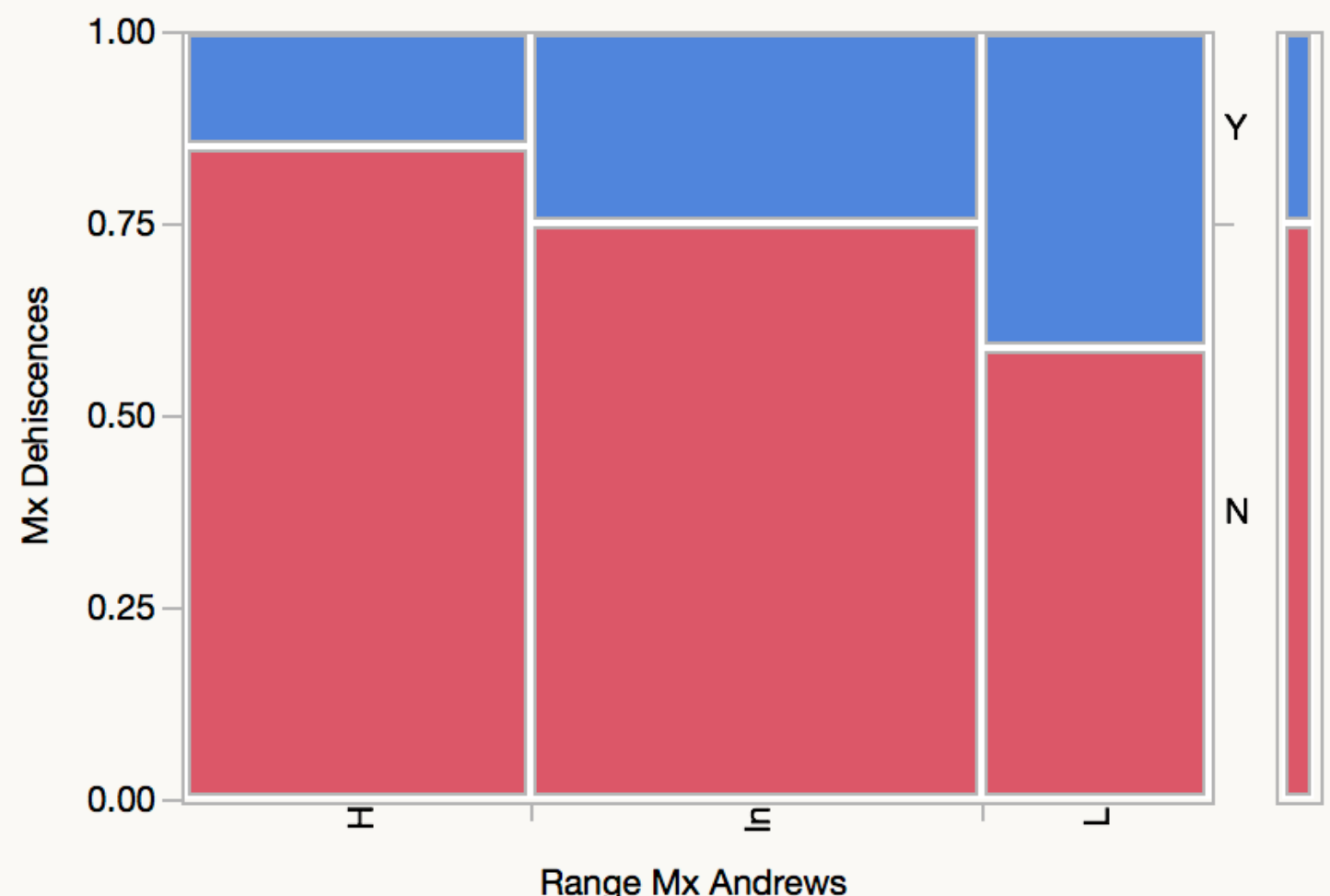

Contingency Table

Range Mx Andrews By Mx Dehiscences 


\begin{tabular}{|c|c|c|c|}
\hline $\begin{array}{l}\text { Count } \\
\text { Total \% } \\
\text { Col \% } \\
\text { Row \% }\end{array}$ & $\mathrm{N}$ & $\bar{Y}$ & Total \\
\hline $\mathrm{H}$ & $\begin{array}{r}29 \\
29.00 \\
38.67 \\
85.29\end{array}$ & $\begin{array}{r}5 \\
5.00 \\
20.00 \\
14.71\end{array}$ & $\begin{array}{r}34 \\
34.00\end{array}$ \\
\hline In & $\begin{array}{r}33 \\
33.00 \\
44.00 \\
75.00\end{array}$ & $\begin{array}{r}11 \\
11.00 \\
44.00 \\
25.00\end{array}$ & $\begin{array}{r}44 \\
44.00\end{array}$ \\
\hline $\mathrm{L}$ & $\begin{array}{r}13 \\
13.00 \\
17.33 \\
59.09\end{array}$ & $\begin{array}{r}9 \\
9.00 \\
36.00 \\
40.91\end{array}$ & $\begin{array}{r}22 \\
22.00\end{array}$ \\
\hline Total & $\begin{array}{r}75 \\
75.00\end{array}$ & $\begin{array}{r}25 \\
25.00\end{array}$ & 100 \\
\hline
\end{tabular}

Tests

$\begin{array}{rrrr}\mathbf{N} & \text { DF } & \text {-LogLike } & \text { RSquare (U) } \\ 100 & 2 & 2.4097078 & 0.0429\end{array}$

$\begin{array}{lrr}\text { Test } & \text { ChiSquare } & \text { Prob>ChiSq } \\ \text { Likelihood Ratio } & 4.819 & 0.0898 \\ \text { Pearson } & 4.891 & 0.0867\end{array}$


Contingency Analysis of Mx Fenestrations By Range Mx Steiner

Mosaic Plot

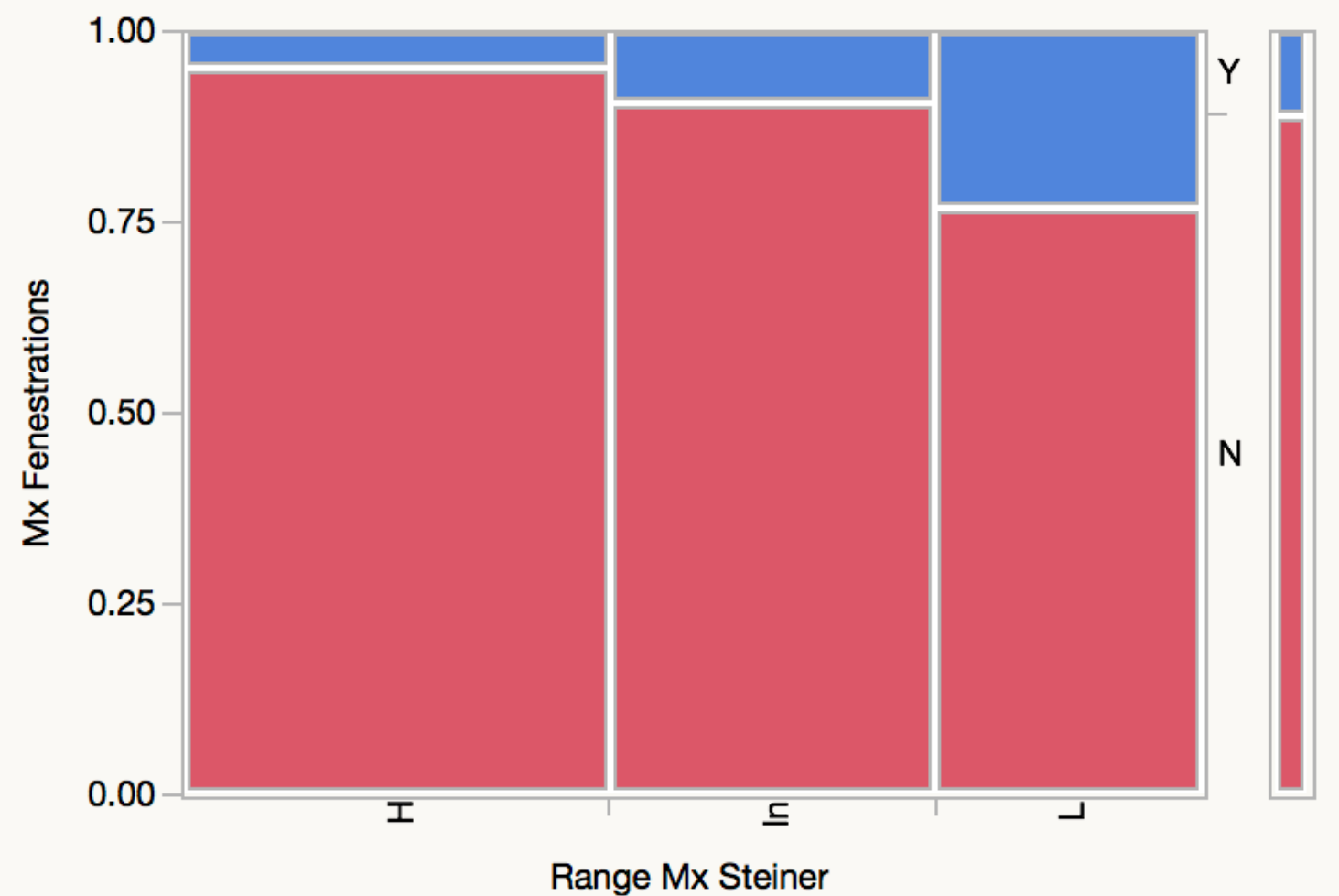

Contingency Table

Range Mx Steiner By Mx Fenestrations

\begin{tabular}{|c|c|c|c|}
\hline $\begin{array}{l}\text { Count } \\
\text { Total \% } \\
\text { Col \% } \\
\text { Row \% }\end{array}$ & $\mathrm{N}$ & $\mathrm{Y}$ & Total \\
\hline$\overline{\mathrm{H}}$ & $\begin{array}{r}40 \\
40.00 \\
44.94 \\
95.24\end{array}$ & $\begin{array}{r}2 \\
2.00 \\
18.18 \\
4.76\end{array}$ & $\begin{array}{r}42 \\
42.00\end{array}$ \\
\hline In & $\begin{array}{r}29 \\
29.00 \\
32.58 \\
90.63\end{array}$ & $\begin{array}{r}3 \\
3.00 \\
27.27 \\
9.38\end{array}$ & $\begin{array}{r}32 \\
32.00\end{array}$ \\
\hline $\mathrm{L}$ & $\begin{array}{r}20 \\
20.00\end{array}$ & $\begin{array}{r}6 \\
6.00\end{array}$ & $\begin{array}{r}26 \\
26.00\end{array}$ \\
\hline
\end{tabular}




\begin{tabular}{|l|r|r|r|}
\hline & 22.47 & 54.55 & \\
& 76.92 & 23.08 & \\
\hline Total & 89 & 11 & 100 \\
& 89.00 & 11.00 & \\
\hline
\end{tabular}

\section{Tests}

$\begin{array}{rrrr}\mathbf{N} & \text { DF } & \text {-LogLike } & \text { RSquare (U) } \\ 100 & 2 & 2.6094416 & 0.0753\end{array}$

$\begin{array}{lrr}\text { Test } & \text { ChiSquare } & \text { Prob>ChiSq } \\ \text { Likelihood Ratio } & 5.219 & 0.0736 \\ \text { Pearson } & 5.629 & 0.0599\end{array}$

Warning: 20\% of cells have expected count less than 5, ChiSquare suspect. Contingency Analysis of Mx Dehiscences By Range Mx Steiner Mosaic Plot

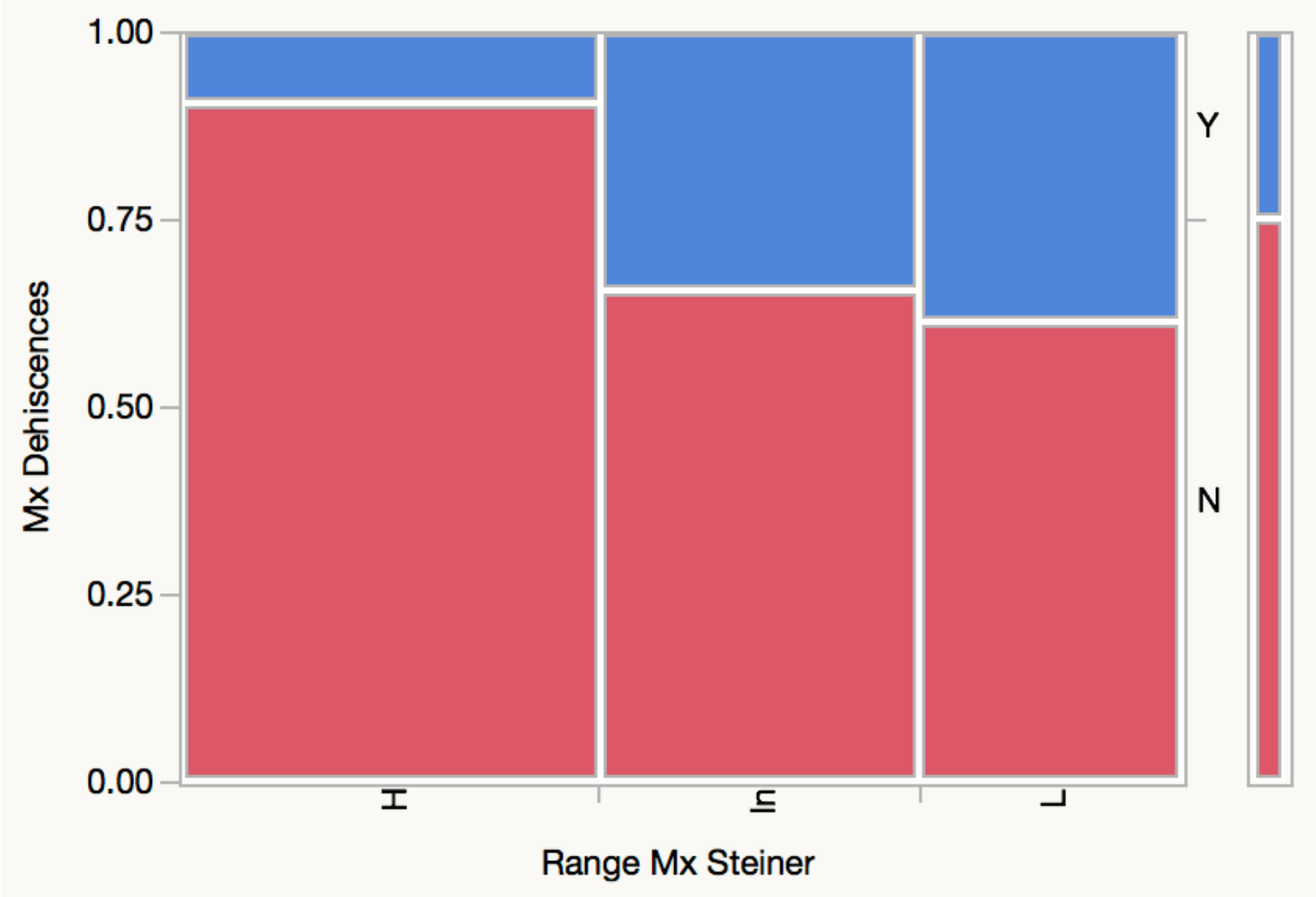

\section{Contingency Table}

Range Mx Steiner By Mx Dehiscences

\begin{tabular}{|l|r|r|r|}
\hline Count & $\mathrm{N}$ & $\mathrm{Y}$ & Total \\
\hline
\end{tabular}




\begin{tabular}{|c|c|c|c|}
\hline $\begin{array}{l}\text { Total \% } \\
\text { Col \% } \\
\text { Row \% }\end{array}$ & & & \\
\hline $\mathrm{H}$ & $\begin{array}{r}38 \\
38.00 \\
50.67 \\
90.48\end{array}$ & $\begin{array}{r}4 \\
4.00 \\
16.00 \\
9.52\end{array}$ & $\begin{array}{r}42 \\
42.00\end{array}$ \\
\hline In & $\begin{array}{r}21 \\
21.00 \\
28.00 \\
65.63\end{array}$ & $\begin{array}{r}11 \\
11.00 \\
44.00 \\
34.38\end{array}$ & $\begin{array}{r}32 \\
32.00\end{array}$ \\
\hline $\mathrm{L}$ & $\begin{array}{r}16 \\
16.00 \\
21.33 \\
61.54\end{array}$ & $\begin{array}{r}10 \\
10.00 \\
40.00 \\
38.46\end{array}$ & $\begin{array}{r}26 \\
26.00\end{array}$ \\
\hline Total & $\begin{array}{r}75 \\
75.00\end{array}$ & $\begin{array}{r}25 \\
25.00\end{array}$ & 100 \\
\hline
\end{tabular}

Tests

\begin{tabular}{rrrr}
$\mathbf{N}$ & DF & -LogLike & RSquare (U) \\
\hline 100 & 2 & 5.1098728 & 0.0909
\end{tabular}

$\begin{array}{lrr}\text { Test } & \text { ChiSquare } & \text { Prob>ChiSq } \\ \text { Likelihood Ratio } & 10.220 & 0.0060^{*} \\ \text { Pearson } & 9.378 & 0.0092^{*}\end{array}$


Contingency Analysis of Mx Fenestrations By Range Mx Burstone

Mosaic Plot

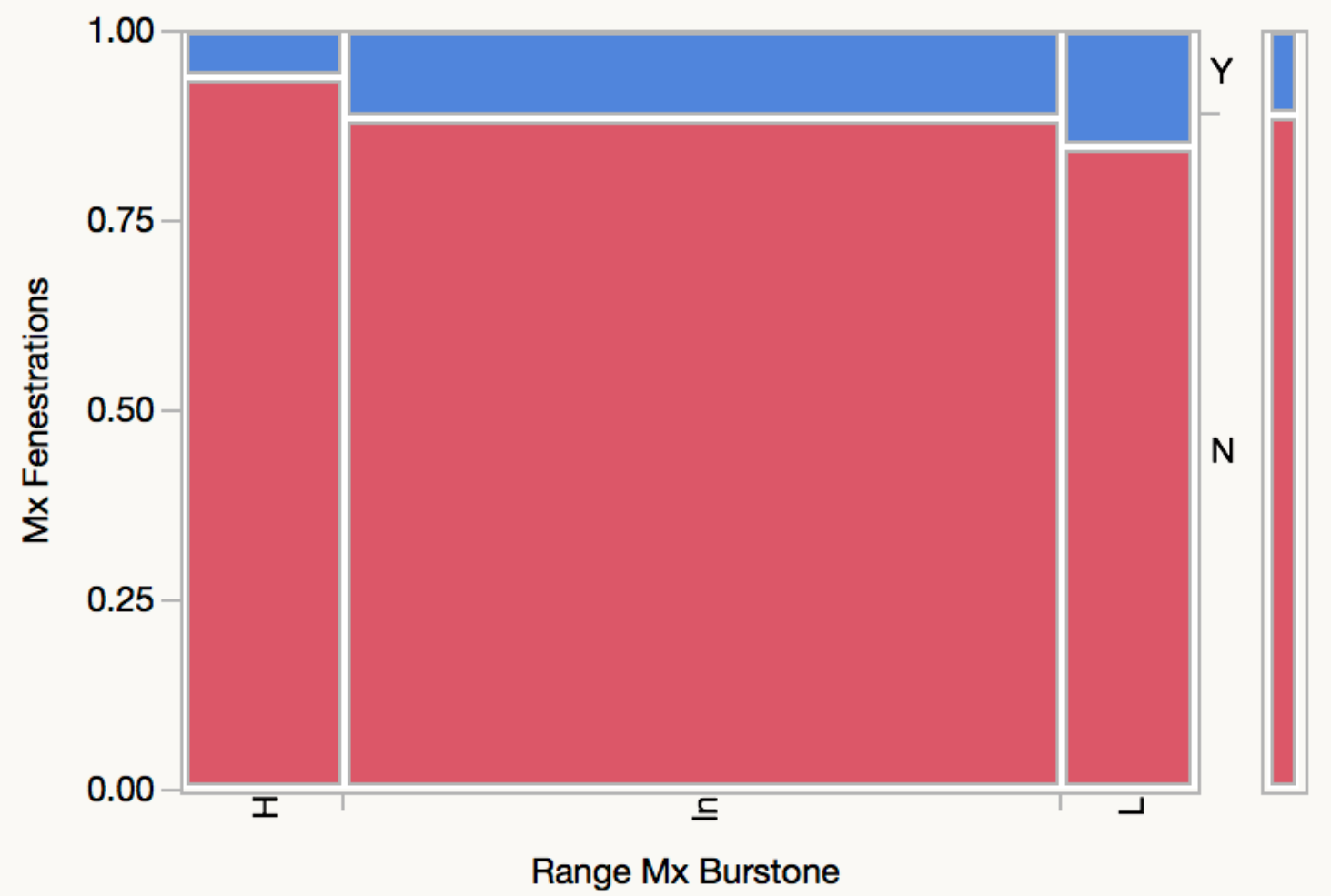

Contingency Table

Range Mx Burstone By Mx Fenestrations

\begin{tabular}{|c|c|c|c|}
\hline $\begin{array}{l}\text { Count } \\
\text { Total \% } \\
\text { Col \% } \\
\text { Row \% }\end{array}$ & $\mathrm{N}$ & $\mathrm{Y}$ & Total \\
\hline$\overline{\mathrm{H}}$ & $\begin{array}{r}15 \\
15.00 \\
16.85 \\
93.75\end{array}$ & $\begin{array}{r}1 \\
1.00 \\
9.09 \\
6.25\end{array}$ & $\begin{array}{r}16 \\
16.00\end{array}$ \\
\hline In & $\begin{array}{r}63 \\
63.00 \\
70.79 \\
88.73\end{array}$ & $\begin{array}{r}8 \\
8.00 \\
72.73 \\
11.27\end{array}$ & $\begin{array}{r}71 \\
71.00\end{array}$ \\
\hline $\mathrm{L}$ & $\begin{array}{r}11 \\
11.00\end{array}$ & $\begin{array}{r}2 \\
2.00\end{array}$ & $\begin{array}{r}13 \\
13.00\end{array}$ \\
\hline
\end{tabular}




\begin{tabular}{|l|r|r|r|}
\hline & 12.36 & 18.18 & \\
& 84.62 & 15.38 & \\
\hline Total & 89 & 11 & 100 \\
& 89.00 & 11.00 & \\
\hline
\end{tabular}

\section{Tests}

$\begin{array}{rrrr}\mathbf{N} & \text { DF } & \text {-LogLike } & \text { RSquare (U) } \\ 100 & 2 & 0.33241669 & 0.0096\end{array}$

$\begin{array}{lrr}\text { Test } & \text { ChiSquare } & \text { Prob }>\text { ChiSq } \\ \text { Likelihood Ratio } & 0.665 & 0.7172 \\ \text { Pearson } & 0.629 & 0.7301\end{array}$

Warning: $20 \%$ of cells have expected count less than 5, ChiSquare suspect.

Contingency Analysis of Mx Dehiscences By Range Mx Burstone

Mosaic Plot

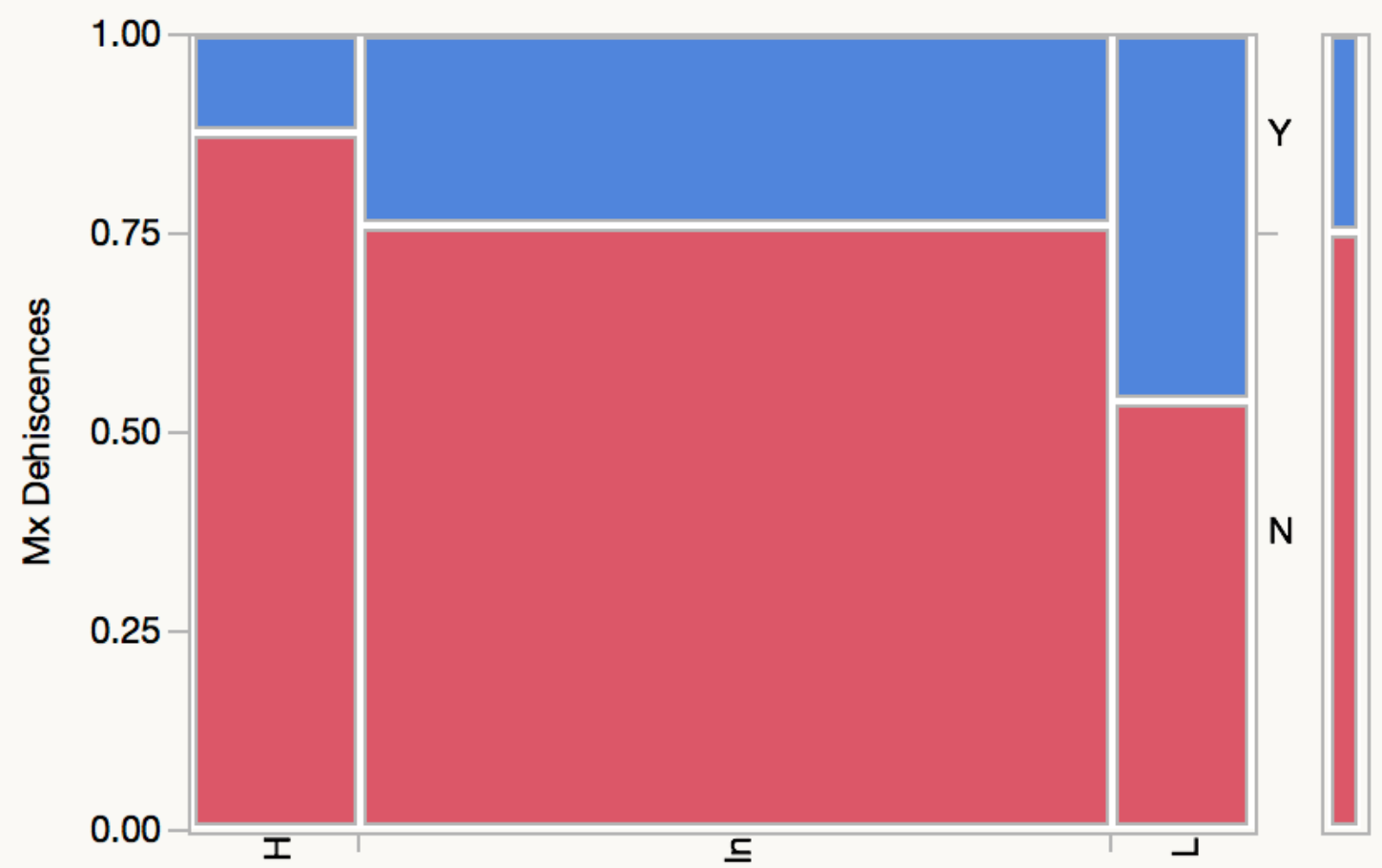

Range Mx Burstone

\section{Contingency Table}

Range Mx Burstone By Mx Dehiscences 


\begin{tabular}{|c|c|c|c|}
\hline $\begin{array}{l}\text { Count } \\
\text { Total \% } \\
\text { Col \% } \\
\text { Row \% }\end{array}$ & $\mathrm{N}$ & $\bar{Y}$ & Total \\
\hline $\mathrm{H}$ & $\begin{array}{r}14 \\
14.00 \\
18.67 \\
87.50\end{array}$ & $\begin{array}{r}2 \\
2.00 \\
8.00 \\
12.50\end{array}$ & $\begin{array}{r}16 \\
16.00\end{array}$ \\
\hline In & $\begin{array}{r}54 \\
54.00 \\
72.00 \\
76.06\end{array}$ & $\begin{array}{r}17 \\
17.00 \\
68.00 \\
23.94\end{array}$ & $\begin{array}{r}71 \\
71.00\end{array}$ \\
\hline $\mathrm{L}$ & $\begin{array}{r}7 \\
7.00 \\
9.33 \\
53.85\end{array}$ & $\begin{array}{r}6 \\
6.00 \\
24.00 \\
46.15\end{array}$ & $\begin{array}{r}13 \\
13.00\end{array}$ \\
\hline Total & $\begin{array}{r}75 \\
75.00\end{array}$ & $\begin{array}{r}25 \\
25.00\end{array}$ & 100 \\
\hline
\end{tabular}

Tests

$\begin{array}{rrrr}\mathbf{N} & \text { DF } & \text {-LogLike } & \text { RSquare (U) } \\ 100 & 2 & 2.1522722 & 0.0383\end{array}$

$\begin{array}{lrr}\text { Test } & \text { ChiSquare } & \text { Prob>ChiSq } \\ \text { Likelihood Ratio } & 4.305 & 0.1162 \\ \text { Pearson } & 4.478 & 0.1066\end{array}$

Warning: $20 \%$ of cells have expected count less than 5 , ChiSquare suspect.

Fit Group

Contingency Analysis of Mx Fenestrations By Range \% lower 
Mosaic Plot

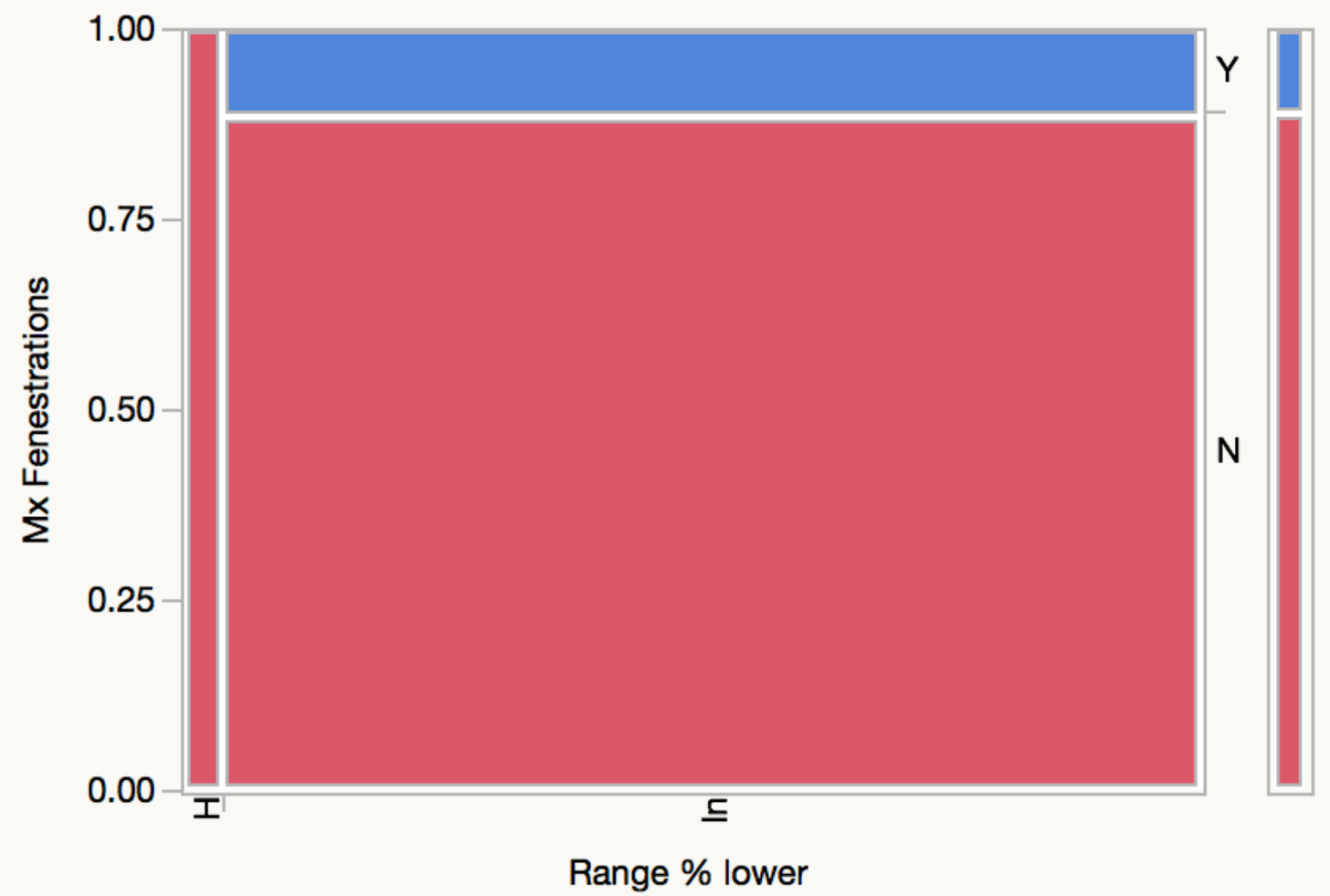

Contingency Table

Range \% lower By Mx Fenestrations

\begin{tabular}{|l|r|r|r|}
\hline Count & N & Y & Total \\
Total \% & & & \\
Row \% & & & \\
\hline H & 4 & 0.00 & 4.00 \\
& 4.00 & 0.00 & \\
& 100.00 & 0.00 & \\
\hline In & 85 & 11 & 96 \\
& 85.00 & 11.00 & 96.00 \\
& 95.51 & 100.00 & \\
& 88.54 & 11.46 & \\
\hline Total & 89 & 11 & \\
\hline
\end{tabular}




\begin{tabular}{|l|r|r|r|}
\hline & 89.00 & 11.00 & \\
\hline
\end{tabular}

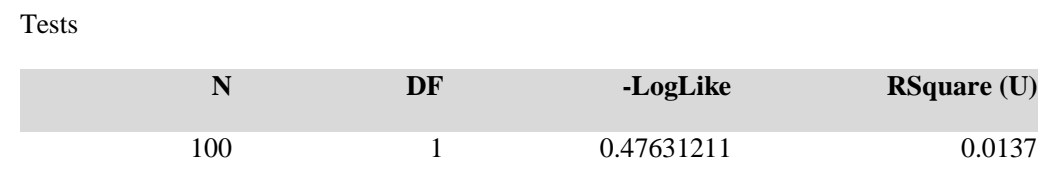

$\begin{array}{lrr}\text { Test } & \text { ChiSquare } & \text { Prob>ChiSq } \\ \text { Likelihood Ratio } & 0.953 & 0.3291 \\ \text { Pearson } & 0.515 & 0.4730\end{array}$

$\begin{array}{ll}\text { Fisher's Exact Test } & \text { ProbAlternative Hypothesis } \\ \text { Left } & \text { 1.0000Prob(Mx Fenestrations=Y) is greater for Range \% lower=H than In } \\ \text { Right } & 0.6227 \mathrm{Prob}(\mathrm{Mx} \text { Fenestrations=Y) is greater for Range \% lower=In than H } \\ \text { 2-Tail } & \text { 1.0000Prob(Mx Fenestrations=Y) is different across Range \% lower }\end{array}$

Contingency Analysis of Mx Dehiscences By Range \% lower

Mosaic Plot 


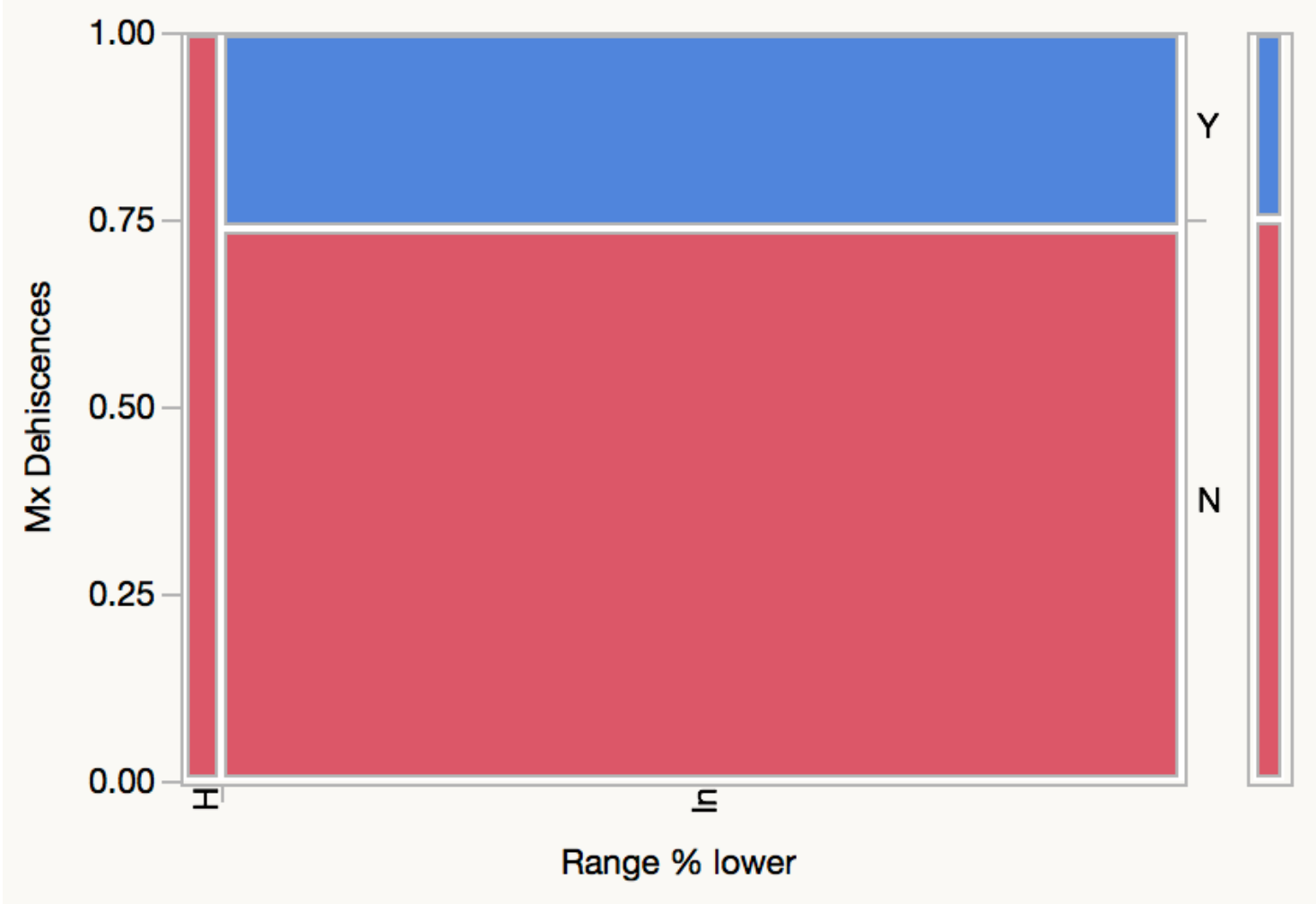

Contingency Table

Range \% lower By Mx Dehiscences

\begin{tabular}{|l|r|r|r|}
\hline Count & N & Y & Total \\
Total \% & & & \\
Row \% & & & \\
\hline H & 4.00 & 0.00 & 4.00 \\
& 5.33 & 0.00 & \\
& 100.00 & 0.00 & \\
\hline In & 71 & 25 & 96 \\
& 71.00 & 25.00 & 96.00 \\
& 94.67 & 100.00 & \\
\hline Total & 73.96 & 26.04 & \\
\hline & 75.00 & 25.00 & \\
\hline
\end{tabular}


Tests

\begin{tabular}{rrrr}
$\mathbf{N}$ & DF & -LogLike & RSquare (U) \\
\hline 100 & 1 & 1.1782550 & 0.0210
\end{tabular}

$\begin{array}{lrr}\text { Test } & \text { ChiSquare } & \text { Prob>ChiSq } \\ \text { Likelihood Ratio } & 2.357 & 0.1248 \\ \text { Pearson } & 1.389 & 0.2386\end{array}$

Fisher's Exact Test $\begin{aligned} & \text { ProbAlternative Hypothesis } \\ & \text { 1.0000Prob(Mx Dehiscences=Y) is greater for Range \% lower=H than In } \\ & \text { Left } \\ & \text { Right } \\ & \text { 2-Tail }\end{aligned}$ 0.5695Prob(Mx Dehiscences=Y) is different across Range \% lower

Distributions

Sex

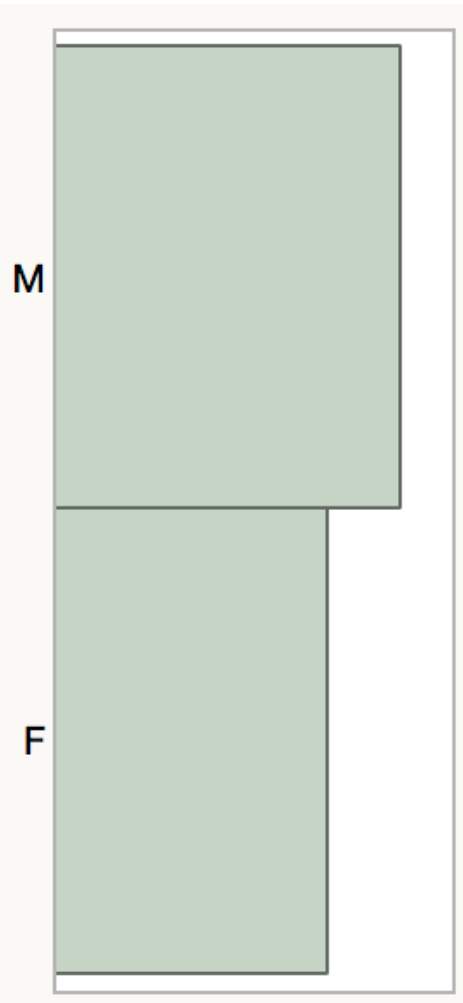




\section{Frequencies}

$\begin{array}{lrr}\text { Level } & \text { Count } & \text { Prob } \\ \text { F } & 44 & 0.44000 \\ \text { M } & 56 & 0.56000 \\ \text { Total } & 100 & 1.00000\end{array}$

N Missing0

2 Levels Age

18

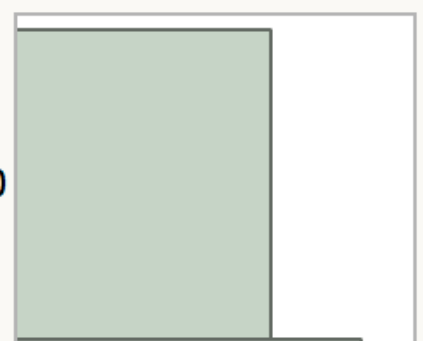

17
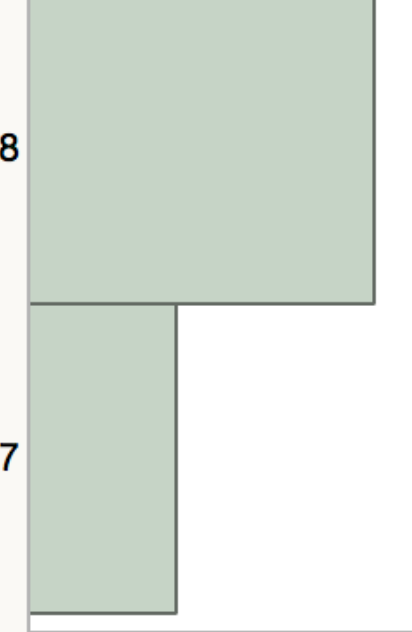

\section{Frequencies}

$\begin{array}{lrr}\text { Level } & \text { Count } & \text { Prob } \\ 17 & 20 & 0.20000 \\ 18 & 46 & 0.46000 \\ 20 & 34 & 0.34000 \\ \text { Total } & 100 & 1.00000\end{array}$

N Missing0

3 Levels 
Distributions

Range Downs

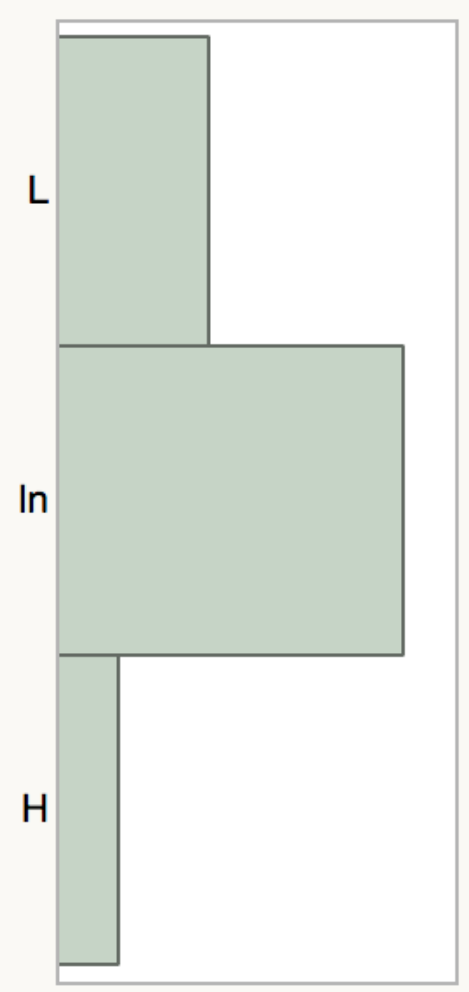

Frequencies

$\begin{array}{lrr}\text { Level } & \text { Count } & \text { Prob } \\ \text { H } & 11 & 0.11000 \\ \text { In } & 62 & 0.62000 \\ \text { L } & 27 & 0.27000 \\ \text { Total } & 100 & 1.00000\end{array}$

N Missing0 


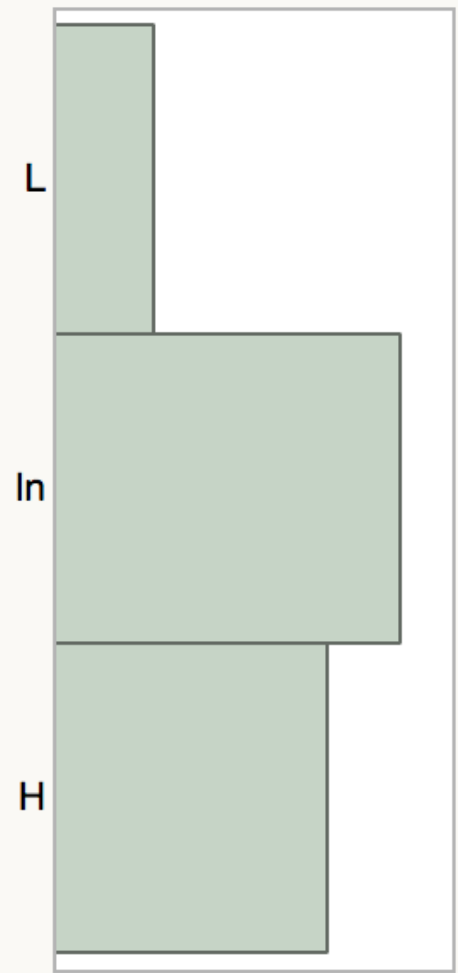

Frequencies

$\begin{array}{lrr}\text { Level } & \text { Count } & \text { Prob } \\ \mathrm{H} & 38 & 0.38000 \\ \text { In } & 48 & 0.48000 \\ \mathrm{~L} & 14 & 0.14000 \\ \text { Total } & 100 & 1.00000\end{array}$

N Missing0 


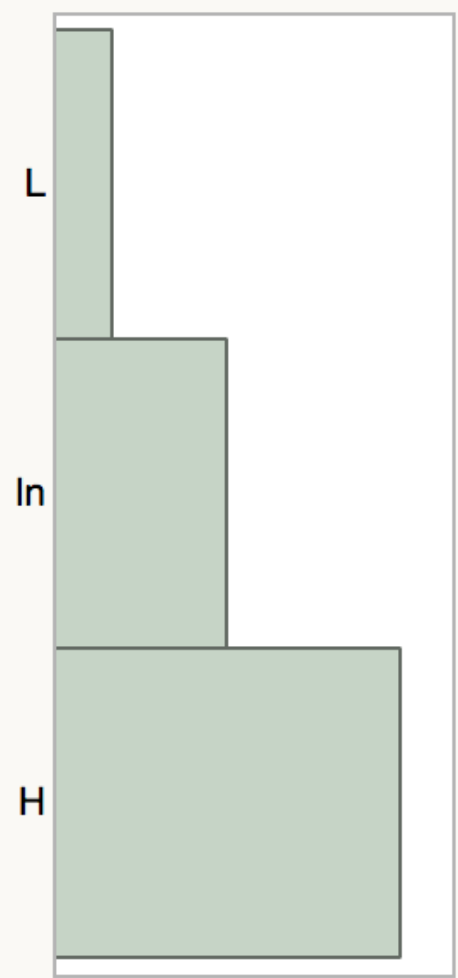

Frequencies

$\begin{array}{lrr}\text { Level } & \text { Count } & \text { Prob } \\ \text { H } & 60 & 0.60000 \\ \text { In } & 30 & 0.30000 \\ \text { L } & 10 & 0.10000 \\ \text { Total } & 100 & 1.00000\end{array}$

N Missing0 
Range Andrews

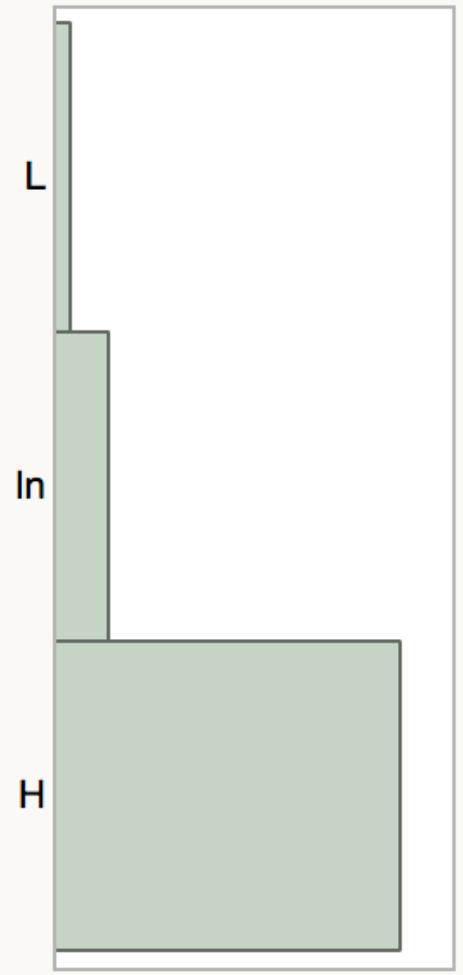

Frequencies

$\begin{array}{lrr}\text { Level } & \text { Count } & \text { Prob } \\ \text { H } & 83 & 0.83000 \\ \text { In } & 13 & 0.13000 \\ \text { L } & 4 & 0.04000 \\ \text { Total } & 100 & 1.00000\end{array}$

N Missing0 
Range Ricketts

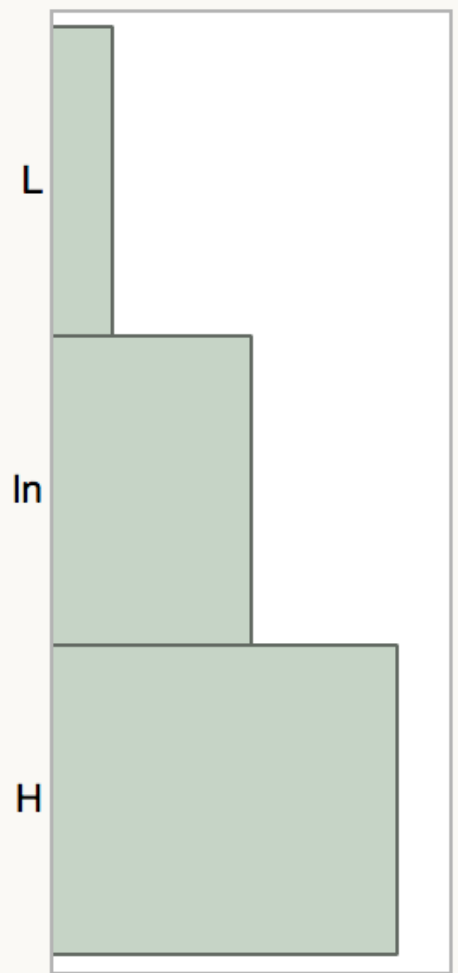

Frequencies

$\begin{array}{lrr}\text { Level } & \text { Count } & \text { Prob } \\ \text { H } & 57 & 0.57000 \\ \text { In } & 33 & 0.33000 \\ \text { L } & 10 & 0.10000 \\ \text { Total } & 100 & 1.00000\end{array}$

N Missing0 
Range ANB

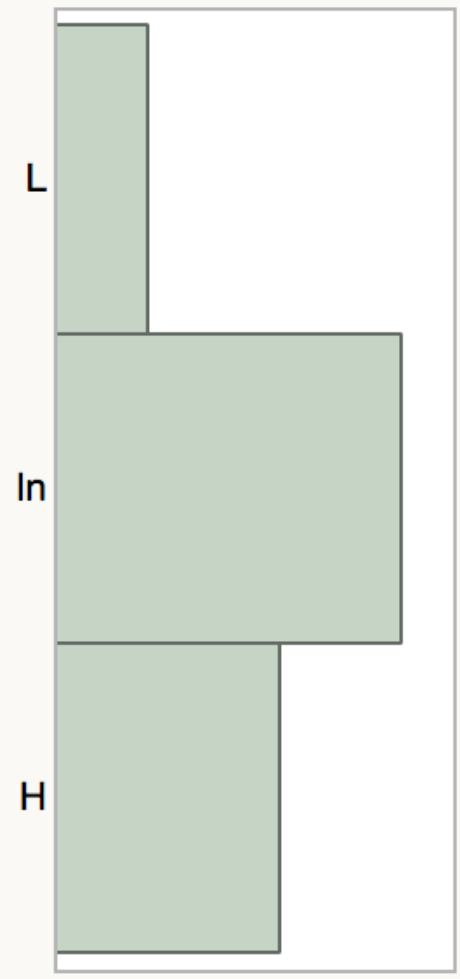

Frequencies

$\begin{array}{lrr}\text { Level } & \text { Count } & \text { Prob } \\ \mathrm{H} & 34 & 0.34000 \\ \text { In } & 52 & 0.52000 \\ \mathrm{~L} & 14 & 0.14000 \\ \text { Total } & 100 & 1.00000\end{array}$

N Missing0 


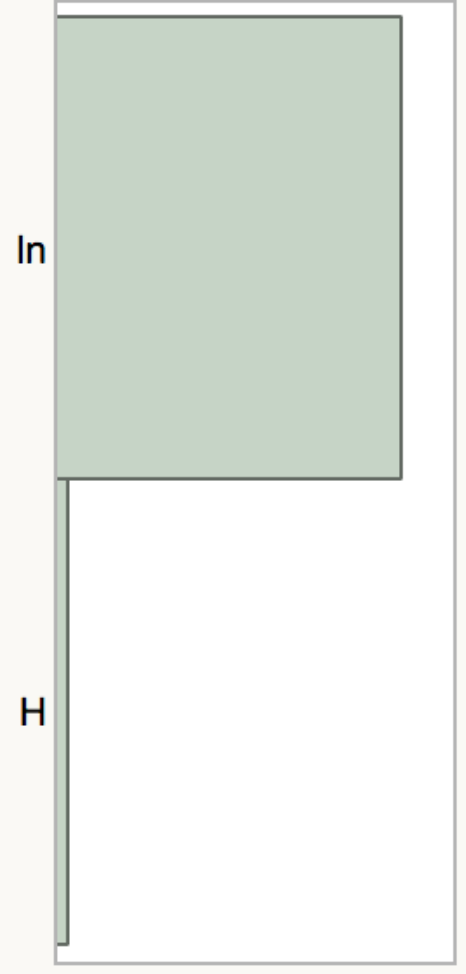

Frequencies

$\begin{array}{lrr}\text { Level } & \text { Count } & \text { Prob } \\ \mathrm{H} & 4 & 0.04000 \\ \text { In } & 96 & 0.96000 \\ \text { Total } & 100 & 1.00000\end{array}$

N Missing0 
Range Mx Andrews

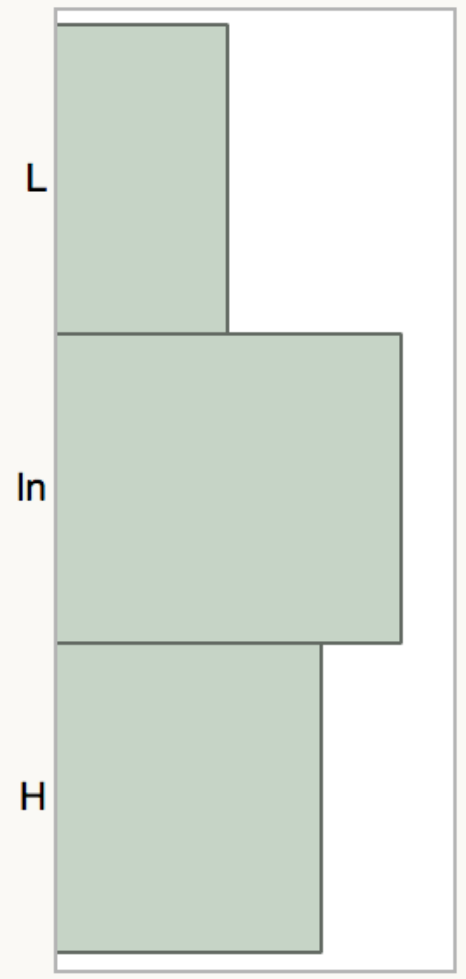

Frequencies

$\begin{array}{lrr}\text { Level } & \text { Count } & \text { Prob } \\ \mathrm{H} & 34 & 0.34000 \\ \mathrm{In} & 44 & 0.44000 \\ \mathrm{~L} & 22 & 0.22000 \\ \text { Total } & 100 & 1.00000\end{array}$

N Missing0 


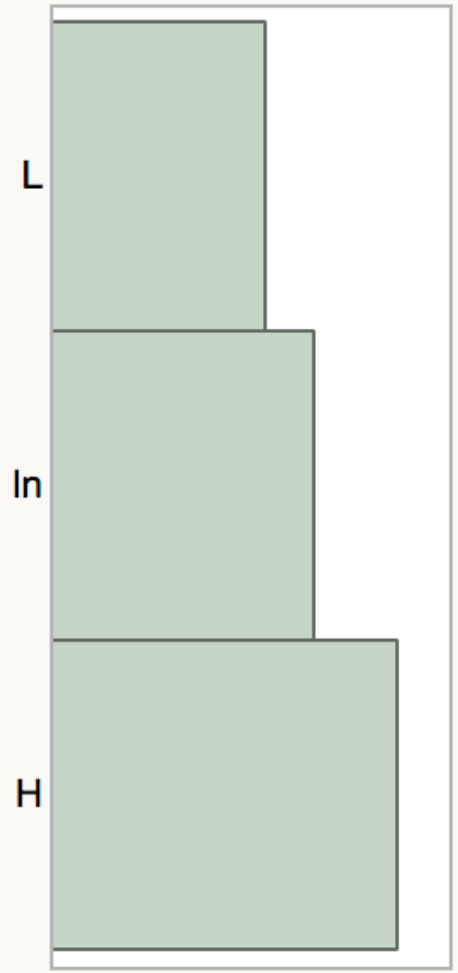

Frequencies

$\begin{array}{lrr}\text { Level } & \text { Count } & \text { Prob } \\ \text { H } & 42 & 0.42000 \\ \text { In } & 32 & 0.32000 \\ \text { L } & 26 & 0.26000 \\ \text { Total } & 100 & 1.00000\end{array}$

N Missing0 


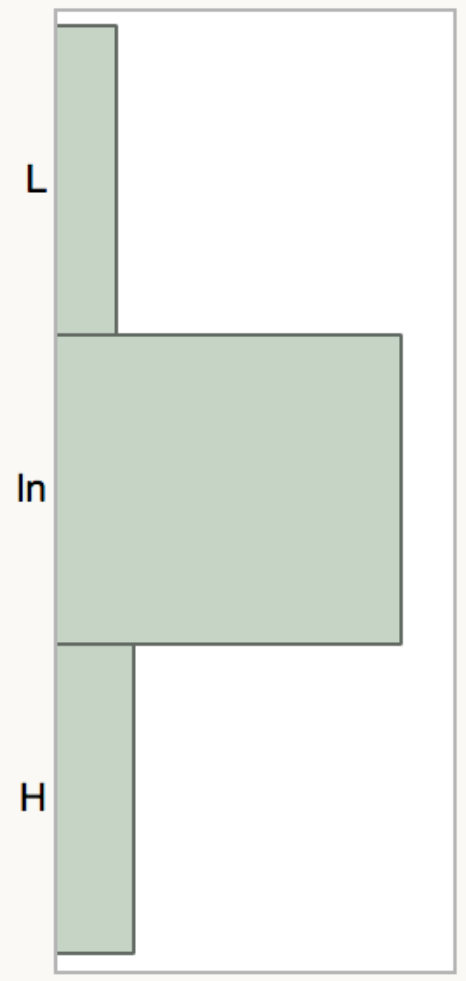

Frequencies

$\begin{array}{lrr}\text { Level } & \text { Count } & \text { Prob } \\ \mathrm{H} & 16 & 0.16000 \\ \text { In } & 71 & 0.71000 \\ \mathrm{~L} & 13 & 0.13000 \\ \text { Total } & 100 & 1.00000\end{array}$

N Missing0

3 Levels 
Bivariate Fit of diff CR apex md By MdDowns

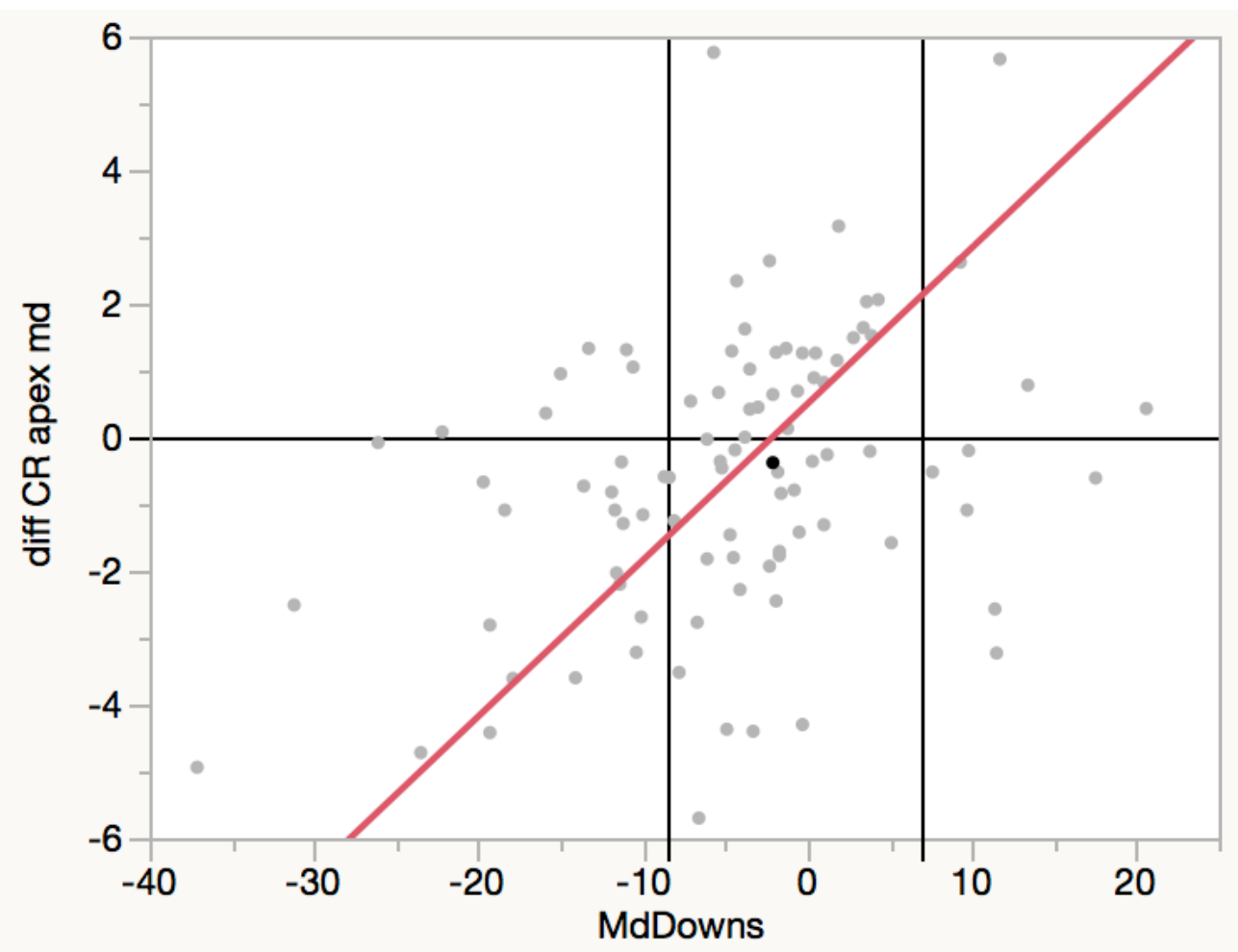

\section{Orthogonal Fit Ratio $=0.055$}

Orthogonal Fit Ratio=0.055

$\begin{array}{lrrrr}\text { Variable } & \text { Mean } & \text { Std Dev } & \text { Variance Ratio } & \text { Correlation } \\ \text { MdDowns } & -4.4558 & 9.615646 & 0.054649 & 0.3877 \\ \text { diff CR apex md } & -0.5428 & 2.24786 & & \end{array}$

\begin{tabular}{|rrrrr}
\hline Intercept & Slope & LowerCL & UpperCL & Alpha \\
\hline 0.498837 & 0.233771 & 0.139169 & 0.392681 & 0.05000
\end{tabular}


Bivariate Fit of diff CR apex md By MdSteiner

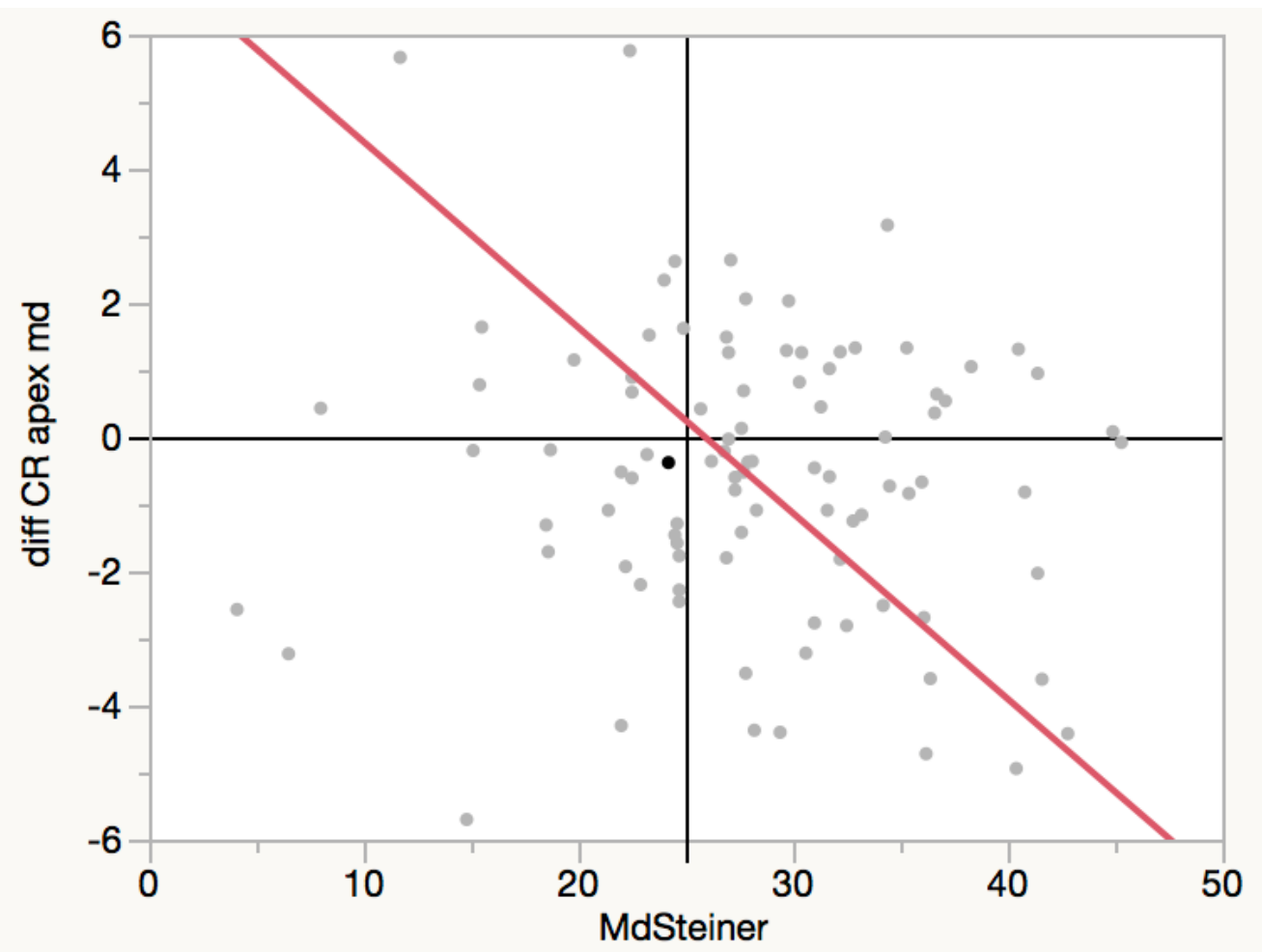

\section{Orthogonal Fit Ratio $=0.077$}

Orthogonal Fit Ratio=0.077

$\begin{array}{lrrrr}\text { Variable } & \text { Mean } & \text { Std Dev } & \text { Variance Ratio } & \text { Correlation } \\ \text { MdSteiner } & 27.868 & 8.121027 & 0.076615 & -0.1031 \\ \text { diff CR apex md } & -0.5428 & 2.24786 & & \end{array}$

\begin{tabular}{rrrrr} 
Intercept & Slope & LowerCL & UpperCL & Alpha \\
\hline 7.170922 & -0.27679 &. & & 0.05000
\end{tabular}


Bivariate Fit of diff CR apex md By MdTweed

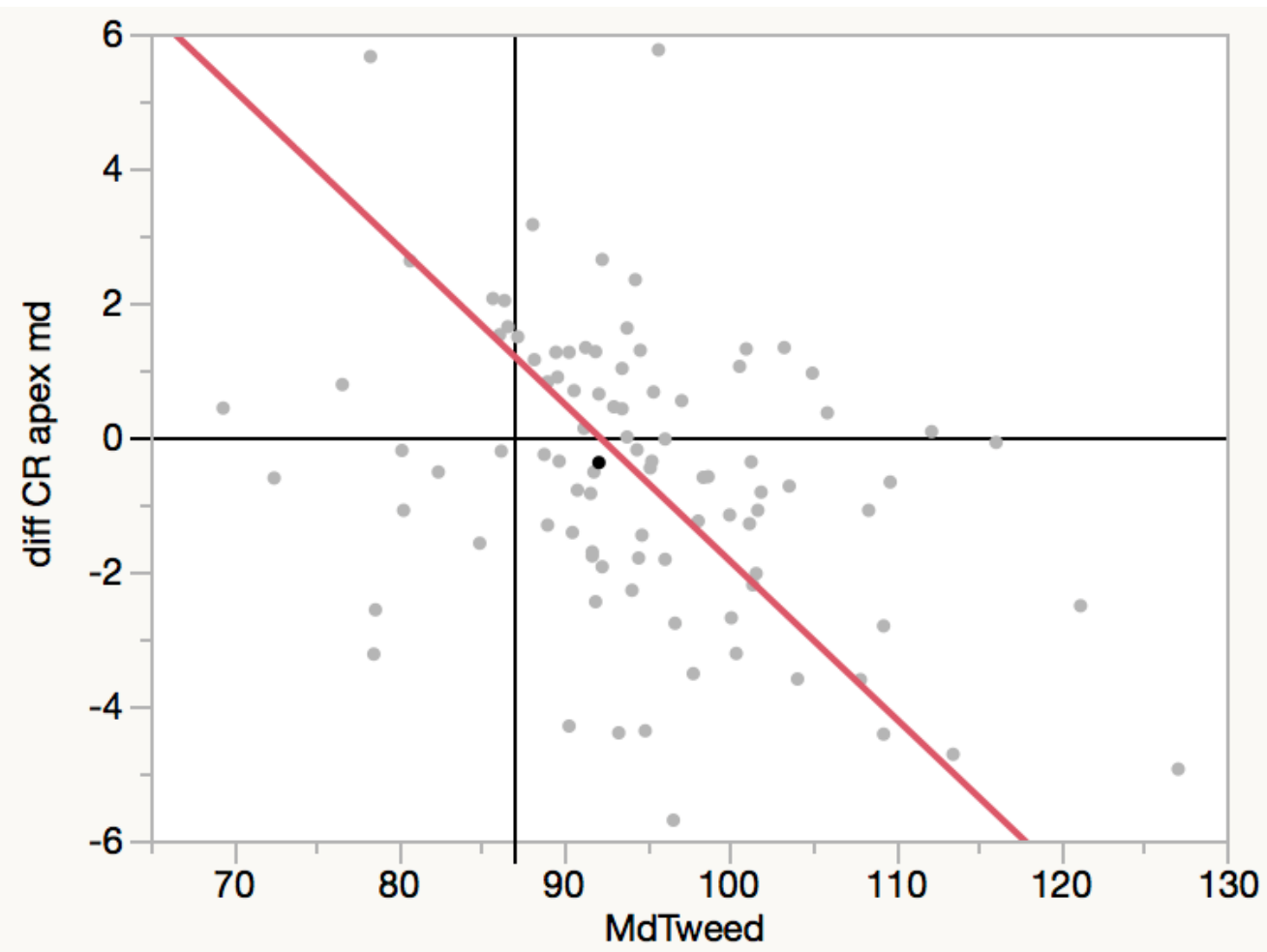

\section{Orthogonal Fit Ratio $=0.055$}

Orthogonal Fit Ratio=0.055

$\begin{array}{lrrrr}\text { Variable } & \text { Mean } & \text { Std Dev } & \text { Variance Ratio } & \text { Correlation } \\ \text { MdTweed } & 94.4558 & 9.615646 & 0.054649 & -0.3877 \\ \text { diff CR apex md } & -0.5428 & 2.24786 & & \end{array}$

\begin{tabular}{rrrrr} 
Intercept & Slope & LowerCL & UpperCL & Alpha \\
\hline 21.53823 & -0.23377 & -0.39268 & -0.13917 & 0.05000
\end{tabular}


Bivariate Fit of diff CR apex md By MdAndrews

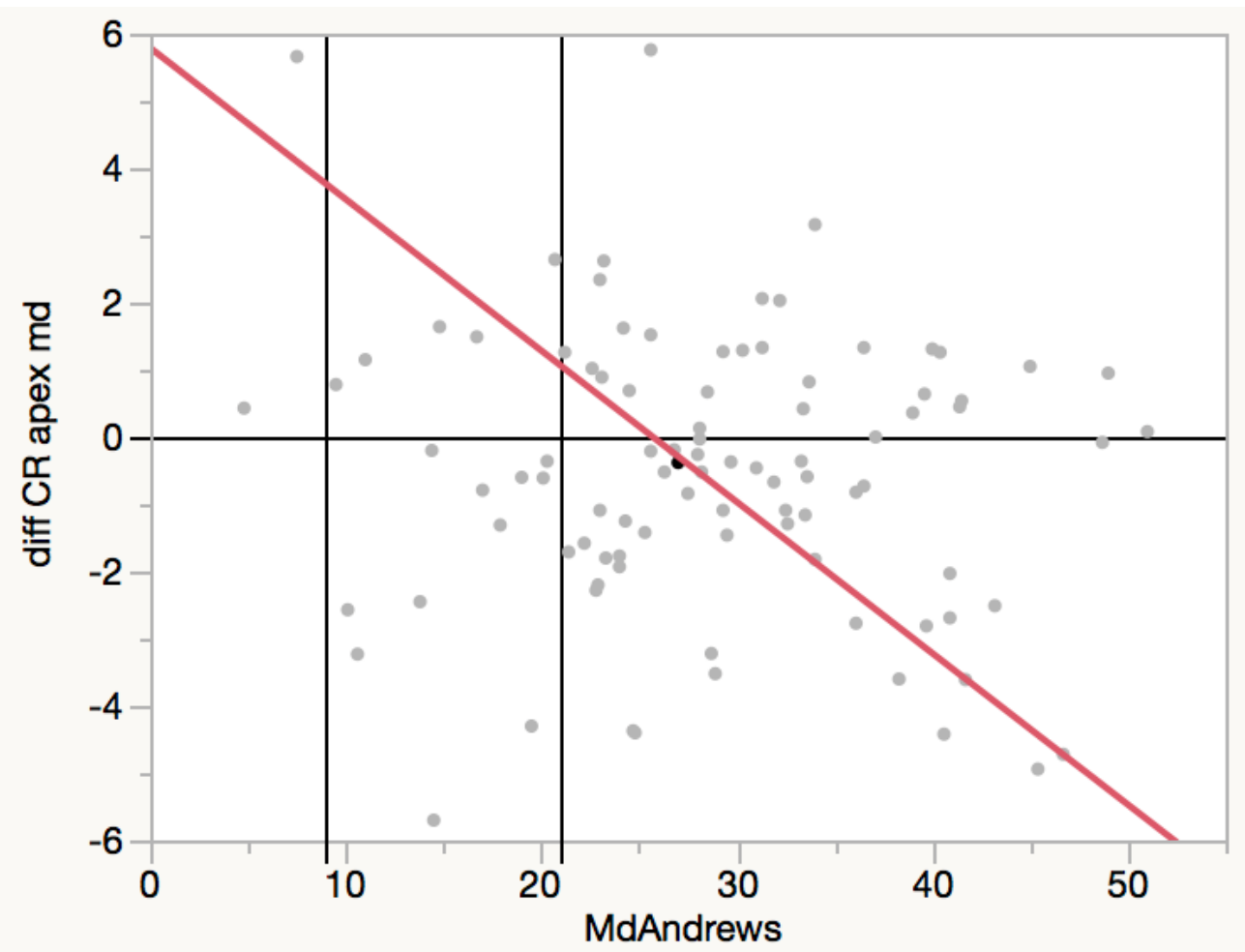

\section{Orthogonal Fit Ratio $=0.051$}

Orthogonal Fit Ratio=0.051

$\begin{array}{lrrrr}\text { Variable } & \text { Mean } & \text { Std Dev } & \text { Variance Ratio } & \text { Correlation } \\ \text { MdAndrews } & 28.125 & 9.986914 & 0.050661 & -0.1381 \\ \text { diff CR apex md } & -0.5428 & 2.24786 & & \end{array}$

\begin{tabular}{rrrrr} 
Intercept & Slope & LowerCL & UpperCL & Alpha \\
\hline 5.787589 & -0.22508 &. & & 0.05000
\end{tabular}


Bivariate Fit of diff CR apex md By MdRicketts

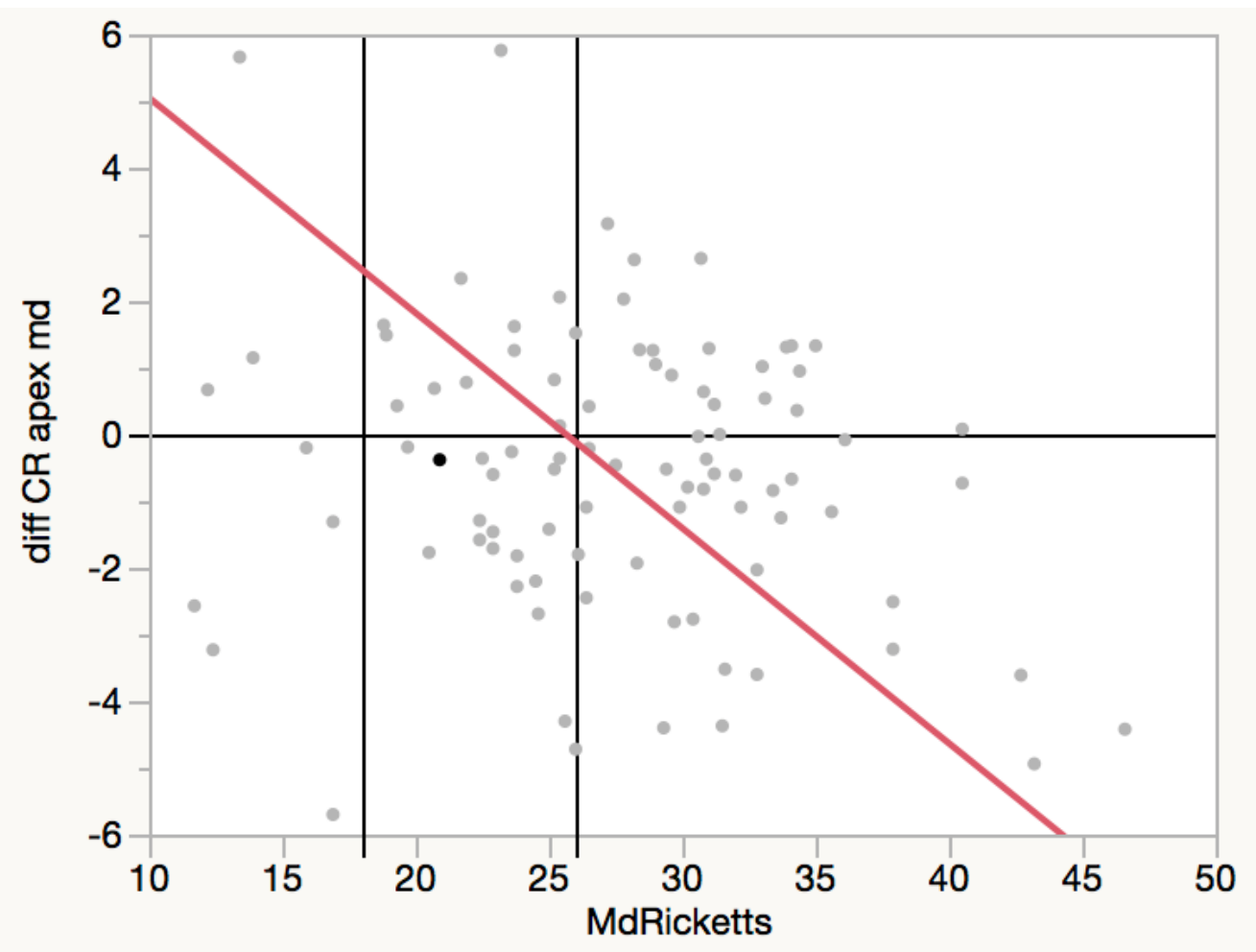

\section{Orthogonal Fit Ratio=0.104}

Orthogonal Fit Ratio=0.104

$\begin{array}{lrrrr}\text { Variable } & \text { Mean } & \text { Std Dev } & \text { Variance Ratio } & \text { Correlation } \\ \text { MdRicketts } & 27.329 & 6.965866 & 0.104133 & -0.1991 \\ \text { diff CR apex md } & -0.5428 & 2.24786 & & \end{array}$

\begin{tabular}{rrrrr} 
Intercept & Slope & LowerCL & UpperCL & Alpha \\
\hline 8.276169 & -0.3227 & -3.92779 & -0.02651 & 0.05000
\end{tabular}


Bivariate Fit of Md B Bone CR - Md L Bone CR By MdDowns

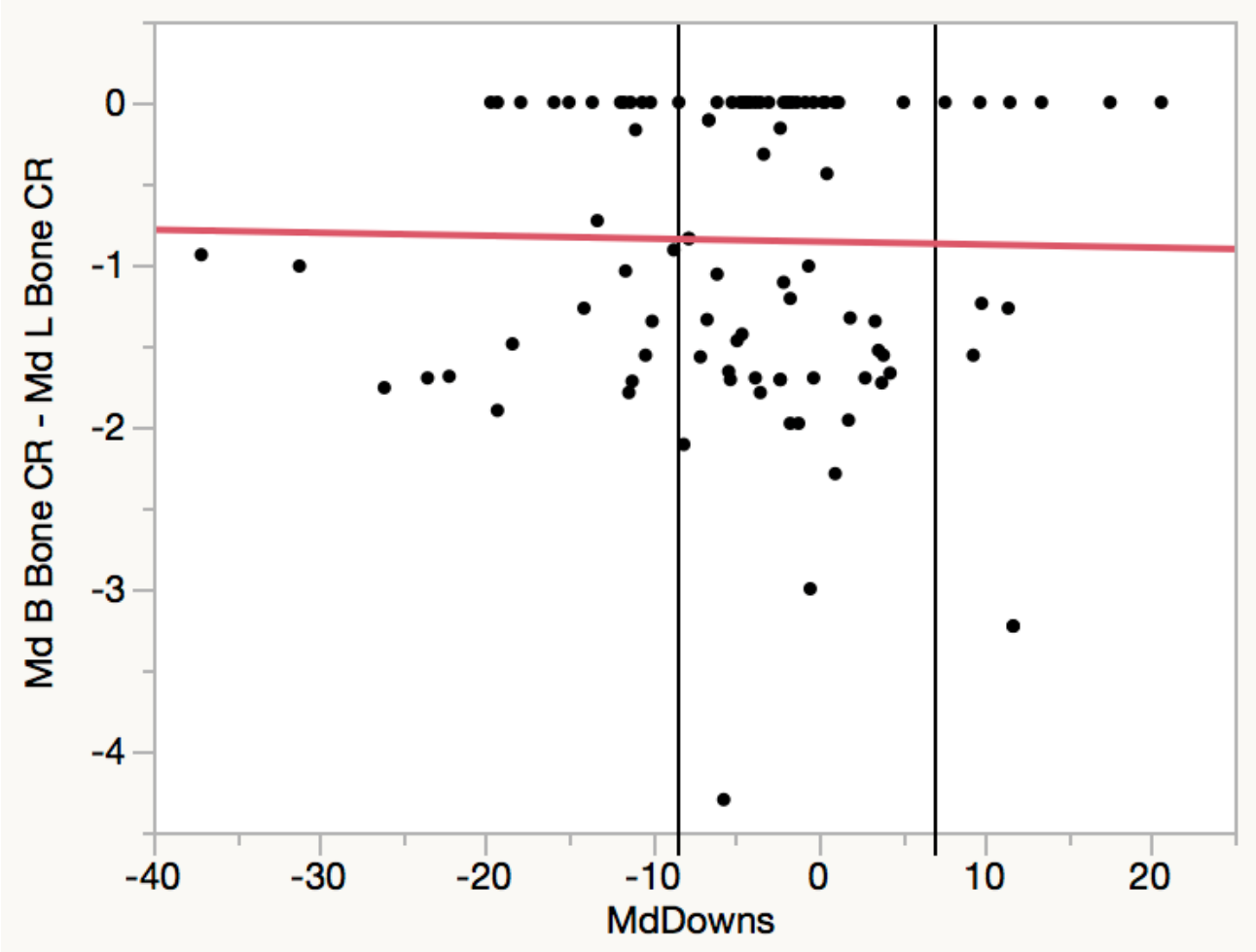

_Linear Fit 
Bivariate Fit of Md B Bone Apex-Md L Bone Apex By MdDowns

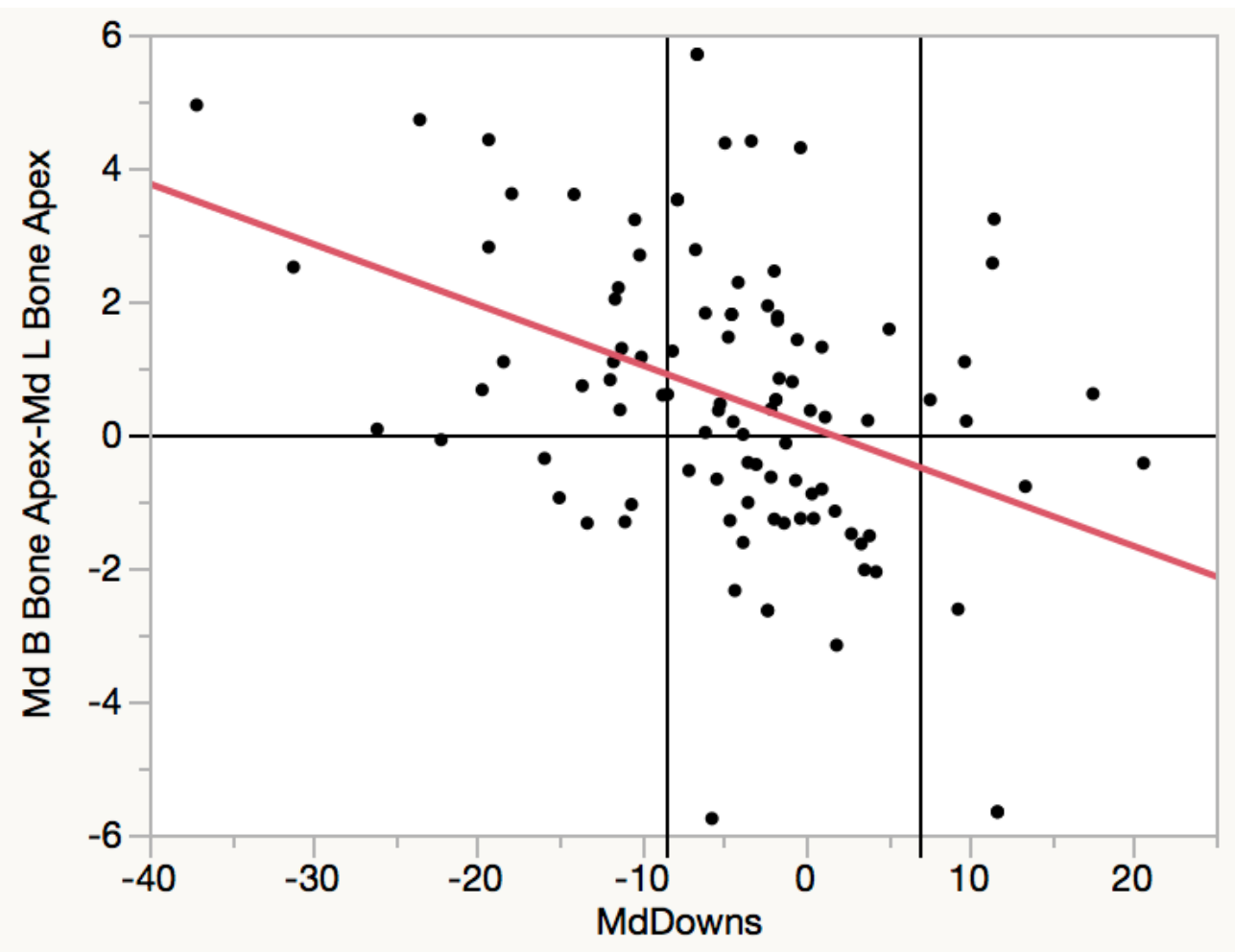

Linear Fit 
Bivariate Fit of Md B Bone CR - Md L Bone CR By MdSteiner

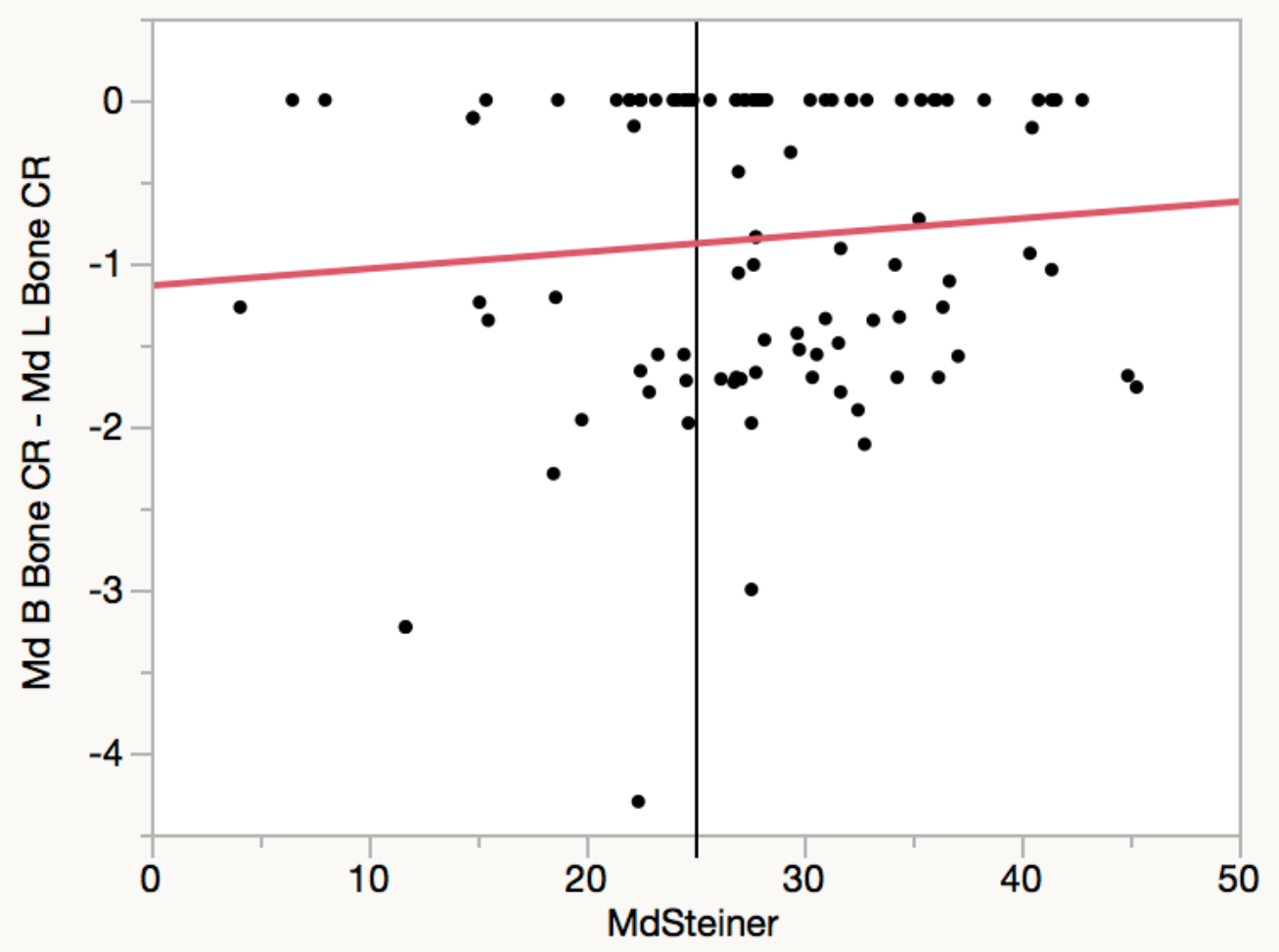

Linear Fit 
Bivariate Fit of Md B Bone Apex-Md L Bone Apex By MdSteiner

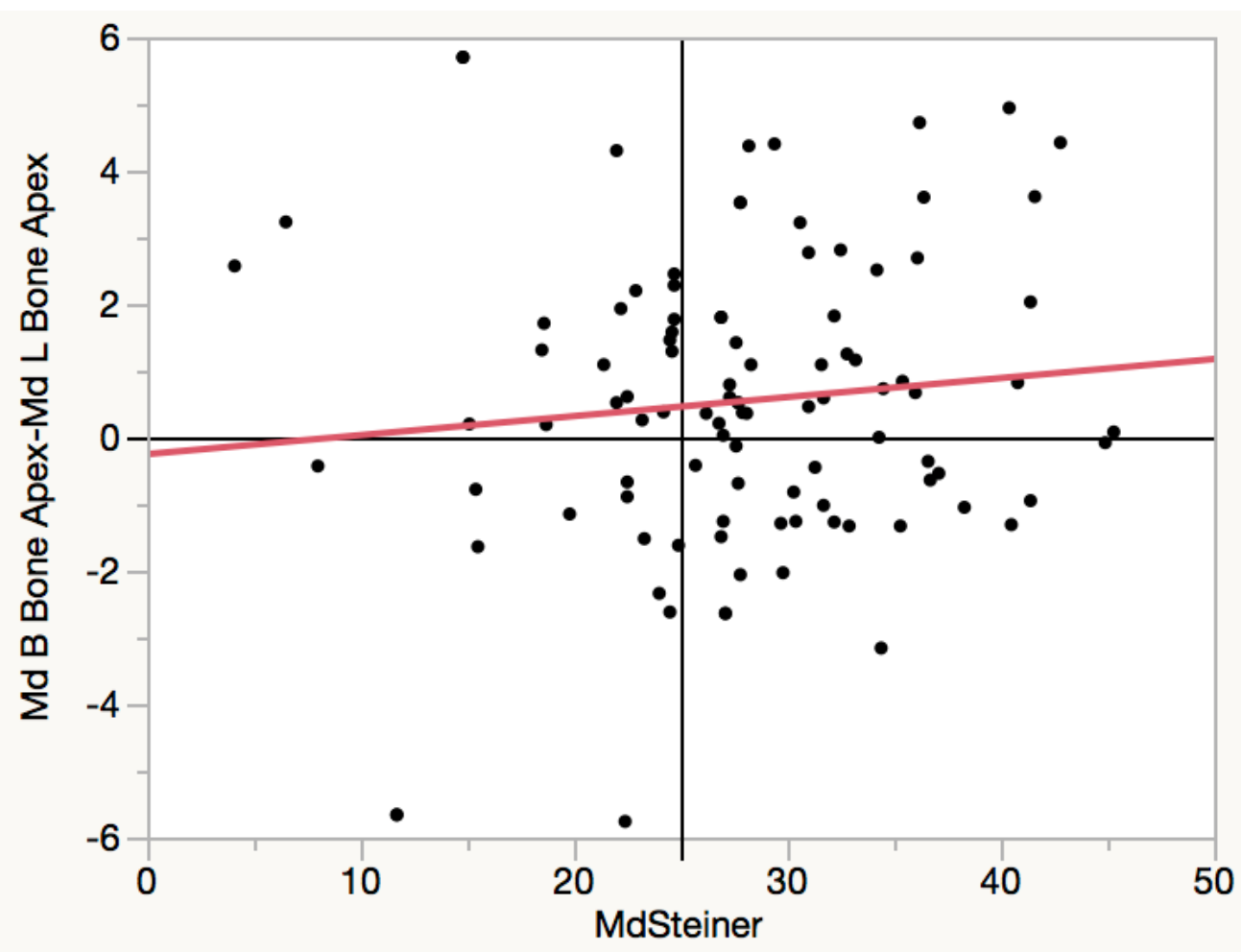

Linear Fit 
Bivariate Fit of Md B Bone CR - Md L Bone CR By MdTweed

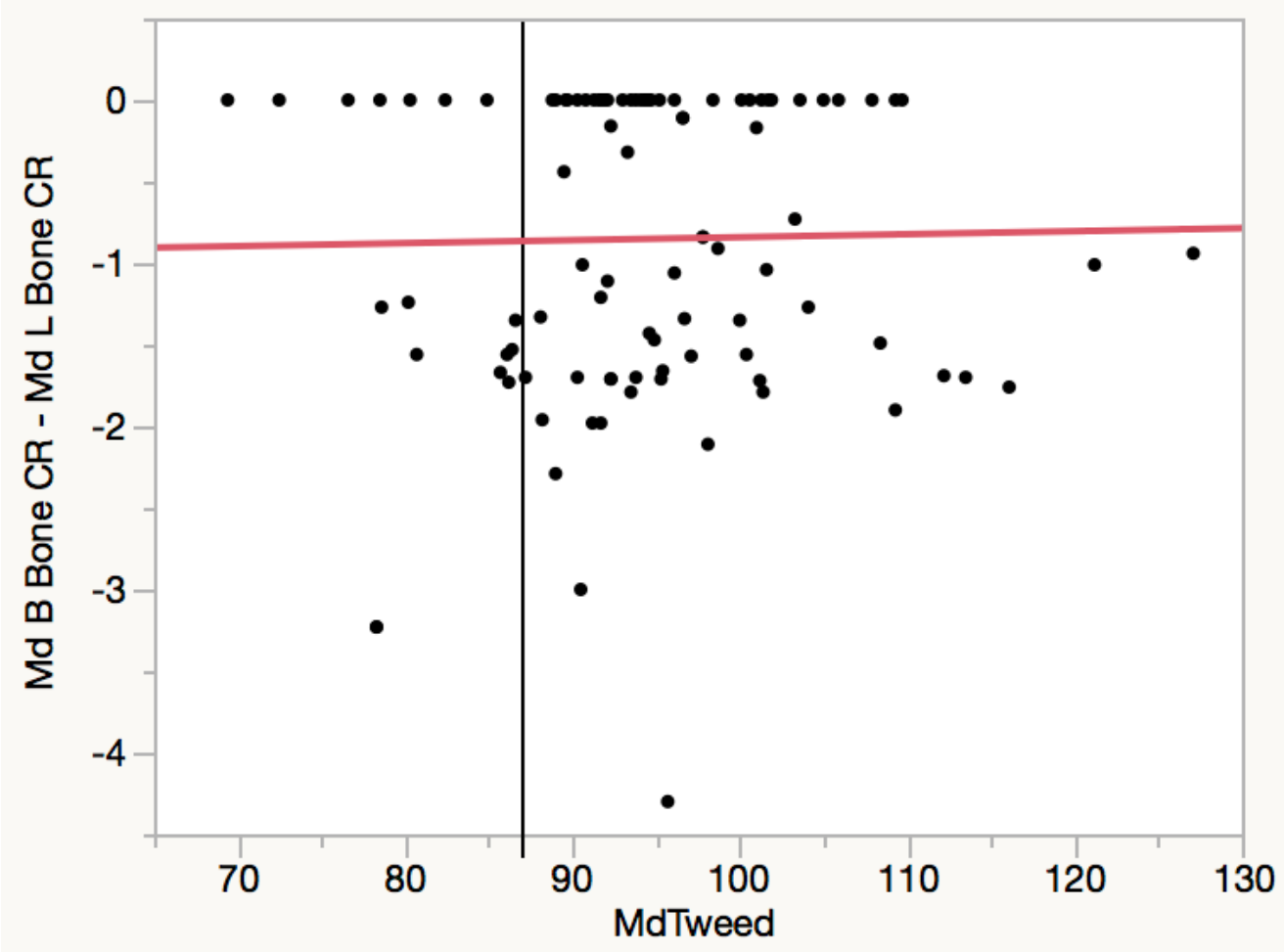

Linear Fit 
Bivariate Fit of Md B Bone Apex-Md L Bone Apex By MdTweed

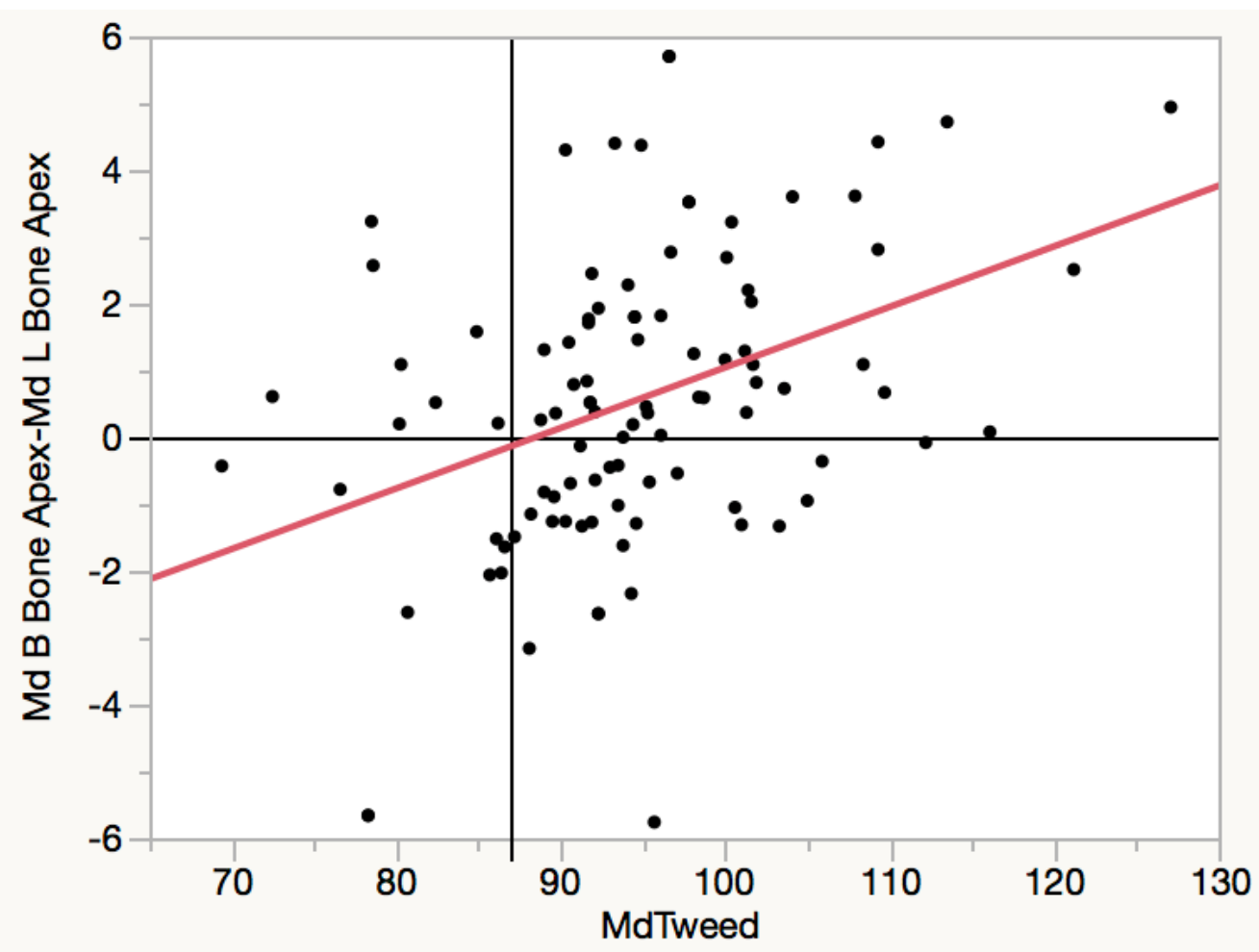

Linear Fit 
Bivariate Fit of Md B Bone CR - Md L Bone CR By MdAndrews

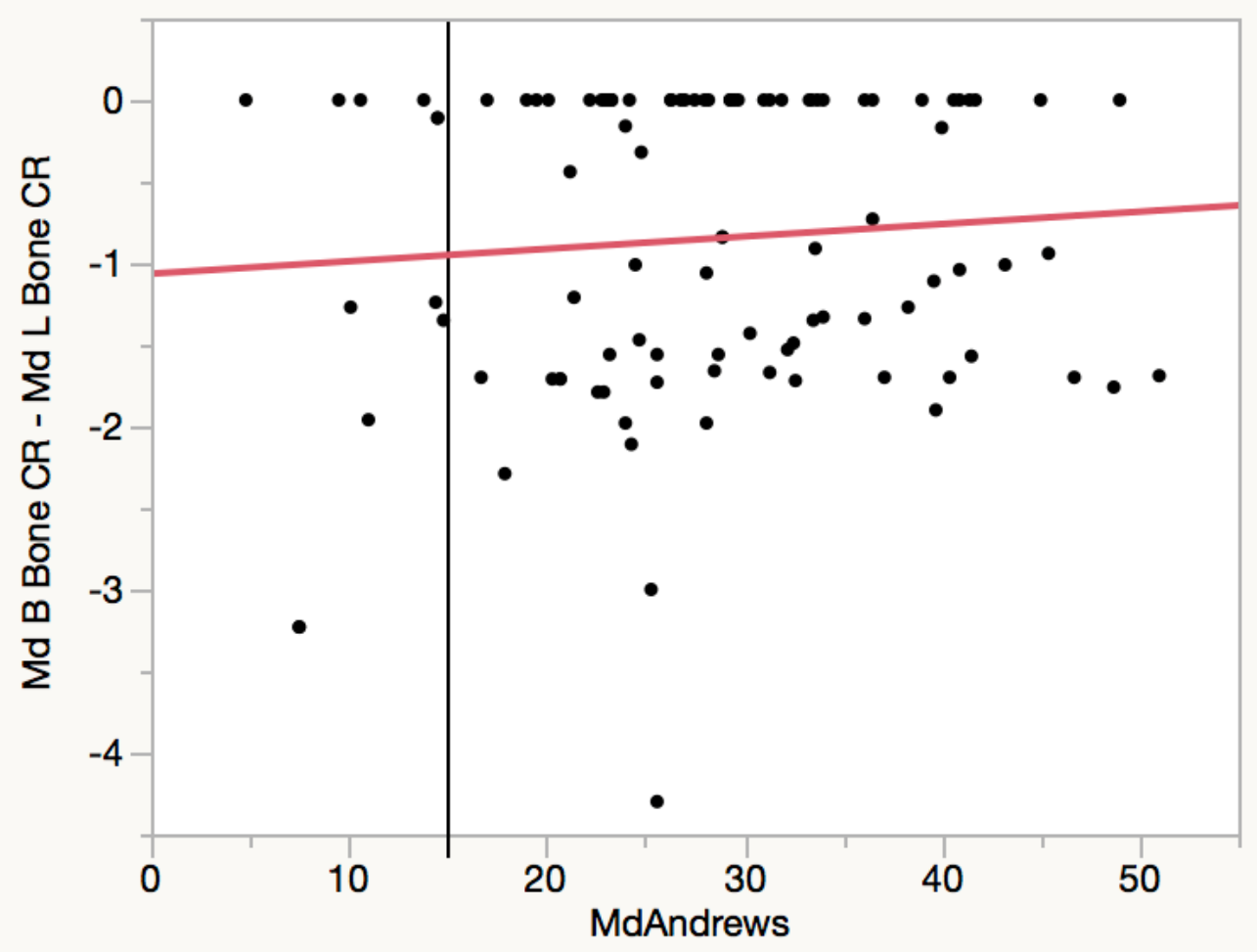

Linear Fit 
Bivariate Fit of Md B Bone Apex-Md L Bone Apex By MdAndrews

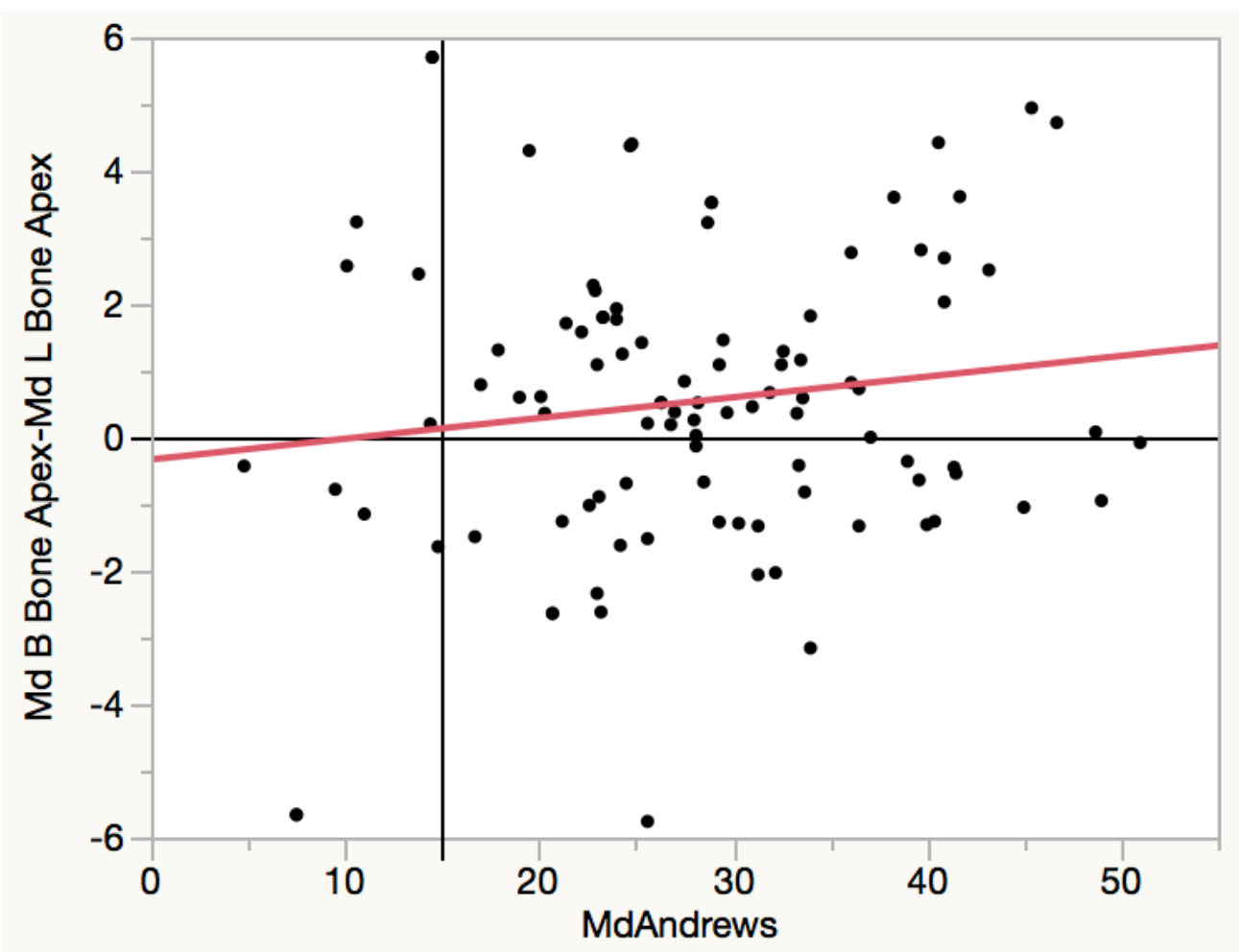

Linear Fit 
Bivariate Fit of Md B Bone CR - Md L Bone CR By MdRicketts

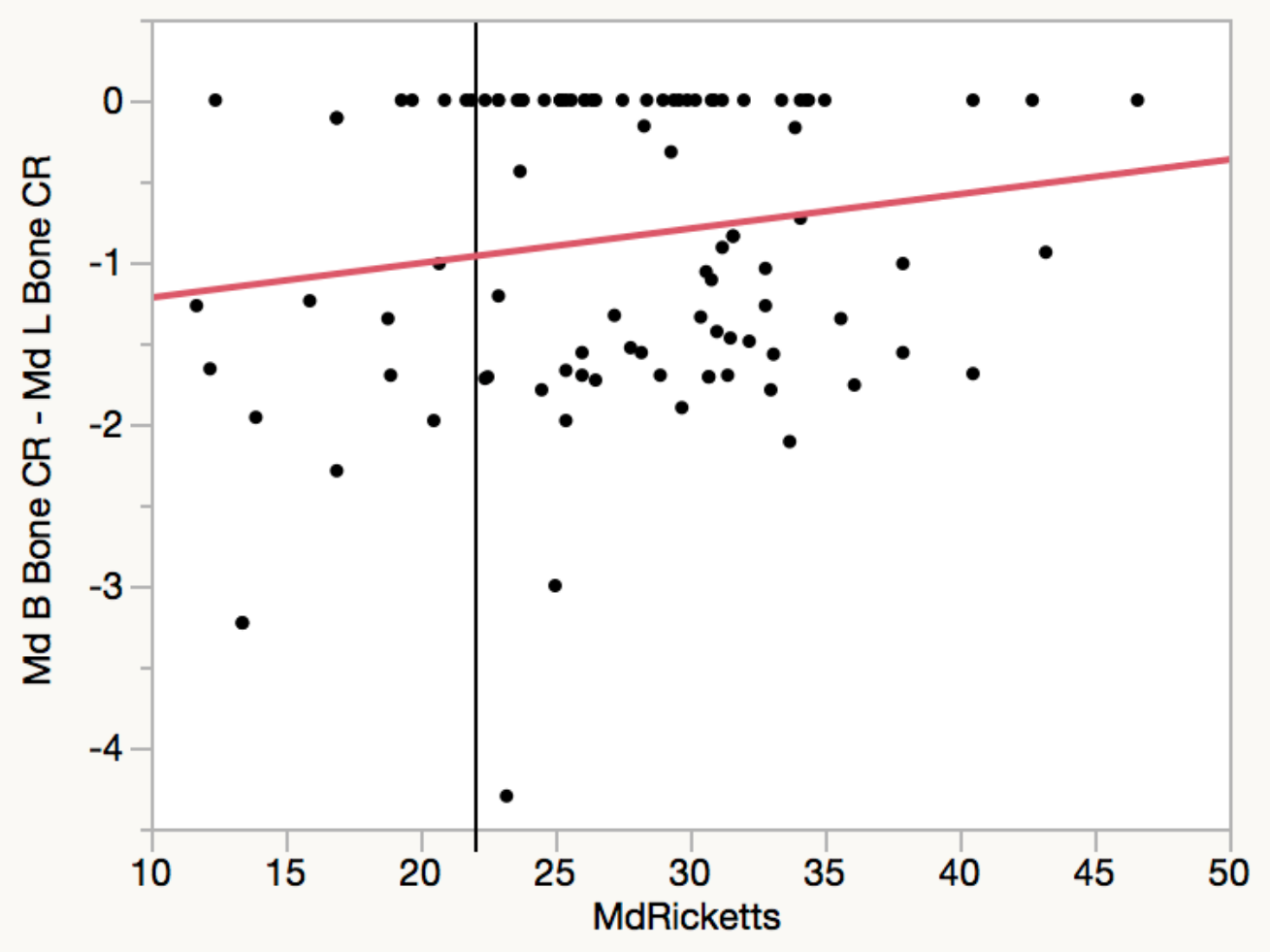

Linear Fit 
Bivariate Fit of Md B Bone Apex-Md L Bone Apex By MdRicketts

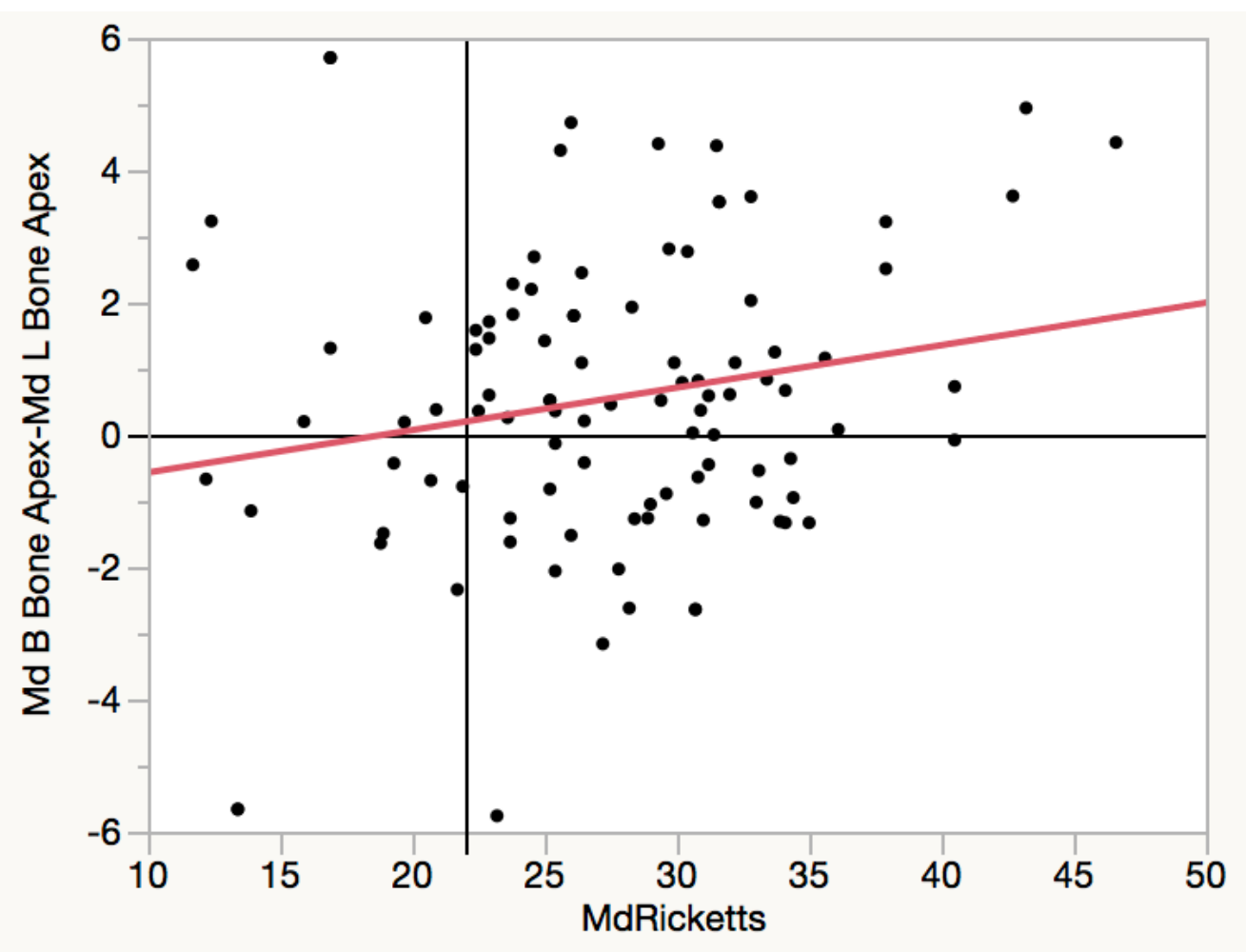

\section{Linear Fit}

Fit Group

Oneway Analysis of diff CR By Skel Class Mx 


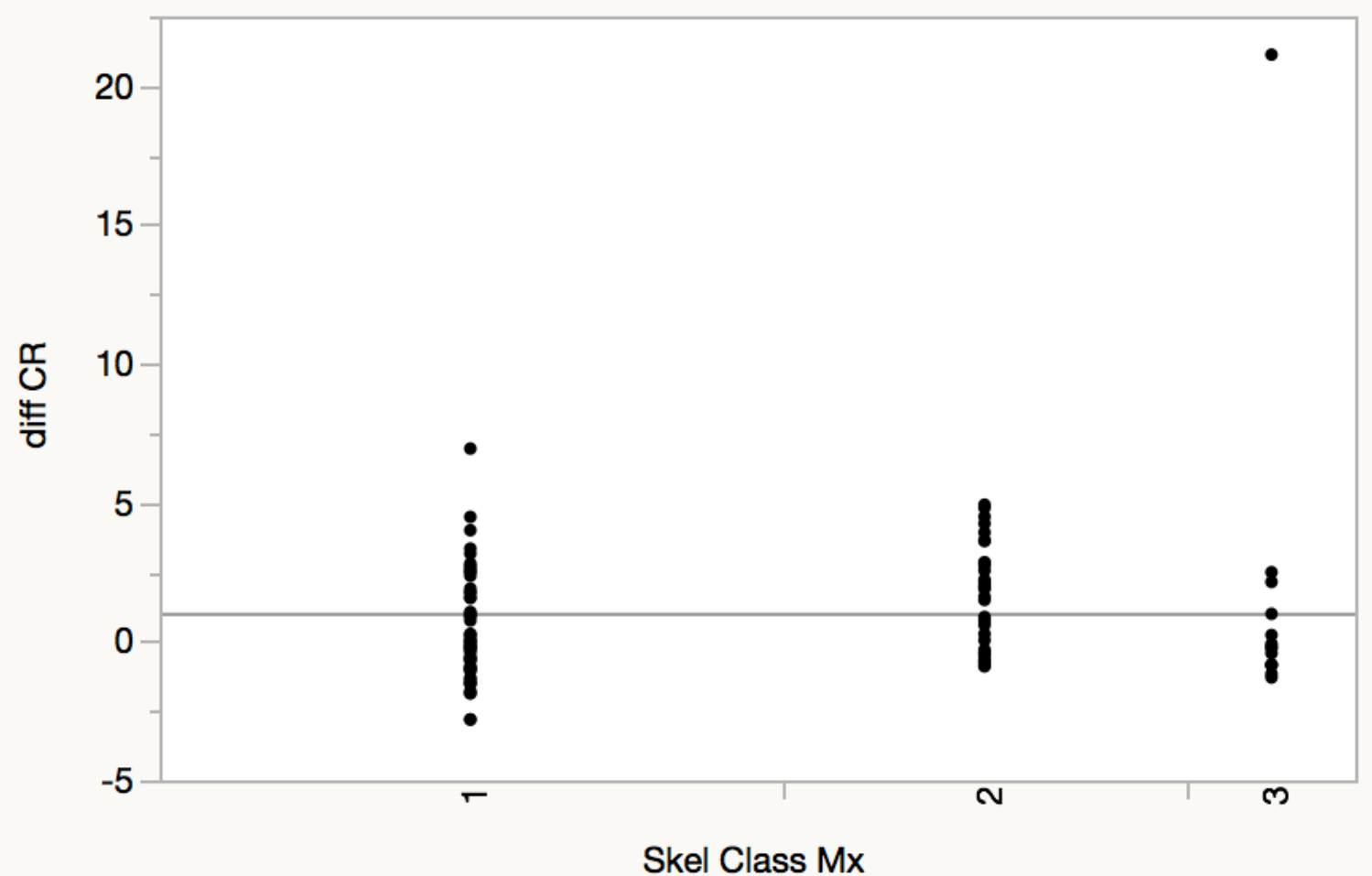

Oneway Analysis of diff CR apex By Skel Class Mx 


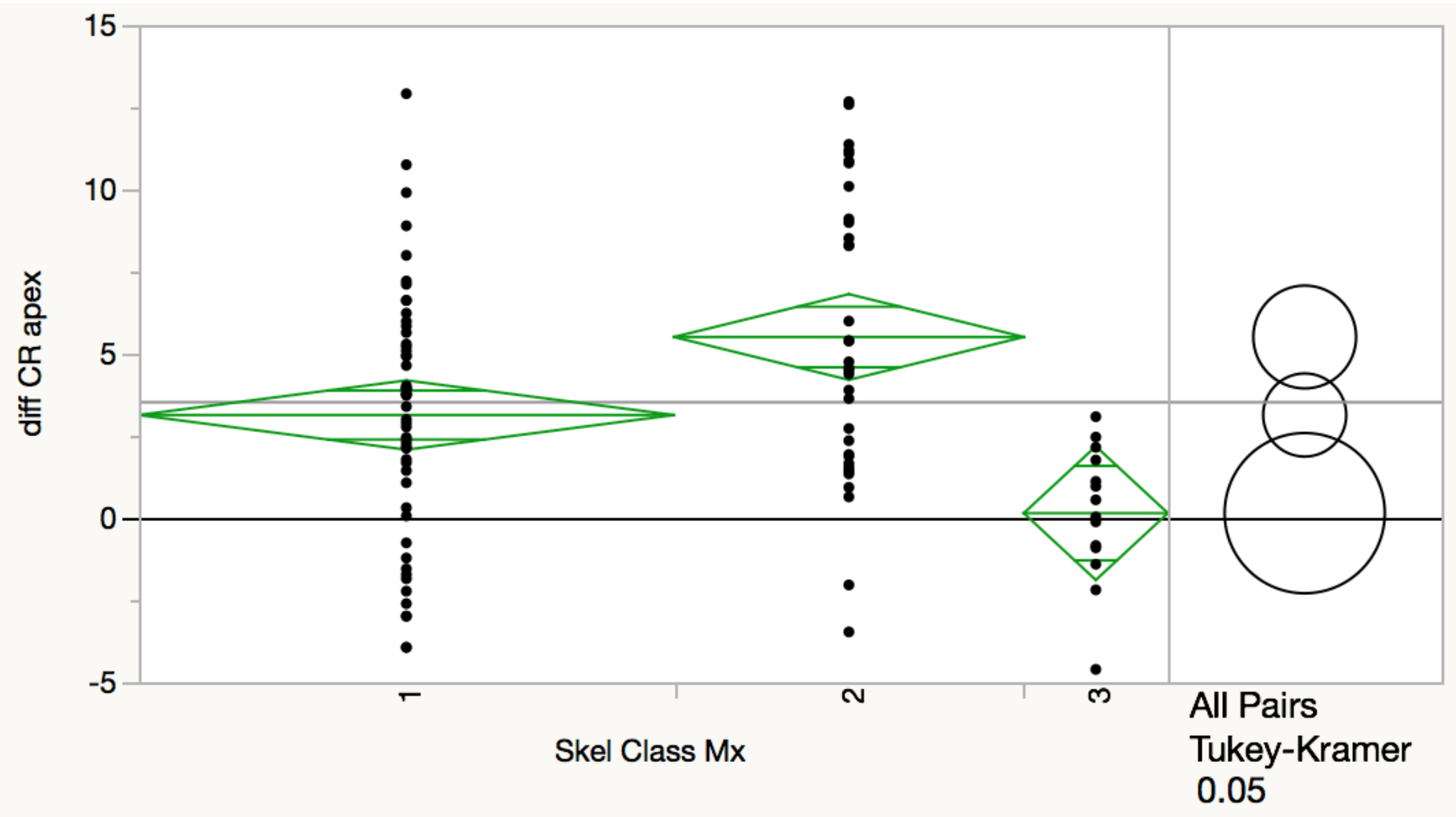

Oneway Anova

Summary of Fit

Rsquare

0.174557

Adj Rsquare

0.157538

Root Mean Square Error

3.833482

Mean of Response

3.5203

Observations (or Sum Wgts)

100

Analysis of Variance

Source

DF

Sum of Squares

Mean Square

F Ratio

Prob > F 


$\begin{array}{lrccc}\text { Skel Class Mx } & 2 & 301.4458 & 150.723 & 10.2563<.0001^{*} \\ \text { Error } & 97 & 1425.4717 & 14.696 & \\ \text { C. Total } & 99 & 1726.9175 & & \end{array}$

Means for Oneway Anova

$\begin{array}{rrrrrr}\text { Level } & \text { Number } & \text { Mean } & \text { Std Error } & \text { Lower 95\% } & \text { Upper 95\% } \\ 1 & 52 & 3.13115 & 0.5316 & 2.076 & 4.1862 \\ 2 & 34 & 5.50559 & 0.6574 & 4.201 & 6.8104 \\ 3 & 14 & 0.14429 & 1.0245 & -1.889 & 2.1777\end{array}$

Std Error uses a pooled estimate of error variance

Means Comparisons

Comparisons for all pairs using Tukey-Kramer HSD

Confidence Quantile

$\begin{array}{rr}\mathbf{q}^{*} & \text { Alpha } \\ 2.38024 & 0.05\end{array}$

\section{HSD Threshold Matrix}

Abs(Dif)-HSD

$\begin{array}{rrrr} & \mathbf{2} & \mathbf{1} & \mathbf{3} \\ 2 & -2.2130 & 0.3620 & 2.4637 \\ 1 & 0.3620 & -1.7895 & 0.2395 \\ 3 & 2.4637 & 0.2395 & -3.4488\end{array}$

Positive values show pairs of means that are significantly different. 
Connecting Letters Report

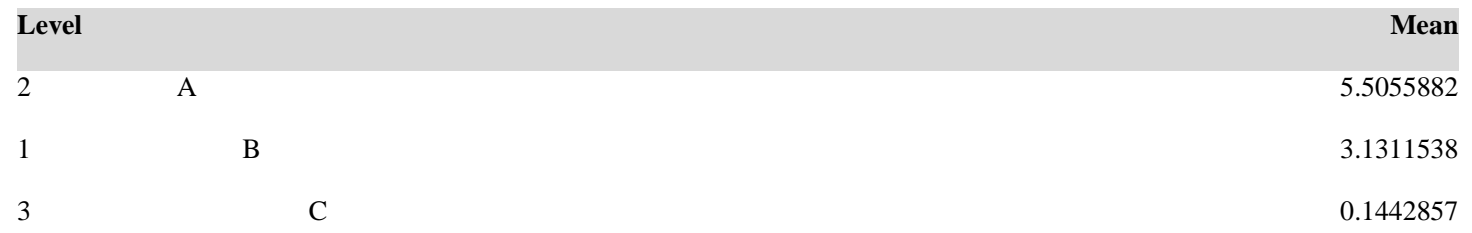

Levels not connected by same letter are significantly different.

Ordered Differences Report

\begin{tabular}{|c|c|c|c|c|c|c|}
\hline Level & - Level & Difference & Std Err Dif & Lower CL & Upper CL & p-Value \\
\hline 2 & 3 & 5.361303 & 1.217336 & 2.463748 & 8.258857 & $<.0001 *$ \\
\hline 1 & 3 & 2.986868 & 1.154250 & 0.239475 & 5.734261 & 0.0297 * \\
\hline 2 & 1 & 2.374434 & 0.845476 & 0.361996 & 4.386873 & $0.0164 *$ \\
\hline
\end{tabular}

\section{Fit Group}




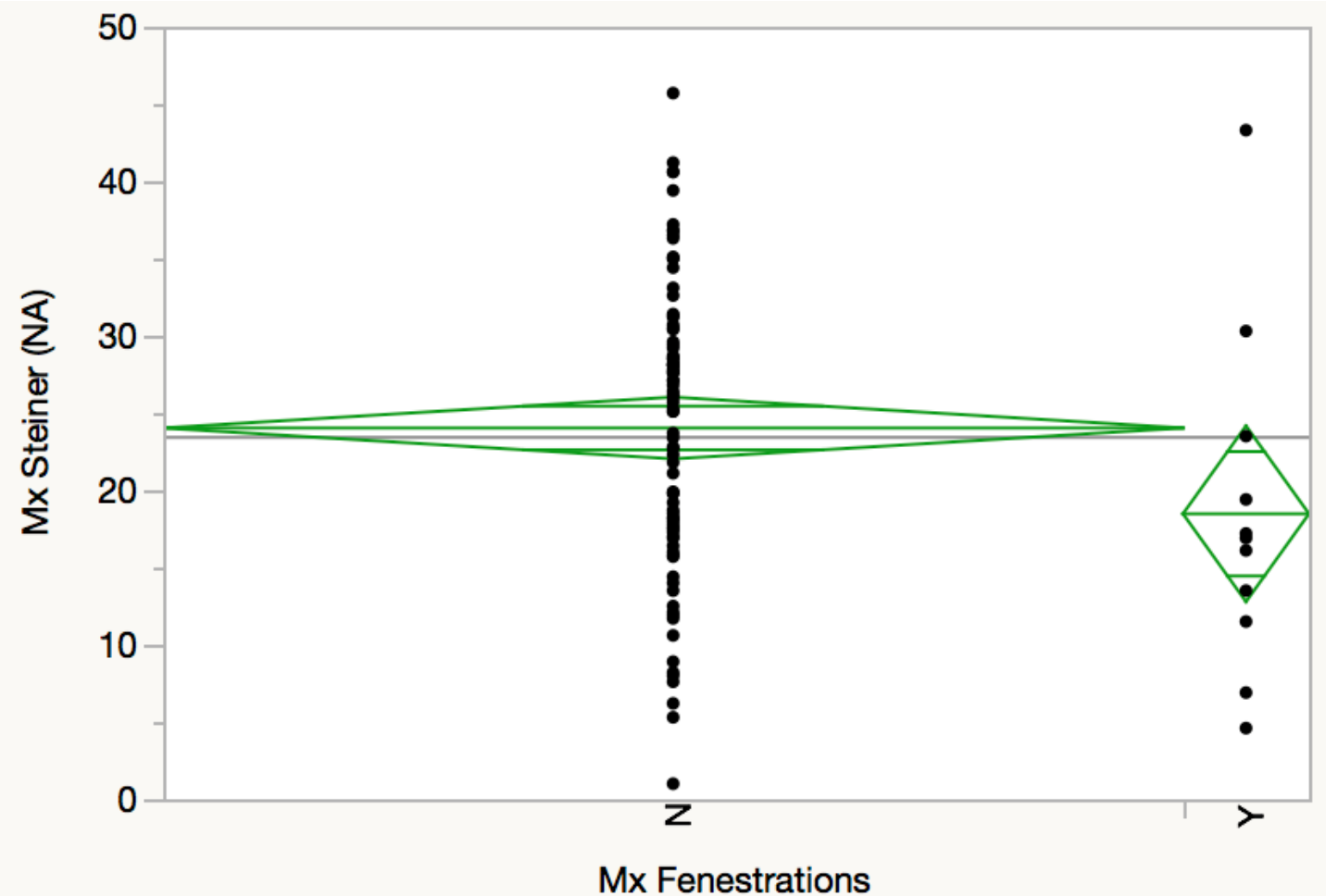

Oneway Anova

Summary of Fit

Rsquare

0.032945

Adj Rsquare

0.023077

Root Mean Square Error

9.511152

Mean of Response

23.416

Observations (or Sum Wgts)

100

t Test

Y-N

Assuming equal variances 


$\begin{array}{lcr}\text { Difference } & -5.554 \mathrm{t} \text { Ratio } & -1.82719 \\ \text { Std Err Dif } & 3.040 \mathrm{DF} & 98 \\ \text { Upper CL Dif } & 0.478 \text { Prob }>|t| & 0.0707 \\ \text { Lower CL Dif } & -11.587 \text { Prob }>\mathrm{t} & 0.9646 \\ \text { Confidence } & 0.95 \text { Prob }<\mathrm{t} & 0.0354^{*}\end{array}$

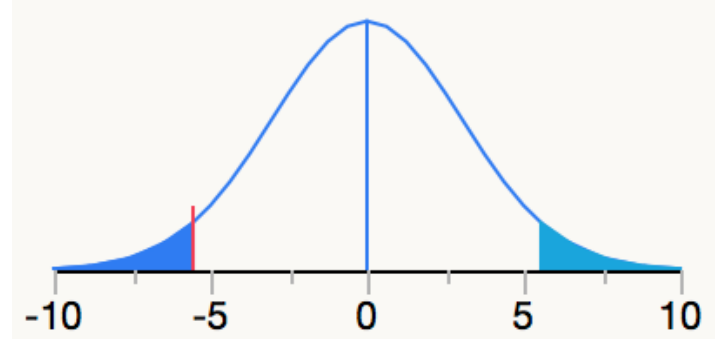

Analysis of Variance

$\begin{array}{lrrrrr}\text { Source } & \text { DF } & \text { Sum of Squares } & \text { Mean Square } & \text { F Ratio } & \text { Prob > F } \\ \text { Mx Fenestrations } & 1 & 302.0173 & 302.017 & 3.3386 & 0.0707 \\ \text { Error } & 98 & 8865.2771 & 90.462 & & \\ \text { C. Total } & 99 & 9167.2944 & & \end{array}$

Means for Oneway Anova

$\begin{array}{lrrrrr}\text { Level } & \text { Number } & \text { Mean } & \text { Std Error } & \text { Lower 95\% } & \text { Upper 95\% } \\ \text { N } & 89 & 24.0270 & 1.0082 & 22.026 & 26.028 \\ \text { Y } & 11 & 18.4727 & 2.8677 & 12.782 & 24.164\end{array}$

Std Error uses a pooled estimate of error variance

Oneway Analysis of MxAndrews By Mx Fenestrations 


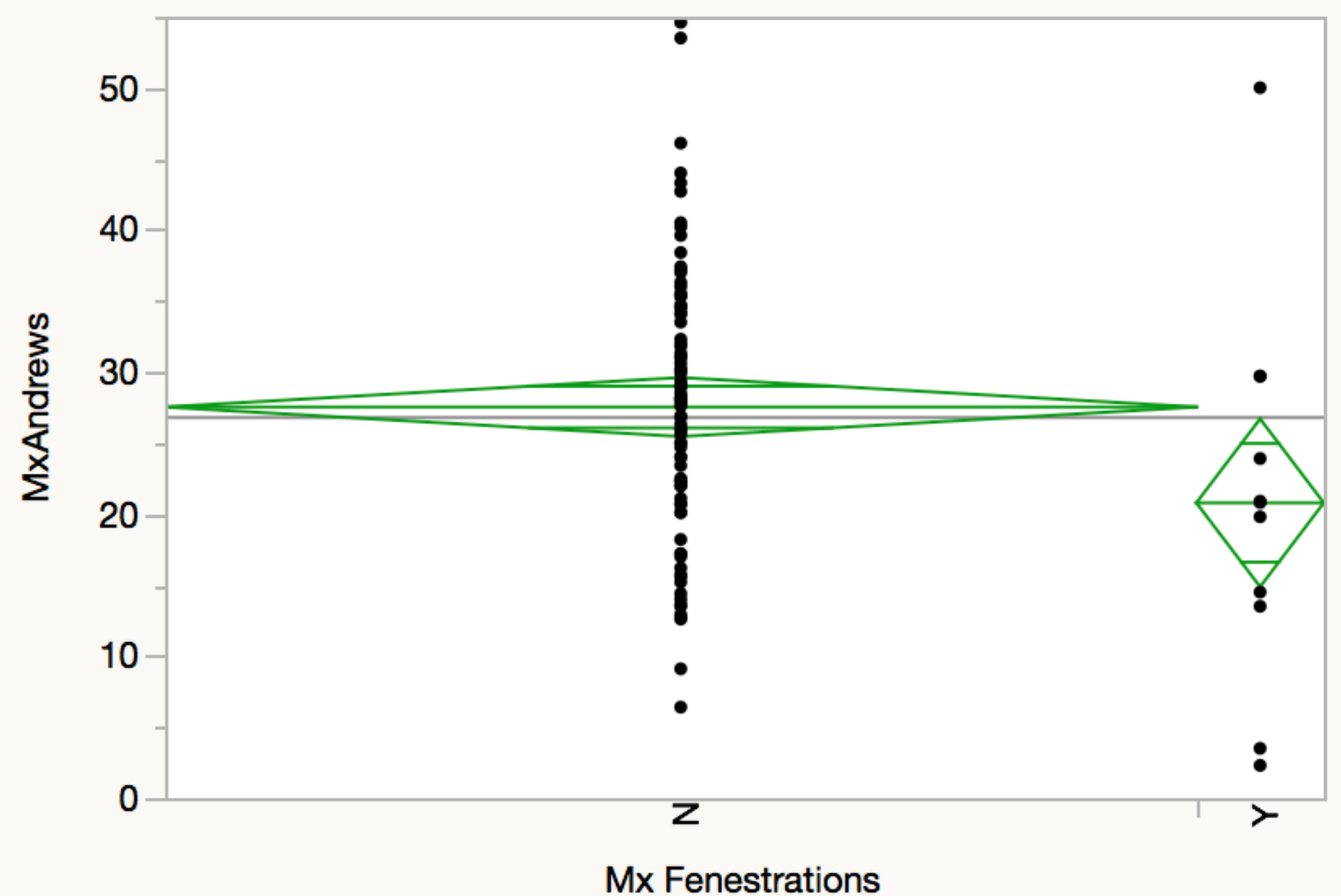

Oneway Anova

Summary of Fit

Rsquare

0.044506

Adj Rsquare

0.034756

Root Mean Square Error

9.878079

Mean of Response

26.785

Observations (or Sum Wgts)

100

t Test

Y-N

Assuming equal variances 


$\begin{array}{llr}\text { Difference } & -6.745 \mathrm{t} \text { Ratio } & -2.13654 \\ \text { Std Err Dif } & 3.157 \mathrm{DF} & 98 \\ \text { Upper CL Dif } & -0.480 \text { Prob }>|\mathrm{t}| & 0.0351^{*} \\ \text { Lower CL Dif } & -13.010 \text { Prob }>\mathrm{t} & 0.9824 \\ \text { Confidence } & 0.95 \text { Prob }<\mathrm{t} & 0.0176^{*}\end{array}$

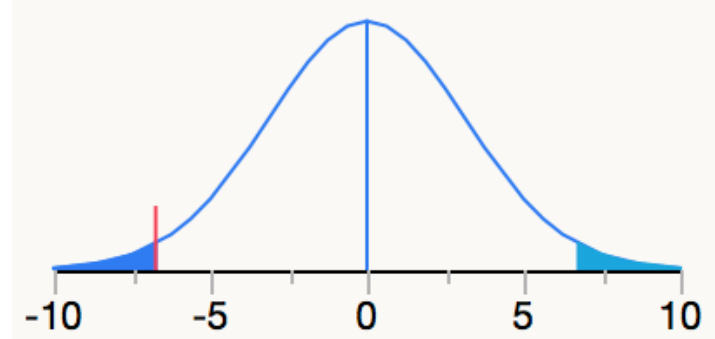

Analysis of Variance

$\begin{array}{lrcccr}\text { Source } & \text { DF } & \text { Sum of Squares } & \text { Mean Square } & \text { F Ratio } & \text { Prob > F } \\ \text { Mx Fenestrations } & 1 & 445.416 & 445.416 & 4.5648 & 0.0351 * \\ \text { Error } & 98 & 9562.492 & 97.576 & & \\ \text { C. Total } & 99 & 10007.908 & & \end{array}$

Means for Oneway Anova

$\begin{array}{rrrrrr}\text { Level } & \text { Number } & \text { Mean } & \text { Std Error } & \text { Lower 95\% } & \text { Upper 95\% } \\ \text { N } & 89 & 27.5270 & 1.0471 & 25.449 & 29.605 \\ \text { Y } & 11 & 20.7818 & 2.9784 & 14.871 & 26.692\end{array}$

Std Error uses a pooled estimate of error variance

Oneway Analysis of MxBurstone By Mx Fenestrations 


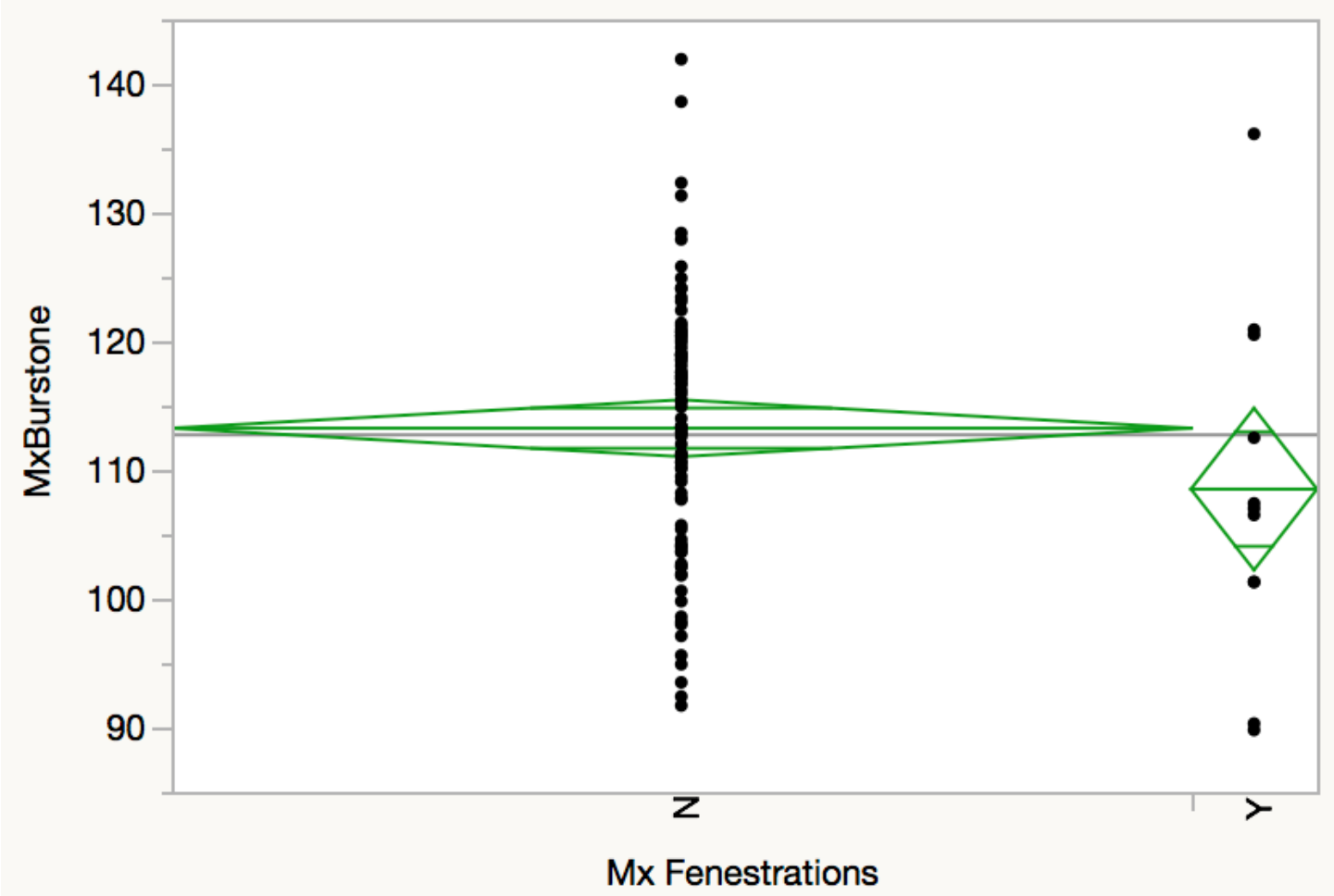

Oneway Anova

Summary of Fit

Rsquare

0.01986

Adj Rsquare

0.009859

Root Mean Square Error

10.50544

Mean of Response

112.72

Observations (or Sum Wgts)

100

t Test

Y-N

Assuming equal variances 


$\begin{array}{lcr}\text { Difference } & -4.731 \mathrm{t} \text { Ratio } & -1.40917 \\ \text { Std Err Dif } & 3.358 \mathrm{DF} & 98 \\ \text { Upper CL Dif } & 1.932 \text { Prob }>|\mathrm{t}| & 0.1620 \\ \text { Lower CL Dif } & -11.394 \text { Prob }>\mathrm{t} & 0.9190 \\ \text { Confidence } & 0.95 \text { Prob }<\mathrm{t} & 0.0810\end{array}$

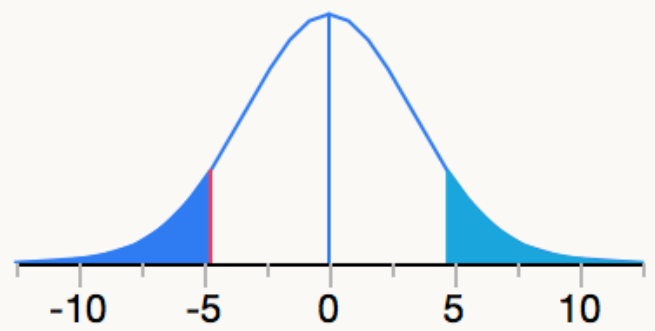

Analysis of Variance

$\begin{array}{lrrrrr}\text { Source } & \text { DF } & \text { Sum of Squares } & \text { Mean Square } & \text { F Ratio } & \text { Prob > F } \\ \text { Mx Fenestrations } & 1 & 219.157 & 219.157 & 1.9858 & \\ \text { Error } & 98 & 10815.703 & 110.364 & & \\ \text { C. Total } & 99 & 11034.860 & & \end{array}$

Means for Oneway Anova

$\begin{array}{rrrcrr}\text { Level } & \text { Number } & \text { Mean } & \text { Std Error } & \text { Lower 95\% } & \text { Upper 95\% } \\ \text { N } & 89 & 113.240 & 1.1136 & 111.03 & 115.45 \\ \text { Y } & 11 & 108.509 & 3.1675 & 102.22 & 114.79\end{array}$

Std Error uses a pooled estimate of error variance 
Bivariate Fit of 2MxB-MxLCR By Mx Steiner (NA)

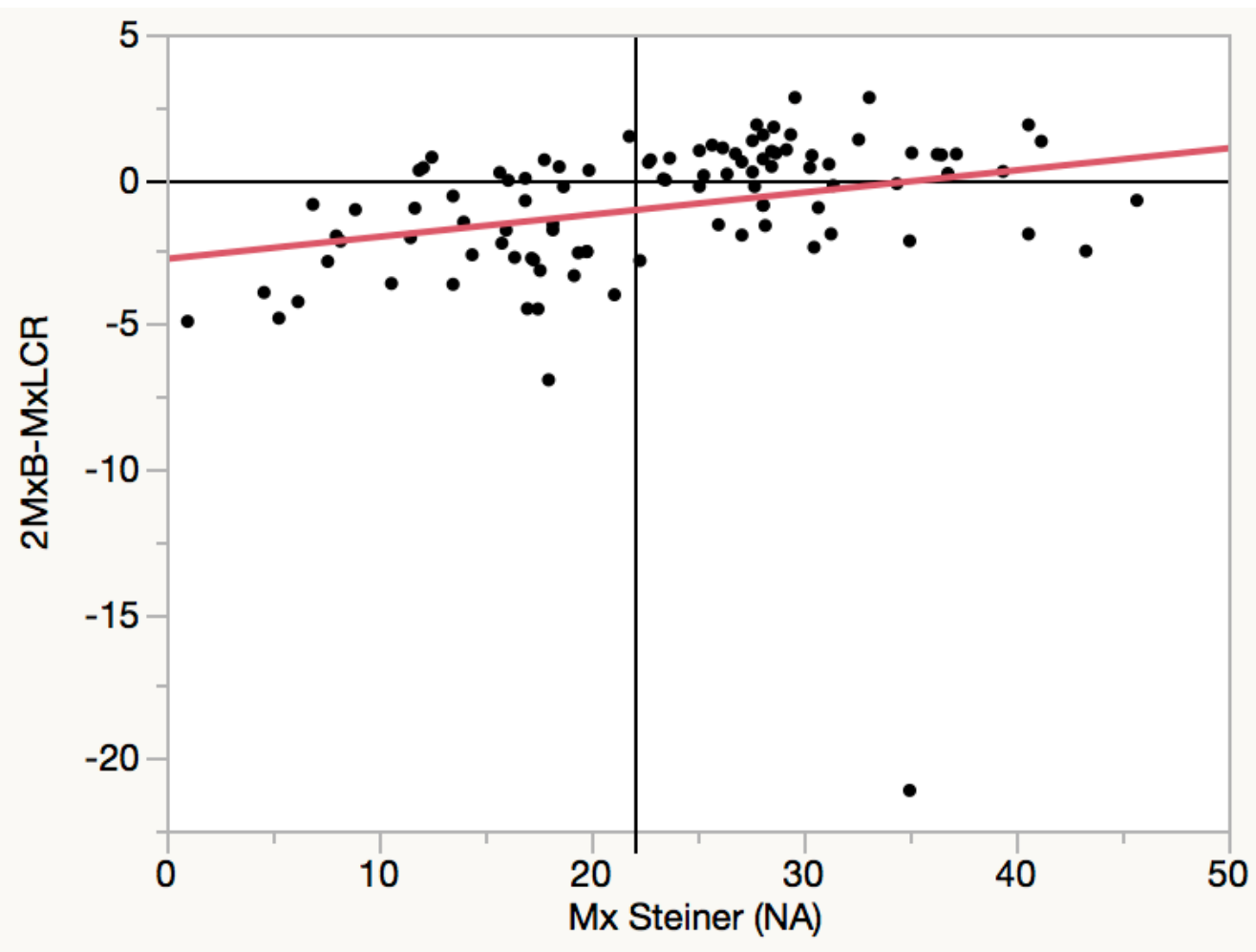

Linear Fit 
Bivariate Fit of 2MxB-MxL Apex By Mx Steiner (NA)

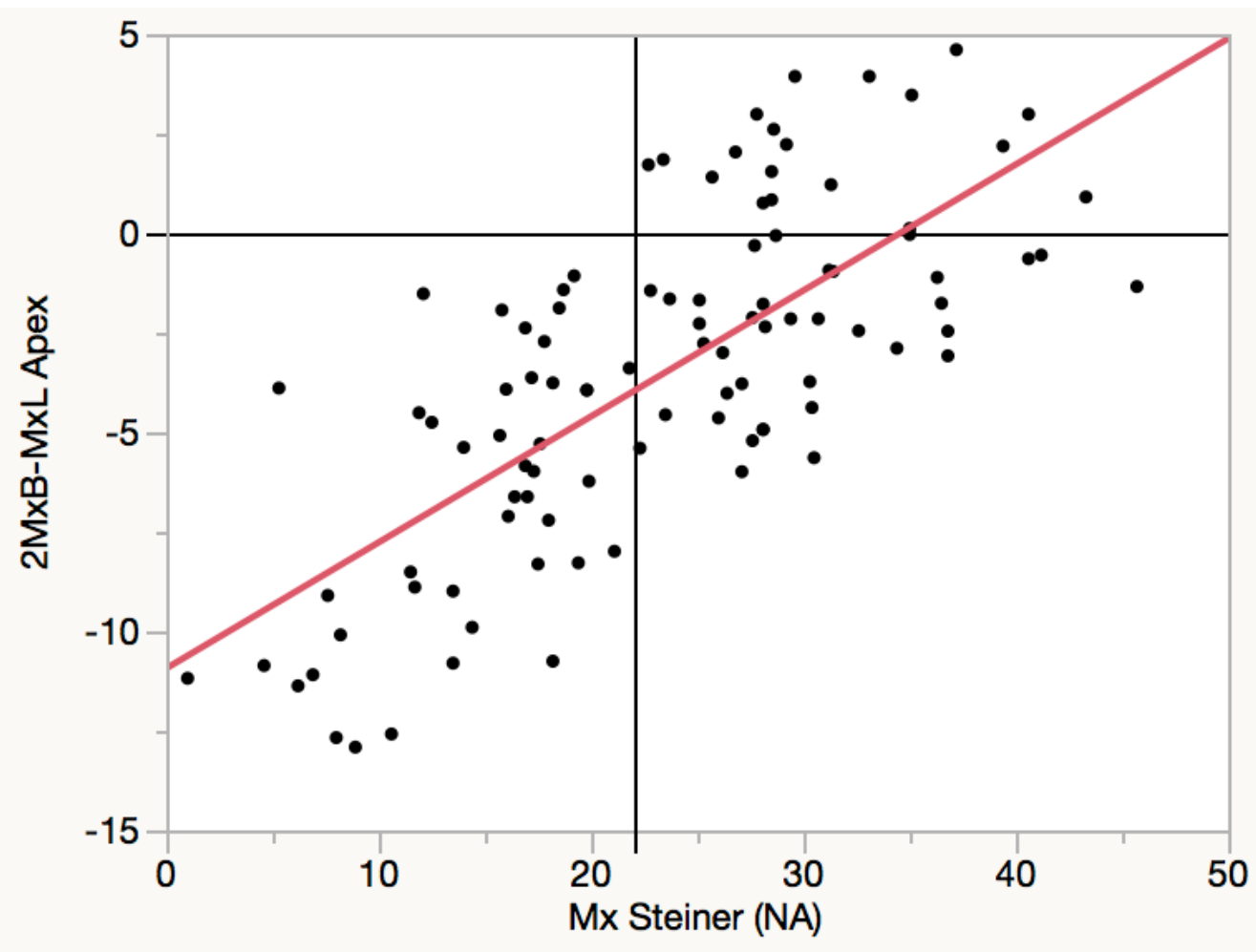

Linear Fit 
Bivariate Fit of 2MxB-MxLCR By MxAndrews

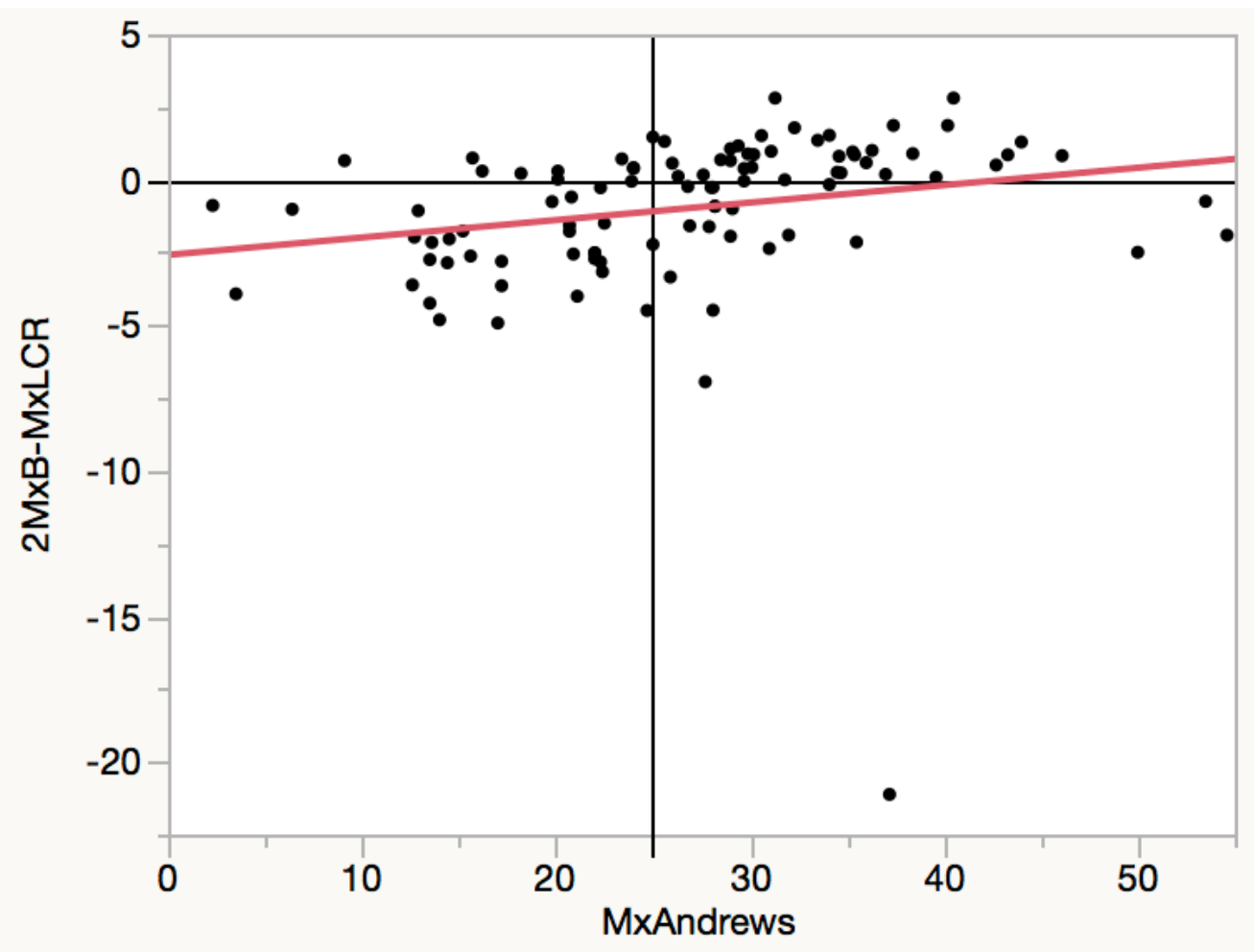

Linear Fit 
Bivariate Fit of 2MxB-MxL Apex By MxAndrews

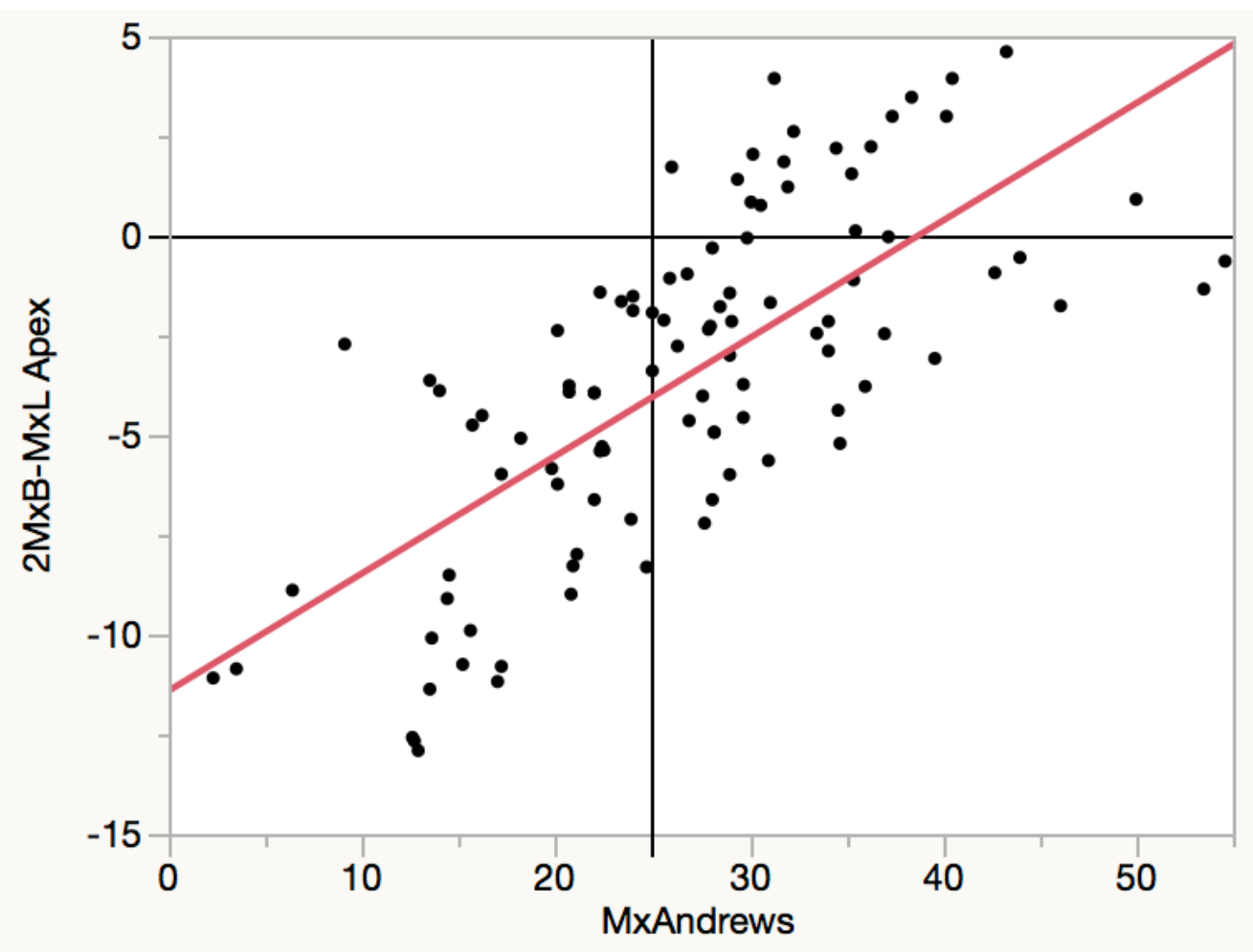

Linear Fit 
Bivariate Fit of 2MxB-MxLCR By MxBurstone

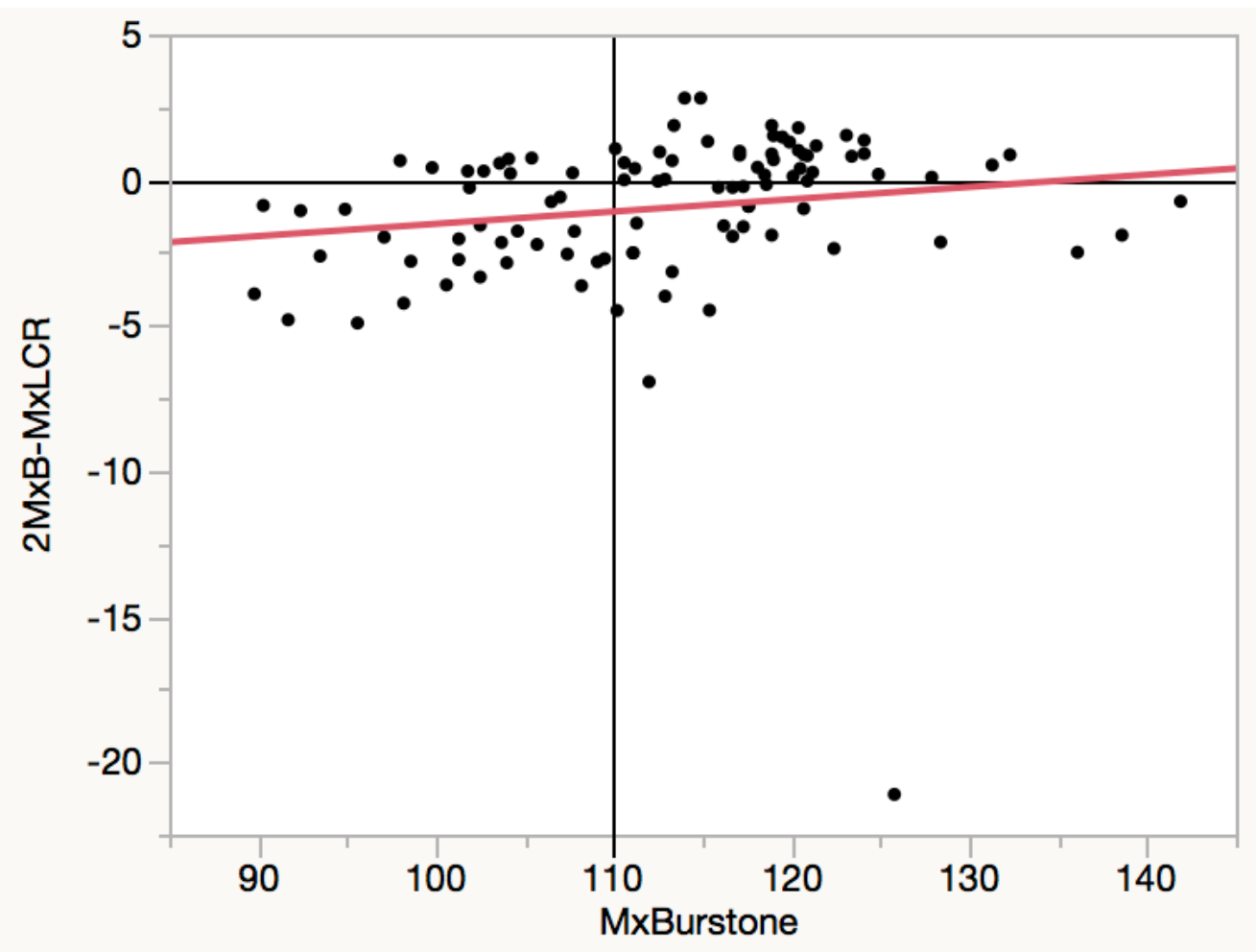

Linear Fit 
Bivariate Fit of 2MxB-MxL Apex By MxBurstone

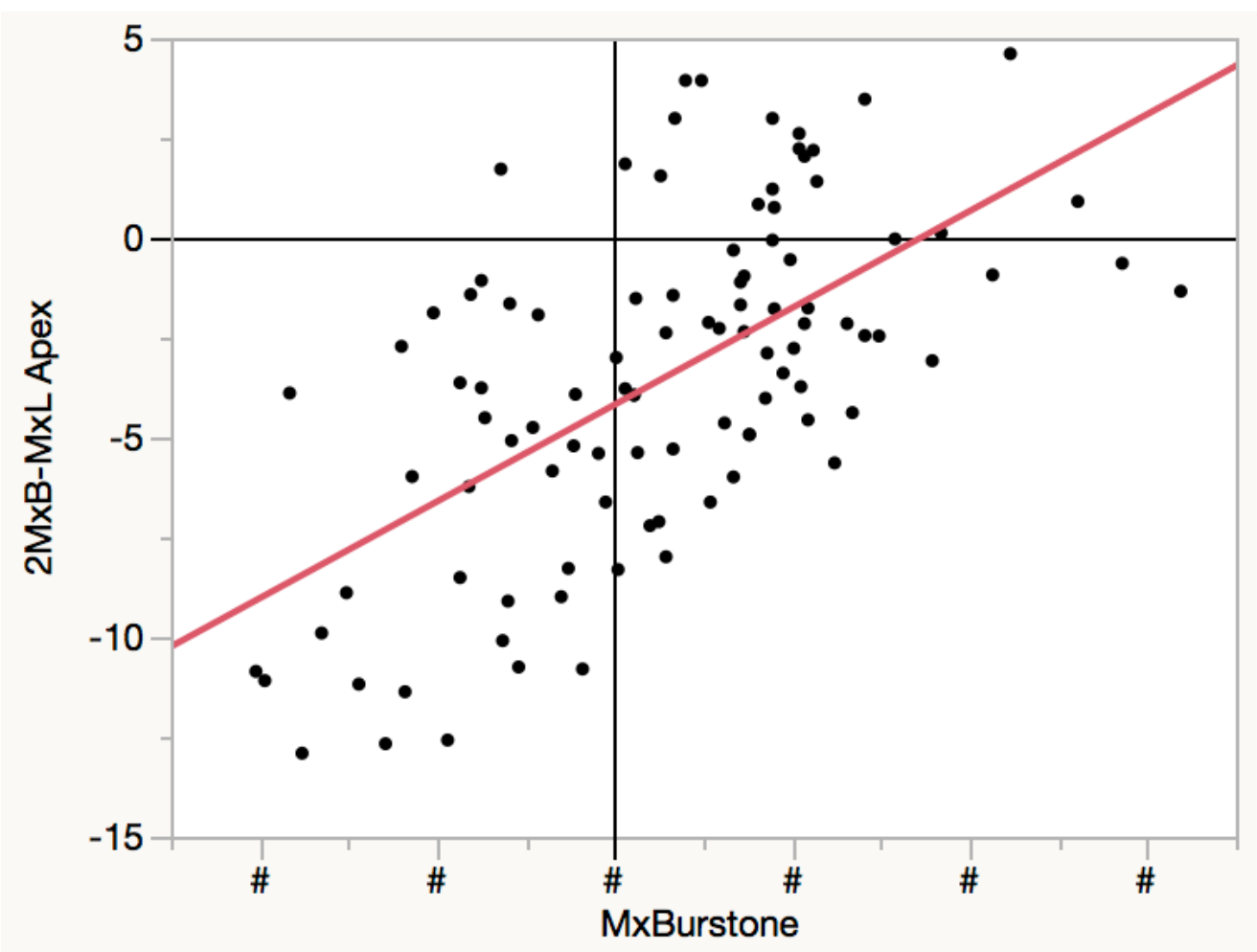

\section{Linear Fit}

Fit Group

Contingency Analysis of Mx Fenestrations By Range ANB

Mosaic Plot 


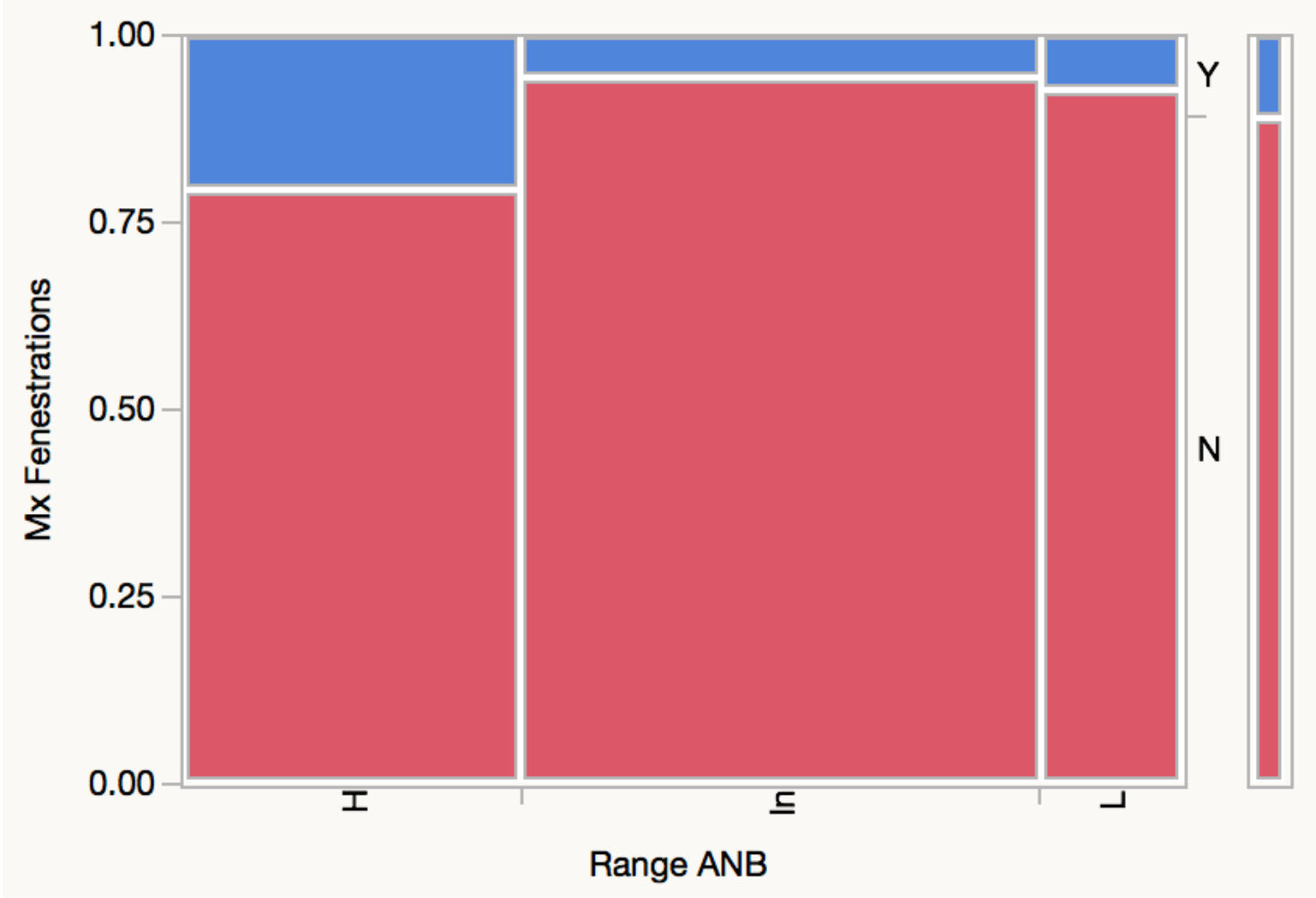

Contingency Table

Range ANB By Mx Fenestrations

\begin{tabular}{|l|r|r|r|}
\hline Count & $\mathrm{N}$ & $\mathrm{Y}$ & Total \\
Total \% & & & \\
Rol \% & & & \\
\hline H & 27 & 7.00 & 34.00 \\
& 27.00 & 63.64 & \\
& 30.34 & 20.59 & \\
\hline In & 79.41 & 3 & 52 \\
& 49 & 3.00 & 52.00 \\
& 59.00 & 27.27 & \\
\hline $\mathrm{L}$ & 54.23 & 5.77 & 14.00 \\
\hline
\end{tabular}




\begin{tabular}{|l|r|r|r|}
\hline & 14.61 & 9.09 & \\
& 92.86 & 7.14 & \\
\hline Total & 89 & 11 & 100 \\
& 89.00 & 11.00 & \\
\hline
\end{tabular}

Tests

\begin{tabular}{rrrr}
$\mathbf{N}$ & DF & -LogLike & RSquare (U) \\
\hline 100 & 2 & 2.2921394 & 0.0661
\end{tabular}

$\begin{array}{lrr}\text { Test } & \text { ChiSquare } & \text { Prob>ChiSq } \\ \text { Likelihood Ratio } & 4.584 & 0.1011 \\ \text { Pearson } & 4.859 & 0.0881\end{array}$

Warning: $20 \%$ of cells have expected count less than 5, ChiSquare suspect.

Contingency Analysis of Mx Dehiscences By Range ANB

Mosaic Plot 


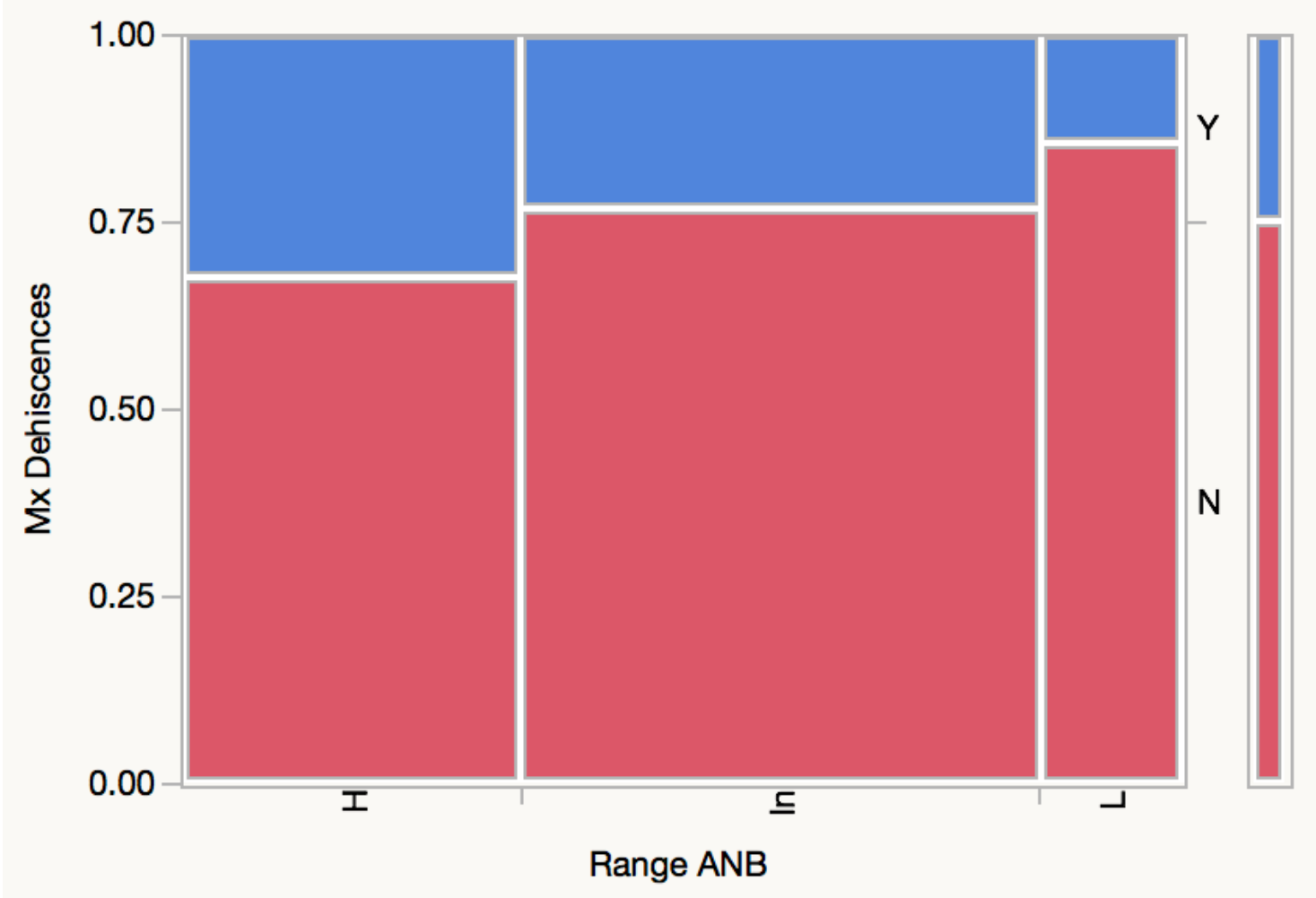

Contingency Table

Range ANB By Mx Dehiscences

\begin{tabular}{|l|r|r|r|}
\hline Count & $\mathrm{N}$ & $\mathrm{Y}$ & Total \\
Total \% & & & \\
Rol \% & & & \\
\hline H & 23 & 11 & 34 \\
& 23.00 & 11.00 & 34.00 \\
& 30.67 & 44.00 & \\
\hline In & 67.65 & 32.35 & \\
& 40 & 12 & 52 \\
& 40.00 & 12.00 & 52.00 \\
& 53.33 & 48.00 & \\
\hline $\mathrm{L}$ & 76.92 & 23.08 & 14.00 \\
\hline
\end{tabular}




\begin{tabular}{|l|r|r|r|}
\hline & 16.00 & 8.00 & \\
& 85.71 & 14.29 & \\
\hline Total & 75 & 25 & 100 \\
& 75.00 & 25.00 & \\
\hline
\end{tabular}

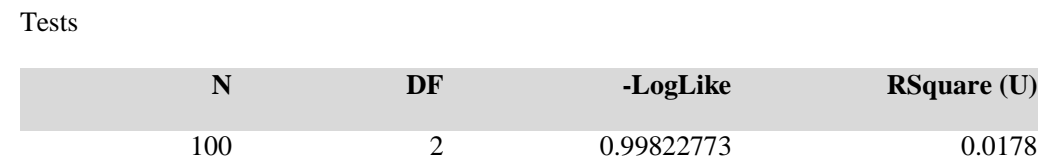

$\begin{array}{lrr}\text { Test } & \text { ChiSquare } & \text { Prob>ChiSq } \\ \text { Likelihood Ratio } & 1.996 & 0.3685 \\ \text { Pearson } & 1.940 & 0.3791\end{array}$

\section{Multivariate \\ Correlations}

\begin{tabular}{|c|c|c|c|c|c|}
\hline & diff CR apex & $\operatorname{diff} \mathbf{C R}$ & Mx Steiner (NA) & MxAndrews & MxBurstone \\
\hline diff CR apex & 1.0000 & 0.3764 & -0.7290 & -0.7092 & -0.6130 \\
\hline diff CR & 0.3764 & 1.0000 & -0.2639 & -0.2165 & -0.1601 \\
\hline Mx Steiner (NA) & -0.7290 & -0.2639 & 1.0000 & 0.9036 & 0.8673 \\
\hline MxAndrews & -0.7092 & -0.2165 & 0.9036 & 1.0000 & 0.8822 \\
\hline MxBurstone & -0.6130 & -0.1601 & 0.8673 & 0.8822 & 1.0000 \\
\hline
\end{tabular}


Scatterplot Matrix

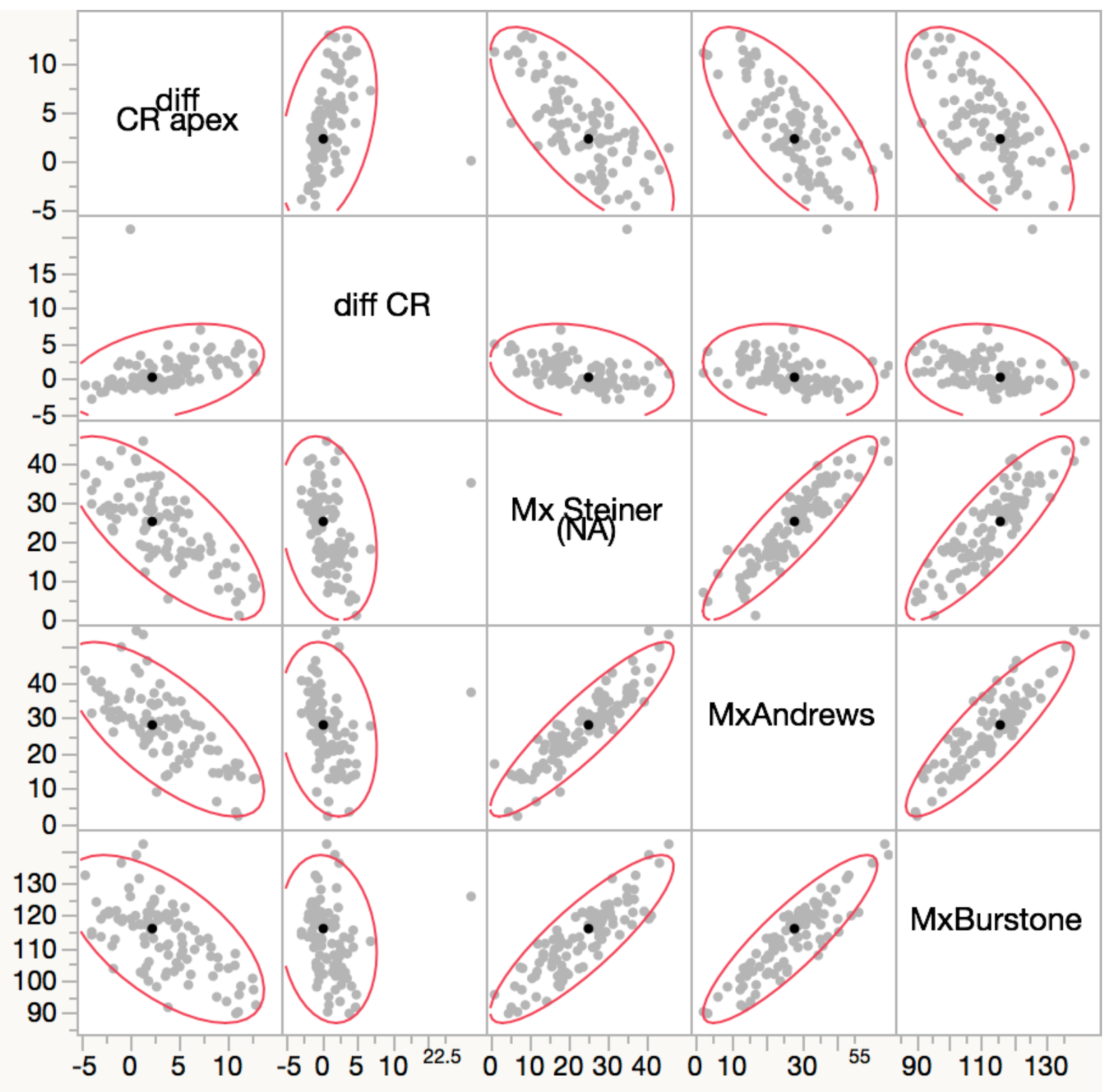


Bivariate Fit of diff CR apex By Mx Steiner (NA)

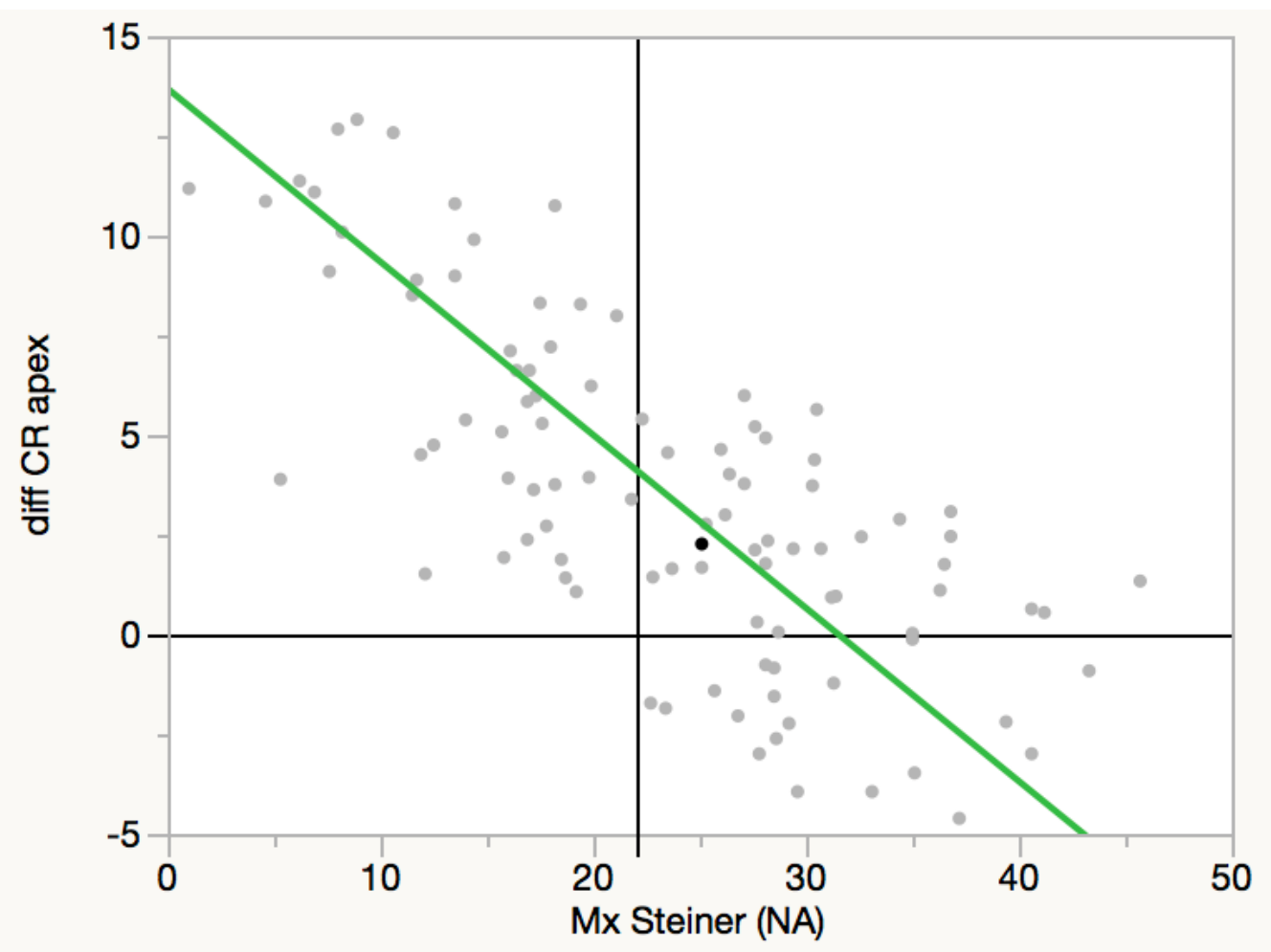

\section{Orthogonal Fit Ratio $=0.188$}

Orthogonal Fit Ratio=0.188

$\begin{array}{lrrrr}\text { Variable } & \text { Mean } & \text { Std Dev } & \text { Variance Ratio } & \text { Correlation } \\ \text { Mx Steiner (NA) } & 23.416 & 9.622834 & 0.188378 & -0.7290 \\ \text { diff CR apex } & 3.5203 & 4.176555 & & \end{array}$

\begin{tabular}{|rrrrr}
\hline Intercept & Slope & LowerCL & UpperCL & Alpha \\
\hline 13.68344 & -0.43403 & -0.5251 & -0.35875 & 0.05000
\end{tabular}


Bivariate Fit of diff CR By Mx Steiner (NA)

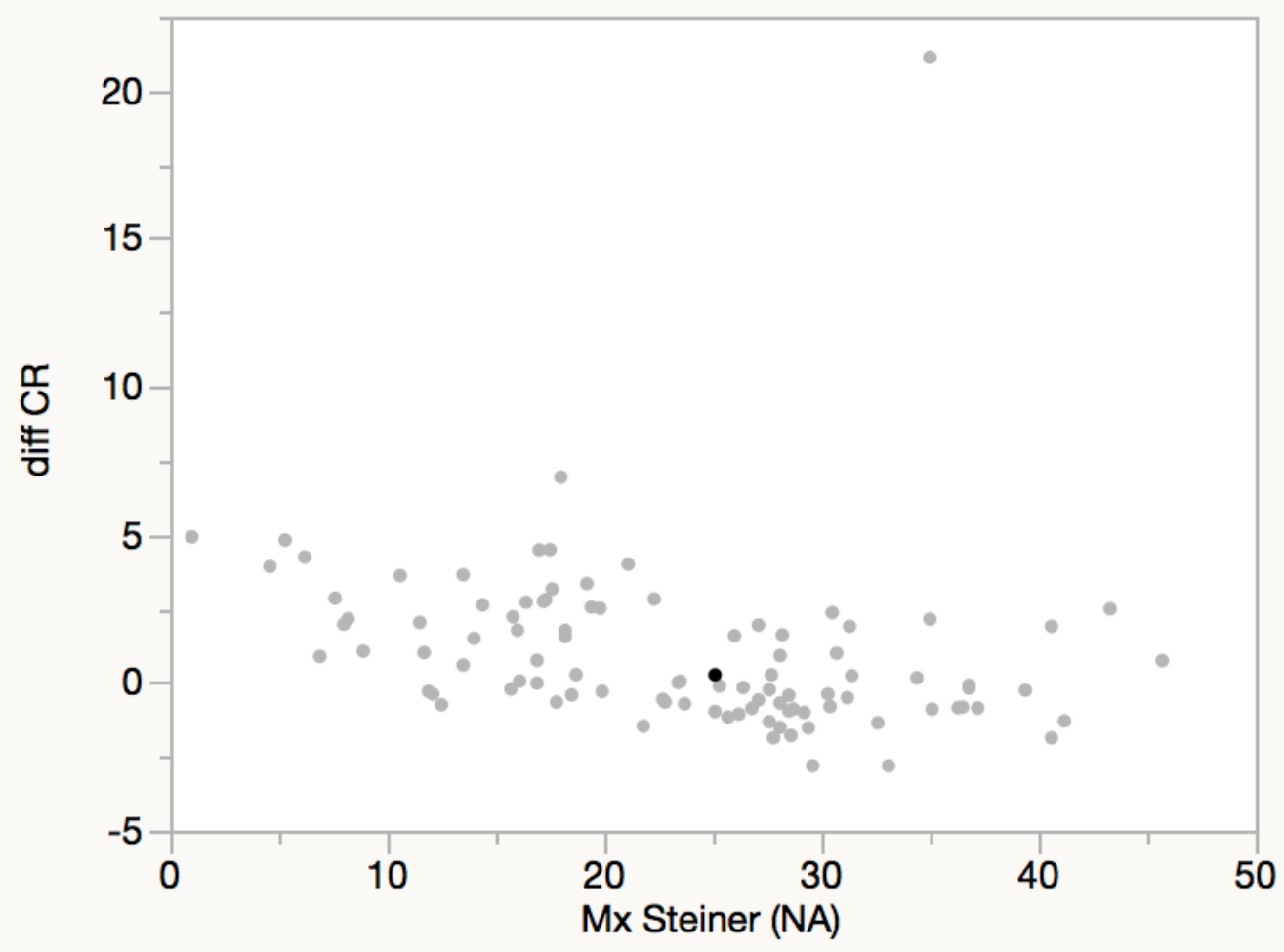

Bivariate Fit of diff CR apex By MxAndrews

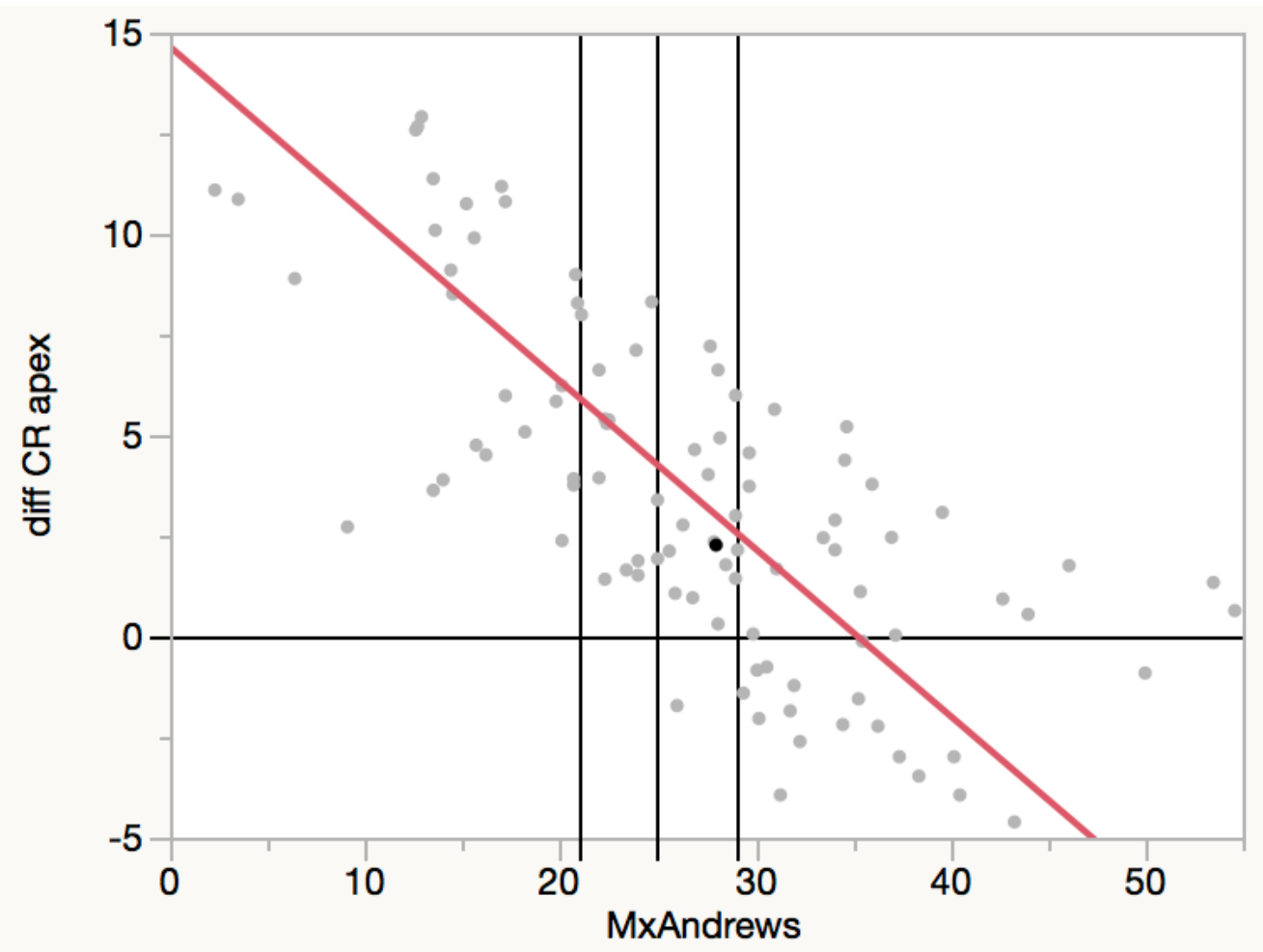




\section{- Orthogonal Fit Ratio $=0.173$}

Orthogonal Fit Ratio=0.173

$\begin{array}{lrrrr}\text { Variable } & \text { Mean } & \text { Std Dev } & \text { Variance Ratio } & \text { Correlation } \\ \text { MxAndrews } & 26.785 & 10.05435 & 0.172555 & -0.7092 \\ \text { diff CR apex } & 3.5203 & 4.176555 & & \end{array}$

\begin{tabular}{|rrrrr} 
Intercept & Slope & LowerCL & UpperCL & Alpha \\
\hline 14.64673 & -0.4154 & -0.50836 & -0.33943 & 0.05000
\end{tabular}

Bivariate Fit of diff CR By MxAndrews

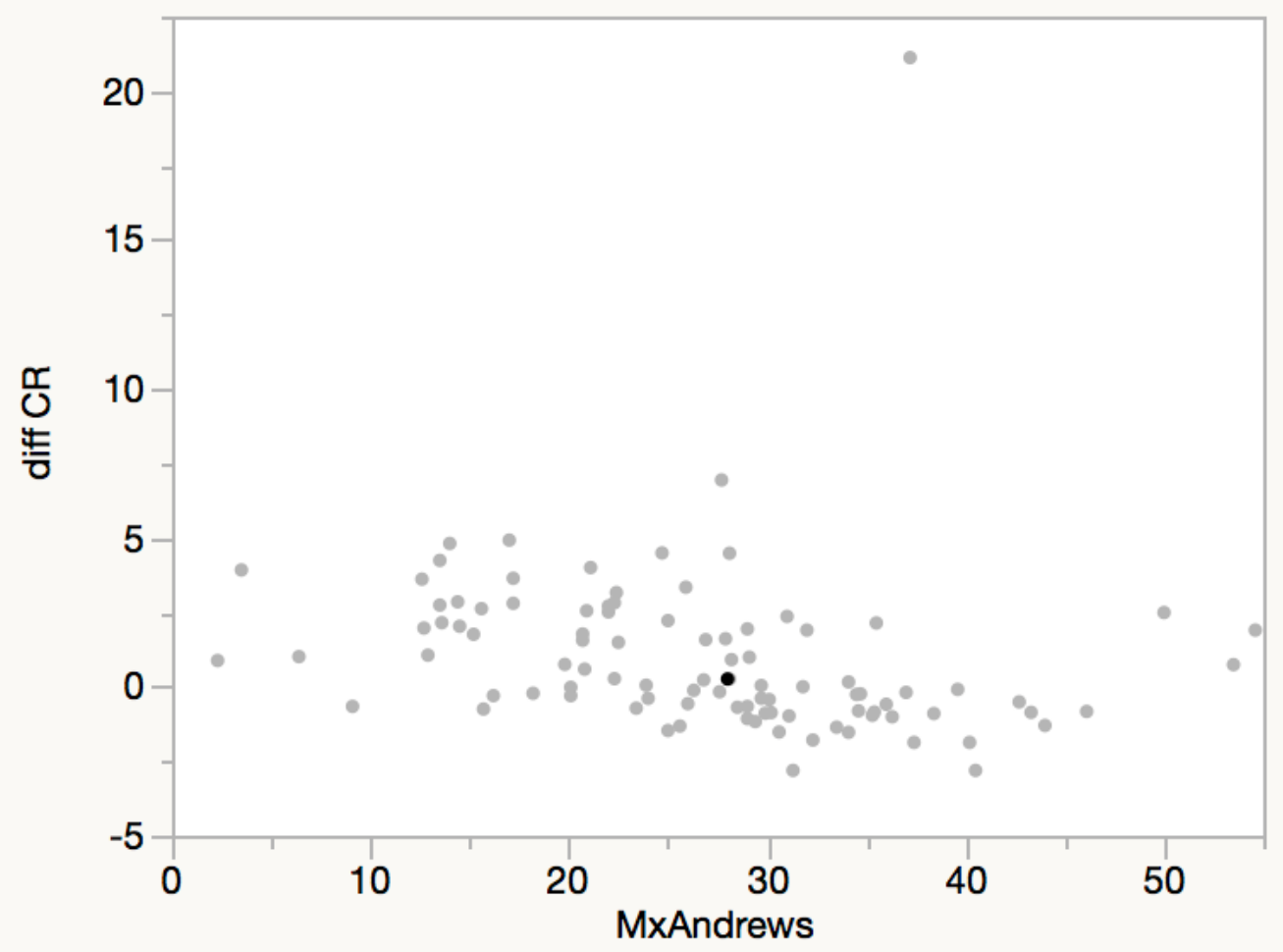


Bivariate Fit of diff CR apex By MxBurstone

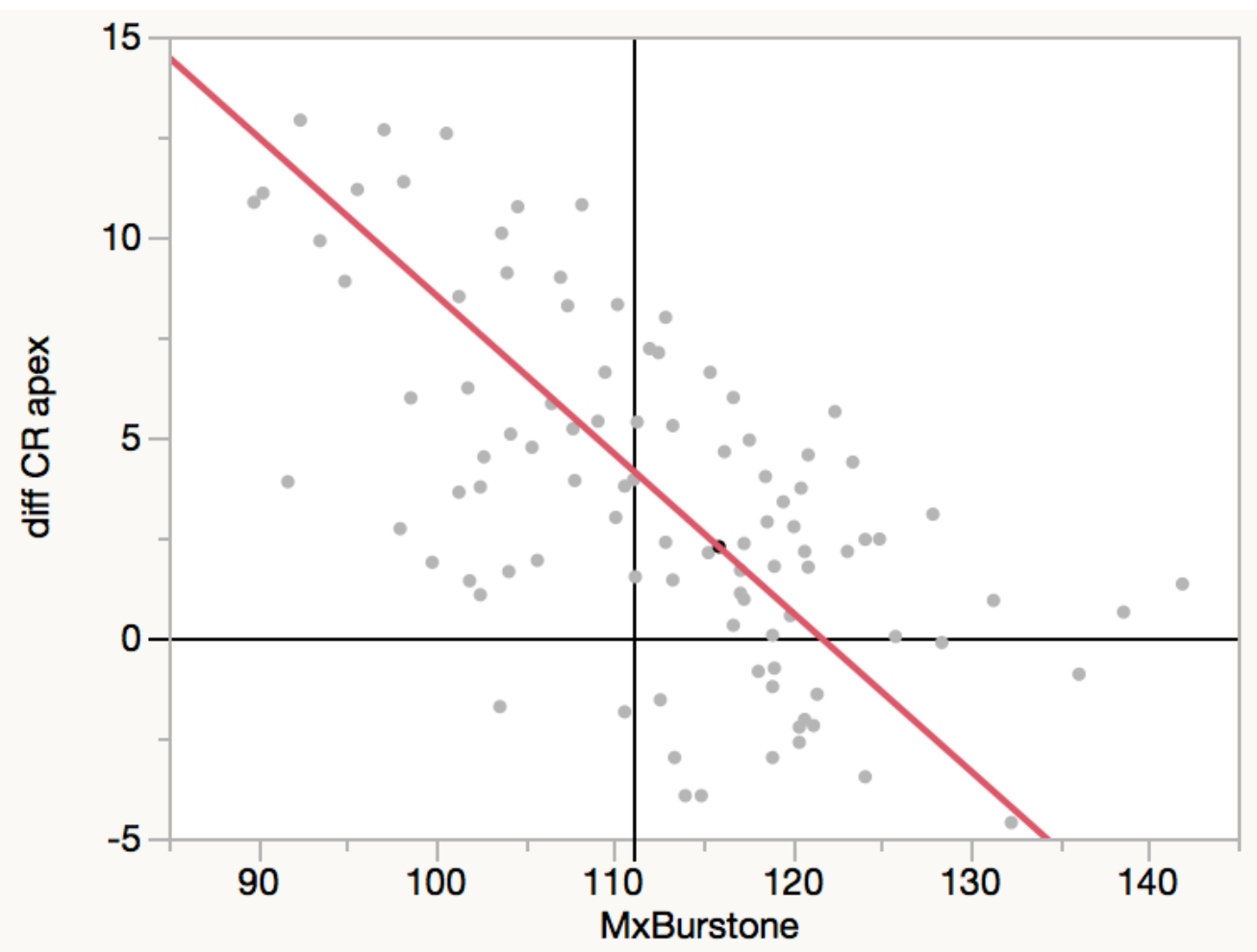

\section{Orthogonal Fit Ratio $=0.156$}

Orthogonal Fit Ratio=0.156

$\begin{array}{lrrrr}\text { Variable } & \text { Mean } & \text { Std Dev } & \text { Variance Ratio } & \text { Correlation } \\ \text { MxBurstone } & 112.72 & 10.55761 & 0.156497 & -0.6130 \\ \text { diff CR apex } & 3.5203 & 4.176555 & & \end{array}$

\begin{tabular}{|rrrrr}
\hline Intercept & Slope & LowerCL & UpperCL & Alpha \\
\hline 48.11193 & -0.3956 & -0.5153 & -0.3037 & 0.05000
\end{tabular}


Bivariate Fit of diff CR By MxBurstone

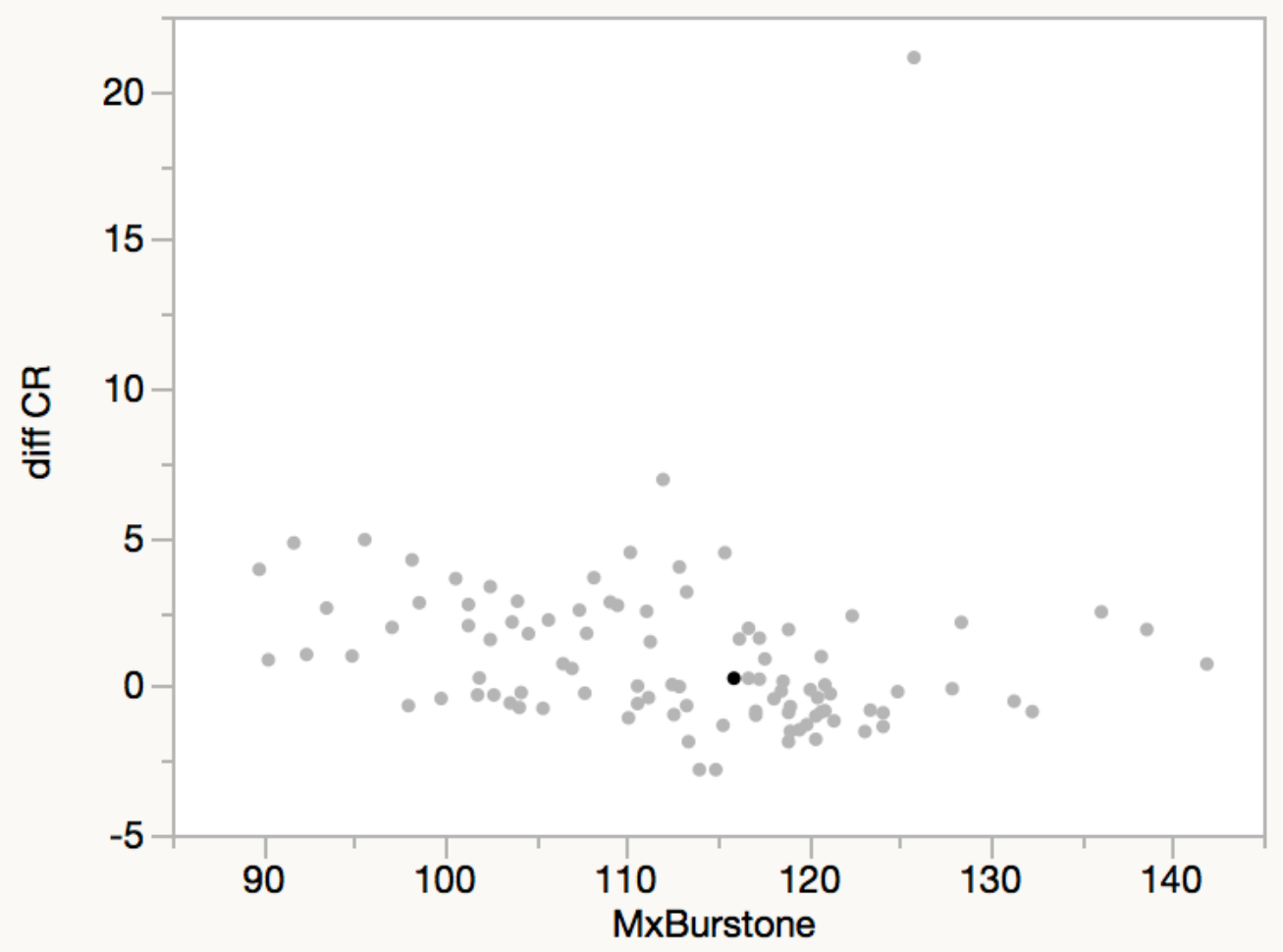

